\title{
MODELAGEM, ANÁLISE E CONTROLE DE UM SISTEMA DE BOBINAMENTO DE TIRAS DE AÇO
}

Fábio Lima

Dissertação apresentada à Escola de Engenharia de São Carlos da Universidade de São Paulo, como parte dos requisitos para a obtenção do Título de Mestre em Engenharia Elétrica.

ORIENTADOR: Prof. Dr. Azauri Albano de Oliveira Jr. 
À minha família, pelo apoio $e$ incentivo em todos os momentos da minha vida, e sem a qual eu não seria nada. 


\section{AGRADECIMENTOS}

A Deus, pela vida e por me dar forças para realizar este trabalho.

Ao meu orientador, Azauri Albano de Oliveira Júnior, pela excelente orientação e pela amizade.

À Indhira Dias Oliveira, pelo amor, carinho, paciência e compreensão dedicados ao longo de toda a realização deste trabalho.

Ao CNPq, pela bolsa de estudos concedida.

Ao IPT-DIMET, pelo total apoio técnico fornecido e pelo empenho de todo pessoal envolvido no projeto LCT para que esse trabalho acontecesse.

À professora Vilma Alves de Oliveira, pelo apoio. Ao professor Manoel Luís de Aguiar por suas preciosas sugestões ao trabalho.

Ao professor José Denti Filho da UFES, pela colaboração.

A todos os meus amigos, que através de sugestões, auxílios, críticas e incentivos contribuíram de maneira fundamental para a realização desta etapa.

Aos professores da UNESP campus de Bauru, em especial a Alceu Ferreira Alves, Renato Crivellari Creppe, e André Nunes de Souza, pelo apoio, incentivo e amizade.

Aos funcionários do Departamento de Engenharia Elétrica da EESC-USP.

E a todos, que de alguma forma contribuíram para a realização deste trabalho. 


\section{SUMÁRIO}

AGRADECIMENTOS .............................................................................

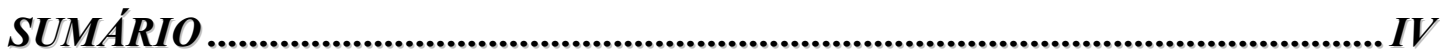

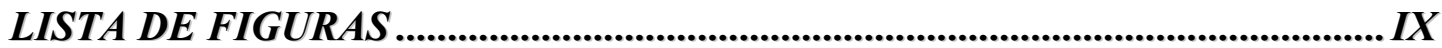

LISTA DE TABELAS .............................................................................

LISTA DE ABREVIATURAS E SIGLAS ......................................................... XIV

LISTA DE SÍMBOLOS …….............................................................................

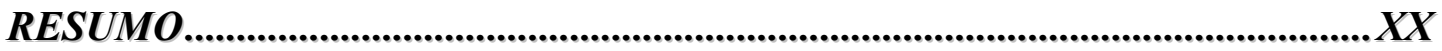

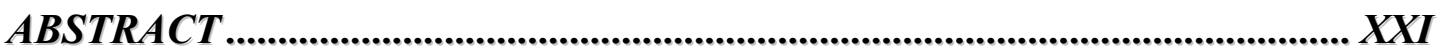

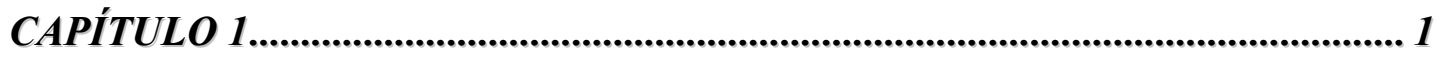

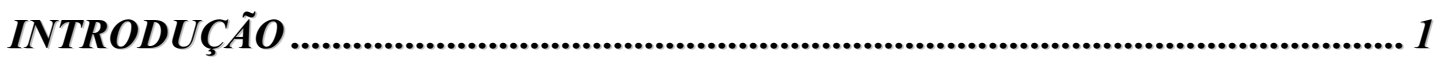

1.1 LingOTAMENTO ConTÍNUO DE TIRAS (LCT) ................................................ 1

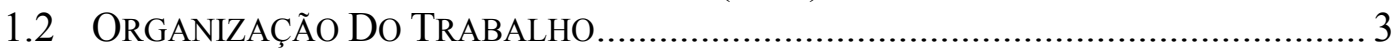

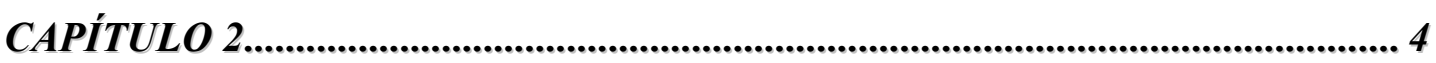

O PROCESSO LCT DO TIPO TWIN ROLL....................................................... 4

2.1 CARACTERÍSTICAS GERAIS.......................................................................... 4

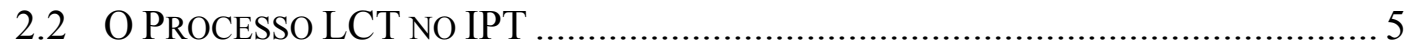

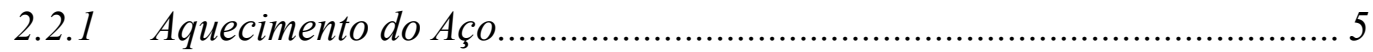

2.2.2 Injeção de Aço Líquido Entre os Rolos..................................................... 6

2.2.3 Análise de Turbulência na Injeção de Aço ............................................. 6

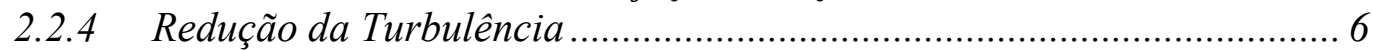

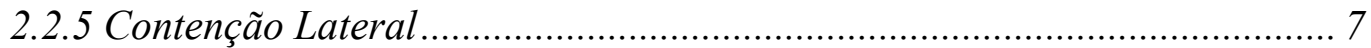

2.2.6 Controle de Velocidade dos Rolos ........................................................ 8

2.2.7 Controle da Força Aplicada aos Rolos.................................................... 9

2.2.8 Considerações Sobre o Bobinamento ……………………………........ 9

2.2.8.1 Tensão Mecânica Aplicada à Tira .......................................................... 9

2.2.8.2 Acionamento do Sistema de Bobinamento do IPT ................................ 11

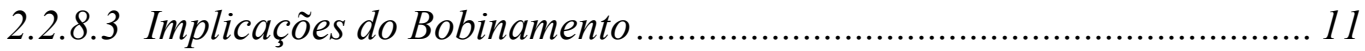


MODELAGEM DO SISTEMA DE BOBINAMENTO .................................... 13

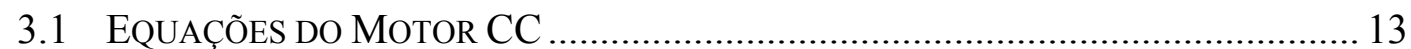

3.2 RELAÇÃO DE REDUÇÃO DE VELOCIDADE ....................................................... 14

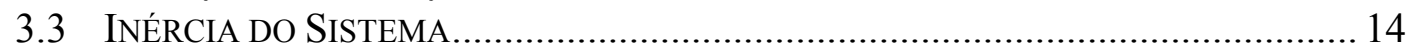

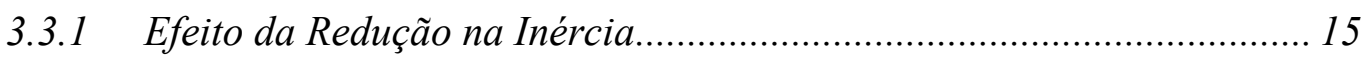

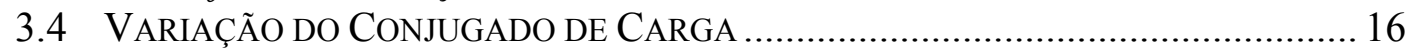

3.4.1 Efeito da Redução no Conjugado de Carga ........................................... 16

3.5 Modelagem MatemátiCA do Sistema de BobinAMENTO............................ 18

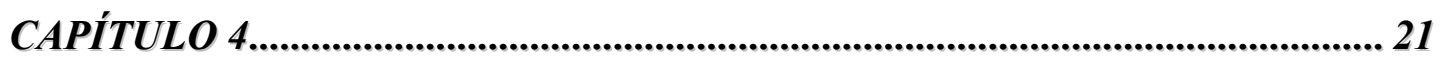

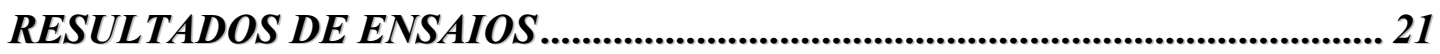

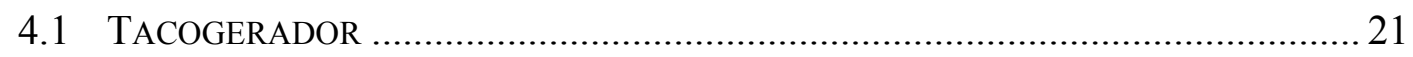

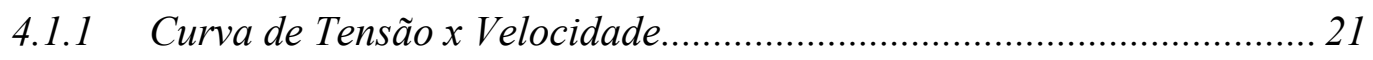

4.2 CURVA PARA CAIXA DE REDUÇÃO ................................................................. 21

4.3 ResPostas de TENSÃO, CoRRENTE E VElocidAdE ..................................... 23

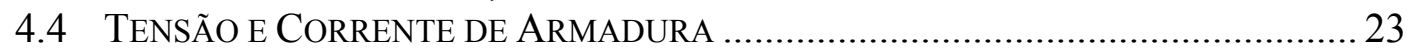

4.5 RESPOSTA TRANSITÓRIA DE VELOCIDADE DO MOTOR ..................................... 25

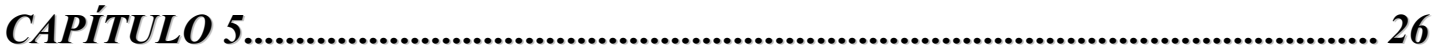

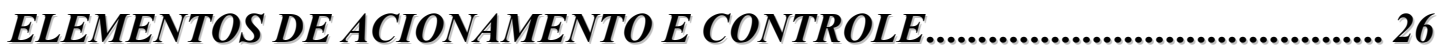

5.1 O CONTROLAdOR LÓGICO PROGRAMÁvEL ..................................................... 26

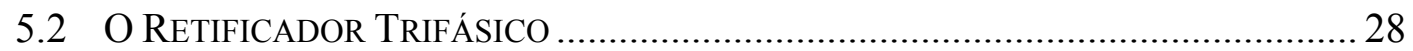

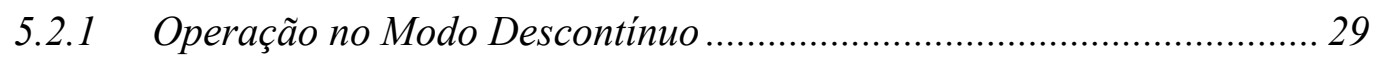

5.2.2 Modelagem do Retificador Trifásico ...................................................... 31

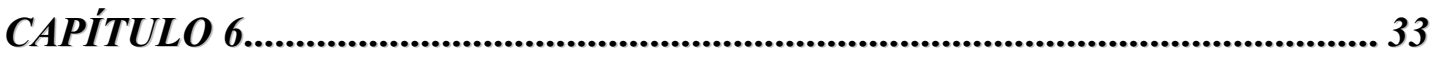

SISTEMA DE CONTROLE DO BOBINAMENTO .............................................. 33

6.1 FUNÇÃO DE TRANSFERÊNCIA DO MOTOR CC …................................................ 33

6.2 INTRODUÇÃo DAS VARIAÇÕES PARAMÉTRICAS PARA O SiSTEMA

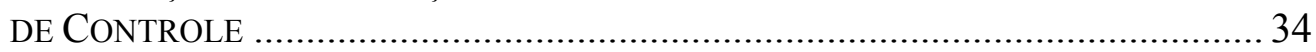

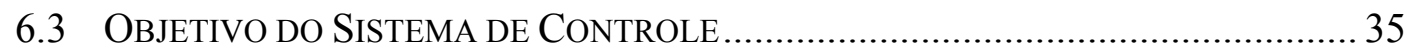

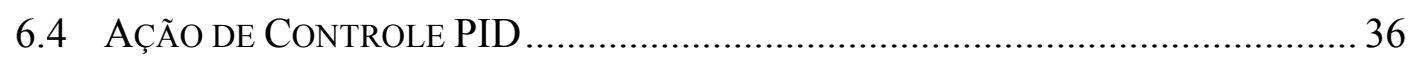

6.4.1 Ação de Controle Proporcional ................................................................ 36

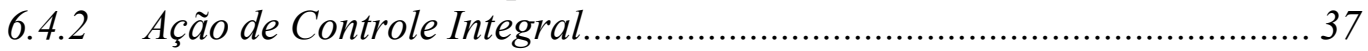

6.4.3 Ação de Controle Proporcional - Integral ........................................... 37

6.4.4 Ação de Controle Proporcional-Derivativa ......................................... 37

6.4.5 Ação de Controle PID.............................................................................. 38

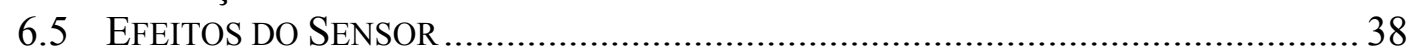

6.6 Sistema de CONTROLE EM MaLHA FeCHAdA ................................................ 39 


\section{SISTEMA DE CONTROLE DO BOBINAMENTO UTILIZANDO SENSOR

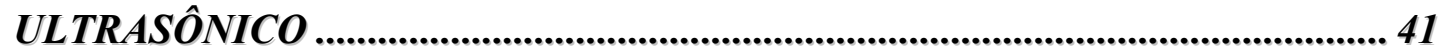

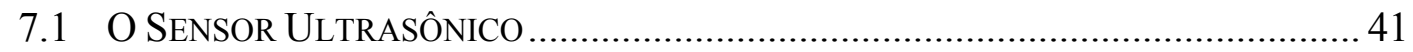

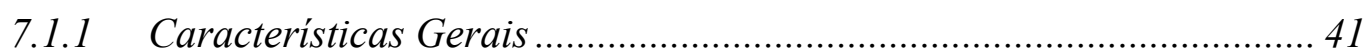

7.1.2 Posicionamento do Sensor ....................................................................... 43

7.1.3 Condicionamento de Sinal Para o Sensor ............................................... 43

7.2 Sistema DE BOBINAMENTO UTILIZANDO O SENSOR ULTRASÔNICO ................. 45

7.3 Sistema DE Bobinamento UtiLIZANDO CONTROLE PID COM SENSOR

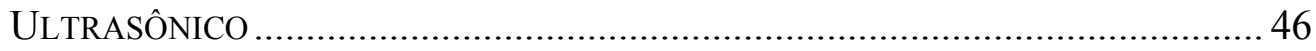

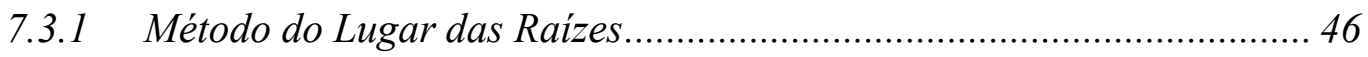

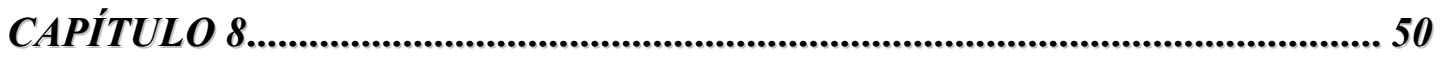

SISTEMA DE CONTROLE ROBUSTO................................................................50

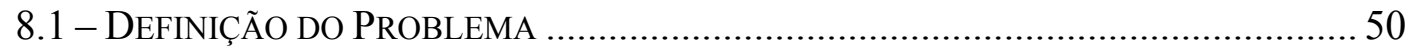

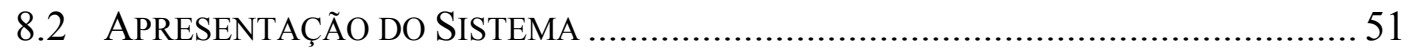

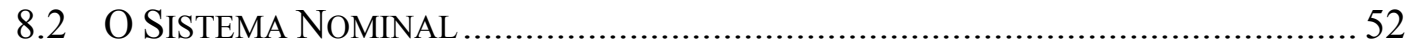

8.2.1 Estabilidade do Sistema Nominal ......................................................... 52

8.2.2 Desempenho do Sistema Nominal ......................................................... 53

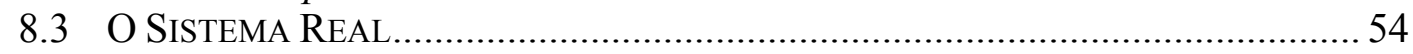

8.3.1 Representação do Erro de Modelagem................................................. 54

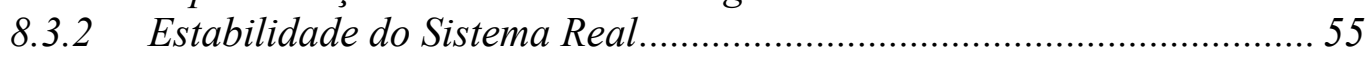

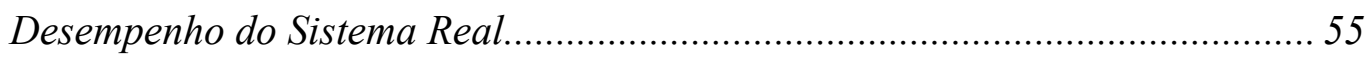

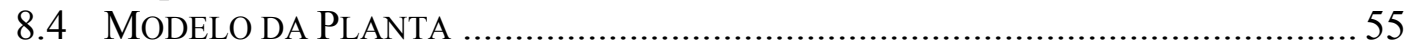

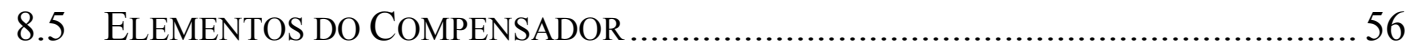

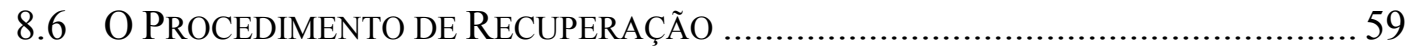

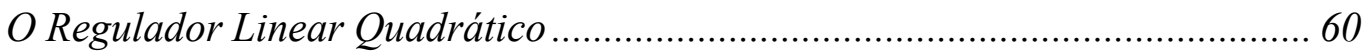

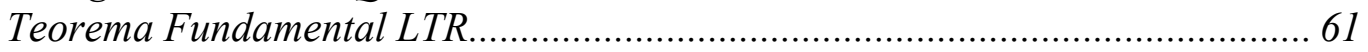

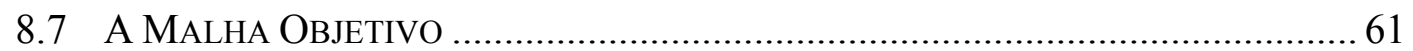

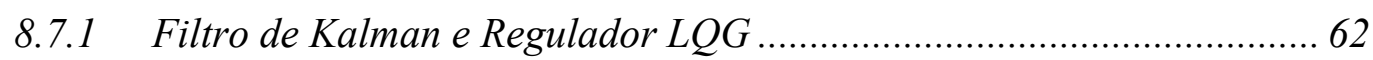

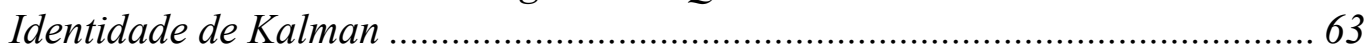

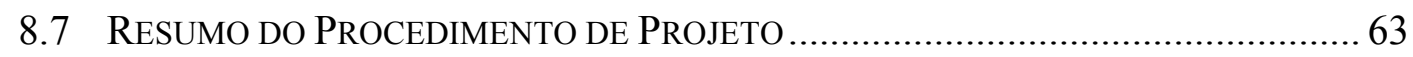

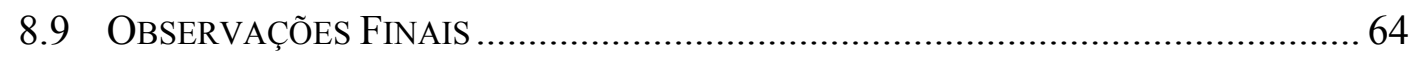

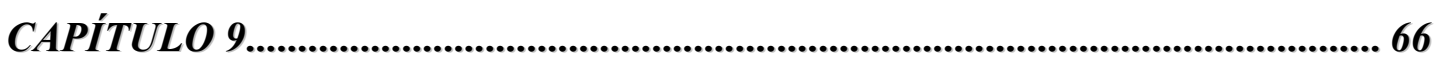

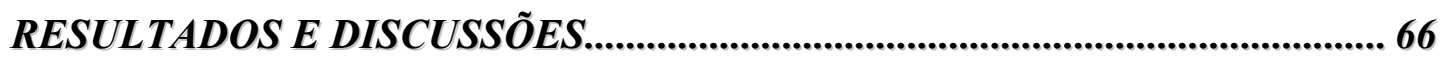

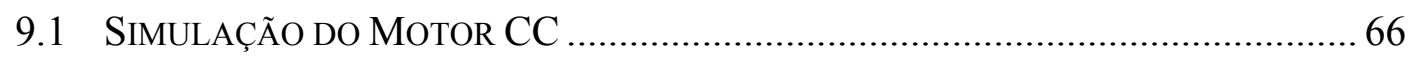

9.1.1 Resultados das Simulações do Motor CC .................................................6 67

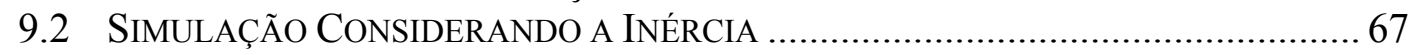

9.2.1 Resultados da Simulação Com o Rolo Bobinador ................................ 68

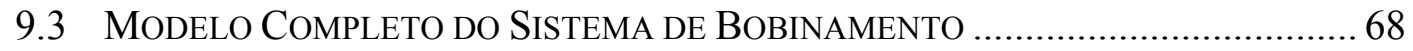

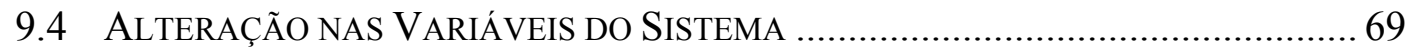

9.4.1 Variação da Densidade Volumétrica do Material ................................. 69

9.4.2 Variação da Espessura da Tira .............................................................. 75

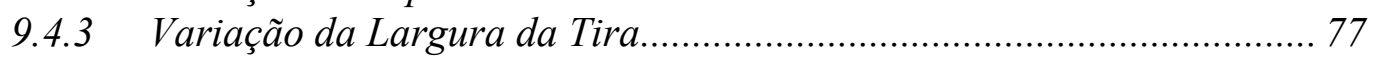


9.5 SiMUlaÇÕES DO SiSTEMA DE CONTROLE .......................................................... 78

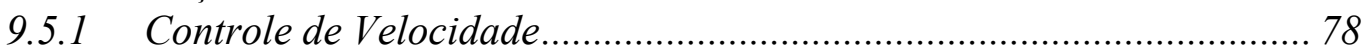

9.5.2 Gráficos de Força Aplicada à Tira e Raio de Bobinamento ................. 80

9.5.3 Potência de Acionamento..................................................................... 82

9.6 Resultados do Sistema de CONTROle Com Sensor Ultrasônico E

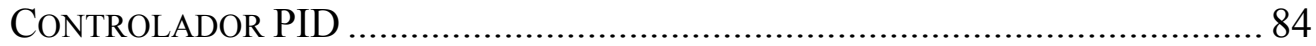

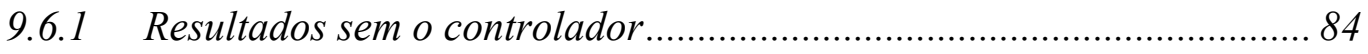

9.6.2 Resultados de Projeto do controlador .................................................... 86

9.7 Resultados do Sistema de Controle Robusto Com Sensor

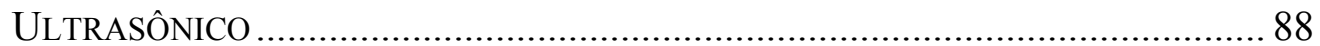

9.7.1 Valores Singulares da Planta Nominal e Real...................................... 88

9.7.2 Barreiras de Robustez e Malha Objetivo............................................... 90

9.7.3 Estabilidade da Malha Objetivo ............................................................ 90

9.7.4 Procedimento de Recuperação ............................................................. 91

9.7.5 Estabilidade do Sistema Final em Malha Fechada .............................. 92

9.7.6 Sistema Final com Compensador em Malha Fechada ......................... 93

9.7.7 Resposta ao Degrau na Referência....................................................... 93

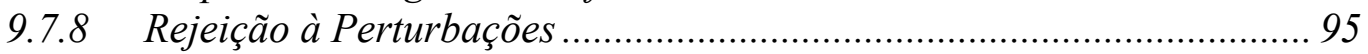

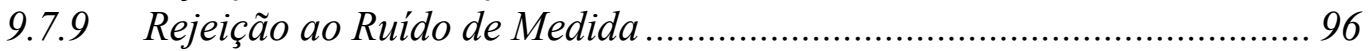

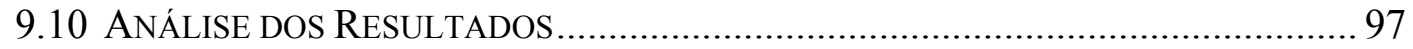

9.10.1 Sistema de Bobinamento Sem Controle ................................................. 97

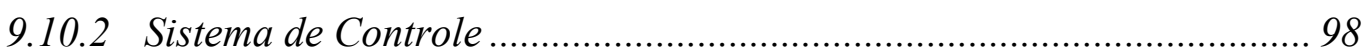

Sistema de Controle PID Com Sensor Ultrasônico .............................................. 98

9.10.4 Sistema de Controle Robusto ................................................................. 99

Comparação Entre o Controlador PID e o Compensador Robusto com Sensor

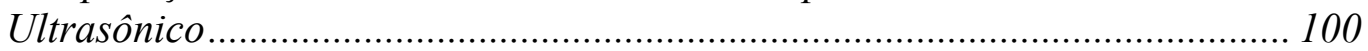

9.10.5 Considerações Sobre a Potência de Acionamento............................... 101

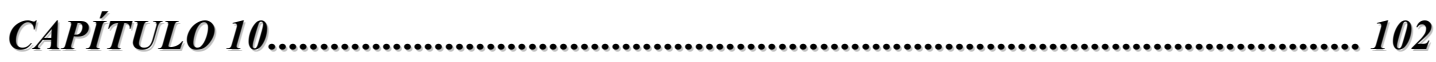

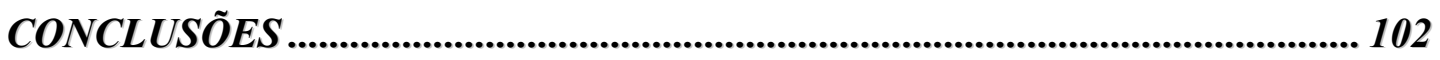

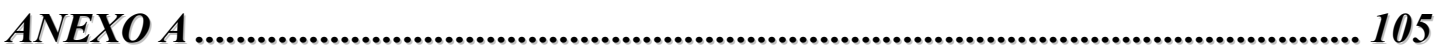

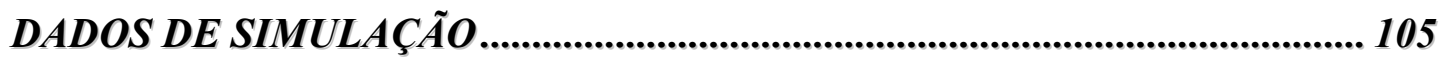

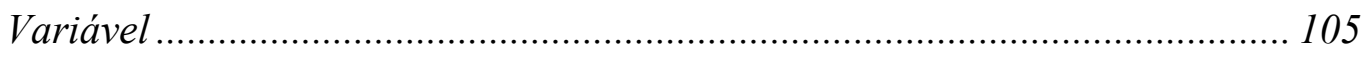

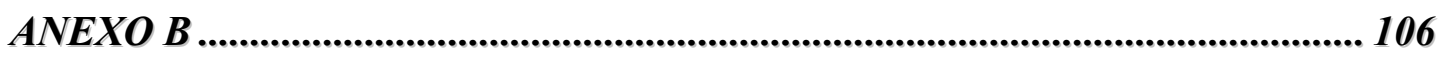

DEDUÇÃO DAS EQUAÇÕES DIFERENCIAIS DO SISTEMA DE

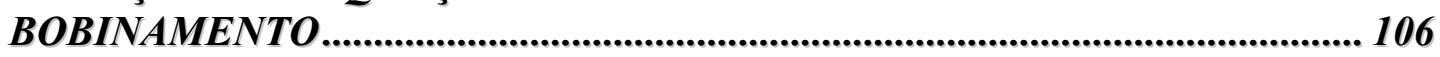

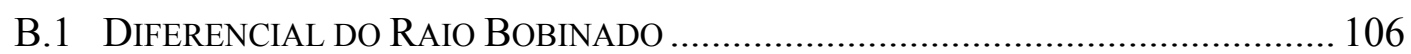

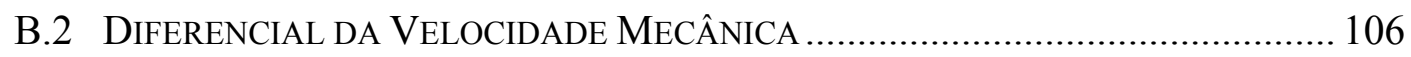

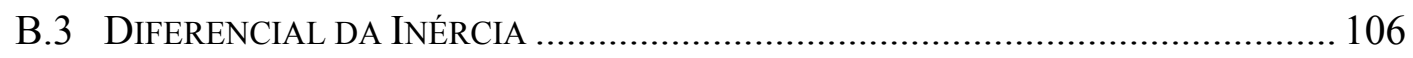


ANEXO C. 108

RESPOSTAS TRANSITÓRIAS DE CORRENTE E VELOCIDADE

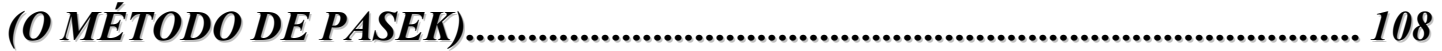

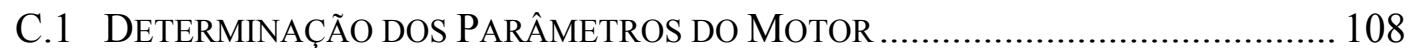

C.1.1 O Método de Pasek ......................................................................... 108

C.1.2 Resultados Experimentais ............................................................ 111

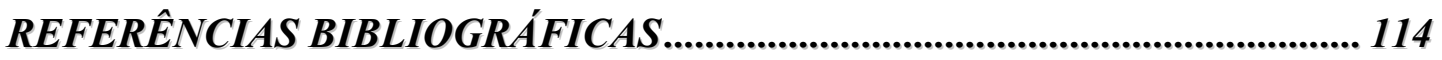

APÊNDICE A

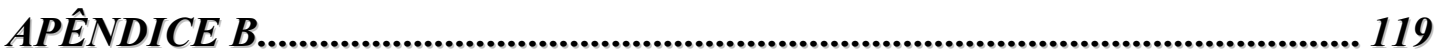




\section{LISTA DE FIGURAS}

FIGURA 2.1 - Representação da solidificação do aço entre os rolos 4

FIGURA 2.2 - A planta de LCT do tipo twin roll do IPT 5

FIGURA 2.3 - Análise da turbulência provocada pela injeção de líquido entre os rolos $\quad 7$

FIGURA 2.4 - Detalhe das saídas de aço do tundish 8

FIGURA 2.5 - Contenção Lateral entre os rolos laminadores 8

FIGURA 2.6 - Representação do sistema de bobinamento 10

FIGURA 2.7 - Diagrama de blocos do sistema de bobinamento 12

FIGURA 2.8 - Representação das implicações do bobinamento 12

$\begin{array}{lll}\text { FIGURA } 3.1 \text { - Modelo do rolo bobinador } & 14\end{array}$

FIGURA 3.2 - Representação do efeito da redução no momento de inércia 15

$\begin{array}{lll}\text { FIGURA } 3.3 \text { - Simples sistema de engrenagens } & 17\end{array}$

$\begin{array}{lll}\text { FIGURA } 3.4 \text { - Diagrama de corpo livre para o sistema de engrenagens } & 18\end{array}$

FIGURA 4.1 - Relação de tensão do tacogerador pela velocidade da bobinadeira 22

FIGURA 4.2 - Relação de velocidades da caixa de redução 22

FIGURA 4.3 - Tensão de saída do retificador ( motor em vazio ) 24

FIGURA 4.4 - Corrente de armadura (motor em vazio) 24

FIGURA 4.5 - Corrente de armadura (motor com carga do rolo bobinador) 25

FIGURA 4.6 - Curva de velocidade transitória do motor (motor em vazio) 25

$\begin{array}{lll}\text { FIGURA 5.1 - Estrutura básica de um CLP } & 27\end{array}$

FIGURA 5.2 - Retificador trifásico totalmente controlado 30

FIGURA $5.3-$ Retificador associado ao motor CC 31

FIGURA 6.1 - Diagrama do motor CC obtido através da FT 34

FIGURA 6.2 - Esquema em malha aberta do motor CC utilizando uma s-function 
FIGURA 6.3 - Esquema do sistema de bobinamento em malha fechada 39

FIGURA 7.1 - Posicionamento do sensor sobre a bobinadeira

FIGURA 7.2 - Condicionamento de sinal do sensor ultrasônico 44

FIGURA 7.3 - Sistema de bobinamento com sensor ultrasônico 45

FIGURA $7.4-$ Sistema de controle 46

FIGURA 7.5 - Localização dos pólos e zeros no plano complexo 49

FIGURA 8.1 - Diagrama de blocos do sistema 52

FIGURA 8.2 - Barreiras de baixa e alta freqüências 53

FIGURA 8.3 - Diagrama de blocos do regulador 57

FIGURA 8.4 - Diagrama de blocos do observador 58

FIGURA 8.5 - Diagrama de blocos do regulador com observador 58

FIGURA 8.6 - Diagrama de blocos do compensador 59

FIGURA 8.7 - Diagrama de blocos para análise do procedimento LTR $\quad 59$

FIGURA 8.8 - Diagrama de blocos do Filtro de Kalman 62

FIGURA 9.1 - Modelo computacional do motor CC no programa Matlab ${ }^{\circledR} /$ Simulink $\quad 66$

FIGURA 9.2 - Corrente de armadura $\quad 67$

$\begin{array}{lll}\text { FIGURA } 9.3 \text { - Velocidade mecânica } & 67\end{array}$

$\begin{array}{lll}\text { FIGURA } 9.4 \text { - Conjugado desenvolvido } & 67\end{array}$

$\begin{array}{lll}\text { FIGURA } 9.5 \text { - Corrente de armadura } & 68\end{array}$

$\begin{array}{lll}\text { FIGURA } 9.6 \text { - Velocidade mecânica } & 68\end{array}$

$\begin{array}{lll}\text { FIGURA } 9.7 \text { - Conjugado desenvolvido } & 68\end{array}$

FIGURA 9.8 - Modelo completo do sistema de bobinamento $\quad 70$

FIGURA 9.9 - Variação do raio ( Sistema de bobinamento completo ) 71

FIGURA 9.10 - Variação da inércia ( Sistema de bobinamento completo ) 71

FIGURA 9.11 - Conjugado desenvolvido ( Sistema de bobinamento completo ) 72

FIGURA 9.12 - Relação $\mathrm{T}_{\mathrm{cl}} / \mathrm{J}_{1 \mathrm{e}}$ ( Sistema de bobinamento completo ) 72

FIGURA 9.13 - Força aplicada à tira ( Sistema de bobinamento completo ) 73

FIGURA 9.14 - Velociade Linear ( Sistema de bobinamento completo ) 73

FIGURA 9.15 - Relação $T_{\mathrm{cl}} / \mathrm{J}_{1 \mathrm{e}}($ Variação de $\rho$ ) 74

FIGURA 9.16 - Força aplicada à tira ( Variação de $\rho$ ) 74

FIGURA 9.17 - Velocidade linear ( Variação de $\rho$ ) 75 
FIGURA 9.18 - Relação $\mathrm{T}_{\mathrm{c1}} / \mathrm{J}_{1 \mathrm{e}}$ ( Variação da espessura ) 75

FIGURA 9.19 - Força aplicada à tira ( Variação da espessura ) 76

FIGURA 9.20 - Velocidade linear ( Variação da espessura ) 76

FIGURA 9.21 - Relação $T_{\mathrm{cl}} / \mathrm{J}_{1 \mathrm{e}}$ ( Variação da Largura ) 77

FIGURA 9.22 - Força aplicada à tira ( Variação da Largura ) 77

$\begin{array}{ll}\text { FIGURA } 9.23 \text { - Velocidade linear ( Variação da Largura ) } & 78\end{array}$

FIGURA 9.24 - Velocidade Linear (Controle PID - tira de 1mm) 78

FIGURA 9.25 - Velocidade angular (Controle PID - tira de 1mm) 79

FIGURA 9.26 - Velocidade Linear (Controle PID - tira de 5mm) 79

FIGURA 9.27 - Velocidade angular (Controle PID - tira de 5mm) 80

$\begin{array}{ll}\text { FIGURA } 9.28 \text { - Força Aplicada à tira de } 1 \mathrm{~mm} & 81\end{array}$

FIGURA 9.29 - Força Aplicada à tira de 5mm $\quad 81$

FIGURA 9.30 - Variação do raio de bobinamento (tiras de $1 \mathrm{~mm}$ e 5mm) 82

FIGURA 9.31 - Potência eletromagnética ( tira de 1mm - considerando B) 82

FIGURA 9.32 - Potência eletromagnética ( tira de $1 \mathrm{~mm}$ - desconsiderando B) 83

FIGURA 9.33 - Potência eletromagnética ( tira de 5mm - considerando B) 83

FIGURA 9.34 - Potência eletromagnética ( tira de 5mm - desconsiderando B) 84

FIGURA 9.35 - Lugares das raízes para sistema de bobinamento com retificador 85

FIGURA 9.36 - Lugares das raízes para sistema de bobinamento sem retificador 86

FIGURA 9.37 - Lugares das raízes para sistema de bobinamento em malha fechada com controle do tipo PID 86

$\begin{array}{ll}\text { FIGURA } 9.38 \text { - Resposta ao degrau na referência } & 87\end{array}$

$\begin{array}{ll}\text { FIGURA } 9.39 \text { - Resposta ao degrau de carga } & 87\end{array}$

FIGURA 9.40 - Valor singular da planta nominal $\quad 89$

FIGURA 9.41 - Valores singulares da planta real 89

FIGURA 9.42 - Barreiras de robustez da estabilidade e desempenho e valores singulares da Malha Objetivo 90

FIGURA 9.43 - Estabilidade da Malha Objetivo com realimentação 91

FIGURA 9.44 - Representação do procedimento de recuperação 92

FIGURA 9.45 - Estabilidade do sistema final 92

FIGURA 9.46 - Sistema de controle final em malha fechada 93

FIGURA 9.47 - Acompanhamento do sinal de referência (Planta Nominal) 94 
FIGURA 9.48 - Acompanhamento do sinal de referência (Planta Real)

FIGURA 9.49 - Rejeição a um degrau unitário de perturbação (Planta Nominal) 95

FIGURA 9.50 - Rejeição a um degrau unitário de perturbação (Planta Real) 95

FIGURA 9.51 - Rejeição a um degrau unitário de ruído de medida (Planta Nominal) 96

FIGURA 9.52 - Rejeição a um degrau unitário de ruído de medida (Planta Real) 96

FIGURA 9.53 - Comparação entre o controlador PID e o compensador robusto 100

$\begin{array}{ll}\text { FIGURA } 9.54 \text { - Sinal de Controle (Controle PID) } & 101\end{array}$

FIGURA 9.55 - Sinal de Controle(Compensador robusto) 101

FIGURA C.1 - Modelo linear do motor CC 109

FIGURA C.2 - Resposta transitória de corrente e velocidade para o modelo de segunda ordem do motor CC 109

$\begin{array}{lll}\text { FIGURA C.3 - Ensaio no motor CC } & 110\end{array}$

FIGURA C.4 - Respostas transitórias de corrente para entrada degrau de tensão de $8 \mathrm{~V}$

FIGURA C.5 - Respostas transitórias de corrente para entrada degrau de tensão de $12 \mathrm{~V}$

FIGURA C.6 - Respostas transitórias de corrente para entrada degrau de tensão de $15 \mathrm{~V}$

FIGURA C.7 - Respostas transitórias de corrente para entrada degrau de tensão de $17 \mathrm{~V}$ 


\section{LISTA DE TABELAS}

TABELA 5.1 - Recursos de programação do CLP 28

TABELA 7.1 - Características do sensor ultrasônico 42

$\begin{array}{ll}\text { TABELA A.1 - Dados de simulação } & 105\end{array}$

$\begin{array}{ll}\text { TABELA C.1 - Valores numéricos de ensaio } & 112\end{array}$ 


\section{LISTA DE ABREVIATURAS e Siglas}

$\begin{array}{ll}\text { ACL } & \text { Ganho de Malha Fechada } \\ \text { Ampop } & \text { Amplificador Operacional } \\ \text { CC } & \text { Corrente Contínua } \\ \text { CLP } & \text { Controlador Lógico Programável } \\ \text { CNPq } & \text { Conselho Nacional de Desenvolvimento Científico e Tecnológico } \\ \text { DIMET } & \text { Divisão de Metalurgia } \\ \text { EAR } & \text { Equação Algébrica de Riccati } \\ \text { EESC } & \text { Escola de Engenharia de São Carlos } \\ \text { FK } & \text { Filtro de Kalman } \\ \text { IPT } & \text { Instituto de Pesquisas Tecnológicas } \\ \text { LCT } & \text { Lingotamento Contínuo de Tiras } \\ \text { LQG } & \text { Linear-Quadratic-Gaussian } \\ \text { LTR } & \text { Loop-Transfer-Recovery } \\ \text { PID } & \text { Proporcional - Integral - Derivativo } \\ \text { SPE } & \text { Semi Plano Esquerdo } \\ \text { TL } & \text { Transformada de Laplace } \\ \text { UCP } & \text { Unidade Central de Processamento } \\ \text { UFES } & \text { Universidade Federal do Espírito Santo } \\ \text { UNESP } & \text { Universidade Estadual Paulista } \\ \text { USP } & \text { Universidade de São Paulo }\end{array}$




\section{LISTA DE SímBOLOS}

$A_{n} \quad$ Matriz constante

B Coeficiente de atrito viscoso

$\mathrm{B}_{\mathrm{n}} \quad$ Matriz constante

C(s) Saída da planta genérica

$\mathrm{C}_{\mathrm{n}} \quad$ Matriz constante

$\mathrm{c}_{\mathrm{N}}(\mathrm{s}) \quad$ Função de transferência em malha fechada do sistema nominal

$\mathrm{c}_{\mathrm{R}}(\mathrm{s}) \quad$ Função de transferência em malha fechada do sistema real

D Posição do zero do termo derivativo

d Largura da tira

d(s) Perturbação na saída da planta com controle robusto

e Espessura da tira

e(t) Sinal de erro no domínio do tempo

E(s) Sinal de erro no domínio da freqüência - controle PID

e(s) Sinal de erro no domínio da freqüência

$\mathrm{e}_{\mathrm{a}} \quad$ Força contra-eletromotriz do motor CC

$\mathrm{E}_{\mathrm{a}}(\mathrm{s}) \quad$ Transformada de Laplace de $\mathrm{e}_{\mathrm{a}}$

$e_{\mathrm{M}} \quad$ Erro de modelagem

$\mathrm{e}_{\mathrm{x}}(\mathrm{t}) \quad$ Erro de estimativa

$\dot{e}_{x}(t) \quad$ Derivada de $\mathrm{e}_{\mathrm{x}}(\mathrm{t})$

$\mathrm{e}_{\mathrm{y}}(\mathrm{s}) \quad$ Erro de observação

F $\quad$ Força de tração aplicada à tira

$\mathrm{F}_{\mathrm{t}} \quad$ Força tangencial de contato nas engrenagens da caixa de redução

$\mathrm{F}_{\mathrm{r}} \quad$ Força aplicada aos rolos de laminação

G Matriz de ganhos de realimentação de estados 
G(s) Função de transferência de uma planta genérica

$\mathrm{G}_{\mathrm{N}} \quad$ Planta nominal

$\mathrm{g}_{\mathrm{N}}(\mathrm{s}) \quad$ Função de transferência da planta nominal

$\mathrm{g}_{\mathrm{R}}(\mathrm{s}) \quad$ Função de transferência da planta real

$\mathrm{G}_{\mathrm{R}} \quad$ Planta real

H Matriz de ganhos do Filtro de Kalman

H(s) Função de transferência do circuito de realimentação genérico

$\mathrm{i}\left(\mathrm{t}_{1}\right) \quad$ Valor de corrente de pico do método de Pasek

$\mathrm{i}\left(2 \mathrm{t}_{1}\right) \quad$ Valor de corrente para um tempo de duas vezes a corrente de pico no método de Pasek

ISC $\quad$ Corrente de armadura para $\mathrm{L}_{\mathrm{aq}}=0$, no método de Pasek

$\mathrm{i}_{\mathrm{a}} \quad$ Corrente de armadura do motor CC

Ia(s) Transformada de Laplace de $\mathrm{i}_{\mathrm{a}}$

J Momento de inércia

$\mathrm{J}_{\mathrm{m}} \quad$ Momento de inércia médio

$\mathrm{J}_{1} \quad$ Momento de inércia próprio do motor $\mathrm{CC}$

$\mathrm{J}_{1 \mathrm{e}} \quad$ Momento de inércia efetivo para o motor $\mathrm{CC}$ considerando o bobinamento

$\mathrm{J}_{2} \quad$ Momento de inércia do rolo bobinador

K Solução da EAR

$\mathrm{K}_{\mathrm{c}} \quad$ Ganho total do controlador PID

k(s) Função de transferência do compensador

$\mathrm{K}_{\mathrm{D}} \quad$ Ganho do retificador

$\mathrm{K}_{\mathrm{d}} \quad$ Ganho derivativo

$\mathrm{K}_{\mathrm{i}} \quad$ Ganho integral

$\mathrm{K}_{\mathrm{p}} \quad$ Ganho proporcional

$\mathrm{K}_{\mathrm{t}} \quad$ Constante de torque do motor CC

$\mathrm{K}_{\mathrm{u}} \quad$ Constante do sensor ultrasônico

$\mathrm{K}_{\mathrm{V}} \quad$ Constante de tensão do motor CC

L Parâmetro de projeto do compensador robusto (Matriz)

$\mathrm{L}_{\mathrm{c}} \quad$ Indutância

$\mathrm{L}_{\mathrm{aq}} \quad$ Indutância de armadura do motor CC 
$\mathrm{m} \quad$ Massa própria do rolo bobinador

M Massa genérica

$\mathrm{M}(\mathrm{t}) \quad$ Massa do rolo bobinador mais incremento de massa devido ao bobinamento

$\mathrm{N}_{\mathrm{a}} \quad$ Número de dentes da engrenagem maior

$\mathrm{N}_{\mathrm{b}} \quad$ Número de dentes da engrenagem menor

n Razão de caixa de redução de velocidade

$\mathrm{n}(\mathrm{s}) \quad$ Ruído de medida no sistema com controle robusto

p Operador de derivada em função do tempo

$p_{c} \quad$ Índice que define a envoltória da barreira de robustez do desempenho

P Posição do zero do termo proporcional

Q Matriz constante

$\mathrm{Q}_{\mathrm{c}} \quad$ Fator de mérito do circuito indutivo

R Matriz constante

$\mathrm{R}_{\mathrm{n}} \quad$ Raiz utilizada no projeto do controle PID

$\mathrm{R}(\mathrm{s}) \quad$ Referência da planta genérica

$\mathrm{R}_{\mathrm{c}} \quad$ Resistência

$\mathrm{R}_{\mathrm{a}} \quad$ Resistência de armadura do motor CC

$r_{a} \quad$ Raio da engrenagem maior

$\mathrm{r}_{\mathrm{b}} \quad$ Raio da engrenagem menor

$\mathrm{r}_{\mathrm{m}} \quad$ Raio médio de bobinamento

$\mathrm{r}_{1} \quad$ Raio interno do rolo bobinador

$\mathrm{r}_{2} \quad$ Raio externo do rolo bobinador

$\mathrm{r}(\mathrm{t}) \quad$ Incremento de raio devido ao bobinamento

r(s) Sinal de referência

$\mathrm{s}_{\mathrm{n}} \quad$ Pólos de malha fechada

$\mathrm{T}$ Conjugado desenvolvido pelo motor CC

$\mathrm{T}(\mathrm{s}) \quad$ Transformada de Laplace de $\mathrm{T}$

$\mathrm{T}_{\mathrm{C}} \quad$ Conjugado de carga

$\mathrm{T}_{\mathrm{cm}} \quad$ Conjugado de carga médio

$\mathrm{T}_{\mathrm{a}} \quad$ Conjugado na engrenagem maior

$\mathrm{T}_{\mathrm{b}} \quad$ Conjugado na engrenagem menor 
$\mathrm{T}_{\mathrm{ba}} \quad$ Conjugado de atrito no apoio da engrenagem maior

$\mathrm{T}_{\mathrm{bb}} \quad$ Conjugado de atrito no apoio da engrenagem menor

$\mathrm{T}_{\mathrm{C} 1} \quad$ Conjugado devido à força de tração na tira efetivo para o motor CC

$\mathrm{T}_{\mathrm{C} 1}(\mathrm{~s}) \quad$ Transformada de Laplace de $\mathrm{T}_{\mathrm{C} 1}$

$\mathrm{T}_{\mathrm{C} 2} \quad$ Conjugado devido à força de tração no rolo bobinador

$\mathrm{T}_{\mathrm{d}} \quad$ Tempo derivativo

$\mathrm{T}_{\mathrm{D}} \quad$ Tempo de atraso do retificador

$\mathrm{T}_{\mathrm{i}} \quad$ Tempo integral

$\mathrm{T}_{\mathrm{p}} \quad$ Tempo de chaveamento do retificador

$\mathrm{t}_{\mathrm{s}} \quad$ Tempo de acomodação

$\mathrm{u}(\mathrm{t}) \quad$ Sinal de controle no domínio do tempo

u(s) Sinal de controle no domínio da freqüência

U(s) Sinal de controle no domínio da freqüência - controle PID

$\mathrm{v}_{2} \quad$ Velocidade linear de bobinamento

$\mathrm{V}_{2}(\mathrm{~s}) \quad$ Transformada de Laplace de $\mathrm{v}_{2}$

$\mathrm{V}_{\mathrm{m}} \quad$ Tensão máxima de fase

$\mathrm{V}_{\text {médio }} \quad$ Tensão média de saída do retificador

$\mathrm{V}_{\mathrm{r}}(\mathrm{s}) \quad$ Transformada de Laplace da entrada de referência para o controlador

$\mathrm{V}_{\text {ta }} \quad$ Tensão terminal de armadura do motor CC

$\mathrm{V}_{\mathrm{TA}}(\mathrm{s}) \quad$ Transformada de Laplace de $\mathrm{V}_{\text {ta }}$

$\mathrm{x}(\mathrm{t}) \quad$ Vetor de estados

$\dot{x}(t) \quad$ Derivada de $\mathrm{x}(\mathrm{t})$

$\hat{x} \quad$ Estado estimado

$\varepsilon_{\mathrm{A}}(\mathrm{s}) \quad$ Erro aditivo

$\varepsilon_{\mathrm{M}}(\mathrm{s}) \quad$ Erro multiplicativo

$\omega \quad$ freqüência angular

$\omega_{\mathrm{m}} \quad$ Velocidade angular do eixo do motor CC

$\Omega_{\mathrm{m}}(\mathrm{s}) \quad$ Transformada de Laplace de $\omega_{\mathrm{m}}$

$\omega_{\mathrm{n}} \quad$ Freqüência natural amortecida

$\omega_{0} \quad$ Maior freqüência da barreira de robustez do desempenho

$\omega_{1} \quad$ Velocidade angular no eixo do motor $\mathrm{CC}$ no sistema de bobinamento

$\omega_{2} \quad$ Velocidade angular do rolo bobinador 
y(s) Sinal de saída com controle robusto

$\mu \quad$ Parâmetro de projeto do compensador robusto (Escalar)

$\alpha \quad$ Ângulo de disparo dos tiristores do retificador

$\rho \quad$ Densidade volumétrica do material da tira

$\rho_{\mathrm{c}} \quad$ Índice utilizado na solução da EAR do procedimento de recuperação

$\sigma \quad$ Valor singular

$\Sigma \quad$ Solução da EAR para o procedimento de recuperação

$\xi \quad$ Coeficiente de amortecimento

$\Omega_{2} \quad$ Velocidade angular da engrenagem maior

$\Omega_{4} \quad$ Velocidade angular da engrenagem menor 


\section{RESUMO}

LIMA, F. (2001). Modelagem, análise e controle de um sistema de bobinamento de tiras de aço. São Carlos, 2001, 104p. Dissertação (Mestrado) - Escola de Engenharia de São Carlos, Universidade de São Paulo.

Em metalurgia, a busca pela qualidade, baixo custo e alta produtividade têm feito empresas e institutos de pesquisa trabalharem juntos, procurando novas tecnologias que supram as necessidades do mercado. Dentre essas novas tecnologias, se destaca o processo de lingotamento contínuo de tiras de aço, utilizando o conceito de twin roll, cuja proposição inicial foi sugerida no século XIX por Henry Bessemer. Este trabalho apresenta a modelagem, análise e controle de um sistema de bobinamento de tiras de aço produzidas através de lingotamento contínuo do tipo twin roll , em uma planta localizada no Instituto de Pesquisas Tecnológicas de São Paulo. As características do processo foram primeiramente apresentadas. A modelagem matemática do sistema de bobinamento foi realizada, levando-se em consideração os componentes envolvidos no sistema. As variações paramétricas foram então evidenciadas. O sistema de controle foi primeiramente implementado utilizando-se um controlador do tipo PID, pelo fato desse tipo de controle ser altamente difundido industrialmente. Para maior precisão do sistema de controle, propôs-se a introdução de um sensor ultrasônico para medição das variações do raio de bobinamento. Por último realizou-se o projeto de um compensador robusto utilizando a metodologia LQG/LTR. Para a realização das simulações utilizou-se o programa Matlab/simulink ${ }^{\circledR}$.

Palavras-chave: bobinamento, modelagem, controle, lingotamento contínuo. 


\section{ABSTRACT}

LIMA, F. Modelling, analysis and control of a steel strip coiling system. São Carlos, 2001, 104p. Dissertação (Mestrado) - Escola de Engenharia de São Carlos, Universidade de São Paulo.

In metallurgy, the quest for quality, low cost, and high productivity have resulted in companies and research institutes working together to find new technologies to satisfy the customer demand. Among these new technologies is the direct steel strip casting, using the twin roll concept suggested in the 19th century by Henry Bessemer. This work presents the modelling, analysis and control of a steel strip coiling system using twin roll direct casting, in a plant installed at the Technological Research Institute of Sao Paulo. The characteristics of the process are first introduced. The mathematic modelling of the coiling system used, take into account the system components. The parametric changes were adressed. The control system was first implemented using a PID controller as this kind of control is highly used in the industry. An ultrasonic sensor was introduced in the system to improve the control precision by coiling radius measurement. Last a robust compensator using the LQG/LTR method was designed. The simulations were done using Matlab $^{\circledR} /$ Simulink software.

Keywords: coiling, modelling, control, direct casting. 


\section{CAPÍtULO 1}

\section{INTRODUÇÃO}

\subsection{Lingotamento Contínuo de Tiras (LCT)}

O processo de lingotamento contínuo de tiras foi introduzido há aproximadamente quarenta anos, para produção de tiras de alumínio, segundo COOK et al. (1995). Anteriormente ao processo de lingotamento contínuo o processo predominante era o de lingotamento estático. No lingotamento estático, o aço líquido era despejado em moldes chamados lingoteiras, as quais possuíam formas e volumes pré-definidos. Após o resfriamento, o lingote era conduzido à transformações mecânicas, como a laminação, para obtenção do produto final.

No processo de lingotamento contínuo, o aço líquido é vazado em moldes em que apenas a largura e a espessura são definidas. O lingote é então continuamente extraído pelo fundo produzindo placas, chapas ou tarugos. Na saída da estação de lingotamento contínuo, uma bancada de corte permite que o produto seja obtido com o comprimento desejado.

Entre as vantagens do lingotamento contínuo sobre o lingotamento estático podem-se citar, de acordo com IRVING (1993):

- Aumento da produtividade

- Redução do consumo de energia

- Redução do esforço humano

- Aumento da qualidade do produto 
- Baixa emissão de poluentes ao meio ambiente e aos operadores da planta

- Redução nos níveis de estoque e prazos de entrega

- Redução de custos para novas plantas

O controle das condições e parâmetros do processo é vital para o sucesso comercial do LCT, conforme CARBONARA (1988).

No processo de lingotamento contínuo é possível obter-se tiras de aço de dimensões muito próximas da dimensão final de muitos produtos siderúrgicos.

Dentre as novas tecnologias de LCT, se destaca o processo de lingotamento contínuo de tiras de aço utilizando o conceito de twin roll (COOK et al. (1995); SHIN et al. (1995) e YUN et al. (2000)), cuja proposição inicial foi sugerida no século XIX por Henry Bessemer (LEE et al. (1996)).

Neste processo, dois rolos de mesma dimensão, refrigerados e separados um do outro por uma distância equivalente à espessura da tira laminada, giram em sentidos opostos. O aço líquido passa entre os rolos, resultando na saída destes uma tira com espessura definida. Após ser produzida através dos rolos, a tira é então conduzida a uma esteira, onde jatos de água são borrifados na mesma. Isto promove um certo resfriamento à tira, sendo inclusive um fator determinante de características finais do material, como a dureza. Finalmente, ao sair da esteira a tira entra em um rolo, acionado por um motor, onde então é bobinada. Esta etapa caracteriza o final do processo.

É exatamente nesta etapa final que este trabalho está concentrado, visando o controle do bobinamento de tiras de aço produzidas através do processo de LCT do tipo twin roll instalado no Instituto de Pesquisas Tecnológicas de São Paulo, Divisão de Metalurgia (IPT-DIMET). O bobinamento deve respeitar algumas características, para que a qualidade da tira produzida não seja prejudicada. Durante o bobinamento, uma força constante deve ser aplicada à tira. Uma força excessiva pode causar deformações na tira, já que apesar do resfriamento recebido através dos jatos de água, na etapa anterior, a tira chega até a bobinadeira em um estado ainda maleável.

Por outro lado, uma força insuficiente implica um bobinamento ineficaz. A aplicação de uma força adequada à tira, portanto, melhora a qualidade da tira 
produzida com relação às suas propriedades mecânicas e também magnéticas do material (ZAPUSKALOV (1999)).

Essa característica de controle de força, associada a um conjugado de carga e um momento de inércia variáveis no tempo, definem a característica de acionamento do motor.

\subsection{Organização Do Trabalho}

No Capítulo 2, uma descrição do processo de LCT do tipo twin roll do IPT será apresentada, detalhando as características principais do processo.

No Capítulo 3, é apresentada a modelagem matemática do sistema de bobinamento, apresentando as equações do motor de corrente contínua e introduzindo as variações particulares ao sistema.

No Capítulo 4 são apresentados os resultados de ensaio no motor de corrente contínua responsável pela movimentação do rolo bobinador, com ênfase no método de Pasek para determinação dos parâmetros do motor.

No Capítulo 5, os componentes de acionamento e controle disponíveis na planta do IPT são apresentados e detalhados.

No Capítulo 6 uma primeira tentativa de controle do sistema de bobinamento é realizada, levando-se em consideração a não-linearidade do sistema. O controlador primeiramente utilizado para simulação foi do tipo Proporcional, Integral e Derivativo (PID), cuja motivação deve-se à ampla aplicação industrial desse tipo de controle.

No Capítulo 7 propõe-se a inclusão de um sensor ultrasônico na planta, com a intenção de tornar o projeto do controlador mais preciso. Novamente, o controlador utilizado foi o PID.

No Capítulo 8, é apresentada a teoria de controle robusto utilizando a metodologia LQG/LTR destacando a sua aplicação ao sistema de bobinamento.

No Capítulo 9, apresenta-se os resultados de simulação para o sistema de bobinamento, como também os resultados obtidos para os sistemas de controle propostos. Neste capítulo, faz-se também as análises dos resultados obtidos.

Finalmente no Capítulo 10 são apresentadas as conclusões e as propostas de continuidade para o trabalho. 


\section{O PROCESSO LCT DO TIPO TWIN ROLL}

\subsection{Características Gerais}

Dentre os processos de lingotamento contínuo, o que alcançou maior sucesso foi o do tipo twin roll onde dois rolos de mesma dimensão giram em sentidos opostos, sendo que a distância entre os mesmos é equivalente à espessura da tira produzida. O aço líquido é depositado entre os dois rolos, formando uma piscina de aço entre os mesmos. Os rolos, refrigerados à água, retiram calor do aço proporcionando uma solidificação do mesmo e ocasionando a formação da tira. $\mathrm{O}$ ponto em que o aço se solidifica é denominado ponto de colapso. A figura 2.1 ilustra essa condição.

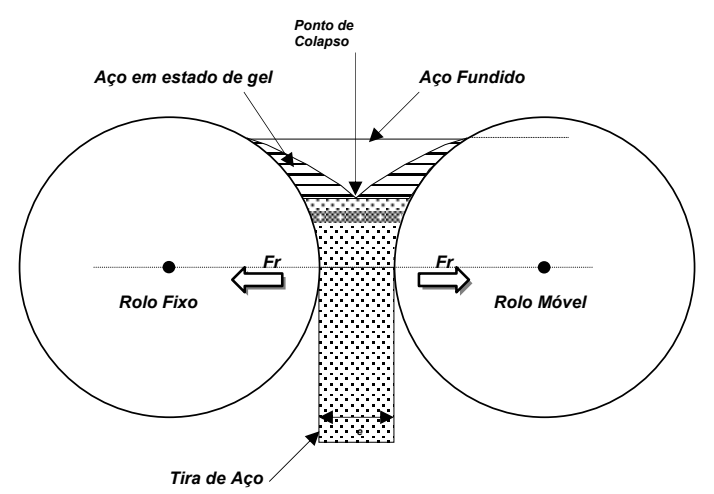

FIGURA 2.1 - Representação da solidificação do aço entre os rolos

O ponto de colapso é fator determinante da qualidade da tira produzida. A altura do ponto de colapso depende da temperatura a qual o aço chega nos rolos, bem 
como da velocidade angular dos mesmos, já que através desta velocidade é possível se controlar a altura da piscina entre os rolos a qual o ponto de colapso está intimamente ligado.

Após a passagem entre os rolos, a tira produzida já se encontra em sua espessura final, como descrito anteriormente.

\subsection{O Processo LCT no IPT}

\subsubsection{Aquecimento do Aço}

A figura 2.2 apresenta a planta de LCT do tipo twin roll do IPT. O aço no estado sólido é primeiramente aquecido até que atinja o ponto de fusão. A temperatura de fusão para o aço Inox, utilizado no IPT, está em torno de $1600^{\circ} \mathrm{C}$. Para tal finalidade é utilizado um forno de indução. $\mathrm{O}$ aço já em estado líquido é então transferido para um tanque denominado distribuidor. Durante a transferência do aço líquido do forno de indução para o distribuidor ocorre um resfriamento do aço por convecção, sendo que um possível reaquecimento do mesmo pode se fazer necessário.

A manutenção da temperatura do aço em valores apropriados é de fundamental importância para o controle do processo, já que o ponto de colapso é dependente desta temperatura, como apresentado.

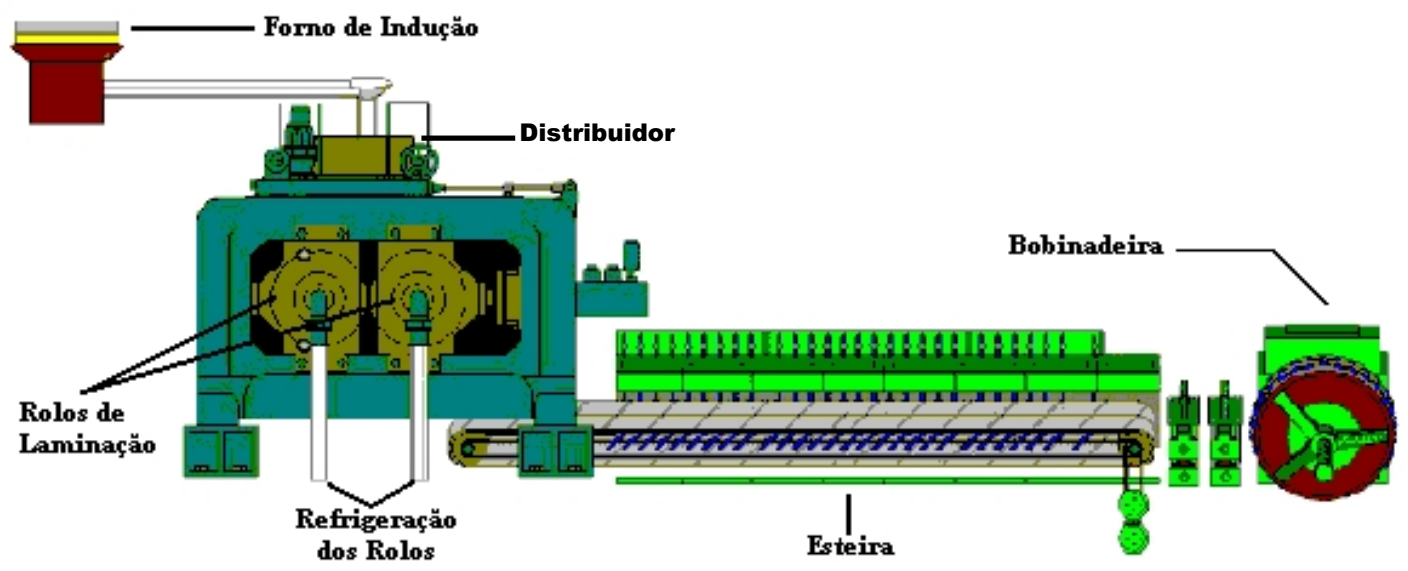

FIGURA 2.2 - A planta de LCT do tipo twin roll do IPT 


\subsubsection{Injeção de Aço Líquido Entre os Rolos}

A passagem do aço líquido do distribuidor para os rolos é controlada através de uma válvula, até o presente momento, manualmente. Esta etapa será controlada futuramente de forma automática através de um sensor que detectará o nível da piscina de aço formada entre os rolos e então um atuador receberá um sinal para que a válvula seja deslocada, liberando mais, ou menos aço.

Tomando-se ainda em consideração o controle da injeção de aço entre os rolos, além da liberação da quantidade ideal de aço, também é necessário que essa injeção seja feita de maneira adequada, de forma a controlar a turbulência na superfície de aço da piscina.

\subsubsection{Análise de Turbulência na Injeção de Aço}

Para a análise desta turbulência, a Divisão de Metalurgia do IPT desenvolveu um modelo em acrílico do sistema de injeção de líquido entre os rolos. O modelo utiliza água como líquido de injeção, sendo que esta escolha está relacionada ao fato da água à temperatura de $20^{\circ} \mathrm{C}$ possuir o mesmo número de Reynolds do aço à temperatura de $1600^{\circ} \mathrm{C}$. De forma prática, isso significa que todas as propriedades de dinâmica do fluido do aço a $1600^{\circ} \mathrm{C}$ são equivalentes para a água a $20^{\circ} \mathrm{C}$. Em SHIN et al. (1995) encontra-se a utilização deste mesmo artifício. A figura 2.3 apresenta o modelo desenvolvido pelo IPT-DIMET, destacando a turbulência entre os rolos.

$\mathrm{Na}$ figura 2.3 percebe-se claramente que caso o aço seja injetado diretamente do bico da válvula entre os rolos, uma grande turbulência pode ocorrer no nível da piscina formada entre os rolos.

\subsubsection{Redução da Turbulência}

Para que o efeito de turbulência fosse minimizado, o IPT-DIMET desenvolveu um segundo distribuidor, denominado distribuidor submerso, intermediário entre a saída do primeiro distribuidor e os rolos de laminação. Este distribuidor submerso possui uma entrada de admissão do aço líquido e seis saídas para injeção do mesmo entre os rolos. 


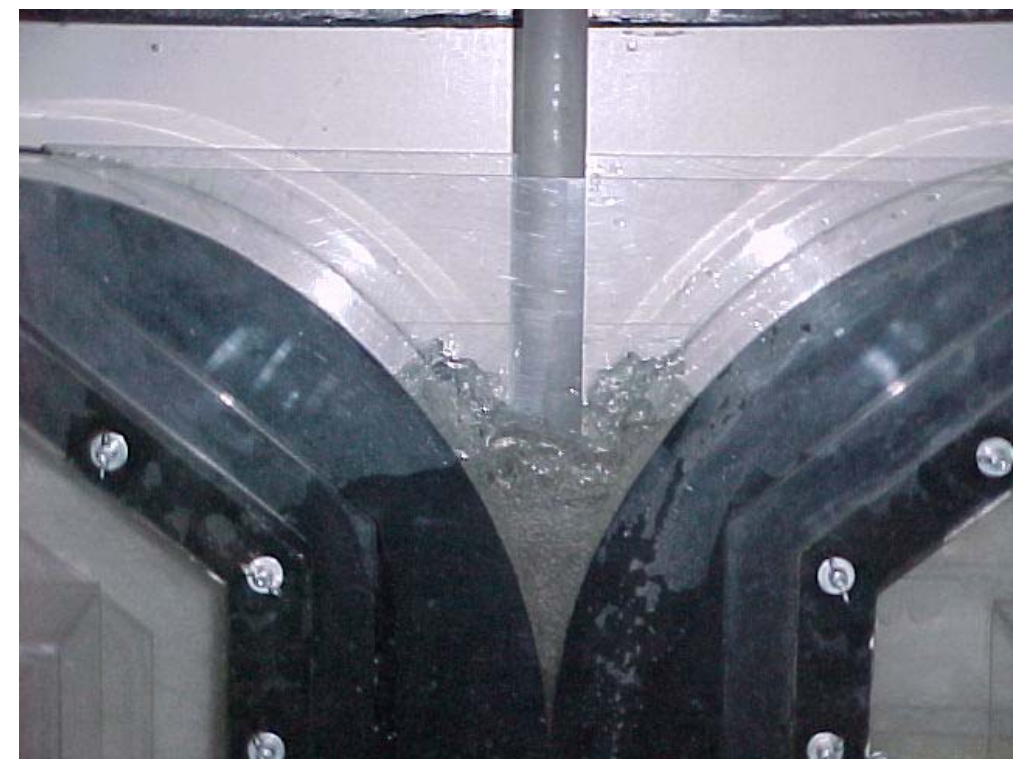

FIGURA 2.3 - Análise da turbulência provocada pela injeção de líquido entre os rolos

As seis aberturas para injeção do aço proporcionam uma injeção do aço entre os rolos de forma transversal, reduzindo a turbulência. A figura 2.4 apresenta o distribuidor submerso em um ensaio com aço realizado no IPT-DIMET. Nesta figura ficam nítidas as seis saídas do distribuidor desenvolvido e a injeção de aço entre os rolos ocorrendo na forma transversal.

Após o controle da injeção de aço entre os rolos, a próxima etapa do processo de LCT consiste no controle da velocidade angular dos rolos de laminação e do controle da força aplicada aos mesmos.

\subsubsection{Contenção Lateral}

Para evitar imperfeições nas bordas da tira produzida, é necessário que se faça uma contenção lateral do aço fundido que está sendo injetado entre os rolos. Essa contenção é vista na figura 2.5 , constituindo-se em mais uma importante e crítica etapa do processo, conforme YUN et al. (2000); SHIN et al. (1995); IRVING (1993) e LIANG et al. (1997). Na figura 2.5, é apresentada uma vista superior dos rolos, onde é destacada uma das placas de contenção lateral. 


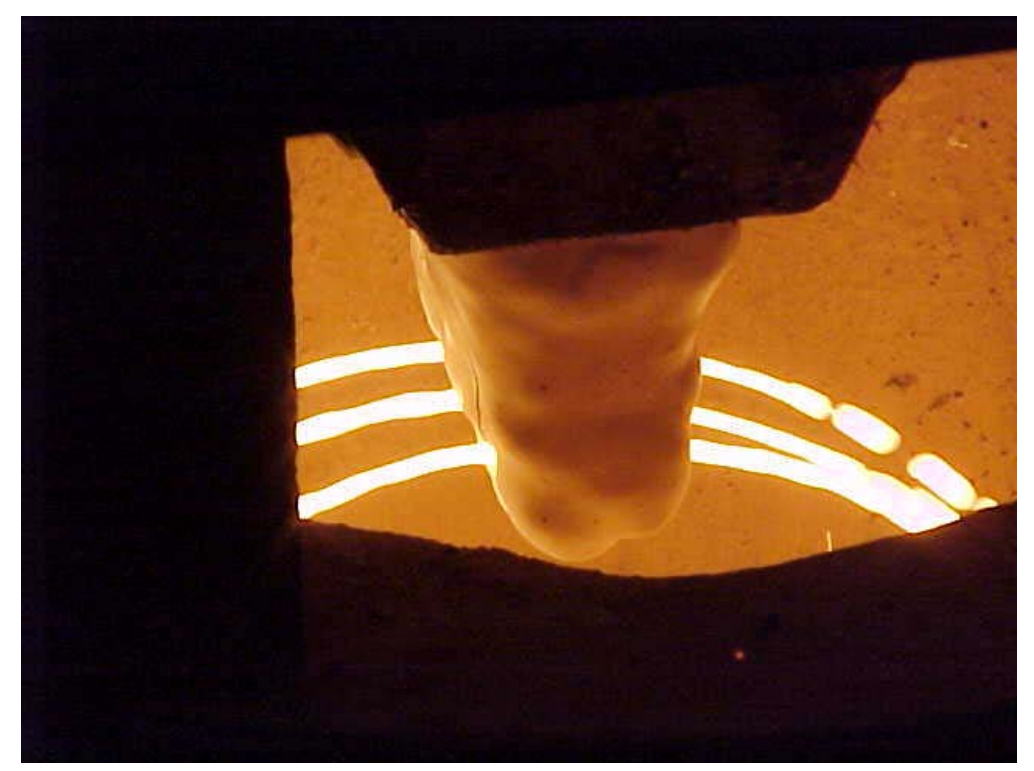

FIGURA 2.4 - Detalhe das saídas de aço do distribuidor

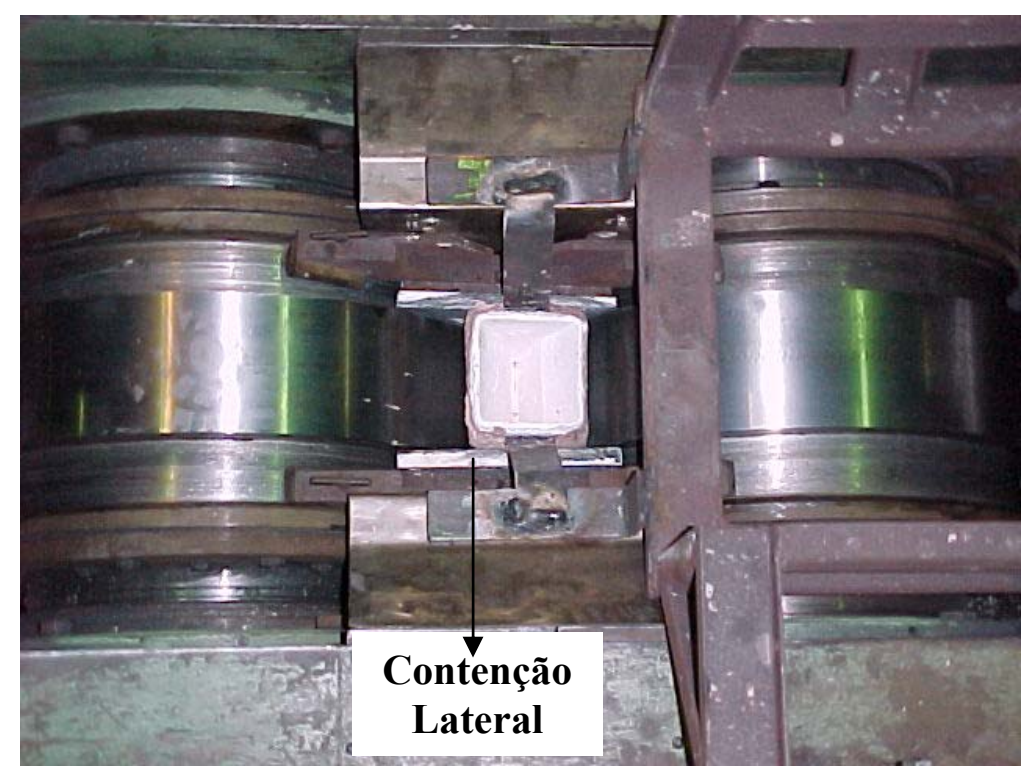

FIGURA 2.5 - Contenção Lateral entre os rolos laminadores

\subsubsection{Controle de Velocidade dos Rolos}

A velocidade é controlada através de um Controlador Lógico Programável (CLP), que recebe um sinal de realimentação de velocidade proveniente de um tacogerador acoplado aos motores de corrente contínua que movimentam os rolos 
laminadores. Os motores que movimentam os rolos laminadores possuem potência de $45 \mathrm{KW}$. O CLP processa o sinal de realimentação de velocidade do tacogerador e envia um sinal de controle para um retificador trifásico totalmente controlado, que então varia a tensão de alimentação dos motores, variando a sua velocidade angular. Os valores de velocidade dos rolos podem ser monitorados através de um programa supervisório.

\subsubsection{Controle da Força Aplicada aos Rolos}

Para controle da força aplicada aos rolos existe uma célula de carga acoplada ao rolo móvel. Esta célula de carga é responsável pela realimentação do sistema de controle da força e espaçamento entre os rolos. O CLP recebe o sinal da célula de carga, processa-os e então envia um sinal de controle para atuadores hidráulicos que atuam sobre o rolo móvel, apresentado na figura 2.1.

Finalmente, após as etapas de controle anteriormente descritas, a tira deixa os rolos de laminação já em sua espessura final. As etapas seguintes consistem no transporte da tira produzida através de uma esteira, onde a mesma recebe resfriamento através de jatos d'água e posteriormente, finalizando o processo, a tira produzida chega até um rolo bobinador.

A etapa de bobinamento constitui o final do processo de produção da tira de aço. No capítulo a seguir, apresenta-se a modelagem matemática para o sistema de bobinamento de tiras de aço do IPT.

\subsubsection{Considerações Sobre o Bobinamento}

\subsubsection{Tensão Mecânica Aplicada à Tira}

Em sistemas de bobinamento de tiras, sabe-se que as bobinas são formadas sob considerável tensão, conforme TSELIKOV \& SMIRNOV (1965). Esta tensão deve ser mantida aproximadamente constante durante todo o bobinamento para que o mesmo tenha eficácia. Como mencionado, a tira recebe um resfriamento antes de chegar ao rolo bobinador. Porém, a tira chega até o rolo bobinador em um estado ainda maleável. 
Por esse motivo, e por se saber que o bobinamento pode ter um efeito negativo sobre as propriedades mecânicas do material (GOES (1998)), o controle da tensão mecânica aplicada à tira torna-se importante.

O limite de tensão exercido na tira é alcançado quando a força de tração dividida pela seção transversal do material, denominado de stress, não ultrapasse o stress admitido pelo material (LARKE (1957)). Uma tensão insuficiente, porém, pode provocar o aparecimento de enrugamentos na tira, segundo YUN et al. (2000).

Em sistemas de bobinamento, a tensão aplicada à tira pode ser mantida aproximadamente constante pelo decréscimo gradual da velocidade rotacional do rolo bobinador, sendo este decréscimo diretamente proporcional ao aumento do diâmetro da bobina, como proposto por LARKE (1957).

Outro fator importante para o sistema de bobinamento é o controle da temperatura em que a tira chega até o rolo bobinador segundo (GUO (1997) e ZAPUSKALOV (1999)), não sendo, entretanto, objetivo deste estudo.

A figura 2.6 apresenta uma representação do sistema de bobinamento e suas principais variáveis envolvidas.

$\mathrm{Na}$ figura 2.6, F é a força de tração aplicada à tira, $\mathrm{v}$ é a velocidade linear de bobinamento, $r(t)$ é o acréscimo de raio devido ao bobinamento, $r_{1}$ e $r_{2}$ são o raio interno e externo do rolo bobinador, respectivamente.

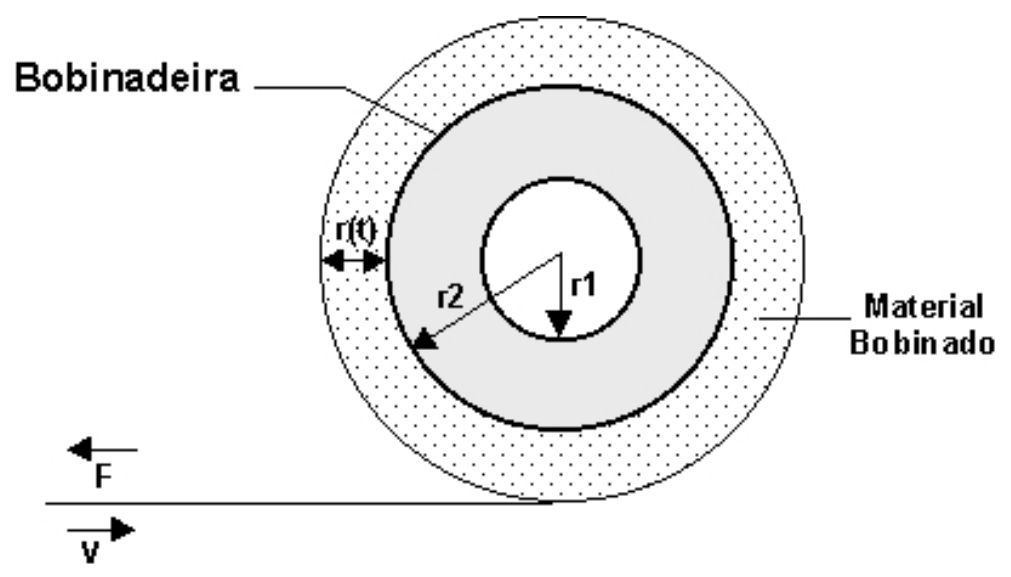

FIGURA 2.6 - Representação do sistema de bobinamento 


\subsubsection{Acionamento do Sistema de Bobinamento do IPT}

O motor responsável por movimentar o rolo bobinador no processo LCT do IPT é de corrente contínua, o qual possui típica aplicação na indústria siderúrgica (WILDI (1991)), com potência de 28,4 KW. Eletricamente, as considerações sobre o controle da tensão aplicada à tira implicam um acionamento do motor à potência aproximadamente constante, conforme LEONHARD (1985). Posteriormente a validação desta afirmação será discutida.

A figura 2.7 apresenta o diagrama de blocos do sistema de bobinamento da máquina de LCT do IPT. O sistema de bobinamento consiste, portanto, de um motor de corrente contínua acionado por um retificador trifásico de onda completa, totalmente controlado. $\mathrm{O}$ acoplamento do motor com o rolo bobinador é feito através de uma caixa mecânica de redução de velocidade. A realimentação de velocidade é feita através de um tacogerador acoplado ao motor.

A velocidade da bobinadeira pode ser monitorada através de um programa supervisório. O programa supervisório permite também que o operador a qualquer momento altere a velocidade da bobinadeira desde que o programa supervisório esteja operando na condição manual.

Até o momento, com o programa supervisório operando na forma automática, a velocidade angular da bobinadeira está sincronizada com a velocidade angular dos rolos de laminação. Como exposto anteriormente, essa não é uma condição ideal para o controle do bobinamento.

A velocidade angular do rolo bobinador deve ser reduzida gradualmente, conforme o incremento do diâmetro da bobina, de forma que a velocidade linear seja mantida constante, conforme DENTI FILHO (1996 a); DENTI FILHO (1996 b) e DENTI FILHO (1999). Este é o controle que será implementado para a bobinadeira.

\subsubsection{Implicações do Bobinamento}

O bobinamento da tira de aço implica em variações de conjugado de carga e inércia para o motor de corrente contínua. A caixa de redução, porém tem atuação decisiva sobre essas variações. De forma simplificada, pode-se isolar os blocos do 
diagrama da figura 2.7 de maneira a ressaltar os efeitos do bobinamento da tira, conforme figura 2.8 .

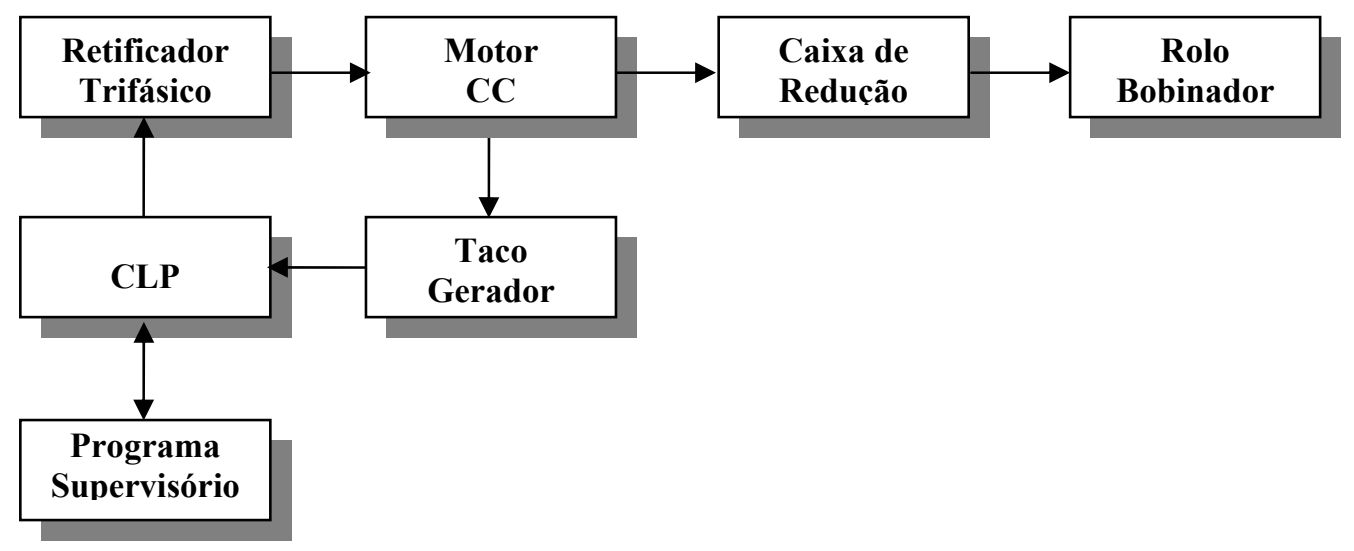

FIGURA 2.7 - Diagrama de blocos do sistema de bobinamento

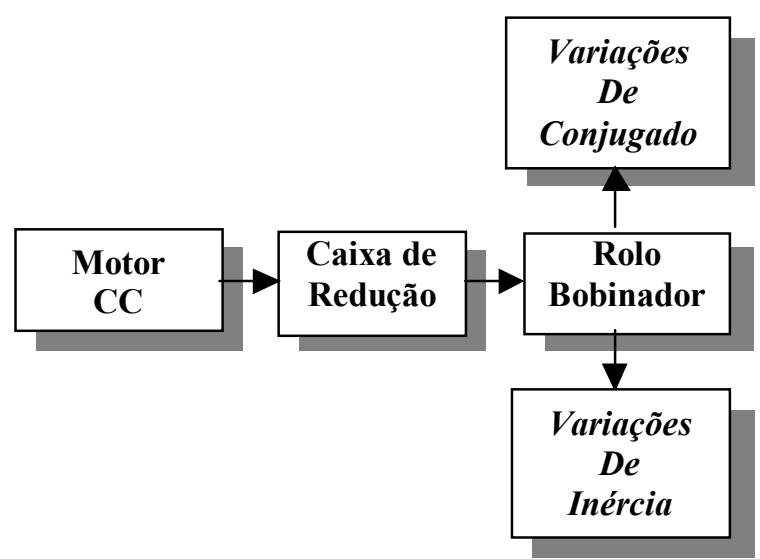

FIGURA 2.8 - Representação das implicações do bobinamento 


\section{CAPÍtulO 3}

\section{ModelAgem do SISTEMA DE BobINAMENTO}

Neste capítulo, apresenta-se a modelagem matemática do sistema de bobinamento, levando-se em consideração as equações eletromecânicas do motor de corrente contínua, responsável pela movimentação do rolo bobinador, e as implicações dos acréscimos de massa e raio sobre o sistema. Os efeitos da caixa de redução de velocidades sobre a inércia e conjugado do sistema são também incluídos.

\subsection{Equações do Motor CC}

Primeiramente, apresentam-se as equações para o motor de corrente contínua operando sem carga. As equações fundamentais do motor CC de excitação independente apresentadas em FITZGERALD et al. (1975), encontram-se reproduzidas nas equações (3.1) e (3.2):

$$
\begin{gathered}
V_{t a}=e_{a}+L_{a q} p i_{a}+R_{a} i_{a} \\
T=J p \omega_{m}+T_{C}
\end{gathered}
$$

onde a força contra - eletromotriz e $e_{\mathrm{a}}$ pode ser calculada como sendo $\mathrm{K}_{\mathrm{v}} \cdot \omega_{\mathrm{m}}$, e $\mathrm{K}_{\mathrm{v}}$ é a constante de tensão do motor de corrente contínua; o conjugado desenvolvido pelo motor (T), definido pela equação (3.2) é expresso por $\mathrm{K}_{\mathrm{t}} \cdot \mathrm{i}_{\mathrm{a}}$, onde $\mathrm{K}_{\mathrm{t}}$ é a constante de torque do motor de corrente contínua; as constantes $K_{v}$ e $K_{t}$ são dependentes de 
parâmetros construtivos do motor de corrente contínua e se unidades consistentes forem utilizadas, elas possuem o mesmo valor numérico, conforme GARCIA (1997).

Ao modelo final do motor, acrescentou-se o termo B. $\omega$ como conjugado resistente na equação mecânica, onde B é o atrito viscoso.

\subsection{Relação de Redução de Velocidade}

O sistema de bobinamento do IPT é dotado de uma caixa de redução entre o motor e o rolo bobinador. Após a realização do ensaio na bobinadeira (Capítulo 4), concluiu-se que a relação de redução existente é de aproximadamente seis vezes.

\subsection{Inércia do Sistema}

O cálculo da inércia, utilizando um modelo aproximado para o rolo bobinador apresentado na figura 3.1, é encontrado na equação (3.3). Esta configuração do rolo bobinador foi utilizada com a finalidade de simplificar o equacionamento do sistema sem perda de precisão.

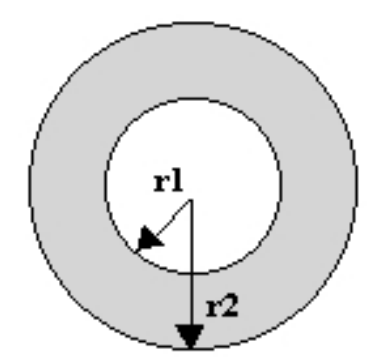

FIGURA 3.1 - Modelo do rolo bobinador

$$
J_{2}=\frac{M}{2}\left(r_{1}^{2}+r_{2}^{2}\right)
$$

onde $\mathrm{M}$ é a massa do rolo bobinador e $\mathrm{J}_{2}$ seu momento de inércia.

Com os valores de massa e raio do rolo bobinador, contidos no Anexo A, e com o auxílio da equação (3.3) tem-se o resultado do momento de inércia para o rolo bobinador apresentado pela equação (3.4). 


$$
J_{2}=\frac{100}{2}\left(0,1^{2}+0,25^{2}\right)=3,625 \mathrm{Kg} \cdot \mathrm{m}^{2}
$$

\subsubsection{Efeito da Redução na Inércia}

Considerando o valor de inércia calculado na equação (3.4) como sendo a inércia do rolo bobinador, a inércia efetiva para o motor, considerando $f 1=f 2$ na figura 3.2, será dada pela equação (3.5), conforme LEONHARD (1985) :

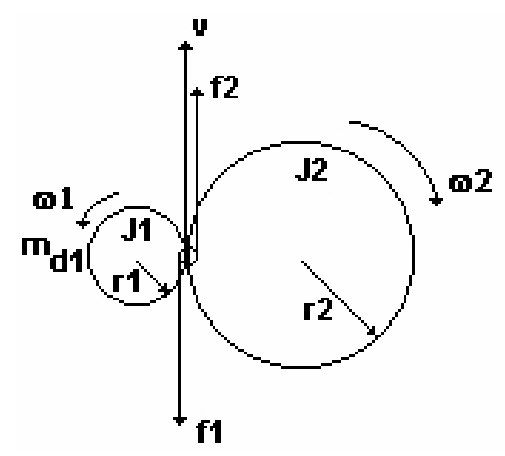

FIGURA 3.2 - Representação do efeito da redução no momento de inércia LEONHARD (1985)

$$
J_{1 e}=J_{1}+\left(\frac{\omega_{2}}{\omega_{1}}\right)^{2} J_{2}
$$

onde $\mathrm{J}_{1 \mathrm{e}}$ é o momento de inércia efetivo para o motor, resultante da inércia própria do motor $\mathrm{J}_{1}$, mais a inércia do rolo bobinador $\mathrm{J}_{2}$, refletida através da caixa de redução. As variáveis $\omega 1$ e $\omega 2$ representam os valores da velocidade angular no eixo do motor e no rolo bobinador, respectivamente. $\mathrm{O}$ valor de $\mathrm{J}_{1 \mathrm{e}}$ para o sistema será dado então pela equação (3.6).

$$
J_{1 e}=0,4+\left(\frac{1}{6}\right)^{2} 3,625=0,5 \mathrm{Kgm}^{2}
$$




\subsection{Variação do Conjugado de Carga}

O bobinamento da tira de aço determina, além de uma variação do momento de inércia, uma variação do conjugado de carga, devido à força de tração na tira solicitado ao motor. Da mesma forma que a caixa de redução de velocidades tem influência sobre a inércia do sistema, esta também tem influência sobre o conjugado de carga do sistema. O ítem 3.4.1 a seguir apresenta esta influência de forma detalhada.

\subsubsection{Efeito da Redução no Conjugado de Carga}

A seguir define-se a relação de conjugados de entrada e saída da caixa de redução com a intenção de definir o efeito que a força aplicada à tira bobinada tem sob o motor. A relação entre conjugados em um sistema de engrenagens é definida como se segue, por SHEARER et al. (1971). As figuras 3.3 e 3.4, apresentam as variáveis do sistema discutido.

Nas equações (3.7) e (3.8), os conjugados desenvolvidos nos lados com maior e menor número de dentes nas engrenagens, $T_{a}$ e $T_{b}$ respectivamente, são equacionados em termos dos torques de atrito nos apoios, $\mathrm{T}_{\mathrm{ba}}$ e $\mathrm{T}_{\mathrm{bb}}$, e da força tangencial de contato aplicada às engrenagens, $\mathrm{F}_{\mathrm{t}}$.

$$
\begin{aligned}
& \mathrm{T}_{\mathrm{a}}-\mathrm{T}_{\mathrm{ba}}=\mathrm{F}_{\mathrm{t}} \mathrm{r}_{\mathrm{a}} \\
& \mathrm{T}_{\mathrm{b}}-\mathrm{T}_{\mathrm{bb}}=\mathrm{F}_{\mathrm{t}} \mathrm{r}_{\mathrm{b}}
\end{aligned}
$$

Por outro lado, considerando-se que a velocidade angular do suporte $\left(\Omega_{1}\right)$ seja nula, e que não haja escorregamento entre as engrenagens, tem-se a relação apresentada pela equação (3.9), onde o sinal negativo indica que as engrenagens estão girando em sentidos opostos. Ainda na equação (3.9), $\mathrm{r}_{\mathrm{a}} / \mathrm{r}_{\mathrm{b}}=\mathrm{N}_{\mathrm{a}} / \mathrm{N}_{\mathrm{b}}$ representa a razão entre as engrenagens, que como apresentado anteriormente é igual a seis para o caso em estudo.

$$
\frac{\Omega_{4}}{\Omega_{2}}=-\frac{r_{a}}{r_{b}}=\frac{N_{a}}{N_{b}}=n
$$




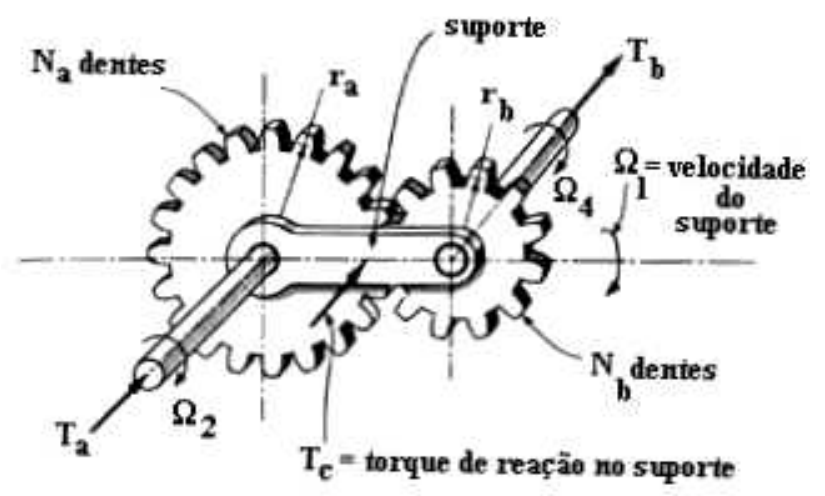

(a)

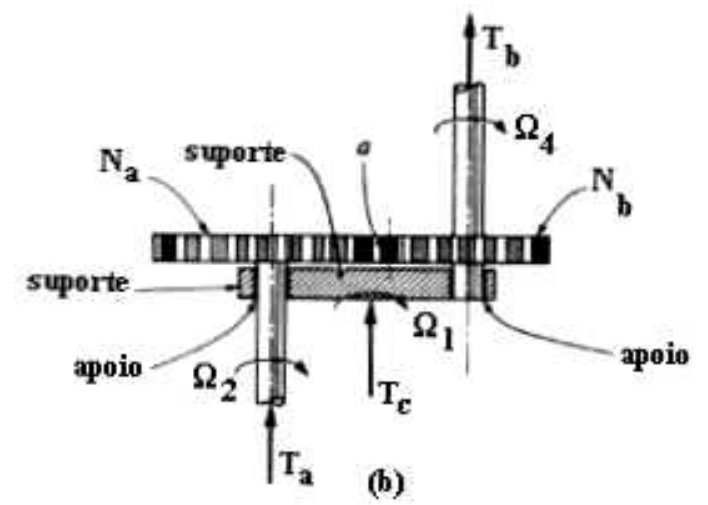

FIGURA 3.3 - Simples sistema de engrenagens .

(a) vista em perspectiva; (b) vista superior; SHEARER et al. (1971).

Complementando, $\Omega_{4}$ e $\Omega_{2}$ são as velocidades angulares em cada eixo das engrenagens, conforme indicado na figura 3.4. Com os torques de atrito desprezados e utilizando os resultados obtidos nas equações (3.7), (3.8) e (3.9) chega-se à equação (3.10).

$$
\frac{T_{b}}{T_{a}}=\frac{r_{b}}{r_{a}}=\frac{N_{b}}{N_{a}}=\frac{-1}{n}
$$

Logo, conclui-se que o conjugado exigido para o motor será $1 / \mathrm{n}$ vezes menor que o conjugado de carga, produzido pela força de tração na tira. Em TAO \& SADLER (1995) encontra-se a modelagem de um sistema eletromecânico tomando-se a mesma consideração da eq. (3.10). 

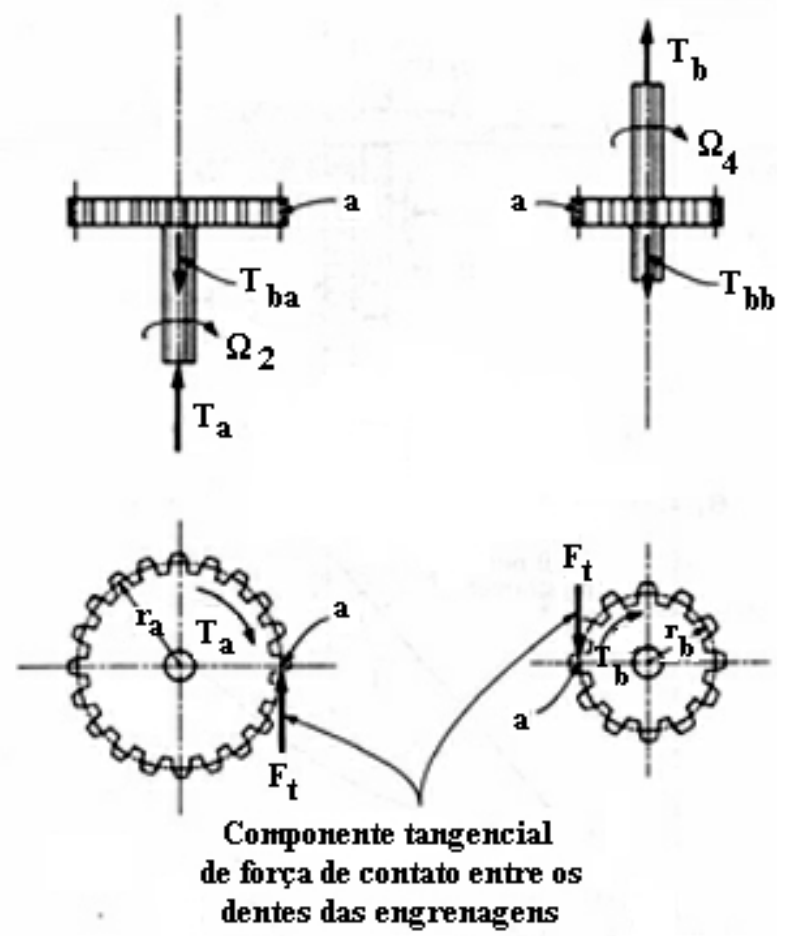

(a)

(b)

FIGURA 3.4 - Diagrama de corpo livre para o sistema de engrenagens.

(a) apenas engrenagem a; (b) apenas engrenagem b; SHEARER et al. (1971).

\subsection{Modelagem Matemática do Sistema de Bobinamento}

Com as considerações feitas a respeito da influência da caixa de redução de velocidades sobre o conjugado de carga e inércia do sistema de bobinamento, podese realizar agora o modelagem matemática do referido sistema, determinando o comportamento de suas variáveis.

A variação do raio bobinado em função do tempo é dado pela equação (3.11).

$$
r(t)=\int_{0}^{t} \frac{\omega_{2} e}{2 \pi} d t
$$


onde $\omega_{2}$ é a velocidade angular do rolo bobinador, t é o tempo de bobinamento e $e$ é a espessura da tira bobinada.

O momento de inércia para a configuração da figura 3.1, conforme foi adotado para o rolo bobinador, levando em consideração a variação do raio com o bobinamento é dado pela equação (3.12).

$$
J_{2}=\frac{M}{2}\left(r_{1}^{2}+\left(r_{2}+r(t)\right)^{2}\right)
$$

onde $\mathrm{M}$ é a massa total do rolo bobinador, mais o incremento de massa devido ao bobinamento da tira. Isso define uma massa variável com o tempo, apresentada pela equação (3.13).

$$
M(t)=m+\left(2 \pi r_{2} r(t)+\pi r(t)^{2}\right) \rho d
$$

onde $\mathrm{m}$ é a massa própria do rolo bobinador, $\rho$ é a densidade volumétrica do material do qual é constituída a tira, e $d$ é a largura da tira. Dessa forma, o momento de inércia final para o rolo bobinador é dado pela equação (3.14).

$$
J_{2}=\frac{M(t)}{2}\left(r_{1}^{2}+\left(r_{2}+r(t)\right)^{2}\right)
$$

A variação do conjugado de carga, devido à força de tração na tira com o bobinamento é dada pela equação (3.15), onde F é a tensão mecânica a qual a tira está submetida e Tc2(t) é o conjugado de carga no tempo, devido a essa força de tração. O efeito deste conjugado para o motor é apresentado na equação (3.16).

$$
\begin{aligned}
& T_{C 2}(t)=F\left(r_{2}+r(t)\right) \\
& T_{C 1}(t)=\frac{F}{n}\left(r_{2}+r(t)\right)
\end{aligned}
$$


O momento de inércia efetivo para o eixo do motor, considerando-se as equações (3.5), (3.13) e (3.14), é apresentado na equação (3.17).

$$
J_{1 e}=J_{1}+\left(\frac{\omega_{2}}{\omega_{1}}\right)^{2}\left(\frac{\left(m+\left(2 \pi r_{2} r(t)+\pi r(t)^{2}\right) \rho d\right)\left(r_{1}^{2}+\left(r_{2}+r(t)\right)^{2}\right)}{2}\right)
$$

Considerando-se o conjugado devido a inércia do rolo bobinador, a força aplicada à tira pode ser calculada através da equação (3.18).

$$
F=\frac{J_{2}(t) p \omega_{2}(t)+\omega_{2}(t) p J_{2}(t)}{\left(r_{2}+r(t)\right)}
$$




\section{CAPÍtulo 4}

\section{RESULTADOS DE ENSAIOS}

O presente capítulo tem por objetivo apresentar os resultados de ensaios realizados na bobinadeira do IPT. Os ensaios realizados visaram determinar tanto as condições de operação da bobinadeira como quantificar a relação de tensão $\mathrm{x}$ velocidade do tacogerador, relação de velocidades da caixa de redução.

No Anexo $\mathrm{C}$ as respostas transitórias de corrente de armadura e velocidade mecânica são apresentas juntamente com a teoria do método de Pasek.

\subsection{Tacogerador}

\subsubsection{Curva de Tensão x Velocidade}

A figura 4.1 apresenta os valores de velocidade da bobinadeira, obtidos com o auxílio de um tacômetro, pela tensão de saída do tacogerador.

Através do gráfico da figura 4.1, pode-se determinar o ganho do tacogerador, em função da velocidade, utilizado nas simulações envolvendo o sistema de controle.

\subsection{Curva para Caixa de Redução}

O gráfico da figura 4.2 apresenta a curva de velocidade no eixo do motor, pela velocidade do rolo bobinador, determinando então a razão de velocidade da caixa de redução. 


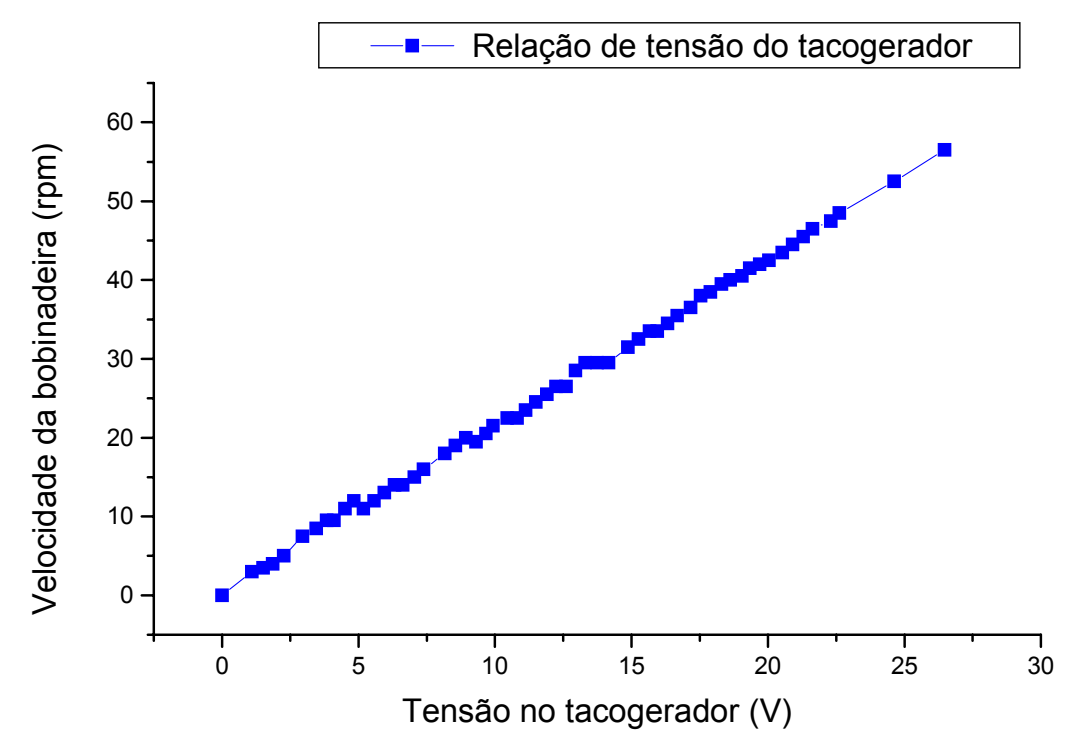

FIGURA 4.1 - Relação de tensão do tacogerador pela velocidade da bobinadeira

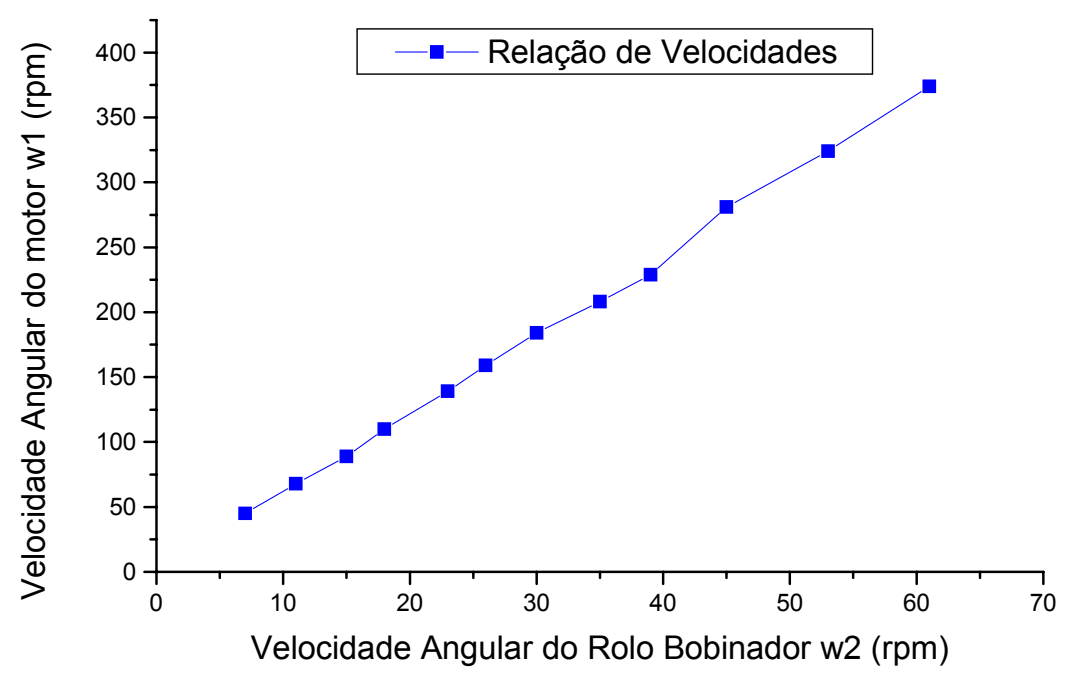

FIGURA 4.2 - Relação de velocidades da caixa de redução 


\subsection{Respostas de Tensão, Corrente e Velocidade}

Após determinadas a relação (tensão x velocidade) do tacogerador e relação da caixa de redução de velocidade, anteriormente apresentadas, apresentam-se agora as respostas obtidas para a tensão de armadura fornecida pelo retificador, corrente transitória de armadura e velocidade transitória. Para que estas curvas pudessem ser obtidas, montou-se o experimento apresentado na figura C.3 (página 110). O osciloscópio utilizado para as medições foi o TEKTRONIX ${ }^{\circledR}$ modelo THS720P. Para medição da corrente de armadura, foi utilizado um sensor de efeito Hall, calibrado de maneira que 1A de corrente na entrada do sensor fornecesse uma tensão de saída de $1 \mathrm{~V}$.

Com as respostas de corrente e tensão de armadura obtidas, constatou-se que o retificador trifásico responsável pela alimentação do motor está operando no modo descontínuo. As formas de onda as quais caracterizam este tipo de operação do retificador são apresentadas no ítem a seguir sendo as características deste tipo de operação serão discutidas com maior profundidade no capítulo 5.

\subsection{Tensão e Corrente de Armadura}

As figuras 4.3 e 4.4, apresentam as formas de onda de tensão de saída do retificador e de corrente de armadura do motor, respectivamente, caracterizando a operação no modo descontínuo, conforme mencionado anteriormente. As respectivas formas de onda referem-se ao motor operando em vazio. A figura 4.5 apresenta a forma de onda de corrente de armadura, porém com o rolo bobinador acoplado ao motor através da caixa de redução de velocidades. As formas de onda são relativas a um ensaio com uma velocidade do rolo bobinador de $18 \mathrm{rpm}$ (medida), e tensão média de $17 \mathrm{~V}$ indicada no retificador. 


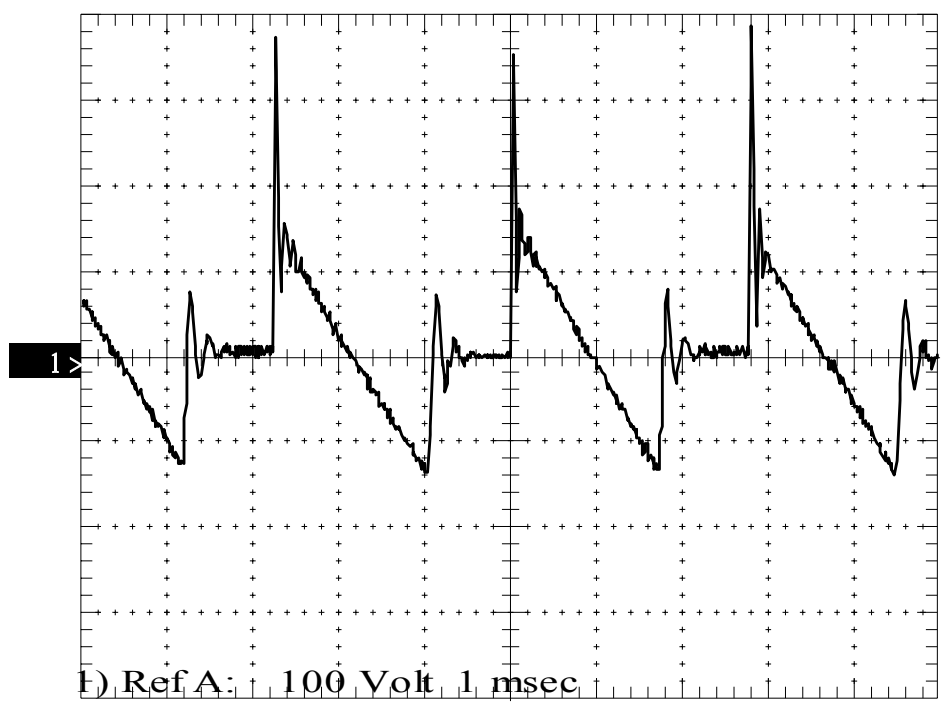

FIGURA 4.3 - Tensão de saída do retificador ( motor em vazio )

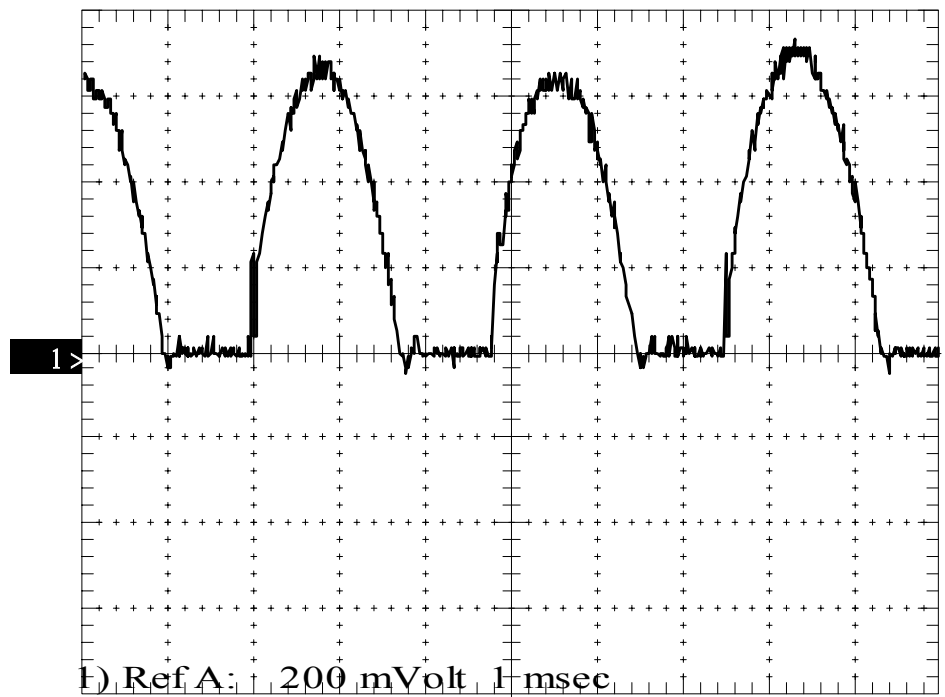

VALOR DE CORRENTE: $200 \mathrm{~mA} / \mathrm{Div}$. $(1 \mathrm{~A} / \mathrm{V})$

FIGURA 4.4 - Corrente de armadura (motor em vazio) 


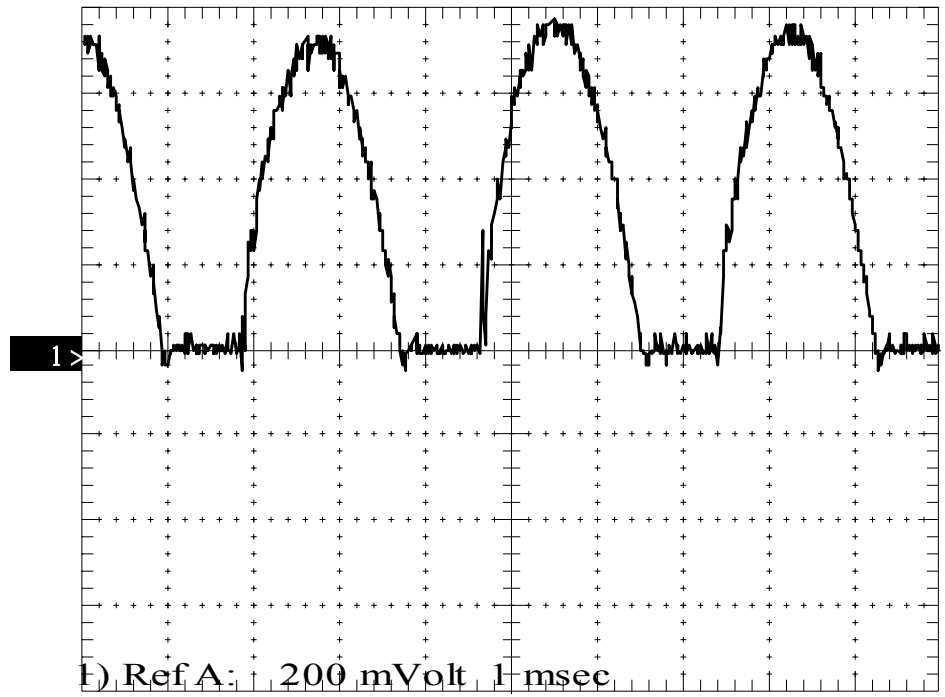

VALOR DE CORRENTE: $200 \mathrm{~mA} /$ Div. (1A/V)

FIGURA 4.5 - Corrente de armadura (motor com carga do rolo bobinador)

\subsection{Resposta Transitória de Velocidade do Motor}

A figura 4.6 apresenta a resposta de velocidade transitória do motor da bobinadeira, para as condições de ensaio apresentadas no item 4.2.

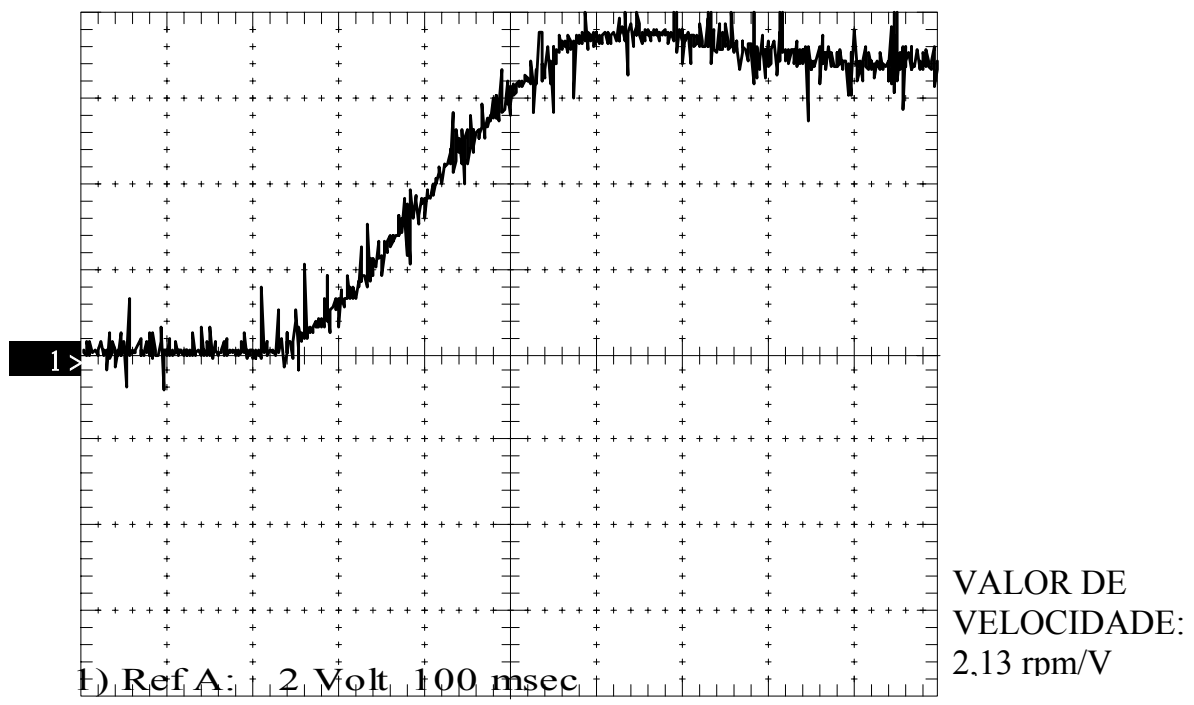

FIGURA 4.6 - Curva de velocidade transitória do motor (motor em vazio) 


\section{CAPÍtulO 5}

\section{Elementos de Acionamento e Controle}

Como apresentado no capítulo 1, o sistema de bobinamento é composto de um motor de corrente contínua, sendo acionado por um retificador trifásico totalmente controlado e um tacogerador é responsável pela realimentação de velocidade, conforme esquema apresentado na figura 2.7. O acoplamento entre o motor de corrente contínua e o rolo bobinador é realizado através de uma caixa de redução de velocidade, com uma relação de seis vezes conforme o Capítulo 4. Os sinais de comunicação entre o tacogerador, o CLP e o retificador trifásico seguem o padrão analógico de $4 \mathrm{~mA}$ a $20 \mathrm{~mA}$. A comunicação entre o programa supervisório e o CLP é feita de forma serial. A seguir, os componentes envolvidos no sistema de acionamento do motor são apresentados com maiores detalhes.

\subsection{O Controlador Lógico Programável}

O CLP é um dispositivo amplamente utilizado na automação de processos industriais devido à sua robustez e confiabilidade. Surgiu praticamente para substituir as lógicas a relé, em processos que necessitam de sequenciamento, intertravamento e controle. O CLP é dotado de uma unidade central de processamento (UCP), entradas e saídas digitais e analógicas, unidade de memória e porta de comunicação para transmissão e recepção de dados com o terminal de programação. A figura 5.1 apresenta a estrutura básica de um CLP. 


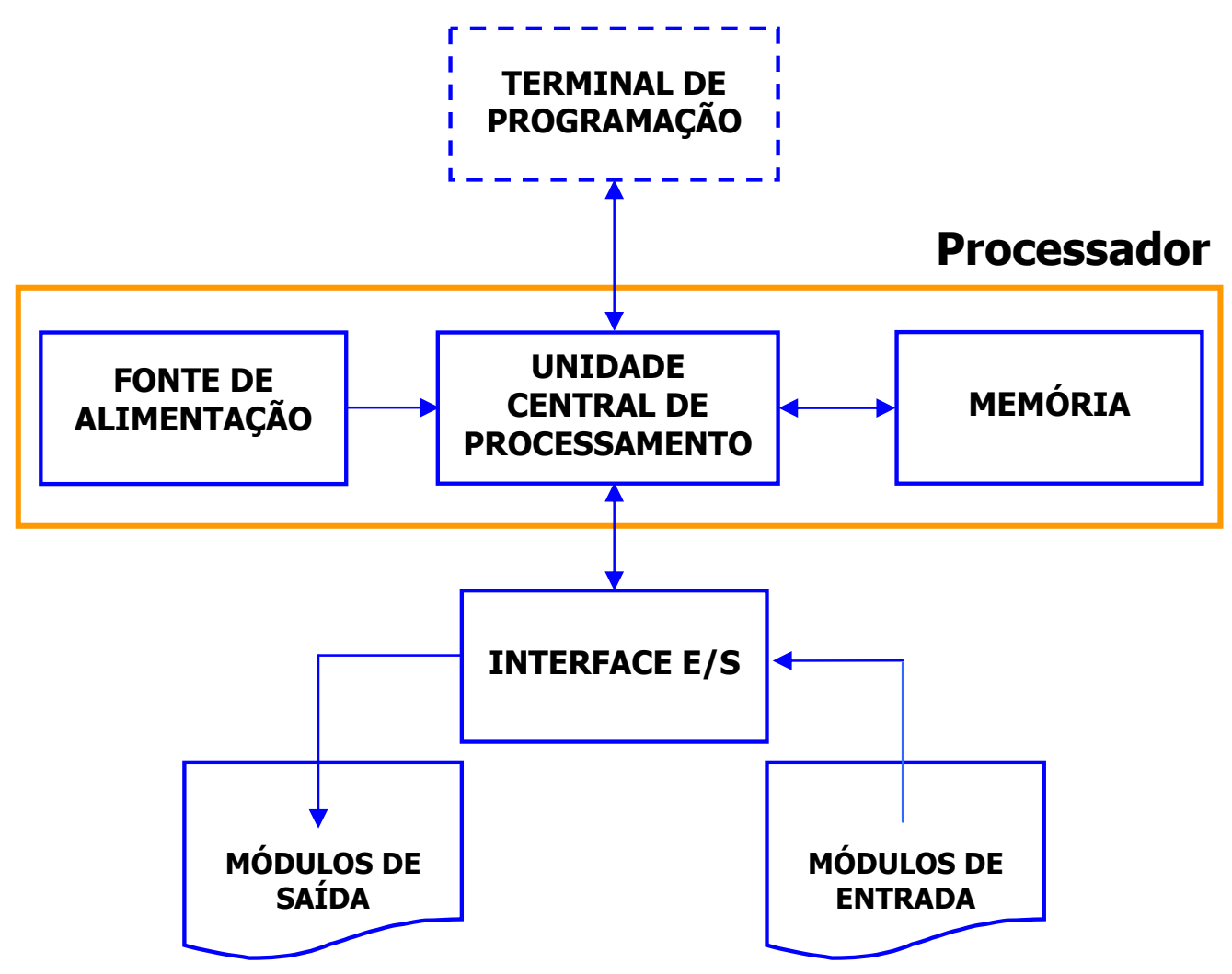

FIGURA 5.1 - Estrutura básica de um CLP

$\mathrm{Na}$ figura 5.1, os módulos de entrada e saída representam um dos elos de ligação do CLP com o mundo externo. Considerando o sistema de bobinamento de tiras de aço do IPT, tem-se que o sinal de realimentação de velocidade proveniente do tacogerador, e devidamente convertido ao padrão de $4 \mathrm{~mA}$ a $20 \mathrm{~mA}$ está conectado a uma entrada analógica do CLP, entrada esta constituinte dos módulos de entrada, apresentado na figura 5.1. Por outro lado uma saída analógica do CLP, com faixa de variação de corrente também entre 4 e $20 \mathrm{~mA}$, está conectada ao retificador trifásico, sendo esta saída constituinte dos módulos de saída.

$\mathrm{Na}$ unidade central de processamento é executado o programa que relaciona entradas e saídas, sejam elas analógicas ou digitais. Durante um ciclo de processamento, as entradas são lidas através dos módulos de entrada, o programa contido na memória do CLP é executado e então as saídas são atualizadas.

A transmissão do programa do usuário é feita através de um microcomputador denominado terminal de programação. Neste microcomputador, 
para o caso em estudo do IPT, encontra-se em execução também um programa supervisório que permite a monitoração do processo, bem como a intervenção por parte do usuário no sistema.

O programa do usuário pode ser construído utilizando-se diversas funções denominadas básicas de programação do CLP, como temporizadores, chaves abertas, chaves fechadas, entre outras, bem como utilizando-se de funções avançadas como controladores do tipo proporcional, integral e derivativo (PID). A tabela 5.1 apresenta algumas funções possíveis de serem implementadas no CLP.

TABELA 5.1 - Recursos de Programação do CLP

\begin{tabular}{|c||c||}
\hline \multicolumn{1}{|c||}{ Recursos } & Descrição \\
\hline \hline \hline Instruções Lógicas de Relé & Energizar ou Desenergizar Saída \\
Temporizadores & $\begin{array}{c}\text { Tempo de Energização } \\
\text { Tempo de Desenergização }\end{array}$ \\
\hline \hline Contadores Crescentes e Decrescentes & Realização de Contagens \\
\hline \hline Operações Matemáticas & Adição, Subtração, Divisão, \\
& Multiplicação, Raiz Quadrada \\
\hline \hline Lógica Booleana & E, OU, XOR, NOT \\
\hline \hline Comparação & $=, \neq, \geq, \leq,>,<$ \\
\hline \hline Fluxo de Programa & Sub-rotina, saltos \\
\hline \hline PID & Função de Controle PID \\
\hline \hline
\end{tabular}

\subsection{O Retificador Trifásico}

O retificador trifásico é o responsável pelo acionamento do motor de corrente contínua da bobinadeira. $\mathrm{O}$ acionamento a velocidade variável é realizado variandose a tensão de armadura do motor. Deste modo, um sinal de corrente entre 4 e $20 \mathrm{~mA}$ proveniente de uma saída analógica do CLP é responsável pela variação do ângulo de disparo dos tiristores do retificador e, consequentemente, pela variação da tensão 
média de saída do retificador. A figura 5.2 apresenta o circuito do retificador trifásico totalmente controlado, bem como as formas de ondas correspondentes para um ângulo de disparo $\alpha=\pi / 3 \mathrm{rad}$. As formas de onda de corrente são relativas a uma carga altamente indutiva. A tensão média de saída em vazio é apresentada na equação. (5.1), onde $\mathrm{V}_{\mathrm{m}}$ é a tensão máxima de fase que alimenta o retificador, conforme RASHID (1999).

$$
V_{\text {médio }}=\frac{3 \sqrt{3} V m}{\pi} \cos \alpha
$$

\subsubsection{Operação no Modo Descontínuo}

As formas de onda apresentadas para o retificador trifásico da figura 5.2, tomam em consideração que o retificador esteja alimentando uma carga altamente indutiva, e que a corrente de saída seja contínua.

A descontinuidade da corrente de carga depende basicamente do fator de mérito $\mathrm{Q}_{\mathrm{c}}$, do circuito de carga quando o retificador alimenta cargas indutivas, com $\mathrm{Q}_{\mathrm{c}}=\mathrm{L}_{\mathrm{c}} / \mathrm{R}_{\mathrm{c}}$, do ângulo de disparo $\alpha$ e da velocidade, para uma máquina elétrica, segundo PEARMAN (1980). Quanto maior o valor de Q, maior o valor do ângulo de disparo $\alpha$, para que a corrente de carga torne-se descontínua.

A operação no modo descontínuo pode se dar para qualquer valor do ângulo de disparo $\alpha$, caso o retificador esteja alimentando uma carga capacitiva, ou uma carga que possua uma força contra-eletromotriz (como é o caso do motor $\mathrm{CC}$ ) e a corrente de carga seja pequena.

O último caso descrito acima representa exatamente a condição de operação do motor do retificador que aciona o motor do IPT, conforme apresentado no Capítulo 4. A necessidade de uma pequena velocidade de rotação do motor, em relação a sua rotação nominal, implica em uma tensão de armadura muito abaixo da nominal, implicando em um grande ângulo de disparo $\alpha$ para os tiristores do retificador.

Por outro lado, o rolo bobinador implica em uma carga pequena para o motor, devido à caixa de redução de velocidades, exigindo portanto uma corrente pequena 
de alimentação. As duas condições, portanto, implicam na operação do retificador no modo descontínuo (Capítulo 4).

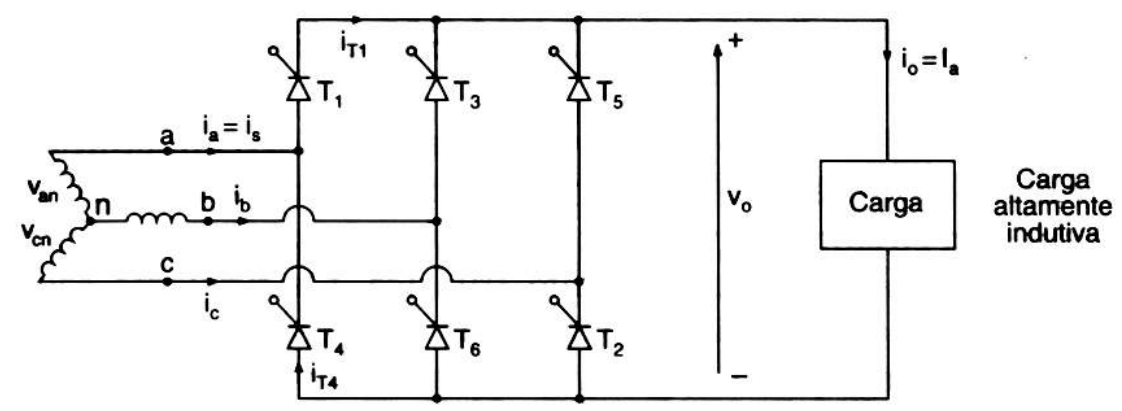

(a) Circuito

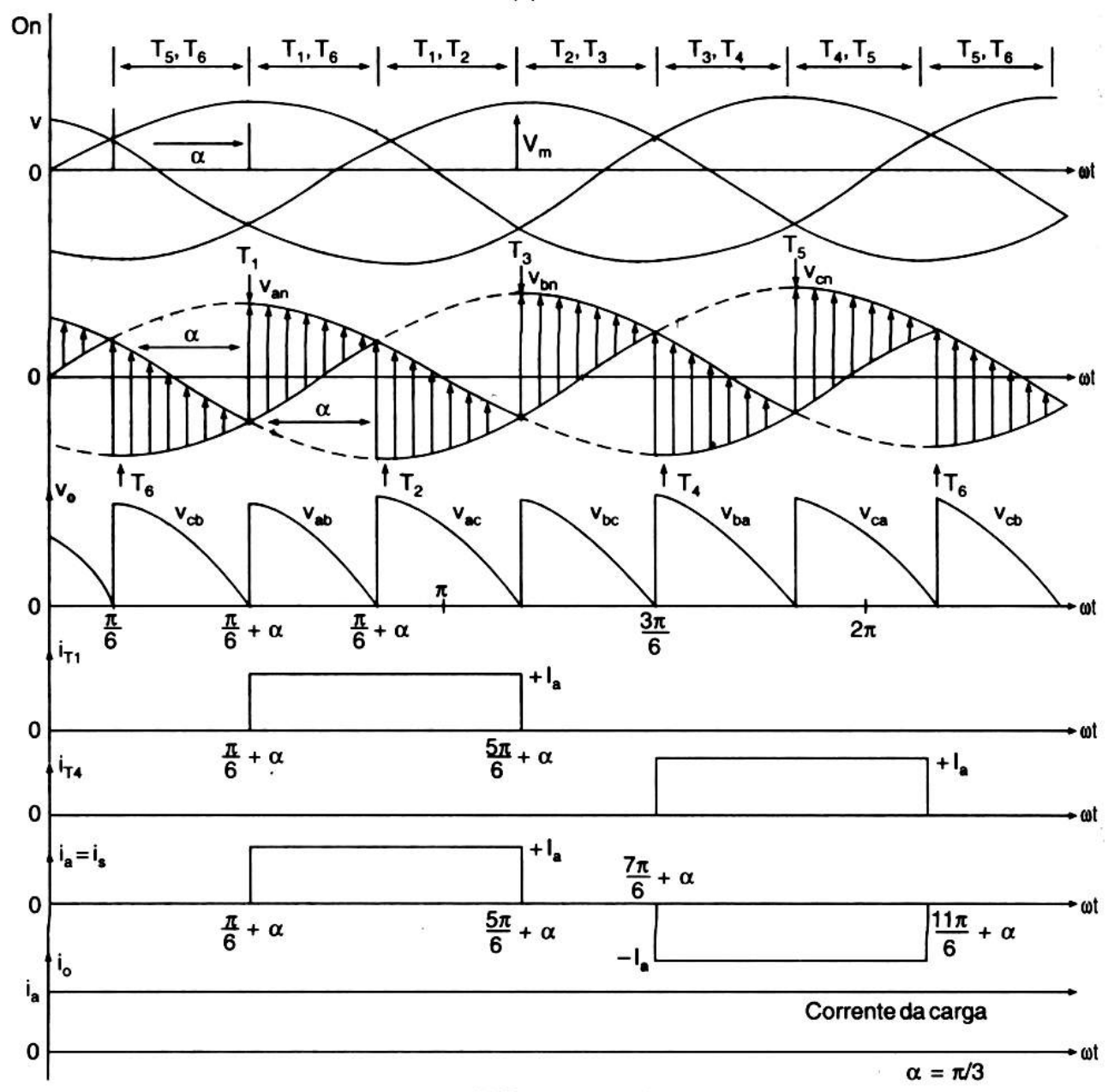

(b) Formas de onda

FIGURA 5.2 - Retificador trifásico totalmente controlado ;RASHID (1999) 


\subsubsection{Modelagem do Retificador Trifásico}

Tomando-se em consideração as indutâncias e resistências internas do retificador, o motor $\mathrm{CC}$ mais o retificador pode ser representado pela figura $5.3 \mathrm{a}$ seguir:

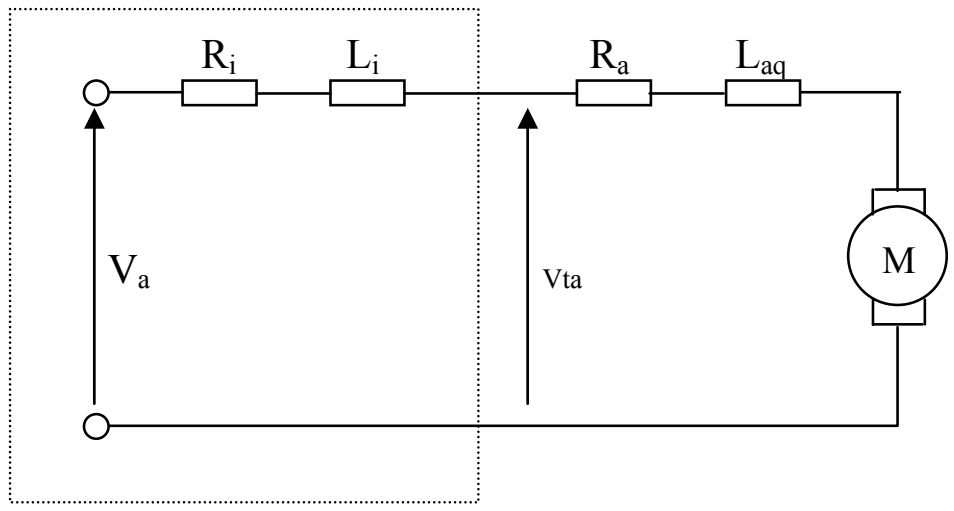

FIGURA 5.3 - Retificador associado ao motor CC

Conforme apresentado na figura 5.3, a constante elétrica do motor CC é alterada com a inclusão da resistência e indutância do retificador. O retificador, porém, pode ser modelado através de um período de atraso proporcional ao período de comutação ou chaveamento.

Denominando o período de chaveamento de $\mathrm{T}_{\mathrm{p}}$, o tempo de atraso adotado é dado pela metade desse período. Denominando-se o tempo de atraso de $\mathrm{T}_{\mathrm{D}}$, tem-se que $T_{D}=T_{p} / 2$. A representação deste atraso na forma de Transformada de Laplace é apresentada na eq.(5.2) a seguir:

$$
e^{-T_{D} s} \approx \frac{1}{T_{D} s+1}
$$

A aproximação considerada na eq.(5.2) é uma aproximação de Padé de primeira ordem e é válida para pequenos tempos de atraso $\mathrm{T}_{\mathrm{D}}$.

$O$ valor da constante $T_{p}$ no retificador é definida através da razão do período da onda de entrada pelo número de pulsos por ciclo. No caso do retificador trifásico 
totalmente controlado em questão, tem-se seis pulsos por ciclo de entrada, resultando em $\mathrm{T}_{\mathrm{p}}=2,77 \mathrm{~ms}$.

O retificador trifásico em questão, tem a função de acoplar a estrutura do controlador, que opera em baixos níveis de potência, com o motor $\mathrm{CC}$, que pode operar em altos níveis de potência. Dessa forma, pode-se entender a modelagem do retificador trifásico como sendo um amplificador de potência com um ganho constante $\left(\mathrm{K}_{\mathrm{D}}\right)$, associado a um termo de atraso $\left(\mathrm{T}_{\mathrm{D}}\right)$, conforme discutido anteriormente.

É necessário, entretanto, ressaltar que o modelo para o retificador acima discutido trata-se de uma aproximação pois o mesmo não é válido para a operação do retificador no modo descontínuo. No entanto, essa aproximação não possui maiores implicações para o sistema, conforme será apresentado posteriormente. 


\section{CAPÍtulO 6}

\section{Sistema dE CONTROLE DO BOBINAMENTO}

Neste capítulo apresenta-se a primeira proposta de controle de força aplicada à tira no sistema de bobinamento. Neste e nos demais capítulos seguintes, objetiva-se obter o controle de força através do controle da velocidade linear de bobinamento. $\mathrm{O}$ tipo de controle utilizado foi o PID por motivos já elucidados.

\subsection{Função de Transferência do Motor CC}

Utilizando-se as equações elétricas e mecânicas do motor de corrente contínua, definidas pelas equações (3.1) e (3.2), respectivamente, e aplicando-se a Transformada de Laplace às respectivas equações obtém-se as expressões das equação (6.1) e (6.2). Foi considerado que o motor estivesse operando sem conjugado de carga.

Considerando-se o termo $\mathrm{E}_{\mathrm{a}}(\mathrm{s})$ na equação (6.1) como sendo $\mathrm{K}_{\mathrm{v}} \Omega_{\mathrm{m}}(\mathrm{s})$, o termo $\mathrm{T}(\mathrm{s})$ como $\mathrm{K}_{\mathrm{t}} \mathrm{Ia}(\mathrm{s})$ na equação (6.2), e tomando-se como variável de entrada a tensão terminal de armadura $\mathrm{V}_{\text {ta }}$, e como variável de saída a velocidade angular mecânica $\omega_{\mathrm{m}}$, pode-se escrever a função de transferência (FT) do motor através da equação (6.3).

$$
\begin{gathered}
V_{T A}(s)=\operatorname{LaqsIa}(s)+\operatorname{RaIa}(s)+E_{a}(s) \\
T(s)=J S \Omega_{m}(s)+B \Omega_{m}(s)
\end{gathered}
$$




$$
\frac{\Omega_{m}(s)}{V_{T A}(s)}=\frac{K_{t}}{\left(J L_{a q}\right) s^{2}+\left(J R_{a}+B L_{a q}\right) s+\left(R_{a} B+K_{t}^{2}\right)}
$$

A função de transferência do motor CC apresentada na equação (6.3) gera o diagrama de blocos da figura 6.1, necessário para o entendimento das etapas seguintes.

\subsection{Introdução das Variações Paramétricas Para o Sistema de Controle}

Com a introdução das variações de raio, inércia e conjugado de carga no modelo do motor CC, torna-se impossível escrever uma FT para o sistema, devido à não-linearidade do mesmo.

Para que o conjugado de carga e as variações de inércia fossem introduzidos no modelo de malha aberta da equação (6.3), foi utilizado um bloco do programa Matlab $^{\circledR} /$ Simulink, denominada s-function. O bloco s-function executa uma determinada rotina de programa que relaciona entrada(s) e saída(s), através de equações diferenciais, de forma a representar o comportamento dinâmico do sistema.

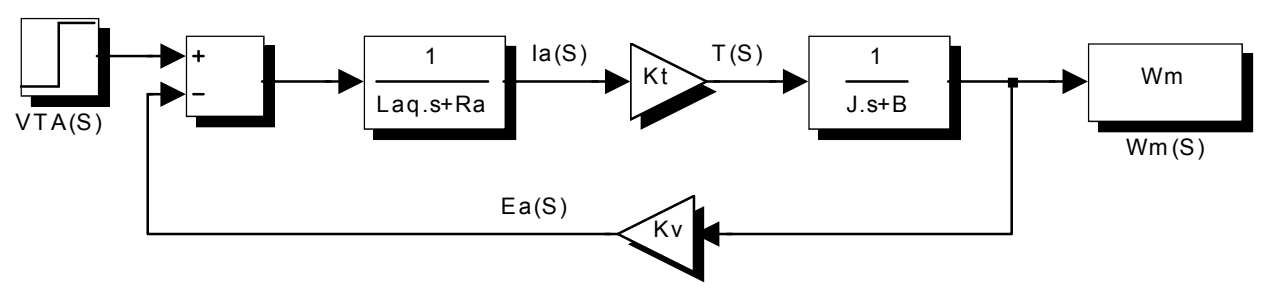

FIGURA 6.1 - Diagrama do motor CC obtido através da FT

Tomando-se o caso específico do sistema de bobinamento, o conjugado desenvolvido foi adotado como sendo a entrada do bloco s-function (denominada velocidade na figura 6.2), e como saída obteve-se a velocidade mecânica, a variação do raio e a variação da inércia. A listagem da rotina s-function, denominada velocidade, bem como as derivações das equações da velocidade mecânica, variação 
do raio e da inércia encontram-se no Apêndice B e Anexo B, respectivamente. $\mathrm{Na}$ figura 6.2 encontra-se o esquema implementado no programa Matlab ${ }^{\circledR} /$ Simulink, utilizando-se da s-function velocidade. O número apresentado nas entradas e saídas de cada bloco representa o número de variáveis correspondente àquela entrada ou saída.

\subsection{Objetivo do Sistema de Controle}

Como apresentado no Capítulo 2, o objetivo do sistema de controle é proporcionar um bobinamento da tira de aço produzida, mantendo a tensão mecânica constante durante todo o bobinamento.

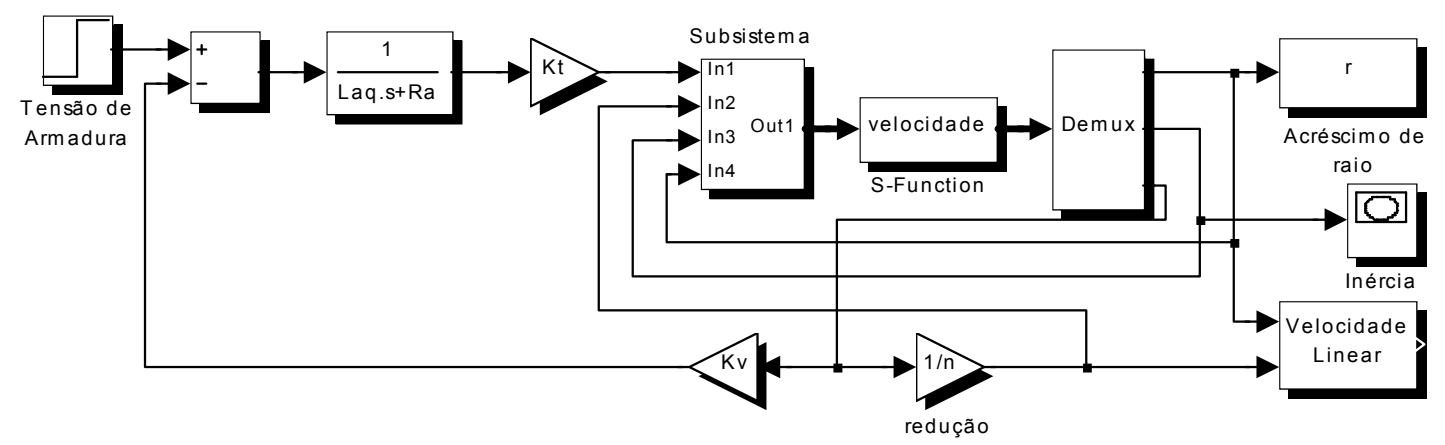

FIGURA 6.2 - Esquema em malha aberta do motor CC utilizando uma s-function

Sabe-se que a velocidade angular do motor, e consequentemente do rolo bobinador, deve ser reduzida conforme o acréscimo do diâmetro do rolo bobinador, produzido pelo acréscimo de material bobinado, conforme LARKE (1957).

Mais especificamente, a velocidade linear deve ser mantida constante durante todo bobinamento (DENTI FILHO (1996a) ; DENTI FILHO (1996b) e DENTI FILHO (1999)). A velocidade linear à qual a tira é bobinada, portanto, deve ser a saída do sistema de bobinamento a ser controlada.

Como entrada de referência para o sistema de controle, tem-se a velocidade a qual a tira será produzida nos rolos de laminação. Esta velocidade é variável para cada espessura de tira produzida.

Para determinar a velocidade de produção para cada espessura de tira, deve-se levar em consideração a vazão de massa que alimenta os rolos de laminação. Um 
valor razoável para a máquina de LCT do IPT é de $1 \mathrm{Kg} / \mathrm{s}$. Este valor, portanto, será adotado para a realização dos cálculos que se seguem.

Tomando-se a densidade do aço como sendo de $7,8 \mathrm{~g} / \mathrm{cm}^{3}$, a vazão volumétrica será de $(1000 / 7,8) \mathrm{cm}^{3} / \mathrm{s}$. Esse cálculo resulta em $128,2 \mathrm{~cm}^{3} / \mathrm{s}$. O volume da tira é dado pelo produto da largura, espessura e comprimento. A largura da tira produzida é fixa e igual a $10 \mathrm{~cm}$. Portanto, o produto da espessura pelo comprimento é igual a $12,82 \mathrm{~cm}^{2}$. Se a tira possuir $1 \mathrm{~mm}$ de espessura, ou seja, $0,1 \mathrm{~cm}$, a velocidade linear, que é o comprimento de tira produzido em um segundo será de $128,2 \mathrm{~cm} / \mathrm{s}$.

Genericamente, e operando-se com a velocidade em $\mathrm{m} / \mathrm{s}$, a velocidade linear pode ser expressa pela equação (6.4).

$$
v_{2}=\frac{12,82 \cdot 10^{-4}}{e} \frac{m^{2}}{s}
$$

onde $\mathrm{v}_{2}$ é a velocidade linear da tira e $e$ é a espessura da tira expressa em metros. Após determinado o valor da referência o sistema de controle em malha fechada pode ser implementado utilizando-se, primeiramente, um controlador do tipo PID.

\subsection{Ação de Controle PID}

\subsubsection{Ação de Controle Proporcional}

$\mathrm{Na}$ ação de controle proporcional, a relação entre a saída do controlador e o sinal de erro é apenas uma ganho, sendo apresentada pela equação (6.5 a). Sua função de transferência é apresentada pela equação (6.5 b).

$$
\begin{gathered}
u(t)=K_{p} e(t) \\
\frac{U(s)}{E(s)}=K_{p}
\end{gathered}
$$




\subsubsection{Ação de Controle Integral}

$\mathrm{Na}$ ação de controle Integral, o valor da saída do controlador u(t), é proporcional à integral do sinal de erro atuante. A equação (6.6 a) apresenta a relação entre o erro e a saída do controlador, sendo sua função de transferência apresentada pela equação (6.6 b).

$$
\begin{gathered}
u(t)=K_{i} \int_{0}^{t} e(t) d t \\
\frac{U(s)}{E(s)}=\frac{K_{i}}{s}
\end{gathered}
$$

\subsubsection{Ação de Controle Proporcional - Integral}

A ação de controle proporcional-integral, reúne as características de ganho proporcional e integral em um único controlador. Sua equação característica é apresentada por (6.7 a), sendo sua função de transferência apresentada por (6.7 b).

$$
\begin{gathered}
u(t)=K_{p} e(t)+\frac{K_{p}}{T_{i}} \int_{0}^{t} e(t) d t \\
\frac{U(s)}{E(s)}=K_{p}\left(1+\frac{1}{T_{i} s}\right)
\end{gathered}
$$

\subsubsection{Ação de Controle Proporcional - Derivativa}

No controlador derivativo, a saída do controlador é proporcional à taxa de variação do erro. Uma grande taxa de variação do erro pode causar uma grande ação corretiva, mesmo que o erro seja pequeno. Por outro lado, caso o sinal de erro não varie, não existirá ação corretiva, mesmo que o erro seja grande. Desta forma, o 
controlador derivativo nunca é utilizado separadamente. Apresenta-se a seguir a formulação do controlador derivativo associado a um ganho proporcional. As equações (6.8 a) e (6.8 b) apresentam a equação característica do controlador proporcional-derivativo e sua função de transferência, respectivamente.

$$
\begin{gathered}
u(t)=K_{p} e(t)+K_{p} T_{d} \frac{d e(t)}{d t} \\
\frac{U(s)}{E(s)}=K_{p}\left(1+T_{d} s\right)
\end{gathered}
$$

\subsubsection{Ação de Controle PID}

O controlador PID, reúne todas as características apresentadas anteriormente. Sua equação característica é dada pela equação (6.9 a) e sua função de transferência pela equação $(6.9$ b).

$$
\begin{gathered}
u(t)=K_{p} e(t)+\frac{K_{p}}{T_{i}} \int_{0}^{t} e(t) d t+K_{p} T_{d} \frac{d e(t)}{d t} \\
\frac{U(s)}{E(s)}=K_{p}\left(1+\frac{1}{T_{i} s}+T_{d} s\right)
\end{gathered}
$$

\subsection{Efeitos do Sensor}

O motor de corrente contínua utilizado para a movimentação do rolo bobinador possui um tacogerador para realimentação de velocidade. Segundo OGATA (1993), se a constante de tempo de um sensor é suficientemente pequena, comparada com as outras constantes de tempo do sistema, a função de transferência do sensor pode ser considerada como uma constante. 
Dessa forma, para o sistema de controle do bobinamento, a função de transferência do tacogerador foi considerada como sendo constante, com seu valor igual a 0,47, determinado através da curva do tacogerador apresentada no Capítulo 4.

\subsection{Sistema de Controle em Malha Fechada}

Com as considerações sobre o sistema de controle realizadas até o momento, pôde-se implementar o esquema do sistema de controle do bobinamento em malha fechada, utilizando o programa Matlab ${ }^{\circledR} /$ simulink. A figura 6.3 apresenta o sistema implementado.

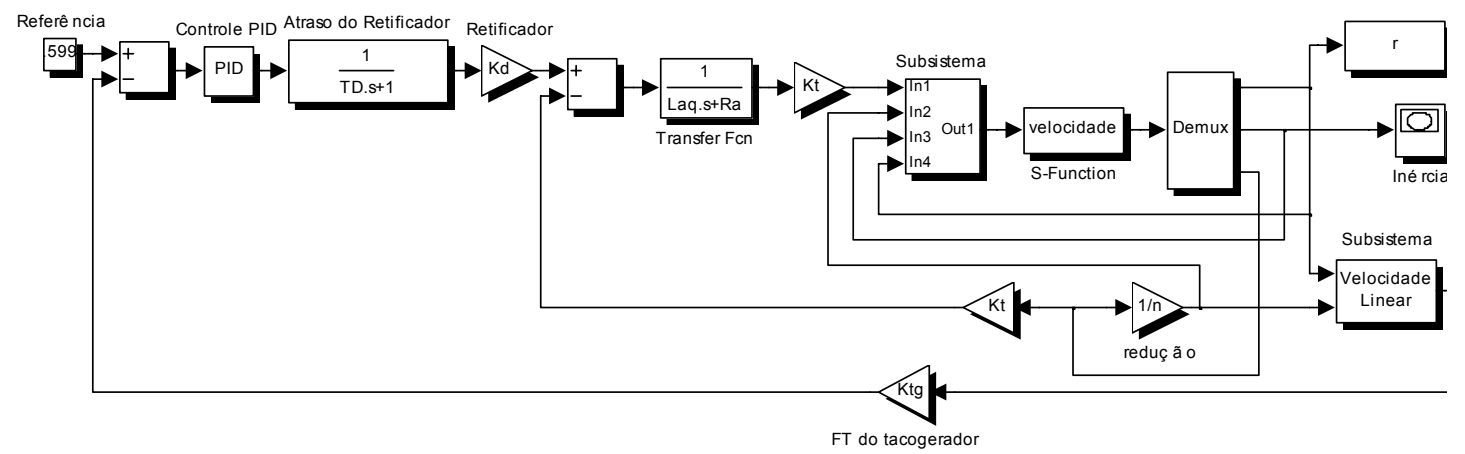

FIGURA 6.3 - Esquema do sistema de bobinamento em malha fechada

A velocidade linear, que é a saída do sistema de controle, pode ser obtida pela equação (6.10).

$$
v_{2}=\omega_{2}(t)\left(r_{2}+r(t)\right)
$$

É importante ressaltar que o controlador do tipo PID é empregado no controle de sistemas lineares. Encontram-se porém, aplicações do controle PID em sistemas não-lineares, como é o caso do sistema de bobinamento. Por tratar-se de um problema de controle não linear, métodos convencionais usados em controles lineares para selecionar os ganhos do controlador não se aplicam. 
Neste sentido, os ganhos do controlador foram selecionados, conforme proposto por TAO \& SADLER (1995), através de "tentativa e erro", procurando-se obter a melhor resposta para o sistema.

O sistema foi simulado para duas espessuras de tira diferentes, $1 \mathrm{~mm}$ e $5 \mathrm{~mm}$. As velocidades lineares para estas espessuras de tira são $1,28 \mathrm{~m} / \mathrm{s}$ e $0,256 \mathrm{~m} / \mathrm{s}$, respectivamente.

Para o cálculo das velocidades lineares de referência foi utilizada a equação (6.4). Com o ganho do tacogerador constante e igual a 0,468 tem-se uma referência de $0,599 \mathrm{~m} / \mathrm{s}$ para tira de $1 \mathrm{~mm}$ e $0,12 \mathrm{~m} / \mathrm{s}$ para a tira de $5 \mathrm{~mm}$.

Após realizadas as simulações do sistema de controle, pode-se apresentar os gráficos de potência elétrica exigida no acionamento. Os resultados encontram-se no Capítulo 9, onde apresentam-se as respostas de controle utilizando-se um valor de referência calculado através da velocidade de produção da tira e da função de transferência do tacogerador. Nos próximos capítulos relacionados com o controle do sistema de bobinamento, para análise dos resultados foram apresentadas respostas obtidas com os sistemas operando à realimentação unitária e entrada degrau unitário. 


\section{CAPÍtULO 7}

\section{Sistema de CONTROLE DO BOBINAMENTO UTILIZANDO SENSOR ULTRASÔNICO}

Este capítulo apresenta uma proposta para a medição do acréscimo de raio, devido ao bobinamento de tiras. A medição do raio bobinado implica uma maior precisão para o sistema de controle, já que os valores de acréscimo de raio serão medidos diretamente do rolo bobinador. Nesse caso, um projeto utilizando lugares das raízes pode ser executado para a sintonização do controlador PID. Com relação ao desempenho do sensor no sistema, um fator importante a ser considerado é o da temperatura de operação. Atualmente, existem sensores ultrasônicos que suportam temperaturas de até $900^{\circ} \mathrm{C}$ como apresentado em STUBBS \& DUTTON (1996).

\subsection{O Sensor Ultrasônico}

\subsubsection{Características Gerais}

O sensor ultrasônico é um tipo de transdutor eletro-acústico, o que significa que ele é um dispositivo que converte energia elétrica em energia acústica e viceversa. O termo ultrasônico refere-se a ondas mecânicas ou acústicas de freqüência maior ou igual a $20 \mathrm{KHz}$, e portanto não detectadas pela audição humana. Com respeito ao sensoriamento e medidas, a alta freqüência evita interferência de ruídos de baixa freqüência devido a máquinas, bombas e vibração de corpos, por exemplo, conforme BAU et al. (1994). 
O sensor ultrasônico mede a distância ou presença de um objeto, enviando a onda sonora ao objeto e então medindo o tempo de retorno do eco proporcionado pela onda sonora. Conhecendo a velocidade do som, o sensor pode determinar a distância do objeto ao elemento transdutor.

Entre as vantagens da utilização do sensor ultrasônico, podem-se citar:

- Dispensa contato: Não há necessidade de contato do transdutor com o objeto sensoriado.

- Saída proporcional a distância: A saída do sensor é proporcional a distância do objeto ao transdutor.

- Alta resolução: Discriminação precisa da posição do objeto.

- Não afetado por características ópticas do objeto: A operação do sensor não é sensível ao nível de iluminação ambiente, cor do objeto ou se o objeto é transparente ou refletor de luz.

- Sensibilidade: Capacidade de detectar grandes e pequenos objetos.

Todas as características acima citadas são favoráveis à utilização do sensor ultrasônico no bobinamento de tiras de aço. No sentido de incorporar o sensor ao projeto, optou-se por um sensor disponível comercialmente e cujas características funcionais principais são apresentadas na tabela 7.1 .

TABELA 7.1 - Características do sensor ultrasônico

\begin{tabular}{|c||c||}
\hline \multicolumn{1}{|c||}{ Parâmetro } & Valor \\
\hline \hline Alimentação & $15-24$ VDC @ $40 \mathrm{~mA}$ \\
\hline \hline Alcance & $0,1016 \mathrm{~m}$ a $1,524 \mathrm{~m}$ \\
\hline \hline Saída & $0-10$ VDC Linear \\
\hline \hline Temperatura & 0 a $70^{\circ} \mathrm{C}$ \\
\hline \hline Período de medida & $50 \mathrm{~ms}$ \\
\hline \hline Massa & $17 \mathrm{~g}$ \\
\hline \hline Dimensão & $7,24 \times 4,7 \times 3,18(\mathrm{~cm})$ \\
\hline \hline Freqüência da onda ultrasônica & $50 \mathrm{KHz}$ \\
\hline
\end{tabular}




\subsubsection{Posicionamento do Sensor}

Com relação a inclusão do sensor ultrasônico na planta de LCT, define-se que o mesmo estará a uma distância de um metro do rolo bobinador. A relação de tensão pela distância para o sensor é de $\mathrm{Ku}=7,87 \mathrm{~V} / \mathrm{m}$, sendo este valor utilizado no projeto de controle, com Ku definida como sendo a constante do sensor ultrasônico. A figura 7.1 ilustra o posicionamento do sensor sobre a bobinadeira.

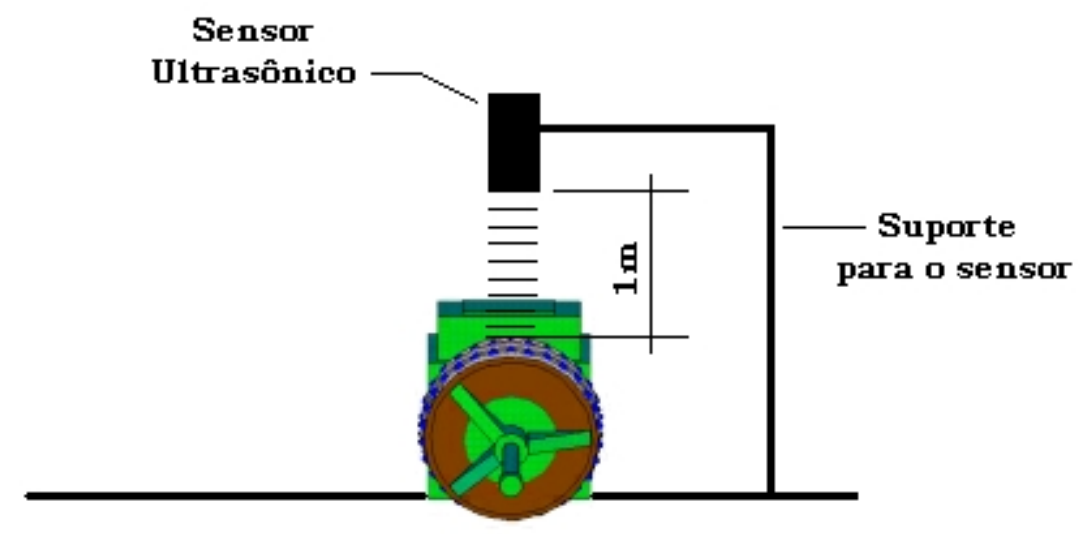

FIGURA 7.1 - Posicionamento do sensor sobre a bobinadeira

\subsubsection{Condicionamento de Sinal Para o Sensor}

De acordo com o funcionamento do sensor ultrasônico anteriormente apresentado, sabe-se que o mesmo fornece uma tensão de saída proporcional a distância do objeto sensoriado. Por outro lado, a tensão de saída fornecida pelo sensor decrementa à medida que o objeto se aproxima do sensor.

Esse efeito é indesejado para o sistema de controle do bobinamento, já que um incremento do raio implica em uma aproximação da tira do sensor, reduzindo a tensão de saída deste.

Para o sistema de controle, portanto, o incremento de raio será interpretado como decremento. Para contornar esse paradoxo, um simples sistema de condicionamento do sinal do sensor ultrasônico é proposto.

O sistema proposto é apresentado na figura 7.2, e utiliza amplificadores operacionais (Ampop) para tal finalidade. 


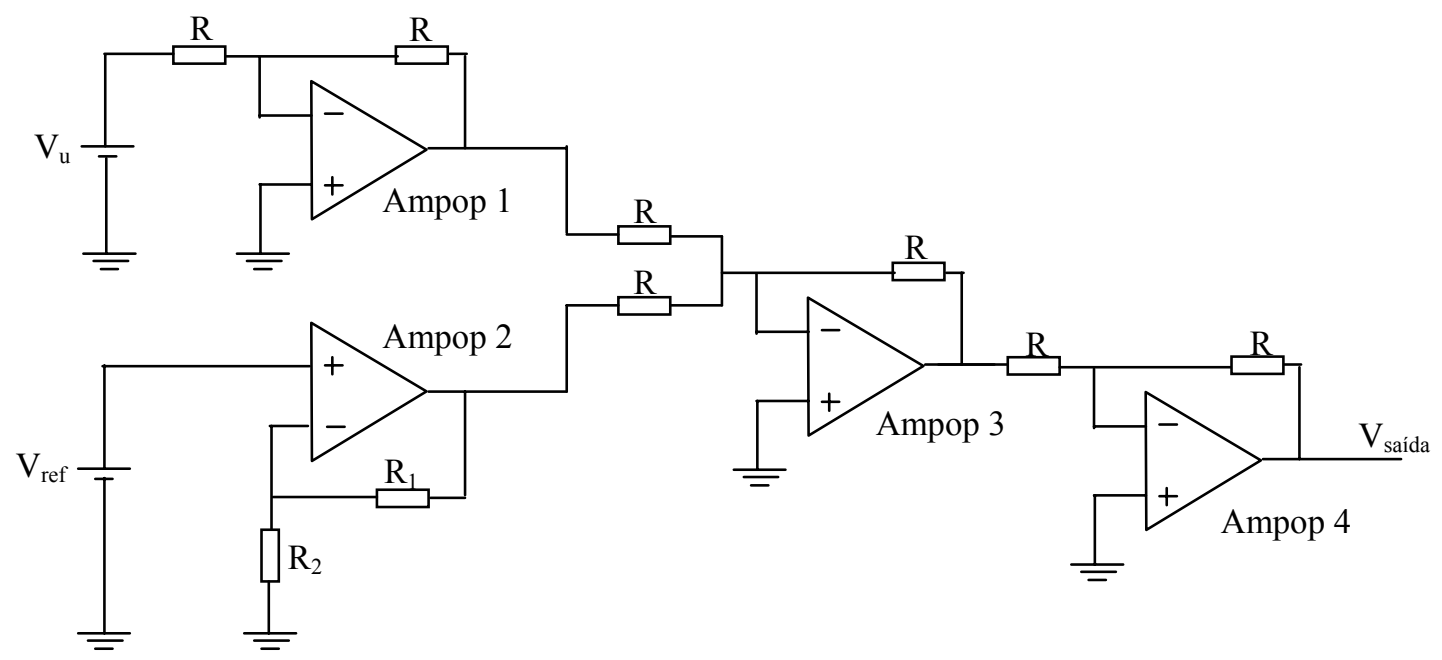

FIGURA 7.2 - Condicionamento de sinal do sensor ultrasônico

No circuito da figura 7.2, $\mathrm{V}_{\mathrm{u}}$ é a tensão proveniente do sensor ultrasônico, $\mathrm{V}_{\text {ref }}$ é igual a constante de tensão do sensor, ou seja, 7,87V e $\mathrm{V}_{\text {saída }}$ é a saída do sinal condicionado.

O circuito funciona da seguinte maneira: no circuito do Ampop1, que é um amplificador inversor com ganho unitário, o sinal do sensor $\mathrm{V}_{\mathrm{u}}$ é invertido . O circuito do Ampop2 é um amplificador não inversor com ganho de malha fechada (ACL) igual a $\left(1+\mathrm{R}_{1} / \mathrm{R}_{2}\right)$. Fazendo-se $\mathrm{R}_{1}$ igual a $\mathrm{R}_{2}$, tem-se um amplificador não inversor com ganho igual a 2. O circuito do Ampop3 é um somador inversor. Com o aumento do raio de bobinamento, a saída do Ampop1 ficará cada vez mais negativa, aumentando a diferença entre a saída do Ampop2 e do Ampop1. Como o circuito do Ampop3 é um somador inversor, o Ampop4 inverte o sinal novamente.

Finalmente, portanto, na saída do Ampop4, tem-se um sinal de tensão positivo, crescente com o aumento do raio bobinado, conforme desejado. No circuito, todos os resistores podem ser de $1 \mathrm{~K} \Omega$. 


\subsection{Sistema de Bobinamento Utilizando o Sensor Ultrasônico}

Após a introdução do sensor ultrasônico no sistema de bobinamento foi possível representá-lo totalmente na forma de uma FT, já que as variações de raio durante o bobinamento são agora medidas.

Quanto ao conjugado de carga, pode-se adotar a hipótese freqüentemente encontrada na literatura que o sistema seja linear, sendo dessa forma a saída de velocidade obtida através do princípio da superposição entre a entrada de referência e de conjugado de carga. A figura 7.3 ilustra o diagrama do sistema com o sensor ultrasônico.

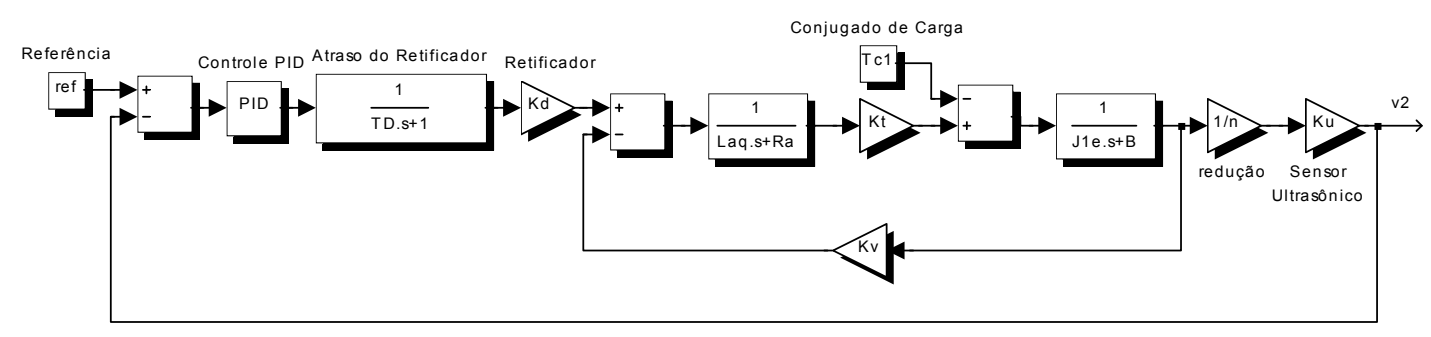

FIGURA 7.3 - Sistema de bobinamento com sensor ultrasônico

Através da figura 7.3 e das considerações anteriores pode-se, portanto, escrever duas funções de transferências. A primeira, fazendo-se o conjugado de carga igual a zero e escrevendo-se a função de transferência entre a saída de velocidade linear e a entrada de referência. A segunda, fazendo-se a entrada de referência igual a zero e escrevendo-se a função de transferência entre a saída de velocidade linear e o conjugado de carga.

Dessa forma, as funções de transferência anteriormente descritas são apresentadas nas eq. (7.1) e (7.2). A eq. (7.1) apresenta a FT entre a saída e a entrada de referência, enquanto a eq.(7.2) apresenta a FT entre a saída e o conjugado de carga.

$$
\frac{V_{2}(s)}{V_{r}(s)}=\frac{K_{D} K_{t} K_{u}(1 / n)}{J T_{D} L_{a q} s^{3}+\left(T_{D} B L_{a q}+T_{D} J R_{a}+J L_{a q}\right) s^{2}+\left(R_{a} T_{D} B+K_{t} K_{v} T_{D}+B L_{a q}+J R_{a}\right) s+} \cdots
$$




$$
\begin{gathered}
\ldots \frac{K_{D} K_{t} K_{u}(1 / n)}{+\left(R_{a} B+K_{t} K_{v}\right)} \\
\frac{V_{2}(s)}{T_{C 1}(s)}=\frac{-\left[\left(T_{D} L_{a q} K_{u} K_{t}(1 / n)\right) s^{2}+\left(L_{a q} K_{u} K_{t}(1 / n)+R_{a} K_{u} K_{t}(1 / n) T_{D}\right) s+R_{a} K_{u} K_{t}(1 / n)\right]}{J T_{D} L_{a q} s^{3}+\left(T_{D} B L_{a q}+T_{D} J R_{a}+J L_{a q}\right) s^{2}+\left(R_{a} T_{D} B+K_{t} K_{v} T_{D}+B L_{a q}+J R_{a}\right) s+} \ldots \\
\ldots \frac{-\left[\left(T_{D} L_{a q} K_{u} K_{t}(1 / n)\right) s^{2}+\left(L_{a q} K_{u} K_{t}(1 / n)+R_{a} K_{u} K_{t}(1 / n) T_{D}\right) s+R_{a} K_{u} K_{t}(1 / n)\right]}{+\left(R_{a} B+K_{t} K_{v}\right)}
\end{gathered}
$$

É necessário destacar que as eq.(7.1) e (7.2) foram obtidas em malha aberta, por motivos que serão posteriormente descritos. A realimentação do sinal de saída é adotada como sendo unitária.

\subsection{Sistema de Bobinamento Utilizando Controle PID com Sensor Ultrasônico}

\subsubsection{Método do Lugar das Raízes}

O método do lugar das raízes é amplamente utilizado na análise de sistemas de controle lineares. Sabe-se de OGATA (1993), que a resposta transitória de um sistema em malha fechada está intimamente ligada à localização dos pólos em malha fechada. Se o sistema possuir um ganho de malha variável então a localização dos pólos em malha fechada dependerá do ganho de malha escolhido.

Para a análise do método dos lugares das raízes será considerado o sistema de controle apresentado na figura 7.4, onde $\mathrm{G}(\mathrm{s})$ e $\mathrm{H}(\mathrm{s})$ são admitidos como sendo frações polinomiais em $s$. Deste sistema pode-se obter a FT em malha fechada (eq.(7.3)) e a equação característica (eq.(7.4)).

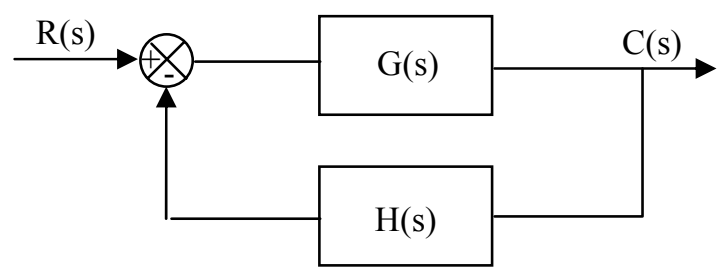

FIGURA 7.4 - Sistema de controle 


$$
\begin{gathered}
\frac{C(s)}{R(s)}=\frac{G(s)}{1+G(s) H(s)} \\
1+G(s) H(s)=0
\end{gathered}
$$

Por envolver entidades complexas, a eq. (7.4) dá origem a duas novas equações de módulo e fase, eq. (7.5) e (7.6) respectivamente:

$$
\begin{gathered}
\angle G(s) H(s)= \pm 180^{\circ}(2 k+1) \quad(\mathrm{k}=0,1,2, \ldots) \\
|G(s) H(s)|=1
\end{gathered}
$$

Os valores de $s$ que satisfazem as condições de módulo e fase são as raízes da equação característica ou os pólos de malha fechada. O gráfico dos pontos no plano complexo que satisfazem a equação de fase e módulo é o lugar das raízes. As raízes da equação característica correspondentes a um determinado valor de ganho podem ser determinadas a partir da equação de módulo.

As considerações acima foram utilizadas para a realização do projeto do controlador PID. Da eq.(7.1), conclui-se que o sistema sem controle possui três raízes, duas devido ao motor de corrente contínua e uma devido ao retificador modelado por uma aproximação de Padé de primeira ordem. Para a realização do projeto do controlador PID a raiz relativa ao atraso do retificador foi desprezada pelo fato da mesma possuir uma velocidade de resposta muito mais rápida do que as raízes do motor $\mathrm{CC}$, conforme será apresentado no capítulo de resultados.

Para as raízes do motor CC escolheu-se um par complexo e conjugado relativo a um valor médio de raio bobinado. Essas raízes são: $R_{n}=-67,4 \pm j 17,68$. Com as raízes adotadas para o projeto, definem-se as características requeridas para o sistema de controle de malha fechada.

Definiu-se primeiramente $\mathrm{o}$ tempo de acomodação $\mathrm{t}_{\mathrm{s}}=35 \mathrm{~ms}$. Para $\mathrm{o}$ coeficiente de amortecimento definiu-se $\xi=0,9$. Finalmente, com os parâmetros anteriores, e adotando-se o critério de 5\% para o tempo de acomodação, pode-se calcular a frequência natural amortecida $\left(\omega_{\mathrm{n}}\right)$, através da eq. (7.7). 


$$
\left.\omega_{n}=\frac{3}{t_{s} \xi} \quad \text { (critério de } 5 \%\right)
$$

Através da eq.(7.7) tem-se que a freqüência natural amortecida é igual a 95,2 $\mathrm{rad} / \mathrm{s}$. Todos os parâmetros definidos até o momento implicam um par de raízes complexas e conjugadas em malha fechada. Para determinar esse par de raízes é necessário saber que a distância das mesmas até a origem do plano complexo é igual à freqüência natural amortecida e o ângulo formado entre o módulo dessas raízes e o eixo real é igual ao coseno do coeficiente de amortecimento. Assim, através de cálculos trigonométricos chega-se que os pólos em malha fechada devem ser $\mathrm{s}_{\mathrm{n}}=-85,68 \pm \mathrm{j} 41,49$, para que o sistema tenha as características desejadas.

Introduz-se agora o controle PID no sistema de bobinamento. O objetivo de projeto é determinar a posição dos zeros introduzidos pelos termos proporcional e derivativo. O termo integral introduz um pólo na origem do plano complexo eliminando assim o erro de regime. Com a posição dos três termos do controlador PID determinada, calcula-se o ganho do controlador para que o sistema em malha fechada possua a resposta de projeto determinada.

A posição do zero do termo proporcional foi arbitrariamente definida na posição $\mathrm{P}=-70$. A partir daí a posição do zero do termo derivativo e o ganho do controlador foram obtidos através do gráfico de pólos e zeros apresentados na figura 7.5 e das equações de módulo e fase anteriormente apresentadas. Na figura 7.5 os zeros são representados por círculos e os pólos por cruzes.

Após calculados os módulos e fases dos pólos e zeros através das eq.(7.5) e (7.6) e com o auxílio da figura 7.5, chegou-se à posição do zero do termo derivativo em $\mathrm{D}=-79,75$.

Para o cálculo do ganho do controlador, foi utilizada a eq.(7.8) abaixo:

$$
K_{c}=\frac{\prod \mid \text { Pólos } \mid}{\prod \mid \text { Zeros } \mid}
$$

A eq.(7.8) apresenta que o ganho do controlador pode ser obtido através da razão do produto do comprimento dos pólos (com relação a raiz $\mathrm{s}_{\mathrm{n}}$ ) e o produto do comprimento dos zeros. 


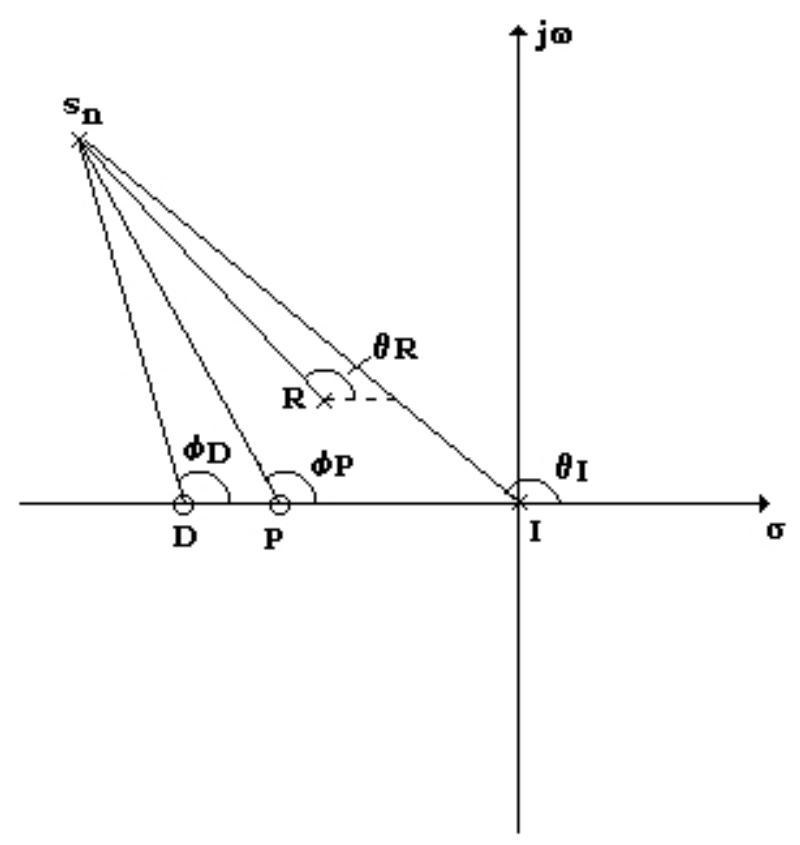

FIGURA 7.5 - Localização dos pólos e zeros no plano complexo

Dessa forma, o ganho do controlador foi calculado para o sistema em questão e obteve-se um ganho $\mathrm{K}_{\mathrm{c}}=0,0018$.

Esse é o ganho total do controlador, envolvendo todos os termos, integral, proporcional e derivativo. Através da equação característica do controlador PID anteriormente apresentada foi possível obter o ganho de cada parcela do controlador. Abaixo encontram-se os valores obtidos:

$\mathrm{K}_{\mathrm{p}}=1$;

$\mathrm{K}_{\mathrm{d}}=6,67 \cdot 10^{-3}$;

$\mathrm{K}_{\mathrm{i}}=37,33$;

Onde $K_{d}=\left(1 / T_{d}\right)$ e $K_{i}=\left(1 / T_{i}\right)$ 


\section{CAPÍtUlO 8}

\section{Sistema DE CONTROLE RoBUSto}

Neste capítulo apresenta-se a aplicação de uma metodologia de controle robusto para o sistema de bobinamento de tiras de aço, conhecida como LQG/LTR (do inglês, Linear Quadritc Gaussian/Loop Transfer Recovery). As regras de projeto adotadas para a aplicação desta metodologia seguem os passos propostos por CRUZ (1996), sendo esta, a principal referência deste capítulo.

Todo o desenvolvimento do projeto é realizado no domínio da frequência, sendo para tal finalidade utilizados os diagramas de Bode.

\section{1 - Definição do Problema}

A robustez para os sistemas de controle é desejada à medida que espera-se uma boa operação do controlador em caso de variações paramétricas e possíveis distúrbios aplicados ao sistema.

Como discutido nos capítulos anteriores, o sistema de bobinamento caracteriza-se por um incremento de raio ao longo do tempo, ocasionando aumento do momento de inércia e conjugado de carga referidos ao motor de corrente contínua.

Possíveis distúrbios na saída do sistema podem ser provocados através de atrito da tira produzida, com a esteira, na etapa anterior ao bobinamento.

Dessa forma, um projeto de um controlador robusto, neste trabalho utilizando a metodologia LQG/LTR, vem de encontro às necessidades do sistema de bobinamento. 
Com base nas considerações anteriores, adotou-se um modelo matemático para o sistema de bobinamento, considerando o rolo bobinador com metade da sua capacidade, sendo o valor de raio correspondente a esta situação denominado $r_{m}$. A esta situação, está associado um momento de inércia médio, $\mathrm{J}_{\mathrm{m}}$, e um conjugado de carga médio $\mathrm{T}_{\mathrm{cm}}$.

Sendo assim, para essas situações, fica definido o modelo da planta utilizado no projeto do compensador, que será denominado planta nominal $\left(\mathrm{G}_{\mathrm{N}}\right)$. Para todas as outras condições, ou seja, raio bobinado mínimo e máximo, define-se uma classe de sistemas, que dão origem a planta real $\left(\mathrm{G}_{\mathrm{R}}\right)$.

Quanto ao desempenho, o projeto do compensador deve ser tal que para o sistema real sejam atendidos os seguintes requisitos:

- Acompanhamento do sinal de referência

- Rejeição de perturbações externas

- Insensibilidade a variações na planta

- Rejeição do erro de medida

Com relação a estabilidade, o compensador deverá ser tal que toda a classe de sistemas reais resulte estável.

\subsection{Apresentação do Sistema}

O diagrama do sistema a ser discutido e analisado ao longo deste capítulo, juntamente com suas variáveis, é apresentado na figura 8.1.

Nesta figura, os sinais representados através de suas Transformadas de Laplace são:

- $r(s)$ : sinal de referência;

- $\mathrm{e}(\mathrm{s})$ : sinal de erro;

- $\mathrm{u}(\mathrm{s})$ : sinal de controle ou entrada;

- $\mathrm{d}(\mathrm{s})$ : perturbação na saída da planta;

- $y(s)$ : sinal de saída; 
- $\mathrm{n}(\mathrm{s})$ : ruído ou erro de medida;

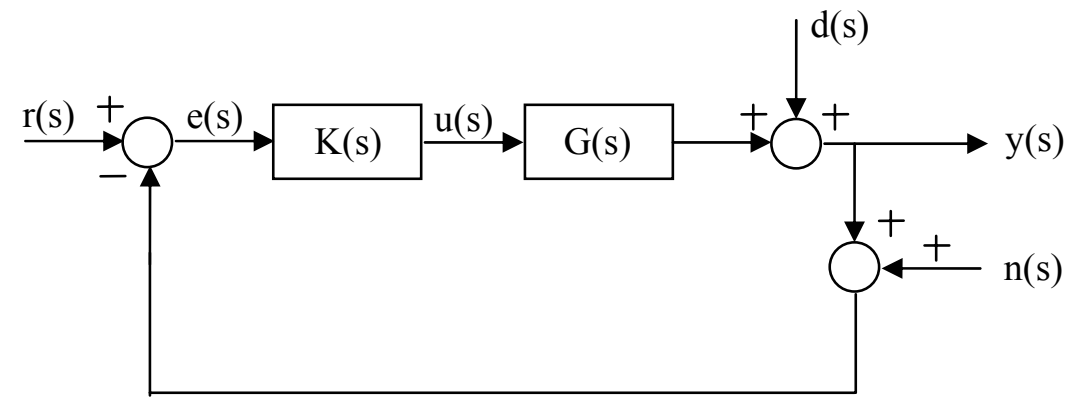

FIGURA 8.1 - Diagrama de blocos do sistema

\subsection{O Sistema Nominal}

Entende-se como sistema nominal da planta aquele utilizado no projeto. $\mathrm{O}$ diagrama de blocos da planta mais o compensador para o sistema nominal, portanto, é o mesmo da figura 8.1 com exceção da função de transferência da planta. Por tratar-se da planta nominal, sua função de transferência será definida como sendo $\mathrm{g}_{\mathrm{N}}(\mathrm{s})$.

\subsubsection{Estabilidade do Sistema Nominal}

O sistema em malha fechada da planta nominal será estável se e apenas se os pólos de malha fechada estiverem localizados no semi-plano esquerdo (SPE) aberto. A função de transferência de malha fechada é apresentada pela eq.(8.1) a seguir:

$$
c_{N}(s)=\frac{g_{N}(s) k(s)}{1+g_{N}(s) k(s)}
$$

onde $\mathrm{c}_{\mathrm{N}}(\mathrm{s})$ é a função de transferência de malha fechada da planta nominal e $\mathrm{k}(\mathrm{s}) \mathrm{a}$ função de transferência do compensador. 


\subsubsection{Desempenho do Sistema Nominal}

As considerações sobre o desempenho do sistema nominal são de fundamental importância para a análise e projeto do compensador. As considerações sobre desempenho, neste caso do sistema nominal, envolvem o acompanhamento do sinal de referência, rejeição de perturbações, insensibilidade a variações na planta e rejeição do erro de medida, conforme mencionado anteriormente.

Para o acompanhamento do sinal de referência, rejeição de perturbações e insensibilidade a variações na planta, necessita-se que $g_{N}(j \omega) \mathrm{k}(\mathrm{j} \omega)$ seja "grande". Por outro lado, tem-se que para rejeição do ruído de medida $g_{N}(j \omega) \mathrm{k}(\mathrm{j} \omega)$ deve ser "pequena".

Na maioria dos problemas práticos, entretanto, ocorre que o acompanhamento do sinal de referência, rejeição de perturbações e insensibilidade a variações na planta tem sua energia mais significativa nas regiões de baixa freqüência e a rejeição do ruído de medida nas regiões de alta freqüência.

O Diagrama de Bode do ganho da função de transferência de malha deve estar localizado entra as barreiras de baixa e altas freqüências, conforme apresentado na figura 8.2.

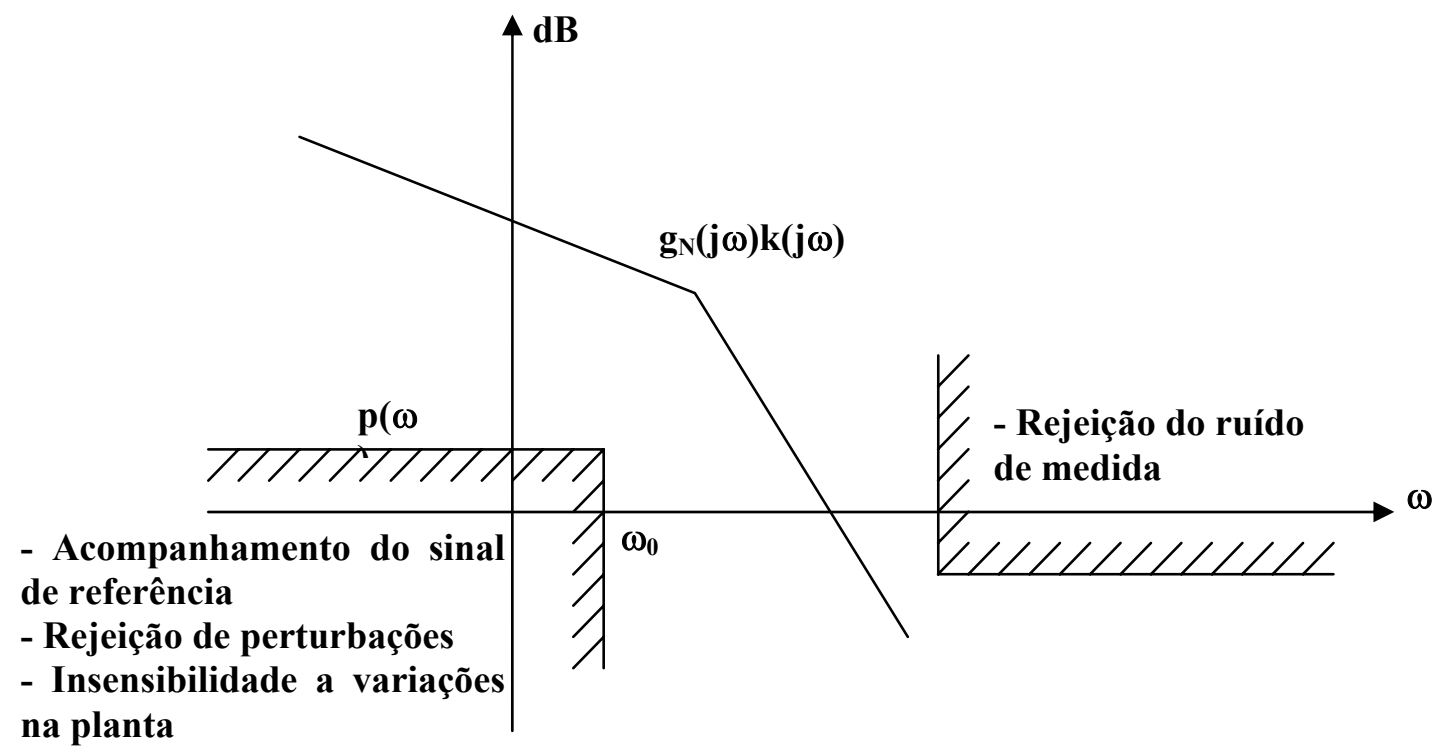

FIGURA 8.2 - Barreiras de baixa e alta freqüência (CRUZ (1996)) 


\subsection{O Sistema Real}

Entende-se como sistema real da planta aquele que aproxima-se melhor do sistema físico, incluindo as possíveis variações paramétricas. O diagrama de blocos da planta mais o compensador para o sistema real, portanto, é o mesmo da figura 8.1 com exceção da função de transferência da planta. Por tratar-se da planta real, sua função de transferência será definida como sendo $\mathrm{g}_{\mathrm{R}}(\mathrm{s})$. $\mathrm{O}$ compensador, por outro lado, é suposto ser o mesmo projetado para o sistema nominal.

\subsubsection{Representação do Erro de Modelagem}

Definiu-se anteriormente as características da planta nominal, utilizada no projeto do compensador, e da planta real, a qual representa exatamente o sistema físico em questão. Existe, portanto, uma diferença entre as duas representações. É interessante do ponto de vista de projeto que haja uma maneira matemática de se representar essa diferença, que a partir de agora será denominada de erro de modelagem.

Como apresentado em LEHTOMAKI* apud CRUZ (1996), uma das maneiras de se apresentar o erro de modelagem é através do erro aditivo, o qual é a diferença entre a planta real e a nominal $\left(\varepsilon_{\mathrm{A}}(\mathrm{s})=\mathrm{g}_{\mathrm{R}}(\mathrm{s})-\mathrm{g}_{\mathrm{N}}(\mathrm{s})\right)$, e que segundo a mesma referência apresenta um inconveniente a respeito da incerteza de fase.

Considerando-se a função de transferência de malha real $g_{R}(s) k(s)$ e o erro aditivo $\left(\varepsilon_{\mathrm{A}}(\mathrm{s})\right)$, pode-se chegar a eq. 8.2 abaixo

$$
\mathrm{g}_{\mathrm{R}}(\mathrm{s}) \mathrm{k}(\mathrm{s})-\mathrm{g}_{\mathrm{N}}(\mathrm{s}) \mathrm{k}(\mathrm{s})=\varepsilon(\mathrm{s}) \mathrm{k}(\mathrm{s})
$$

Como pode ser observado na eq. (8.2), o erro aditivo na função de transferência de malha depende da função de transferência do compensador k(s), o que é inconveniente, já que a intenção do projeto é exatamente obter k(s). É desejável portanto que o erro dependa somente da planta, sendo utilizado por essa razão o erro multiplicativo $\left(\varepsilon_{\mathrm{M}}(\mathrm{s})\right)$, que é uma medida relativa do erro. O erro multiplicativo

$$
\text { é apresentado }
$$

na

eq. 


$$
\varepsilon_{M}(s)=\frac{g_{R}(s)-g_{N}(s)}{g_{N}(s)}
$$

\subsubsection{Estabilidade do Sistema Real}

O sistema em malha fechada da planta real será estável se e apenas se os pólos de malha fechada estiverem localizados no semi-plano esquerdo (SPE) aberto. A condição para que toda classe de sistemas reais resulte estável é apresentada pela eq.(8.4) a seguir, e conhecida como condição de robustez da estabilidade:

$$
\left|g_{N}(j \omega) k(j \omega)\right|<\frac{1}{e_{M}(\omega)} \quad(\forall \omega \in \mathfrak{R})
$$

\subsubsection{Desempenho do Sistema Real}

Da mesma forma que para o sistema nominal, pode-se definir as mesmas condições de desempenho para ao sistema real. Pode-se ainda estabelecer uma condição para a robustez do desempenho, de tal forma que toda a classe de sistemas reais satisfaçam as especificações de desempenho. Essa condição é expressa pela eq. (8.5) abaixo:

$$
\left|g_{N}(j \omega) k(j \omega)\right| \geq \frac{p_{c}(\omega)}{1-e_{M}(\omega)} \quad\left(\forall \omega \leq \omega_{0}\right)
$$

onde $e_{\mathrm{M}}$ representa o erro de modelagem e $\omega_{0}$ é a maior freqüência da barreira de robustez do desempenho, definida pelo projetista, assim como o parâmetro $p_{c}(\omega)$.

\subsection{Modelo da Planta}

Como apresentado anteriormente, define-se uma planta nominal, que será utilizada durante o projeto do compensador. As possíveis variações paramétricas ou quaisquer outros fatores não especificados na planta nominal, que representam o sistema real, devem ser utilizadas para a determinação do erro de modelagem. 
Com relação à planta nominal utilizada no projeto do compensador, tem-se a mesma normalmente apresentada no domínio do tempo na forma de equações de estado conforme a eq. (8.6) abaixo:

$$
\begin{gathered}
\dot{x}(t)=A_{n} x(t)+B_{n} u(t) \\
y(t)=C_{n} x(t)
\end{gathered}
$$

onde $\mathrm{x}(\mathrm{t}) \in \mathbf{R}^{\mathrm{n}}, \mathrm{u}(\mathrm{t}), \mathrm{y}(\mathrm{t}) \in \mathbf{R}^{\mathrm{m}}$ e as matrizes $\mathrm{A}_{\mathrm{n}}, \mathrm{B}_{\mathrm{n}}$ e $\mathrm{C}_{\mathrm{n}}$ são constantes e com dimensões compatíveis.

Dessa forma, pode-se definir as matrizes $A_{n}, B_{n}$ e $C_{n}$ para o sistema de bobinamento de tiras de aço como se segue:

$$
A_{n}=\left[\begin{array}{ll}
\left(\frac{-R_{a}}{L_{a q}}\right) & \left(\frac{-K_{v}}{L_{a q}}\right) \\
\left(\frac{K_{t}}{J_{m}}\right) & \left(\frac{-B}{J_{m}}\right)
\end{array}\right] \quad B_{n}=\left[\begin{array}{c}
\frac{1}{L_{a q}} \\
0
\end{array}\right] \quad C_{n}=\left[\begin{array}{ll}
0 & \frac{\left(\mathrm{Ku}+\mathrm{r}_{\mathrm{m}} \mathrm{Ku}\right)}{\mathrm{n}}
\end{array}\right]
$$

Ainda, caso a planta não possua naturalmente integradores (o que é o caso), os mesmos podem ser adicionados pelo projetista, conforme proposto por CRUZ (1996). Esse procedimento foi então adotado para o sistema e as matrizes de estado tornaram-se:

$$
A=\left[\begin{array}{cc}
0 & 0 \\
B_{n} & A_{n}
\end{array}\right] \quad B=\left[\begin{array}{l}
I \\
0
\end{array}\right] \quad C=\left[\begin{array}{ll}
0 & C_{n}
\end{array}\right]
$$

onde I é a matriz identidade de dimensões adequadas.

\subsection{Elementos do Compensador}

Para definir-se a estrutura do compensador, considera-se o sistema: 


$$
\dot{x}(t)=A x(t)+B u(t)
$$

onde $\mathrm{x}(\mathrm{t}) \in \mathbf{R}^{\mathrm{n}}, \mathrm{u}(\mathrm{t}) \in \mathbf{R}^{\mathrm{m}}$ e o par $(\mathrm{A}, \mathrm{B})$ é controlável.

Adotando-se:

$$
u(t)=-G x(t)
$$

tem-se que a lei de controle resultante é denominada realimentação de estados. A matriz $\mathrm{G}$ é denominada matriz de realimentação de estados. O sistema em malha fechada é denominado regulador. Com essa lei de controle o regulador fica descrito no domínio do tempo pela eq. (8.8), ou no domínio da freqüência pela eq. (8.9) e sua representação encontra-se na figura 8.3:

$$
\begin{aligned}
\dot{x}(t) & =(A-B G) x(t) \\
x(s) & =(s I-A)^{-1} B u(s) \\
u(s) & =-G x(s)
\end{aligned}
$$

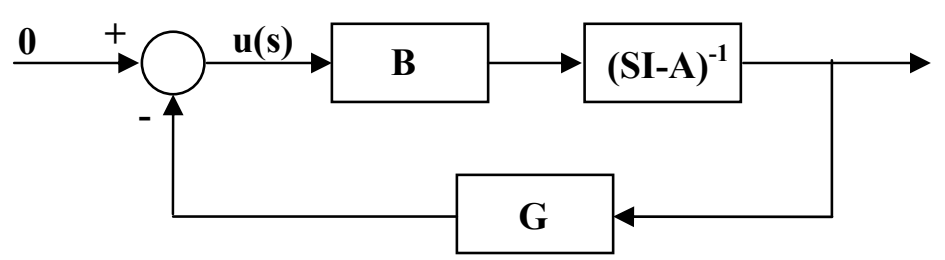

FIGURA 8.3 - Diagrama de blocos do regulador

Para a construção do regulador, portanto adota-se uma lei de controle baseada em realimentação de estados. No entanto, normalmente na resolução de um problema não se têm todos os estados disponíveis para a realimentação. Isto implica na necessidade de implementação de um observador de estados, o qual permite que uma estimativa do estado possa ser feita. Dessa forma, pode-se construir um sistema conforme a figura 8.4, admitindo-se que a saída y(t) possa ser medida e que se deseje 
que o estado estimado se aproxime assintóticamente do estado real. Na figura 8.4, $\mathrm{e}_{\mathrm{y}}(\mathrm{s})$ é o erro de observação e $\hat{x}$ é o estado estimado.

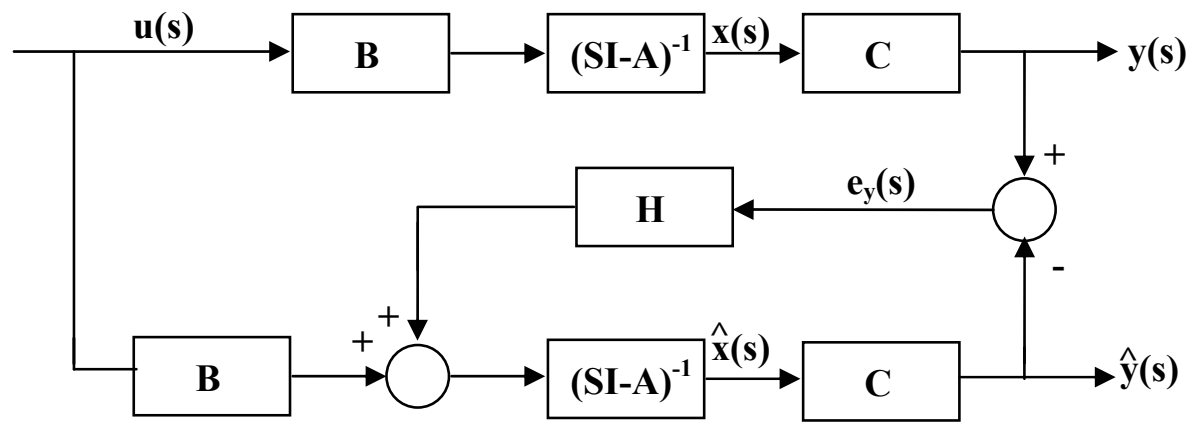

FIGURA 8.4 - Diagrama de blocos do observador

Definindo-se o erro de estimativa por:

$$
e_{x}(t)=x(t)-\hat{x}(t)
$$

resulta que:

$$
\dot{e}_{x}(t)=(A-H C) e_{x}(t)
$$

Da eq (8.11) acima, percebe-se que o erro de estimativa tem sua dinâmica governada pela matriz (A-HC). Se todos os autovalores dessa matriz pertencem ao SPE aberto, a estimativa $\hat{x}(\mathrm{t})$ tende assintóticamente para o estado $\mathrm{x}(\mathrm{t})$ quando $\mathrm{t} \rightarrow \infty$, como apresentado em CRUZ (1996). Pode-se, portanto considerar um regulador operando sobre o estado estimado, conforme a figura 8.5 :

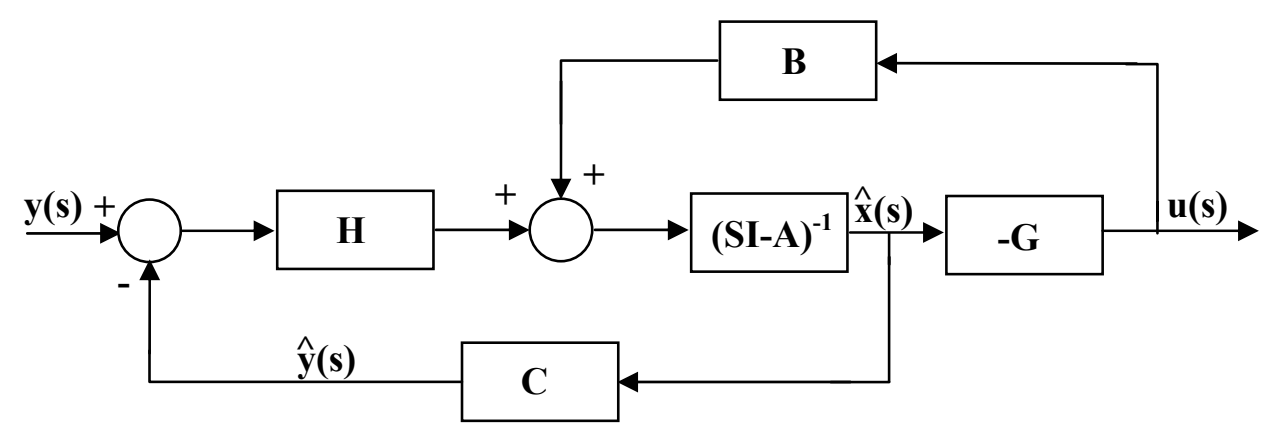

FIGURA 8.5 - Diagrama de blocos do regulador com observador 
No domínio do tempo, segundo o diagrama da figura 8.5 tem-se que :

$$
u(t)=-G \hat{x}(t)
$$

Pode-se ainda, através da figura 8.5 determinar a estrutura do compensador $\mathrm{K}$ (s) desejado, conforme apresentado na figura 8.6. O regulador LQG, possui a mesma estrutura da figura 8.5 , porém a sua construção está baseada no formulação de um problema de controle ótimo estocástico. Dessa forma, as matrizes G e H são determinadas através da solução de uma Equação Algébrica de Riccati (EAR). Esse procedimento será posteriormente apresentado.

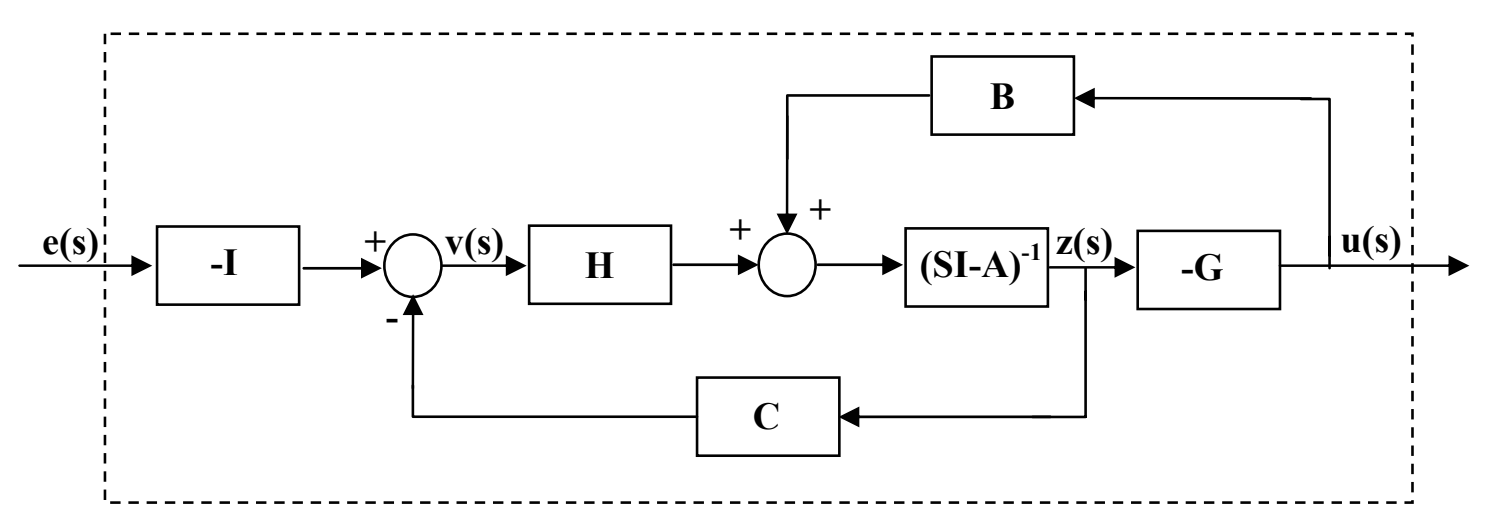

FIGURA 8.6 - Diagrama de blocos do compensador

\subsection{O Procedimento de Recuperação}

Descreve-se agora o procedimento de recuperação responsável pela parte LTR do projeto. Para a análise deste procedimento, toma-se como base a figura 8.7, considerando-se a abertura da planta nos pontos (I) e (II), para a análise do procedimento.

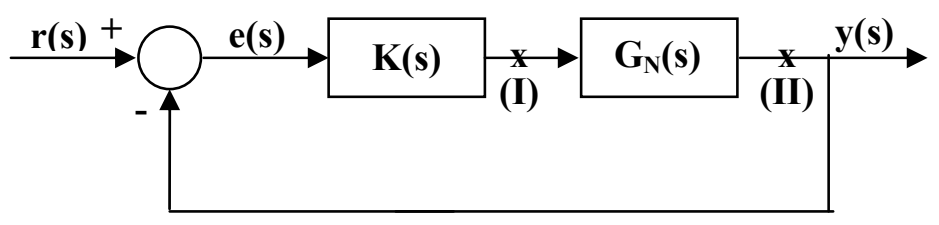

FIGURA 8.7 - Diagrama de blocos para análise do procedimento LTR 
Existem dois procedimentos duais de recuperação: o primeiro associado à matriz de transferência de malha $\mathrm{G}_{\mathrm{N}}(\mathrm{s}) \mathrm{K}(\mathrm{s})$, correspondente à abertura da malha no ponto (II) da figura 8.7 e o segundo associado à matriz de função de transferência de malha $\mathrm{K}(\mathrm{s}) \mathrm{G}_{\mathrm{N}}(\mathrm{s})$, correspondente à abertura da malha no ponto (I) da figura 8.7.

O procedimento apresentado por CRUZ (1996) e aqui reproduzido é o dual, conhecido por LTR na saída da planta no qual a matriz de ganhos do observador H é admitida fixa, ao passo que a matriz de ganhos G é ajustável.

\subsubsection{O Regulador Linear Quadrático}

O regulador linear quadrático consiste na solução do seguinte problema de controle ótimo:

$$
\min J=\int_{0}^{\infty} y^{\prime}(t) y(t)+u^{\prime}(t) R u(t) d t
$$

sujeito às seguintes restrições:

$$
\begin{gathered}
\dot{x}(t)=A x(t)+B u(t) \\
y(t)=C x(t)
\end{gathered}
$$

Considerando-se:

$$
\mathrm{Q}=\mathrm{C}^{\mathrm{T}} \mathrm{C}, \quad \mathrm{Q}=\mathrm{Q}^{\mathrm{T}} \geq 0 \quad \text { e } \mathrm{R}=\mathrm{R}^{\mathrm{T}}>0
$$

Tem-se que:

$$
G=R^{-1} B^{-1} K
$$

onde K é a solução simétrica definida positiva da EAR apresentada na eq. (8.15) a seguir: 


$$
0=-K A-A^{\prime} K-C^{\prime} C+K B R^{-1} B^{\prime} K
$$

Caso a matriz $\mathrm{R}$ seja da forma:

$\mathrm{R}=\rho_{\mathrm{c}} \mathrm{I}\left(\rho_{\mathrm{c}}>0\right)$

e $\rho_{\mathrm{c}} \rightarrow 0^{+}$, o problema é denominado RLQ.

\subsubsection{Teorema Fundamental LTR}

Caso:

I. $\quad(A, B)$ é controlável e $(A, C)$ é observável;

II. $\mathrm{G}_{\mathrm{N}}(\mathrm{s})$ é quadrada;

III. Os zeros de transmissão de $\mathrm{G}_{\mathrm{N}}(\mathrm{s})$ se localizam no SPE aberto:

IV. A matriz de ganhos $\mathrm{G}$ é calculada como

$$
G=\frac{1}{\rho_{c}} B^{\prime} K
$$

onde $\rho_{\mathrm{c}}>0$ e K é a solução da EAR apresentada na eq. (8.17):

$$
0=-K A-A^{\prime} K-C^{\prime} C+\frac{1}{\rho_{c}} K B B^{\prime} K
$$

então:

$$
\lim _{\rho_{c} \rightarrow 0^{+}} K(s)=\left[C(s I-A)^{-1} B\right]^{-1} C(s I-A)^{-1} H
$$

\subsection{A Malha Objetivo}

Pretende-se que a malha objetivo $\left(\mathrm{G}_{\mathrm{KF}}(\mathrm{s})\right)$, satisfaça as condições de estabilidade e desempenho. Associado a esta característica vem o procedimento de recuperação que garante que para $\rho_{c} \rightarrow 0^{+}$, as características de reposta em freqüência 
da malha objetivo sejam reproduzidas pela malha formada pelo compensador e pela planta nominal.

Como anteriormente exposto, a matriz $\mathrm{H}$ do observador de estados foi suposta fixa, enquanto a matriz $\mathrm{G}$ foi determinada através do procedimento de recuperação, com a solução da EAR (8.17), para pequenos valores de $\rho_{\mathrm{c}}$.

Nesta sessão, será demonstrado que a matiz $\mathrm{H}$ do observador de estados pode ser determinada através do Filtro de Kalman (FK) (CRUZ (1996)).

\subsubsection{Filtro de Kalman e Regulador LQG}

O diagrama de blocos do FK é apresentado na figura 8.8, sendo que existe uma relação de dualidade entre o FK e o RLQ.

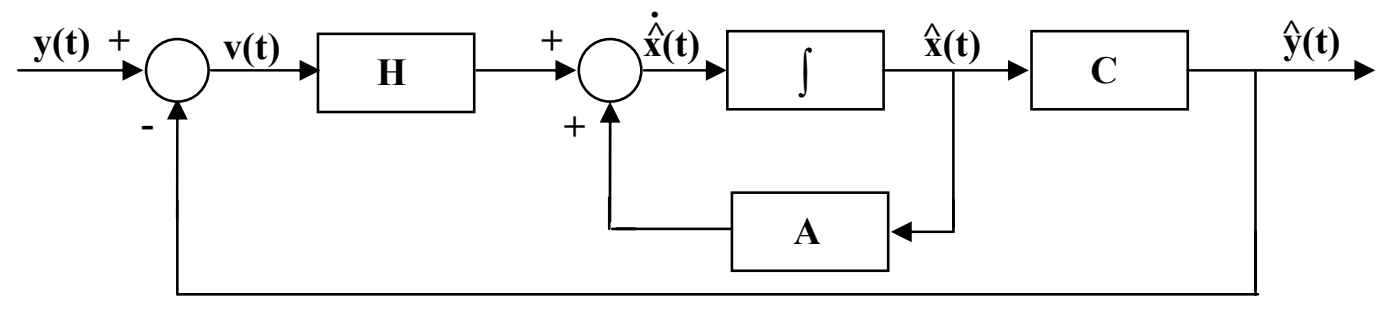

FIGURA 8.8 - Diagrama de blocos do Filtro de Kalman

A matriz de ganhos do FK pode ser calculada através da eq. (8.19) abaixo:

$$
H=\frac{1}{\mu} \Sigma C^{\prime}
$$

com $\Sigma$ calculado através da EAR:

$$
0=A \Sigma+\Sigma A^{\prime}-L L^{\prime}-\frac{1}{\mu_{c}} \Sigma C^{\prime} C \Sigma
$$

onde, $\mu$ e L são parâmetros de projeto que serão posteriormente definidos. 
O desenvolvimento e construção do FK se dá de tal maneira que se considera o processo como sendo estocástico e sujeito a ruídos brancos e gaussianos, tanto no próprio processo quanto nas medições.

Pode-se, dessa forma, resolver um problema de controle ótimo estocástico aplicando-se a matriz de ganhos de um RLQ determinístico à estimativa gerada por um FK. O regulador obtido dessa maneira será então denominado Linear Quadrático Gaussiano (LQG).

\subsubsection{Identidade de Kalman}

Através da Identidade de Kalman (CRUZ (1996)), pode-se realcionar a FT de retorno da malha objetivo com os parâmetros de projeto anteriormente mencionados, $\mu$ que é um escalar maior que zero e a matriz $\mathrm{L} \in \mathrm{R}^{\mathrm{n} \times \mathrm{m}}$. A Identidade de Kalman envolvendo os parâmetros $\mu$ e L pode ser expressa a seguir pela eq. (8.20):

$$
\sigma_{i}\left[G_{K F}(j \omega)\right] \cong \frac{1}{\mu} \sigma_{i}\left[C(j \omega I-A)^{-1} L\right]
$$

onde $\sigma_{\mathrm{i}}$ são os valores singulares da malha objetivo, ou o valor singular, para o problema do sistema de bobinamento em questão.

Dessa forma, $\mu$ e L devem ser escolhidos de tal forma que $\sigma\left[G_{K F}(j \omega)\right]$ respeite a barreira de desempenho.

\subsection{Resumo do Procedimento de Projeto}

O procedimento de projeto é de natureza sistemática (CRUZ (1996)) sendo suas etapas apresentadas a seguir:

I. Escolher $\mu$ e L de maneira que os valores singulares definidos pela eq. (8.20) obedeçam as barreiras de desempenho e estabilidade. Armazenar os valores de $\mu$ e L obtidos;

II. Usando os valores de $\mu$ e L anteriormente obtidos, resolve-se a EAR (8.19) e então calcula-se a matriz de ganhos do FK através da eq. (8.18). Verifica-se 
se vale a condição de robustez da estabilidade de $\mathrm{G}_{\mathrm{KF}}$; caso não seja atendida retorna-se ao ítem I;

III. Calcula-se os zeros de $\mathrm{G}_{\mathrm{N}}(\mathrm{s})$ e verifica-se se os mesmos pertencem ao SPE aberto. Resolve-se a EAR (8.17) para algum valor de $\rho_{\mathrm{c}}>0$, e em seguida calcula-se a matriz de ganhos de realimentação de estados através da eq. (8.16). Calcula-se a matriz de funções de transferências do compensador $\mathrm{K}(\mathrm{s})=\mathrm{G}(\mathrm{sI}-\mathrm{A}+\mathrm{BG}+\mathrm{HC})^{-1} \mathrm{H}$. Calcula-se a matriz de funções de transferências do ramo direto $\mathrm{G}_{\mathrm{N}}(\mathrm{s}) \mathrm{K}(\mathrm{s})$, onde $\mathrm{G}_{\mathrm{N}}(\mathrm{s})$ contém os eventuais integradores adicionados à planta. Exibi-se o valor singular de $\mathrm{G}_{\mathrm{N}}(\mathrm{j} \omega) \mathrm{K}(\mathrm{j} \omega)$. Compara-se o resultado obtido com o item anterior. Se a proximidade for satisfatória, prossegue-se adiante, caso contrário diminui-se o valor de $\rho_{c}$ e repete-se o procedimento novamente. Exibi-se o valor singular do sistema final em malha fechada e verifica-se se a condição de robustez da estabilidade é obedecida. Caso contrário diminui-se $\rho_{\mathrm{c}}$ novamente. Finalmente obtém-se o compensador $\mathrm{K}(\mathrm{s})$ ou $(\mathrm{I} / \mathrm{s}) \mathrm{K}(\mathrm{s})$ caso tenham sido adicionados integradores à planta.

\subsection{Observações Finais}

Para a determinação da barreira de robustez do desempenho definiu-se $p_{c}(\omega)=2$ para freqüências abaixo de $0.5 \mathrm{rad} / \mathrm{s}$. O modelo de atraso do retificador foi desconsiderado no projeto, devido à lenta dinâmica do sistema de bobinamento. $\mathrm{O}$ capítulo 9, de resultados, ilustra esta situação. Da mesma forma que no capítulo anterior o conjugado o sistema foi considerado linear, de forma que as matrizes de estados apresentadas no sistema não contém o conjugado de carga. O conjugado, dessa forma, pode ser entendido como uma perturbação no sistema.

Os parâmetros de projeto $\mu$ e L foram definidos conforme segue:

$\mu=0,6$

$$
L=\left[\begin{array}{l}
1,5 \\
0 \\
0,7
\end{array}\right]
$$


Os valores de $\mu$ e L foram ajustados levando-se em consideração que o parâmetro $\mu$ tem como efeito apenas trasladar os gráficos de Bode da malha objetivo. Já o parâmetro L permite alterar a forma dos diagramas (CRUZ, 1996).

Com os valores de $\mu$ e $\mathrm{L}$ foram obtidas as matrizes $\mathrm{G}$ e $\mathrm{H}$ do compensador apresentadas abaixo:

$$
G=10^{6} \cdot\left[\begin{array}{lll}
0,004 & 0,0043 & 1,4587
\end{array}\right] \quad H=\left[\begin{array}{l}
1,9365 \\
0,9207 \\
1,4659
\end{array}\right]
$$




\section{Capítulo 9}

\section{Resultados e Discussões}

Neste capítulo apresentam-se os resultados de simulações relativos à modelagem do sistema de bobinamento, apresentada no capítulo 3, bem como os resultados obtidos com os sistema de controle anteriormente propostos.

\subsection{Simulação do Motor CC}

Com as equações (3.1) e (3.2), obteve-se o modelo de simulação computacional do programa $\mathrm{Matlab}^{\circledR} /$ Simulink apresentado na figura 9.1. A partir do modelo computacional, pôde-se obter as formas de onda de corrente de armadura, velocidade mecânica e conjugado desenvolvido. Estes gráficos encontram-se nas figuras 9.2, 9.3 e 9.4, respectivamente.

Os dados do motor, extraídos de KUSKO (1969) juntamente com as outras variáveis envolvidas no sistema de bobinamento encontram-se no Anexo A.

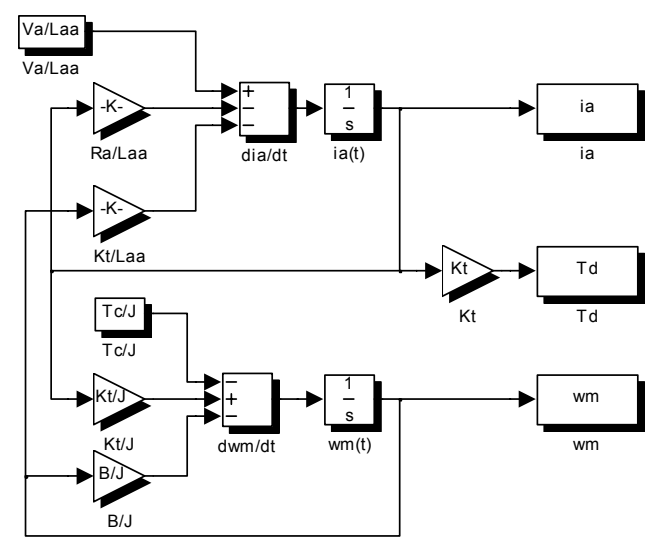

FIGURA 9.1 - Modelo computacional do motor CC no programa Matlab ${ }^{\circledR} /$ Simulink 


\subsubsection{Resultados das Simulações do Motor CC}

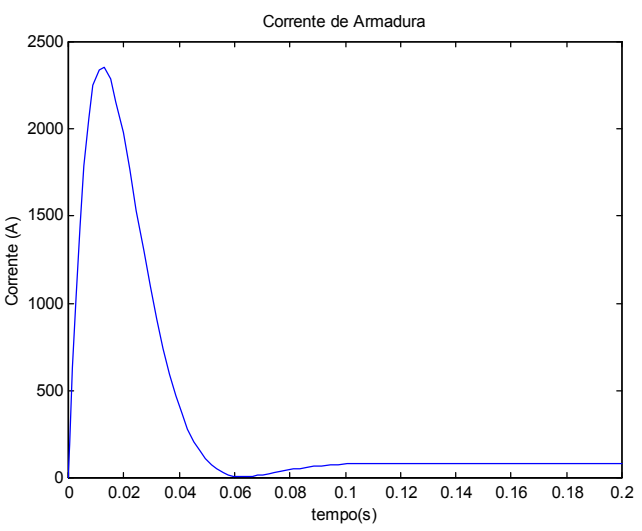

FIGURA 9.2 - Corrente de armadura

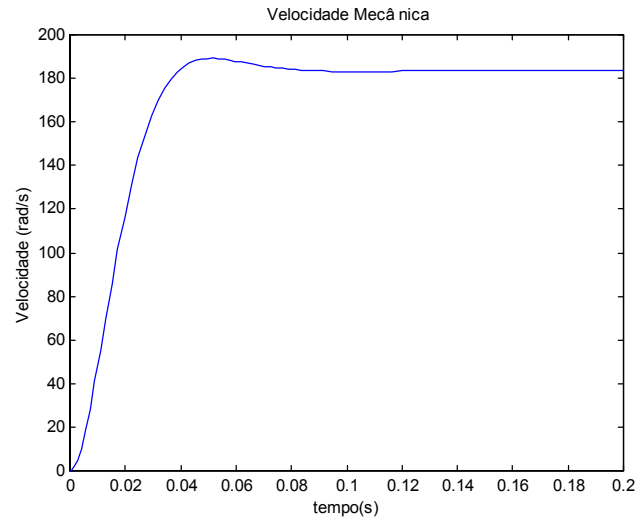

FIGURA 9.3 - Velocidade mecânica

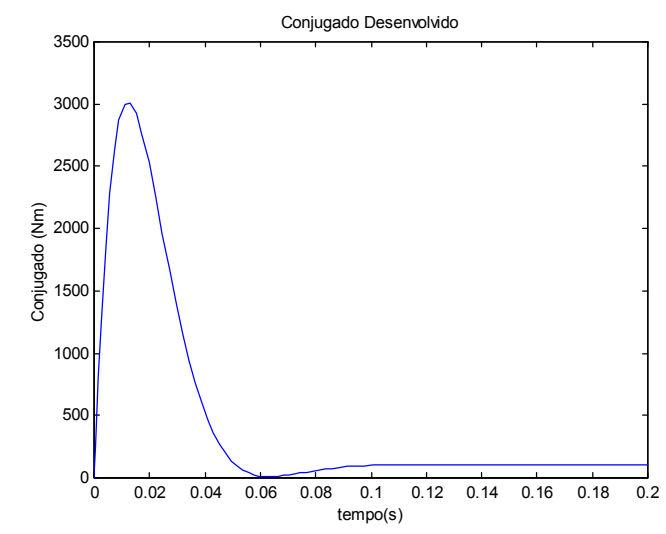

FIGURA 9.4 - Conjugado desenvolvido

\subsection{Simulação Considerando a Inércia}

As simulações a seguir referem-se ao motor operando com as características de inércia apresentadas no item 3.3.1. Para tal simulação foi utilizado o mesmo modelo computacional apresentado na figura 9.1. A partir do modelo computacional, pôde-se obter novamente as formas de onda de corrente de armadura, velocidade mecânica e conjugado desenvolvido, para a nova condição de inércia. Estes gráficos encontram-se nas figuras 9.5, 9.6 e 9.7 respectivamente.

Como pode-se notar, as variações entre as simulações com o motor em vazio, e com o motor movimentando o rolo bobinador são mínimas. 


\subsubsection{Resultados da Simulação Com o Rolo Bobinador}

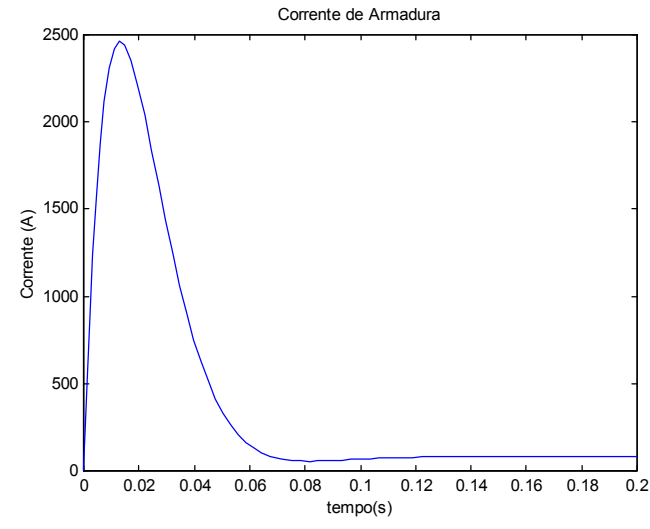

FIGURA 9.5 - Corrente de armadura

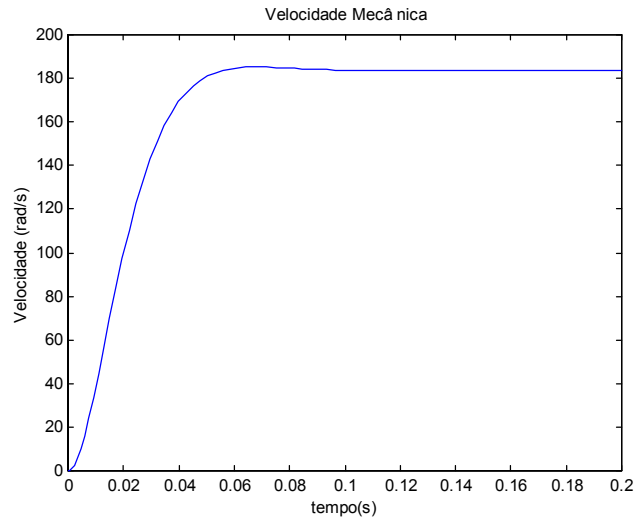

FIGURA 9.6 - Velocidade mecânica

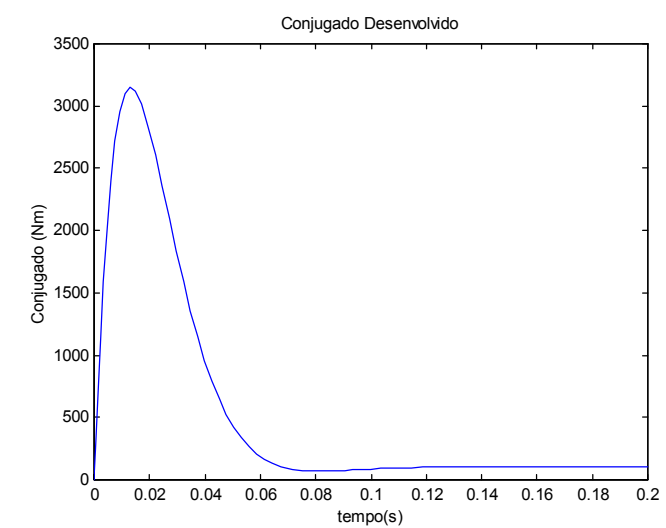

FIGURA 9.7 - Conjugado desenvolvido

\subsection{Modelo Completo do Sistema de Bobinamento}

No modelo da figura 9.8, implementou-se o cálculo da força aplicada à tira conforme a equação (3.18). Utilizando-se este modelo, e novamente os dados contidos no Anexo A, o sistema foi simulado evidenciando-se agora as variáveis de interesse para o sistema de controle, ou seja, a velocidade linear a qual a tira é bobinada e a força aplicada à tira.

Como o momento de inércia do sistema é agora variável, a equação (3.2) agora será escrita na forma da equação (9.1), e, isolando-se a derivada da velocidade 
e considerando-se o termo $\mathrm{B} \omega_{1}$ como conjugado resistente, resulta a equação (9.2) abaixo:

$$
\begin{gathered}
T=p\left(J_{1 e} \omega_{1}\right)+T_{C} \\
p \omega_{1}=\frac{T}{J_{1 e}}-\frac{\omega_{1}}{J_{1 e}} p J_{1 e}-\frac{T_{c 1}}{J_{1 e}}-\frac{B \omega_{1}}{J_{1 e}}
\end{gathered}
$$

A razão do conjugado de carga devido à força aplicada à tira, pela inércia do sistema $\left(\mathrm{T}_{\mathrm{cl}} / \mathrm{J}_{1 \mathrm{e}}\right)$, ambos já refletidos para o eixo do motor através da caixa de redução, é também agora apresentada.

Os gráficos das figuras 9.9, 9.10, 9.11, 9.12, 9.13 e 9.14 apresentam a variação do raio de bobinamento, a variação da inércia, o conjugado desenvolvido, a relação $\left(\mathrm{T}_{\mathrm{c} 1} / \mathrm{J}_{1 \mathrm{e}}\right)$, a força aplicada à tira e a velocidade linear de bobinamento, respectivamente, destacando os efeitos da caixa de redução sobre o momento de inércia e o conjugado desenvolvido.

\subsection{Alteração nas Variáveis do Sistema}

Com o modelo utilizado para as simulações apresentado neste ítem, pode-se variar os parâmetros da produção da tira referentes ao sistema real, com o intuito de definir qual o impacto de cada uma dessas variações sobre o sistema. As variações introduzidas referem-se as características físicas da tira, como a densidade volumétrica do material utilizado, e produtivas, como espessura e largura.

\subsubsection{Variação da Densidade Volumétrica do Material}

Uma das variáveis do sistema que pode sofrer alterações, é a densidade volumétrica que é específica para cada tipo de material. Nos dados apresentados anteriormente, utilizou-se a densidade do aço inox que é de $7,8 \mathrm{~g} / \mathrm{cm}^{3}$. Um material com densidade volumétrica maior implica em uma massa maior para um mesmo volume de material bobinado, implicando consequentemente em um aumento de inércia no sistema. Foi realizada a alteração de densidade volumétrica e o sistema foi 
simulado considerando-se a densidade volumétrica original de $7,8 \mathrm{~g} / \mathrm{cm}^{3}, 9,0 \mathrm{~g} / \mathrm{cm}^{3}$ e $10 \mathrm{~g} / \mathrm{cm}^{3}$ para o material. As figuras $9.15,9.16$ e 9.17 apresentam a relação $T_{\mathrm{cl}} / \mathrm{J}_{1 \mathrm{e}}$, a força aplicada à tira e a velocidade linear, respectivamente.

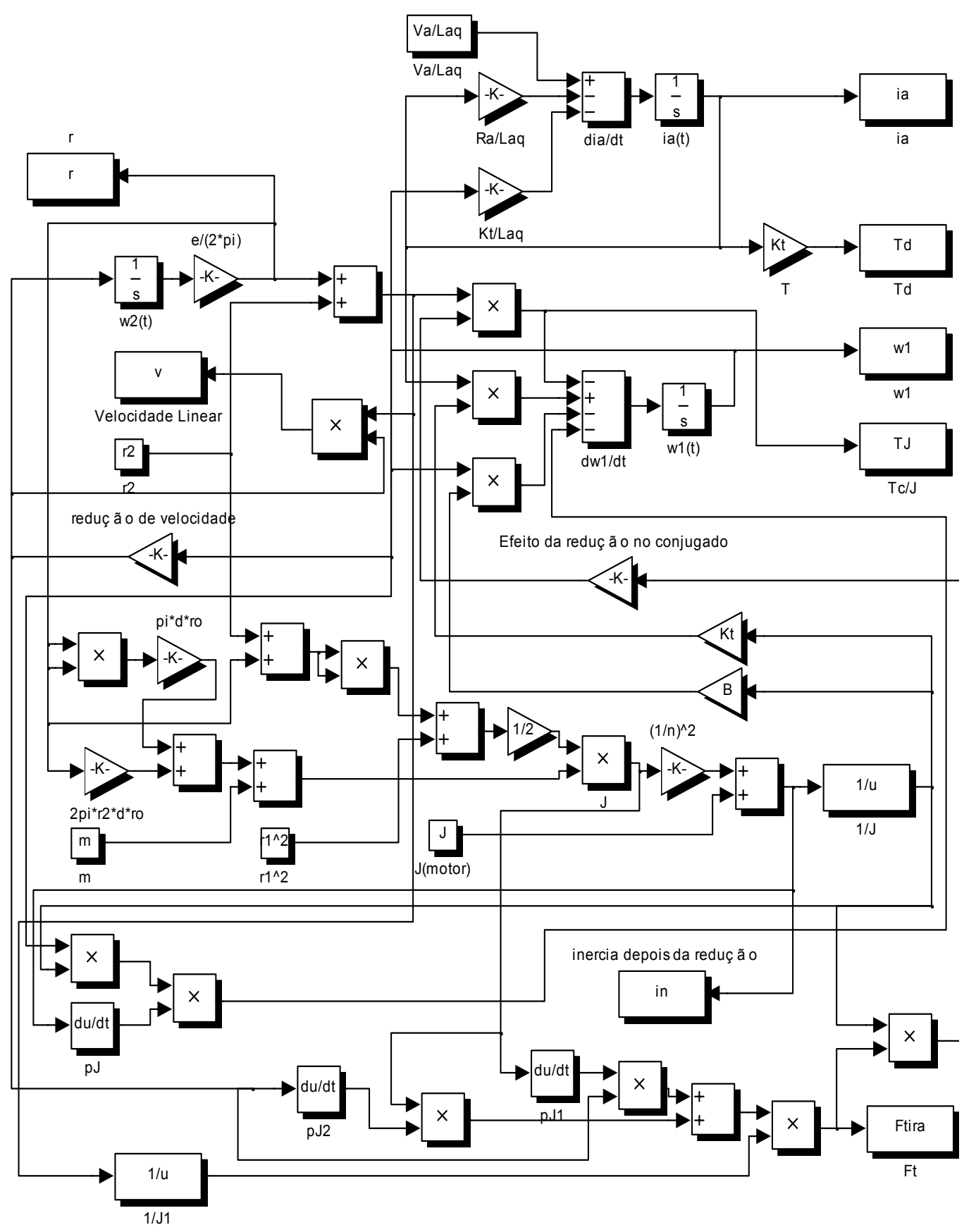

FIGURA 9.8 - Modelo completo do sistema de bobinamento 


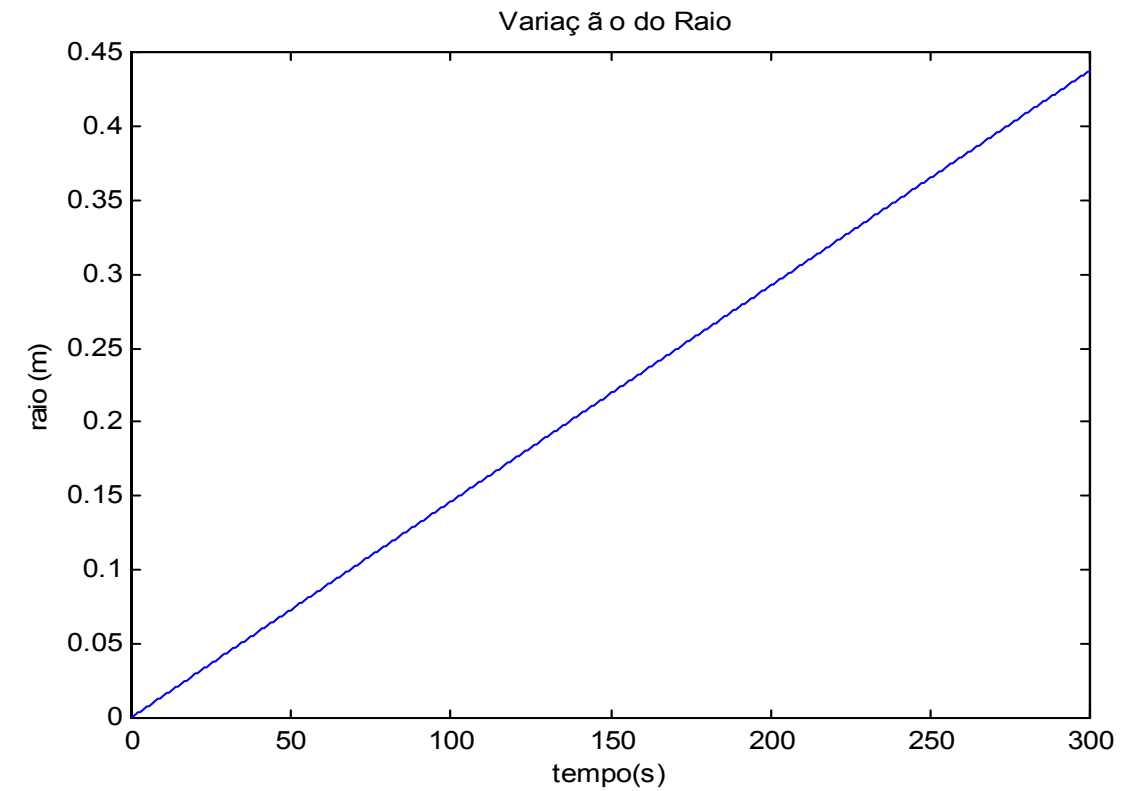

FIGURA 9.9 - Variação do raio ( Sistema de bobinamento completo )

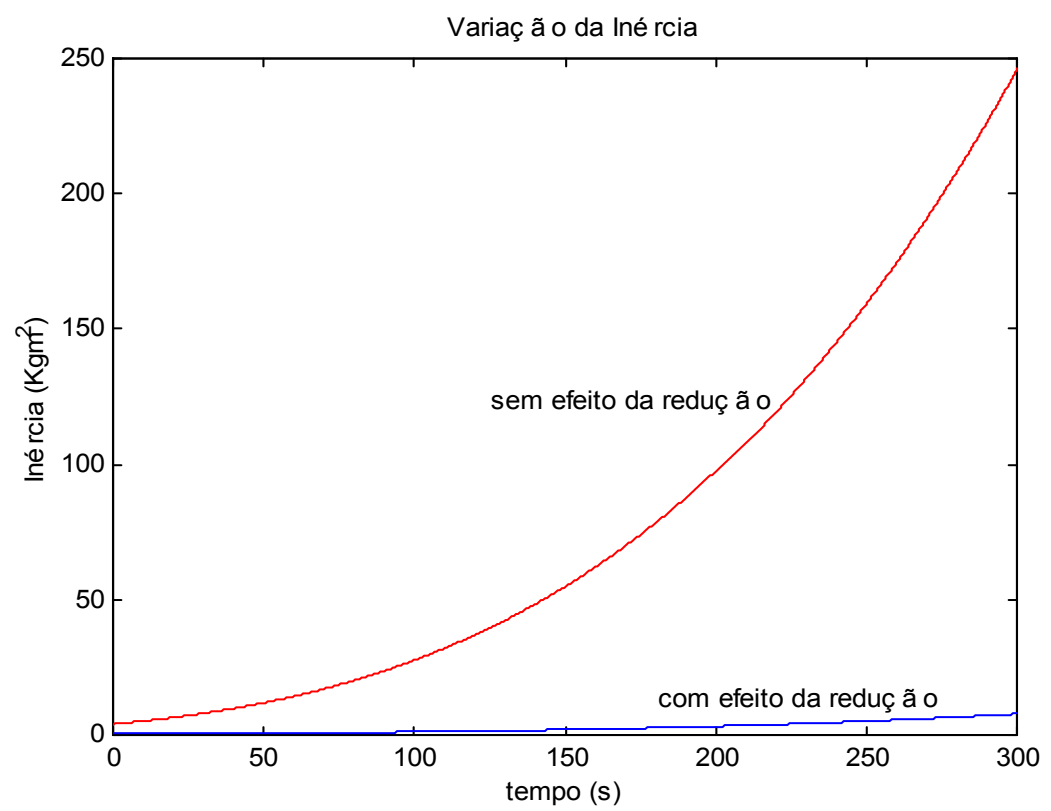

FIGURA 9.10 - Variação da inércia ( Sistema de bobinamento completo ) 


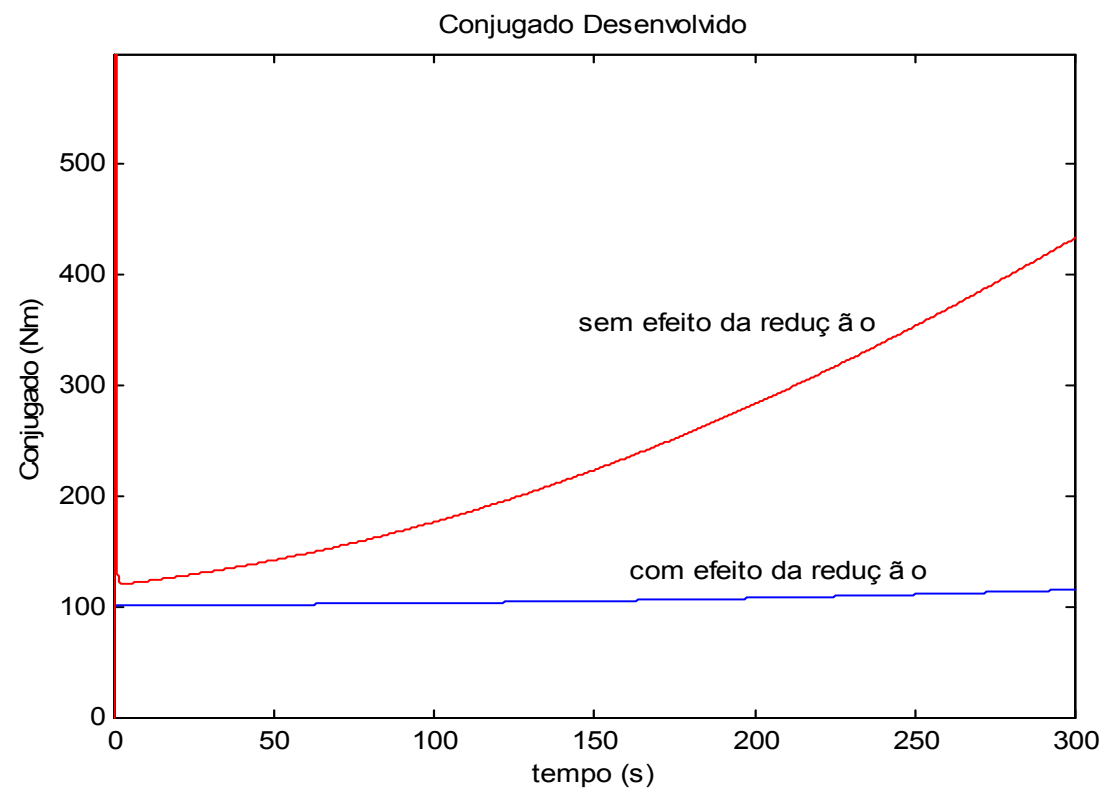

FIGURA 9.11 - Conjugado desenvolvido ( Sistema de bobinamento completo )

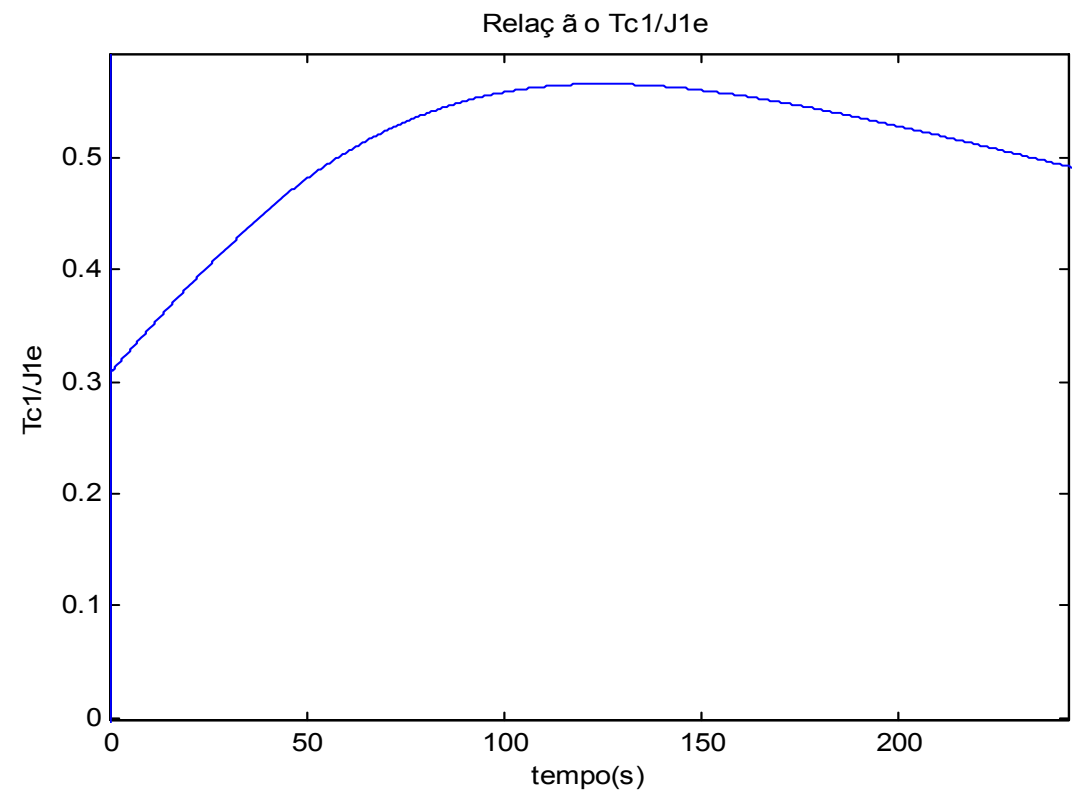

FIGURA 9.12 - Relação $\mathrm{T}_{\mathrm{cl}} / \mathrm{J}_{\mathrm{le}}$ ( Sistema de bobinamento completo ) 


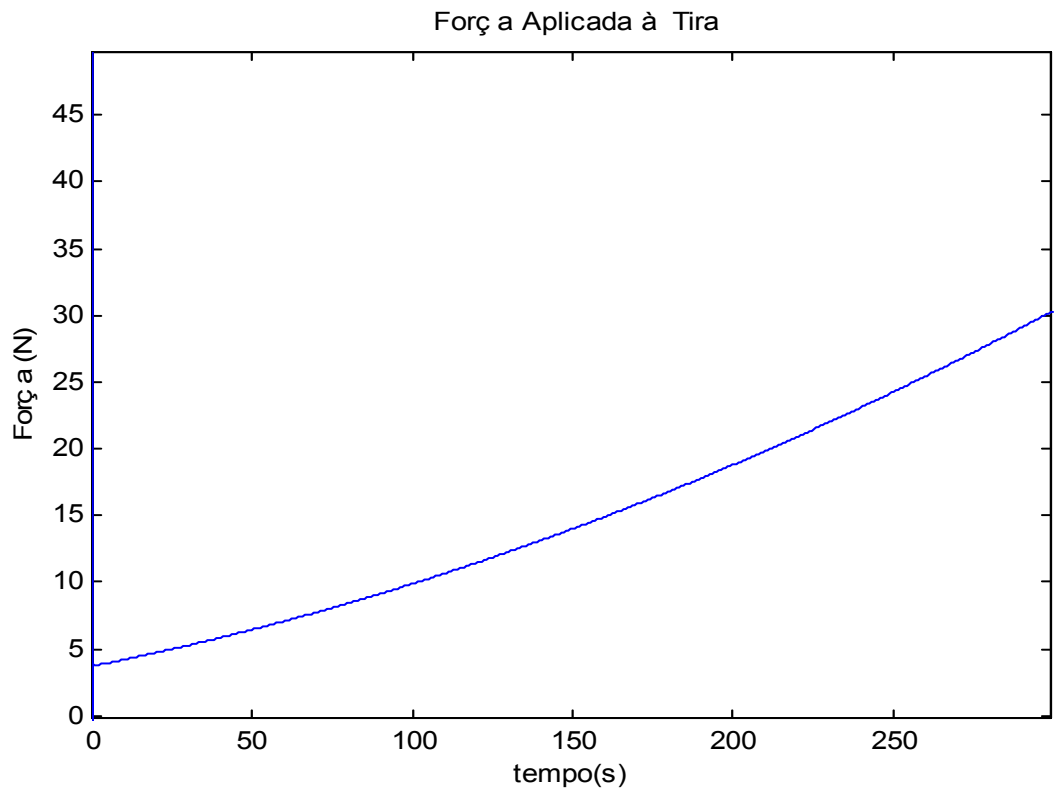

FIGURA 9.13 - Força aplicada à tira ( Sistema de bobinamento completo )

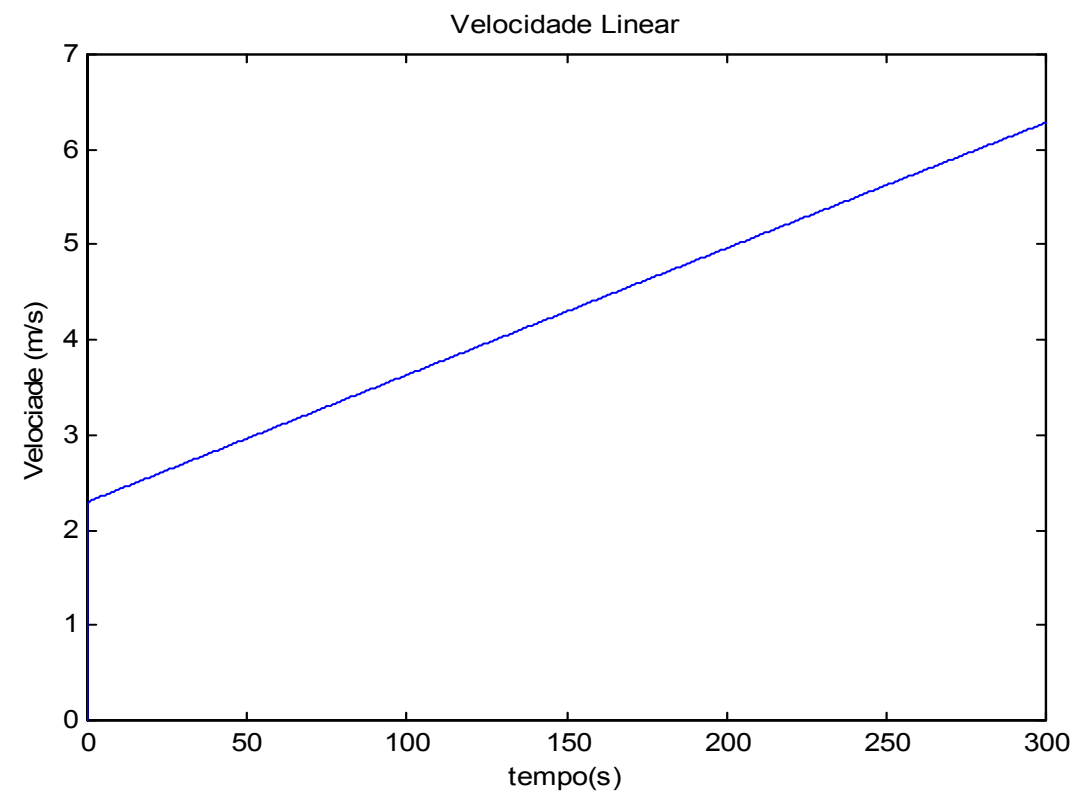

FIGURA 9.14 - Velociade Linear ( Sistema de bobinamento completo ) 


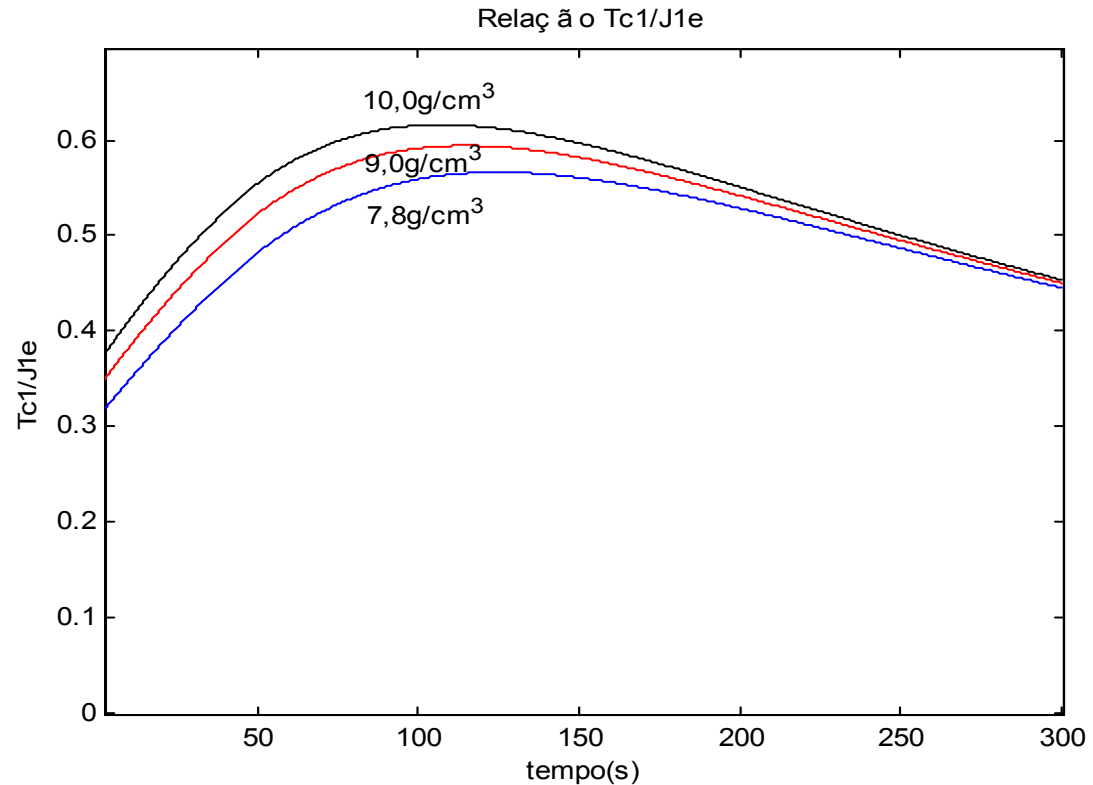

FIGURA 9.15 - Relação $T_{\mathrm{c} 1} / \mathrm{J}_{1 \mathrm{e}}($ Variação de $\rho$ )

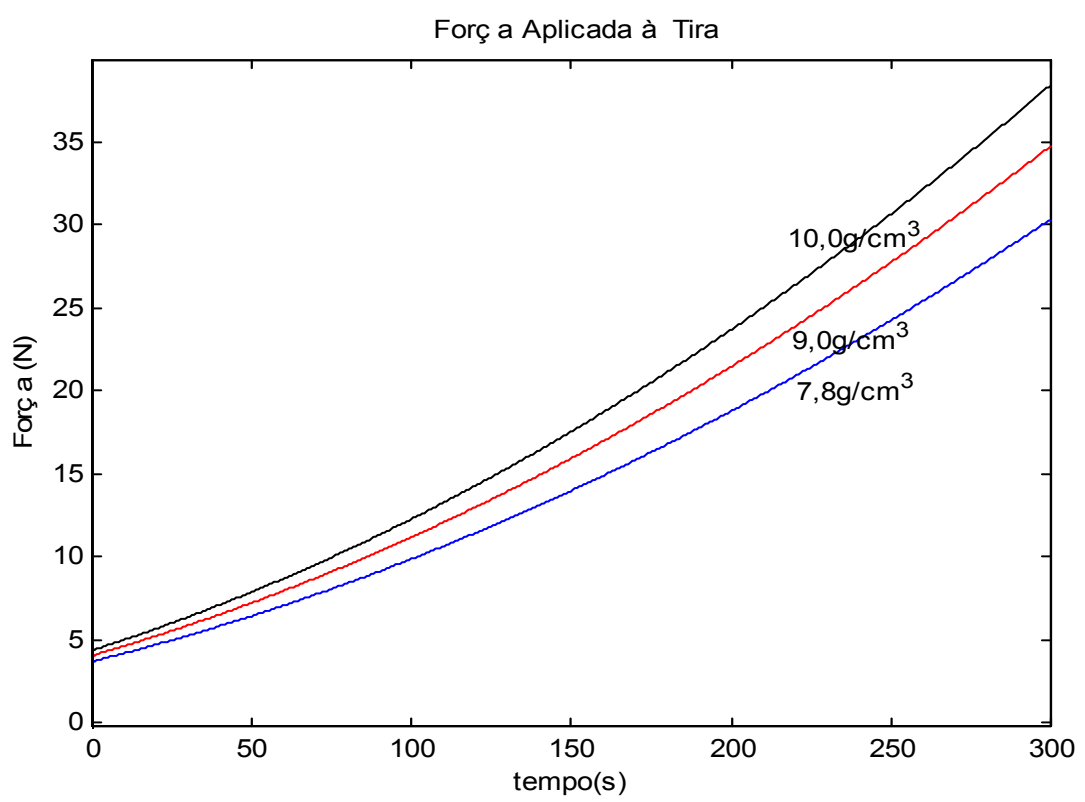

FIGURA 9.16 - Força aplicada à tira ( Variação de $\rho$ ) 


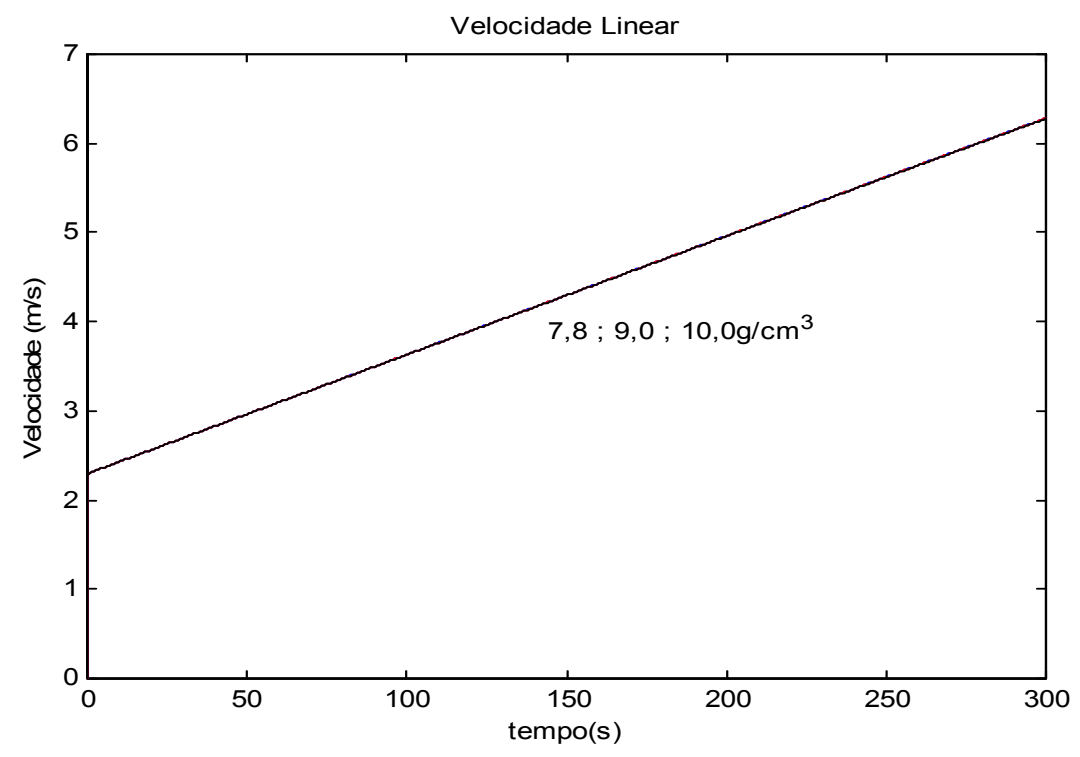

FIGURA 9.17 - Velocidade linear ( Variação de $\rho$ )

\subsubsection{Variação da Espessura da Tira}

Mais um parâmetro passível de variação no sistema é a espessura da tira. Adotando-se a espessura padrão de $1 \mathrm{~mm}$, e variando-se para $3 \mathrm{~mm}$ e $5 \mathrm{~mm}$, obteve-se os resultados apresentados nas figuras 9.18, 9.19 e 9.20. Estes resultados apresentam a relação $T_{c 1} / J_{1 e}$, a força aplicada à tira e a velocidade linear, respectivamente.

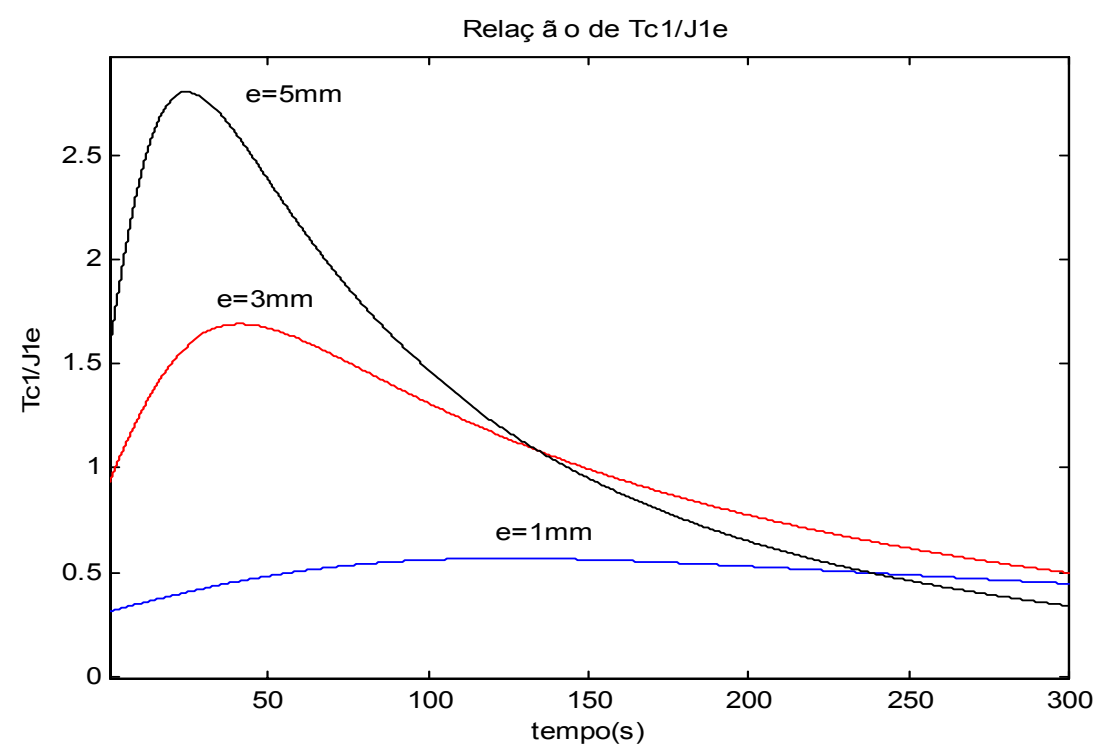

FIGURA 9.18 - Relação $\mathrm{T}_{\mathrm{cl}} / \mathrm{J}_{1 \mathrm{e}}$ ( Variação da espessura ) 


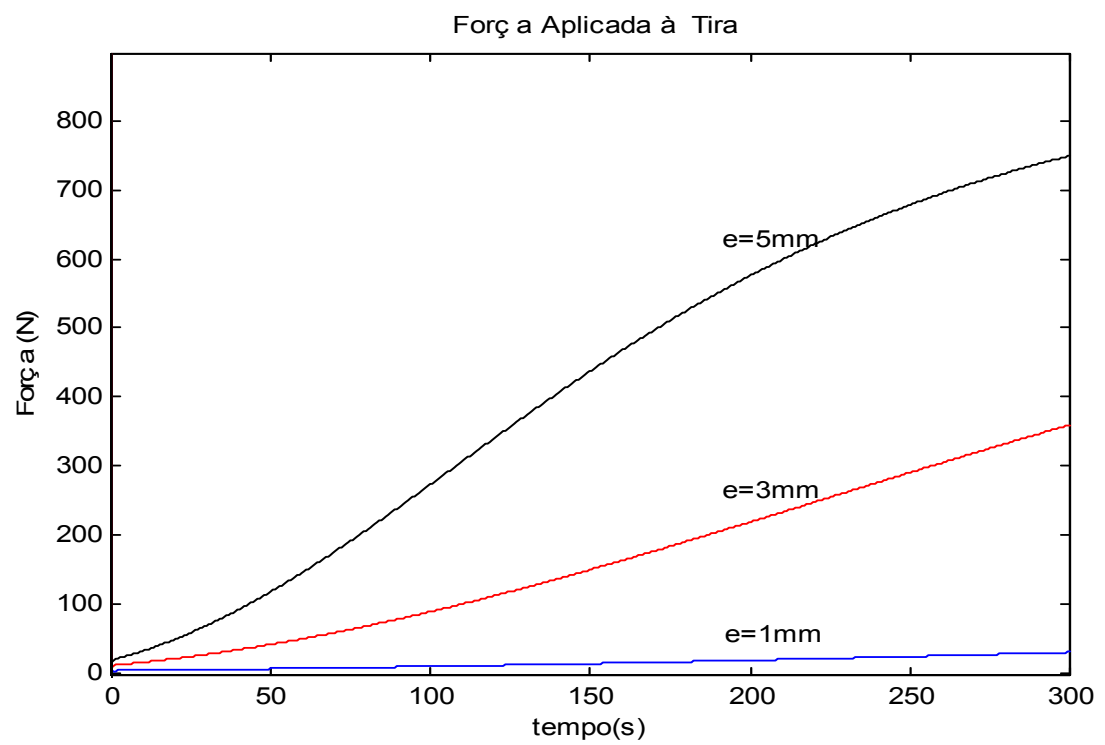

FIGURA 9.19 - Força aplicada à tira ( Variação da espessura )

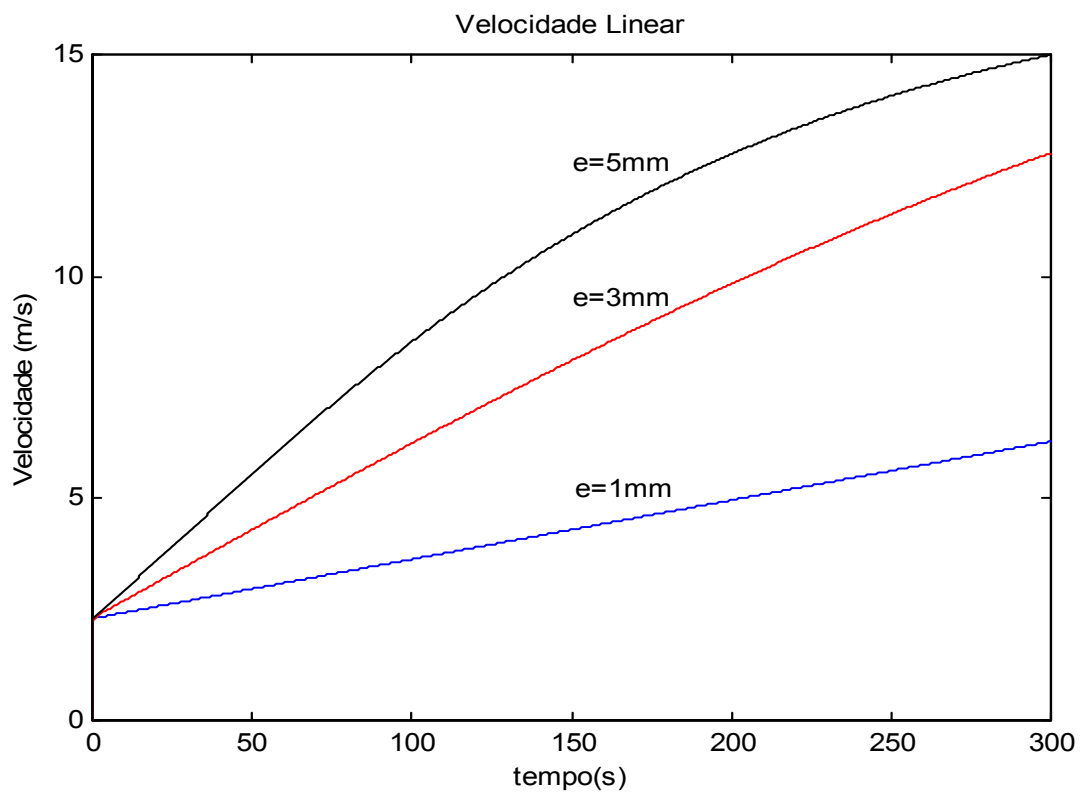

FIGURA 9.20 - Velocidade linear ( Variação da espessura ) 


\subsubsection{Variação da Largura da Tíra}

Finalmente, o último parâmetro passível de variação é a largura do lingote. A partir do valor padrão de $0,1 \mathrm{~m}$, simulou-se o sistema para larguras de tira de $0,15 \mathrm{~m}$ e $0,20 \mathrm{~m}$. Os resultados de simulação encontram-se nas figuras 9.21, 9.22 e 9.23, que apresentam a relação $\mathrm{T}_{\mathrm{cl}} / \mathrm{J}_{1 \mathrm{e}}$, a força aplicada à tira e a velocidade linear, respectivamente.

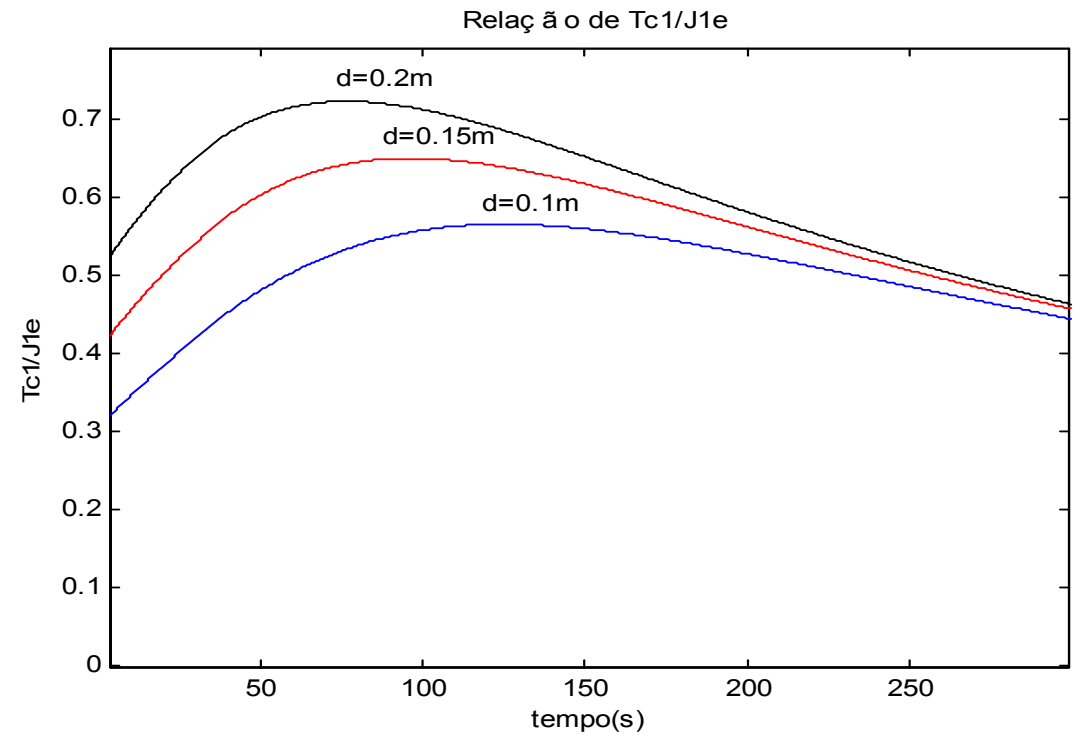

FIGURA 9.21 - Relação $\mathrm{T}_{\mathrm{c} 1} / \mathrm{J}_{1 \mathrm{e}}$ ( Variação da Largura )

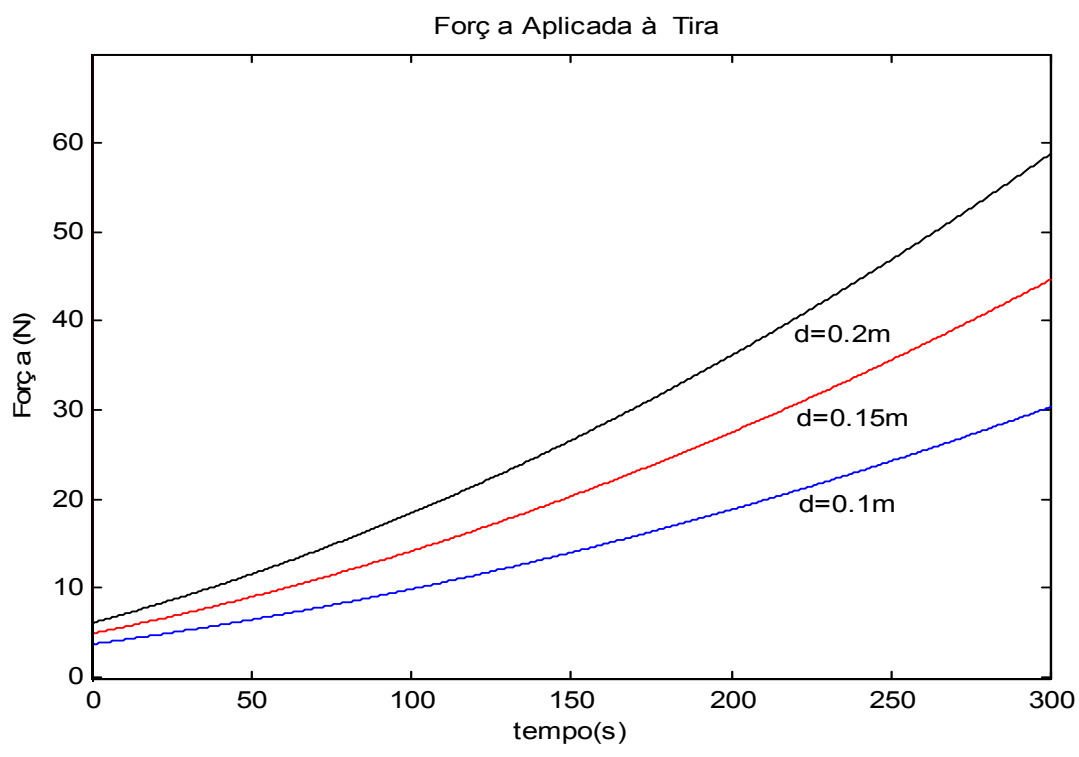

FIGURA 9.22 - Força aplicada à tira ( Variação da Largura ) 


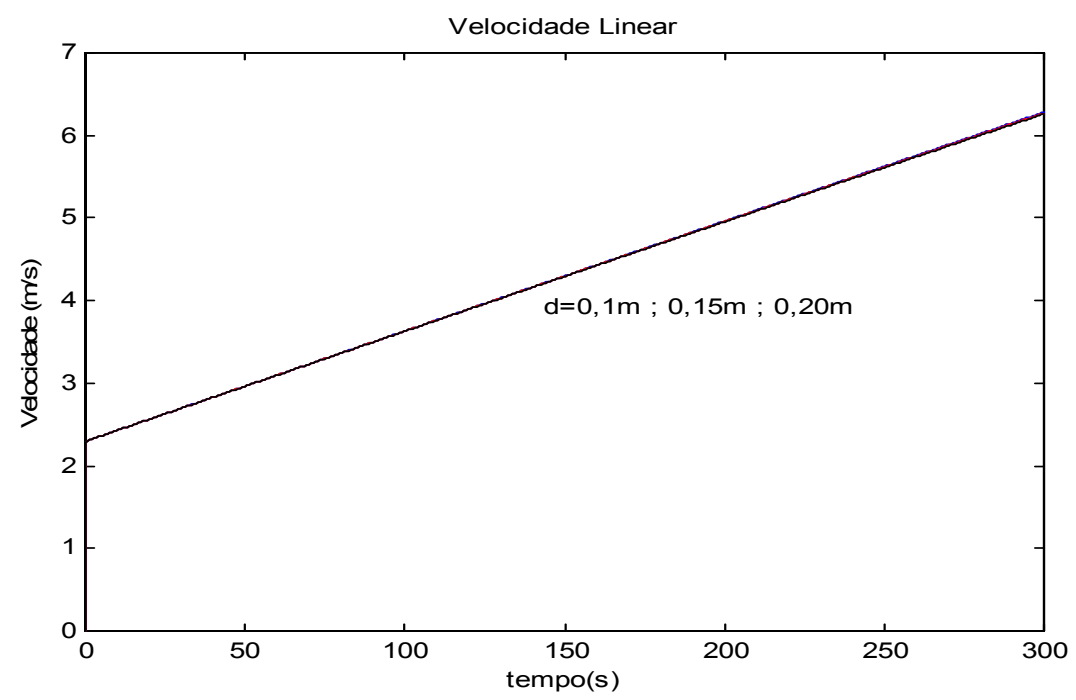

FIGURA 9.23 - Velocidade linear ( Variação da Largura )

\subsection{Simulações do Sistema de Controle}

\subsubsection{Controle de Velocidade}

O sistema de controle, conforme apresentado no capítulo 5, foi simulado para valores de espessura de tira de $1 \mathrm{~mm}$ e $5 \mathrm{~mm}$. O controlador utilizado foi do tipo PI. As figuras 9.24, e 9.25 apresentam a velocidade linear e velocidade angular no rolo bobinador, respectivamente, para a tira de $1 \mathrm{~mm}$ e as figuras 9.26 e 9.27 apresentam as mesmas variáveis, porém para a tira de $5 \mathrm{~mm}$ de espessura.

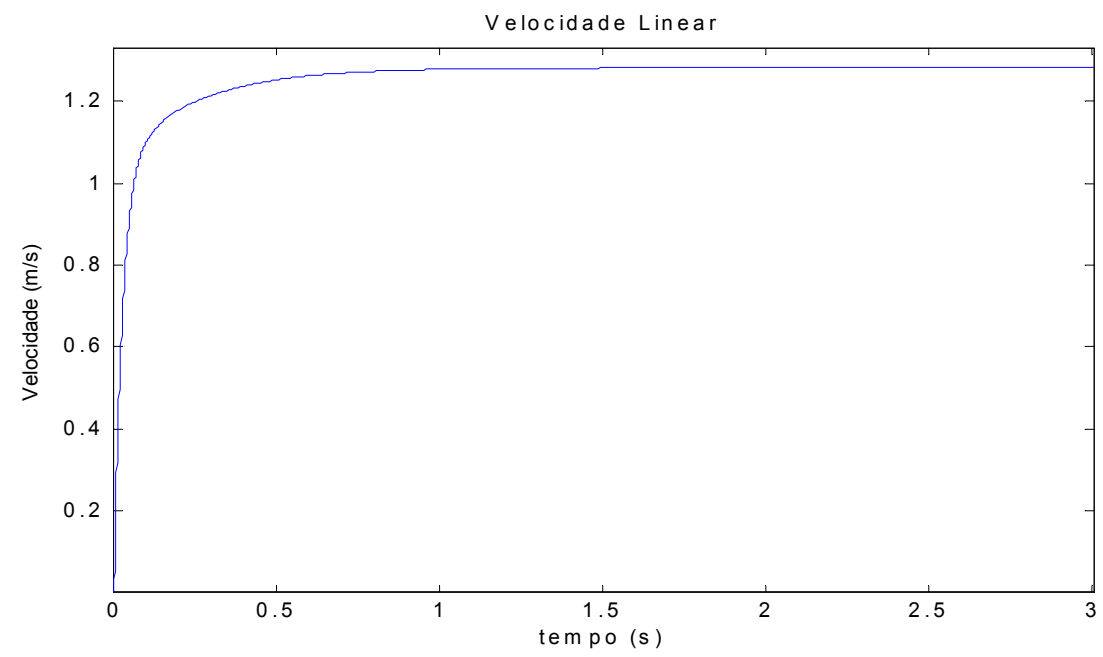

FIGURA 9.24 - Velocidade Linear (Controle PID - tira de 1mm) 


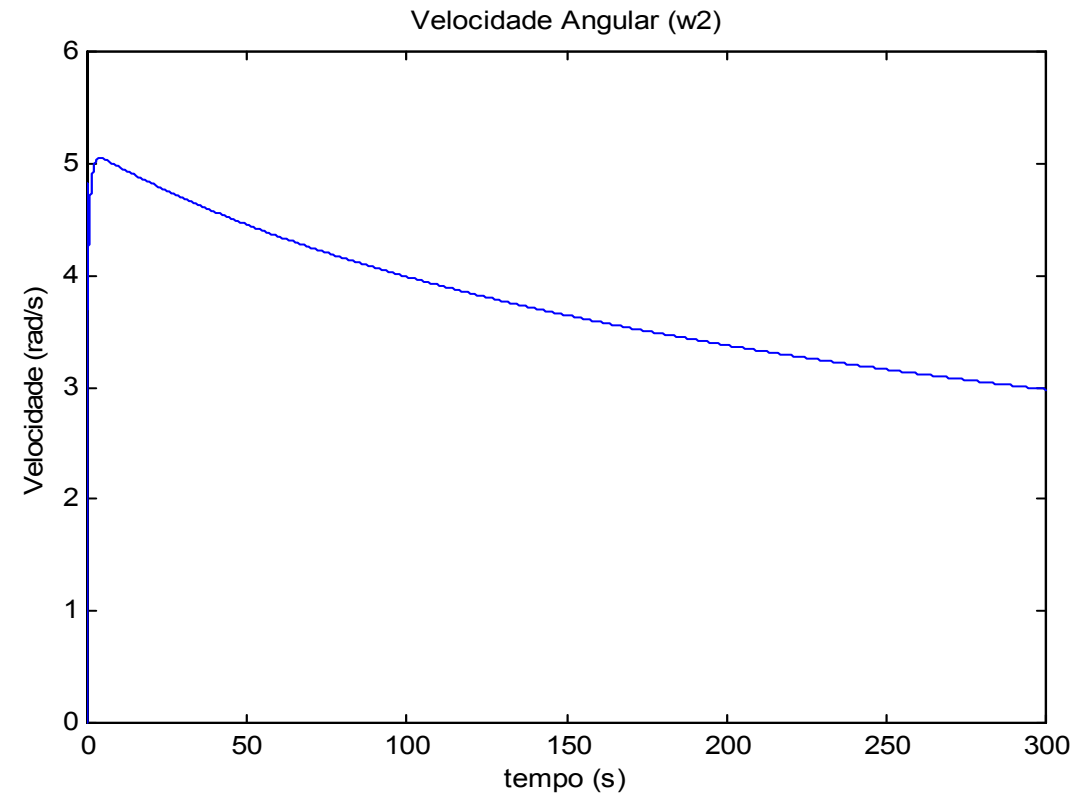

FIGURA 9.25 - Velocidade angular (Controle PID - tira de 1mm)

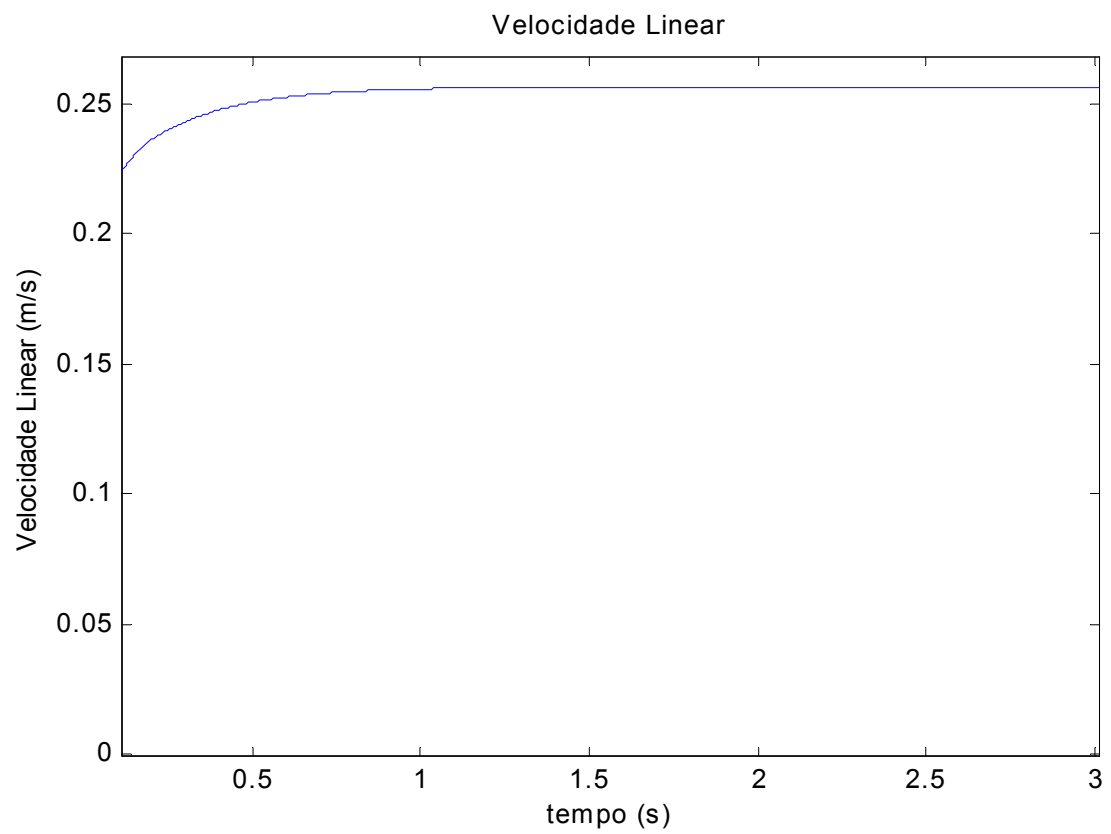

FIGURA 9.26 - Velocidade Linear (Controle PID - tira de 5mm) 


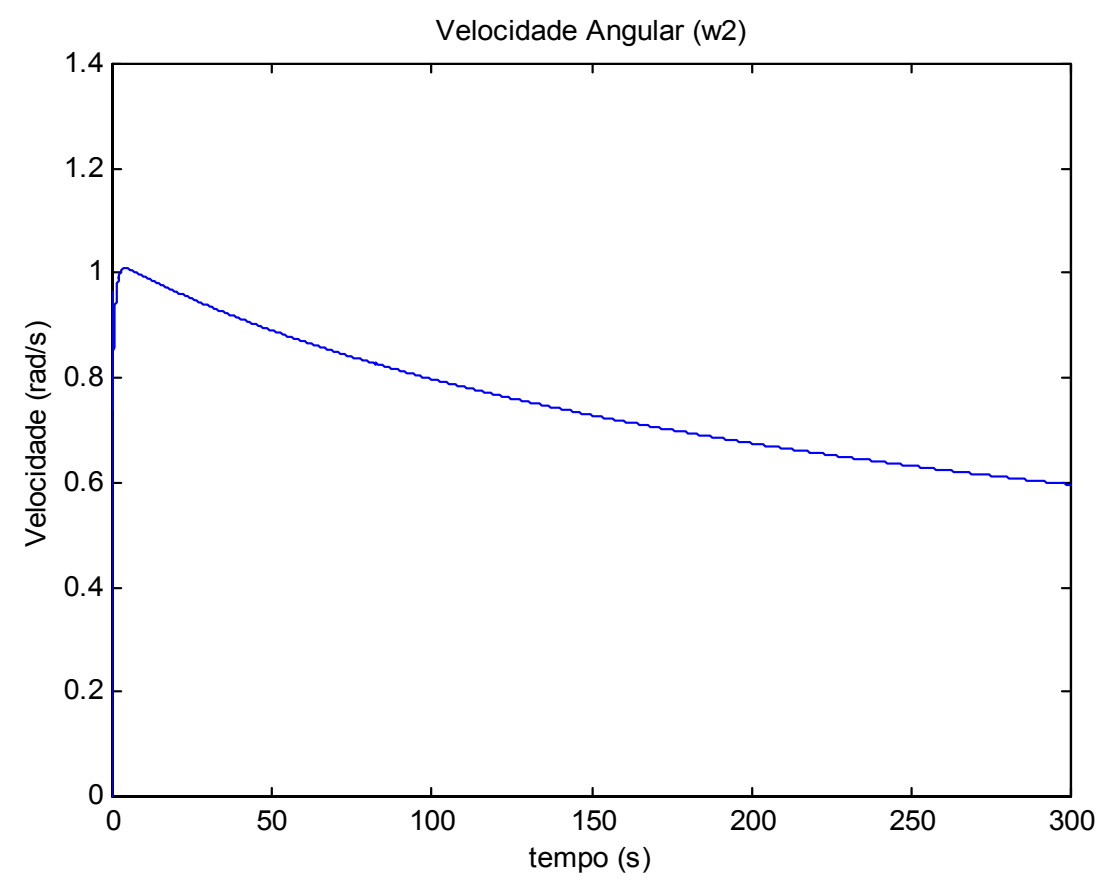

FIGURA 9.27 - Velocidade angular (Controle PID - tira de 5mm)

\subsubsection{Gráficos de Força Aplicada à Tira e Raio de Bobinamento}

Os gráficos das figuras 9.28 e 9.29 apresentam a força aplicada à tira, para tiras de $1 \mathrm{~mm}$ e $5 \mathrm{~mm}$ respectivamente. Pode-se perceber através destas duas figuras que a estratégia de controle de velocidade linear é eficaz. A figura 9.30 apresenta o acréscimo de raio devido ao bobinamento, com o sistema controlado, para as tiras de $1 \mathrm{~mm}$ e $5 \mathrm{~mm}$. 


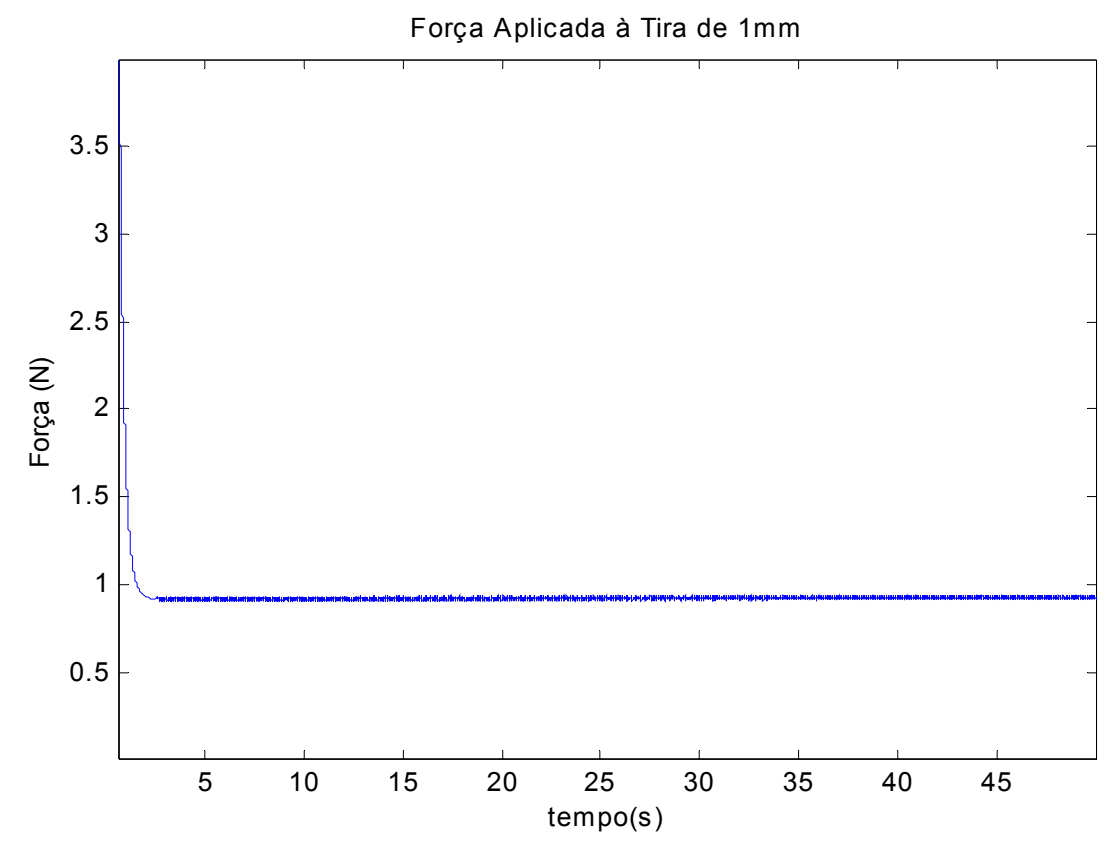

FIGURA 9.28 - Força Aplicada à tira de $1 \mathrm{~mm}$

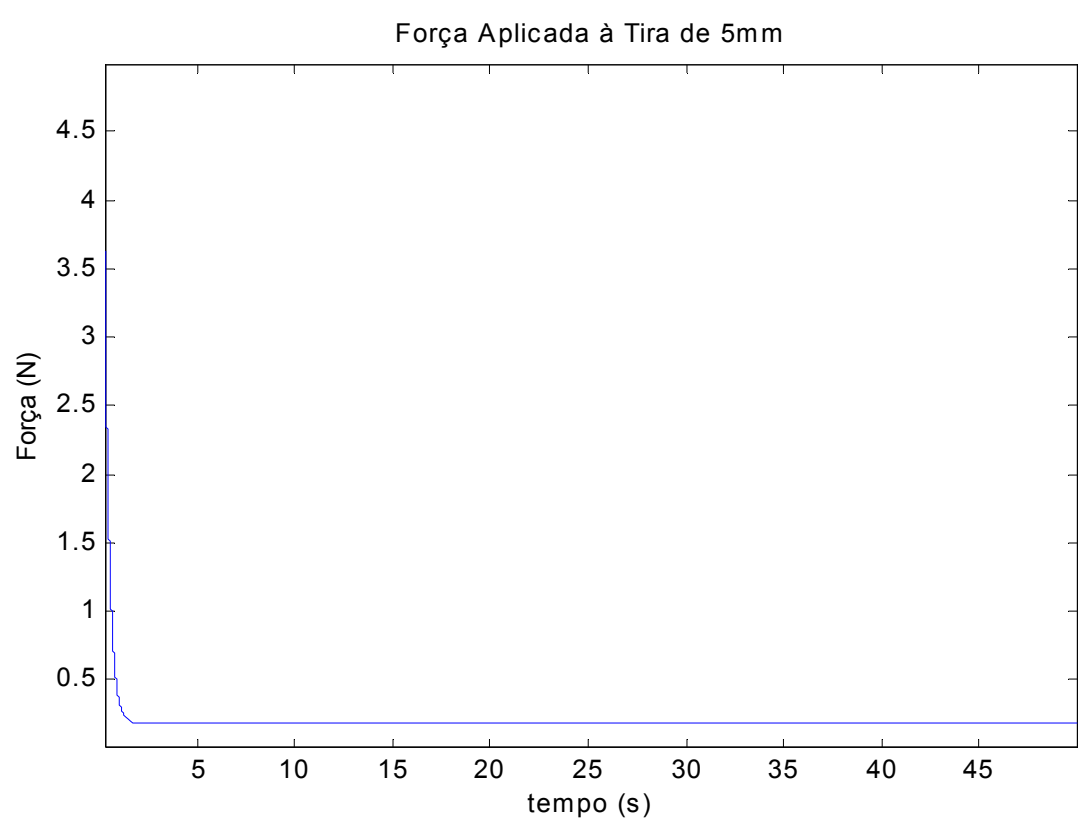

FIGURA 9.29 - Força Aplicada à tira de 5mm 


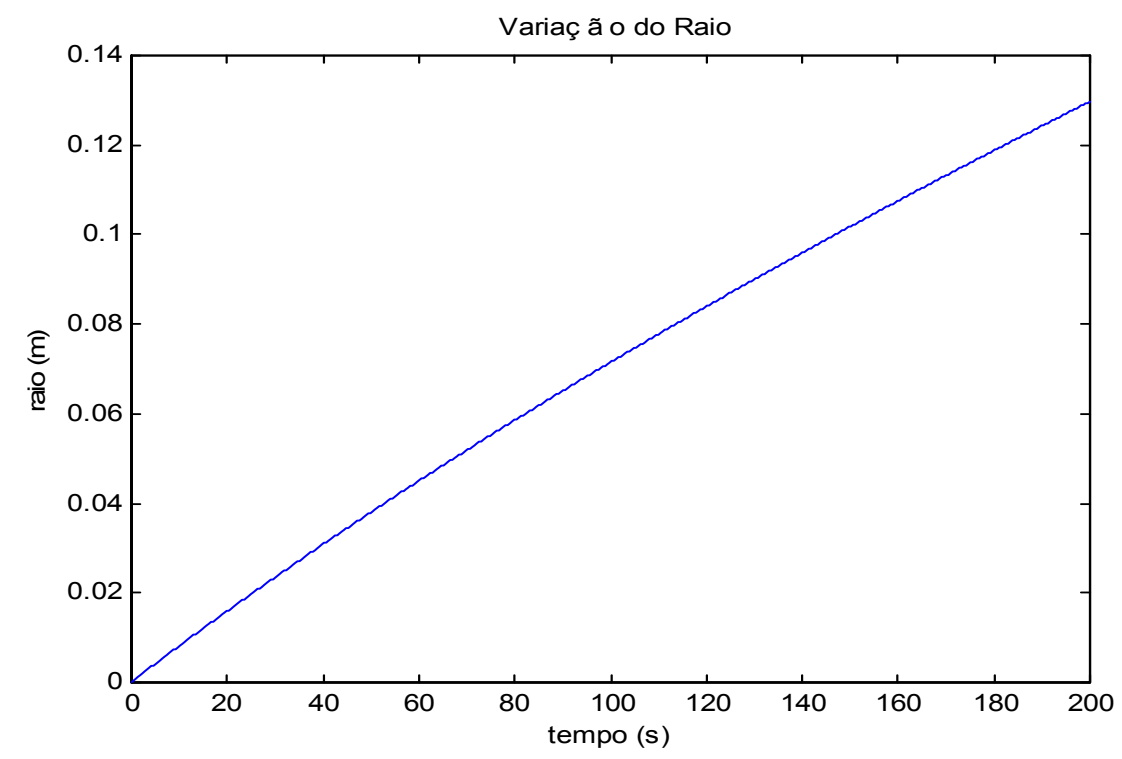

FIGURA 9.30 - Variação do raio de bobinamento (tiras de $1 \mathrm{~mm}$ e $5 \mathrm{~mm}$ )

\subsubsection{Potência de Acionamento}

Os gráficos das figuras 9.31 e 9.32 apresentam o gráfico da potência eletromagnética do motor, para tira de $1 \mathrm{~mm}$ de espessura, considerando o atrito (B), e desconsiderando o atrito, respectivamente. Os gráficos das figuras 9.33 e 9.34 apresentam os mesmos resultados para tira de $5 \mathrm{~mm}$ de espessura.

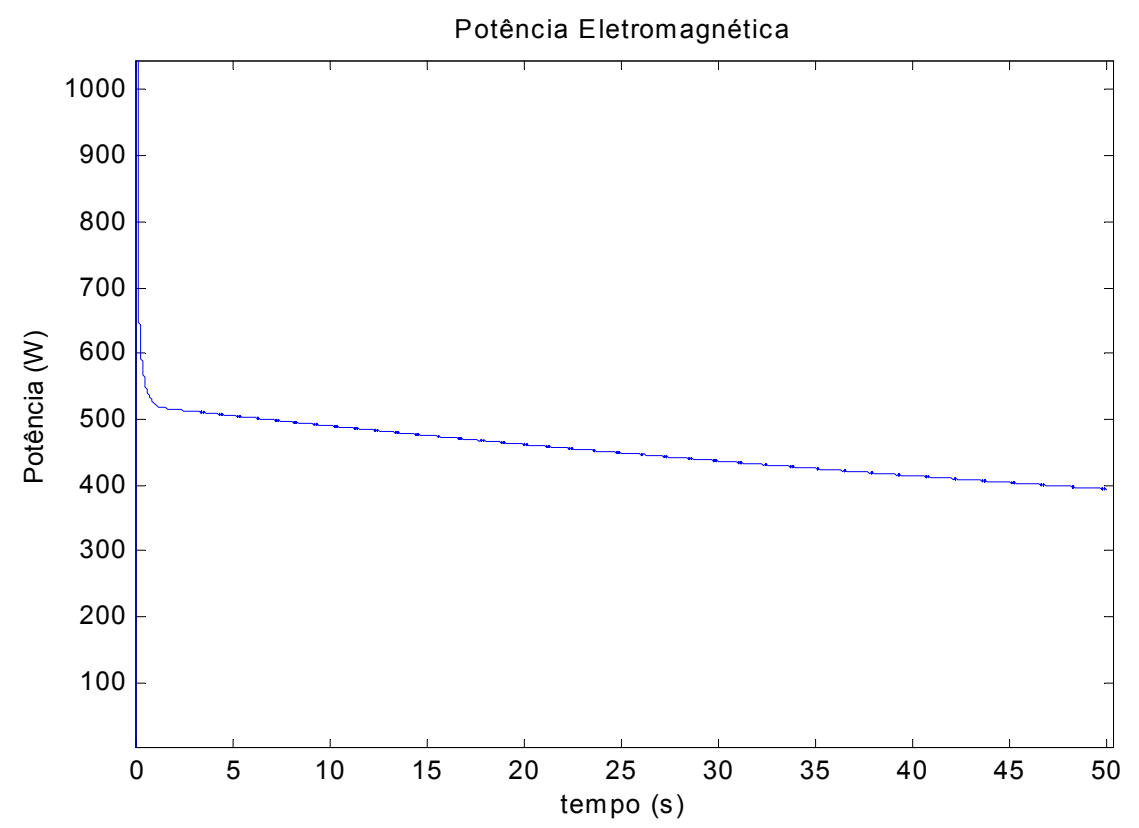

FIGURA 9.31 - Potência eletromagnética ( tira de 1mm - considerando B) 


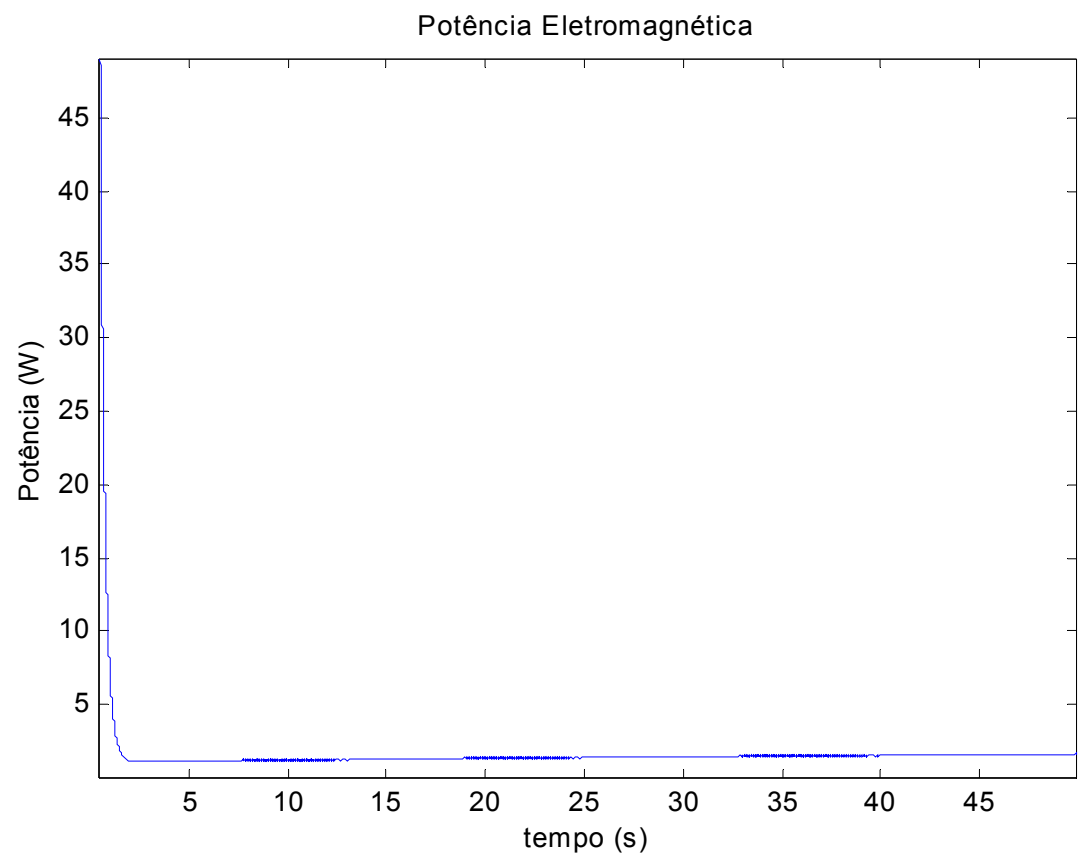

FIGURA 9.32 - Potência eletromagnética ( tira de $1 \mathrm{~mm}$ - desconsiderando B)

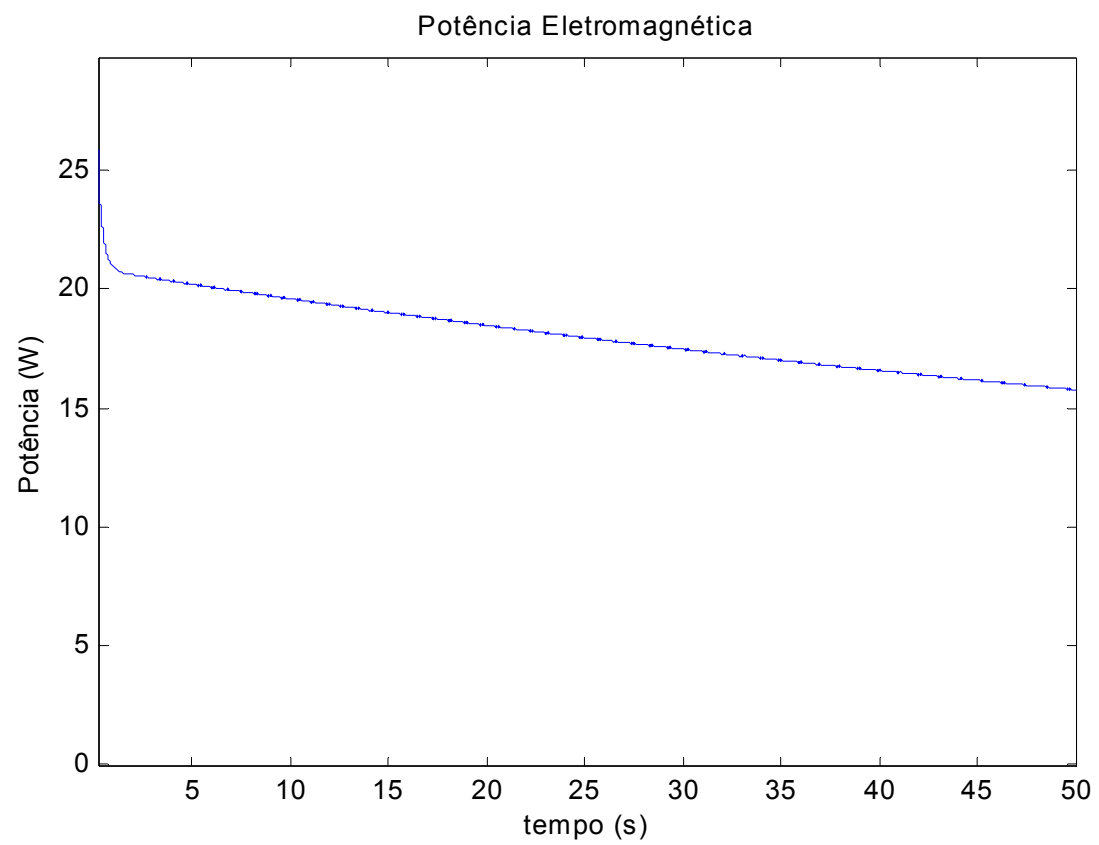

FIGURA 9.33 - Potência eletromagnética ( tira de 5mm - considerando B) 


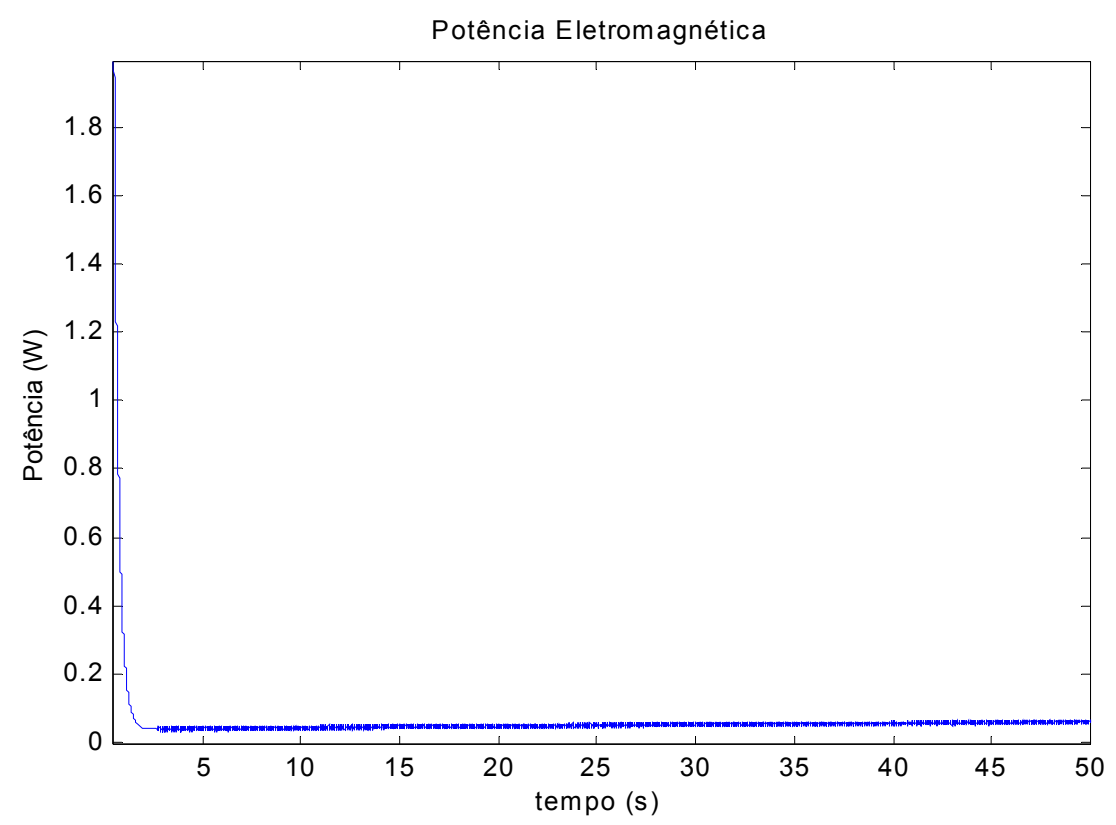

FIGURA 9.34 - Potência eletromagnética ( tira de 5mm - desconsiderando B)

\subsection{Resultados do Sistema de Controle Com Sensor Ultrasônico e Controlador PID}

Nessa sessão serão apresentados os resultados obtidos com o controlador do tipo PID, atuando no sistema de bobinamento considerando a introdução do sensor ultrasônico.

\subsubsection{Resultados sem o controlador}

Com as simulações do sistema de controle do bobinamento realizadas na sessão anterior, onde os parâmetros do controlador PID foram ajustados através de “tentativa e erro", pôde-se definir as variações de raio e momento de inércia do sistema operando a velocidade linear constante.

Essas variações de raio e inércia foram utilizadas para se determinar os lugares das raízes do sistema em malha aberta, considerando o motor de corrente contínua acionado pelo retificador trifásico totalmente controlado. Esse último, 
conforme apresentado no Capítulo 5 foi modelado como um atraso, através da aproximação de Pade.

Observa-se que as variações de raio ao longo do tempo (e consequentemente de momento de inércia), para o sistema operando a velocidade linear constante, são idênticas para qualquer valor de espessura de tira. Isso pode ser facilmente observado através da eq. (6.4), já que a velocidade linear é inversamente proporcional à espessura da tira produzida.

Nesse sentido, utilizou-se os resultados obtidos com o sistema de controle para tira de $1 \mathrm{~mm}$ de espessura, sendo que outras espessuras de tira terão resultados idênticos.

Primeiramente, determinou-se os Lugares das Raízes para o sistema em malha aberta, considerando-se o retificador trifásico totalmente controlado. Esse resultado é apresentado na figura 9.35. Observando-se a figura 9.35, conclui-se que a contribuição para o sistema da raiz referente ao retificador pode ser desprezada, já que a mesma possui uma resposta muito rápida em relação as outras duas raízes referentes ao motor CC. Desta forma, para efeito de projeto, a raiz do retificador foi desprezada, utilizando somente as raízes do motor CC, conforme a figura 9.36.

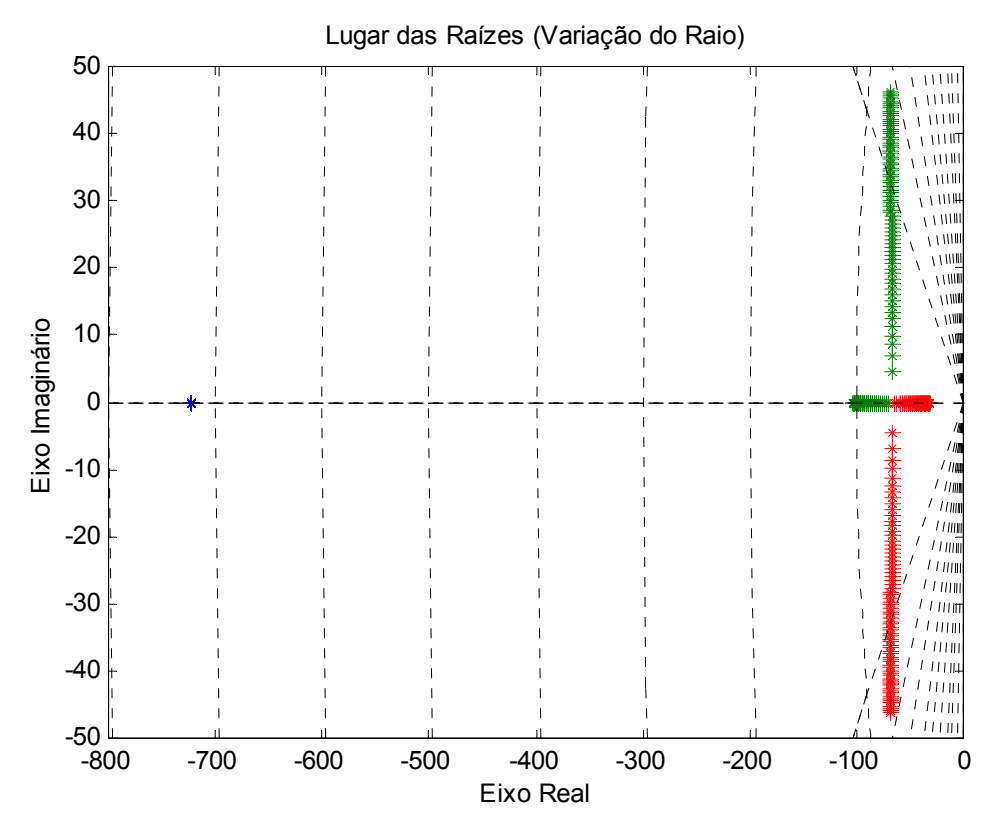

FIGURA 9.35 - Lugares das raízes para sistema de bobinamento com retificador 


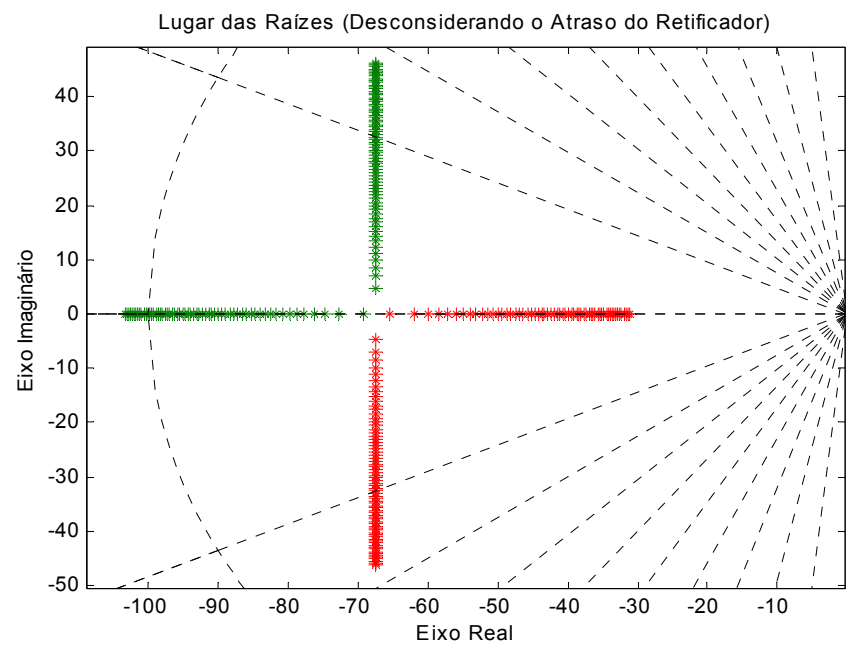

FIGURA 9.36 - Lugares das raízes para sistema de bobinamento sem retificador

\subsubsection{Resultados de Projeto do controlador}

Para o projeto do controlador, como mencionado anteriormente, foram utilizadas apenas as raízes provenientes do motor CC. Além disso, como essas raízes sofrem variações ao longo do bobinamento da tira, conforme apresentado na figura 9.35, o controlador foi projetado escolhendo-se um par de raízes complexas e conjugadas, conforme apresentado no capítulo 7. Com a introdução do controlador PID na planta e com o seu ganho variando de zero a infinito em malha fechada temse os lugares das raízes do sistema controlado, apresentado na figura 9.37.

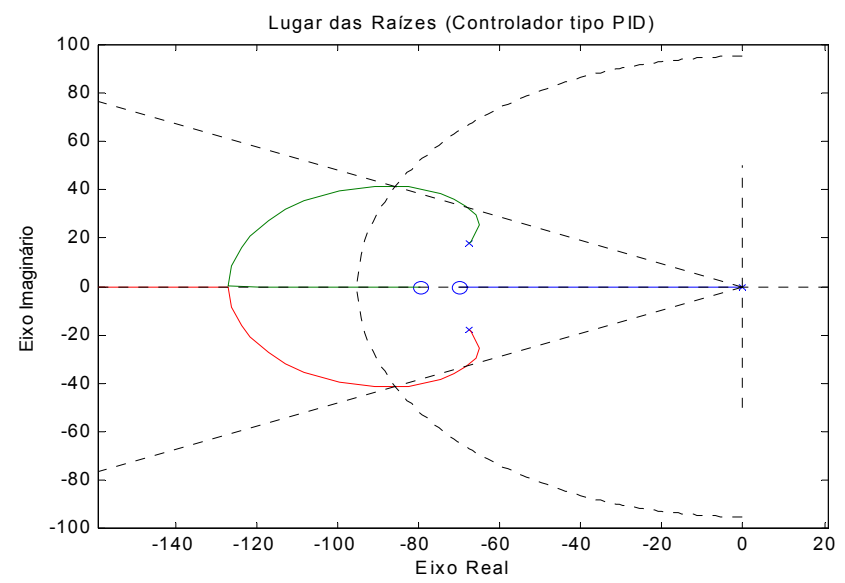

FIGURA 9.37 - Lugares das raízes para sistema de bobinamento em malha fechada com controle do tipo PID 
A figura 9.37 apresenta claramente que as considerações de projeto podem ser atendidas, para um determinado valor de ganho do controlador PID, sendo este ganho determinado através das propriedades de módulo e fase dos lugares das raízes e apresentado no capítulo 7.

Utilizando o ganho do controlador PID previamente calculado, observou-se o desempenho do sistema controlado através de sua resposta ao degrau na referência e de conjugado de carga, para o valor intermediário de raio utilizado no projeto e para valores extremos, ou seja, raio máximo e mínimo. As respostas obtidas encontram-se nas figuras 9.38 e 9.39 a seguir:

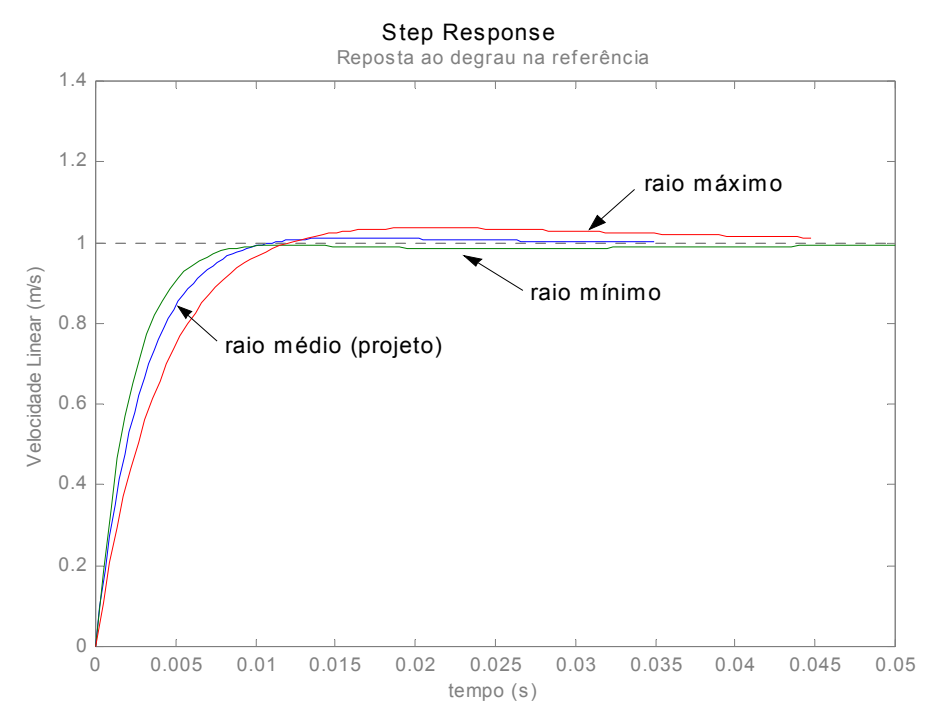

FIGURA 9.38 - Resposta ao degrau na referência

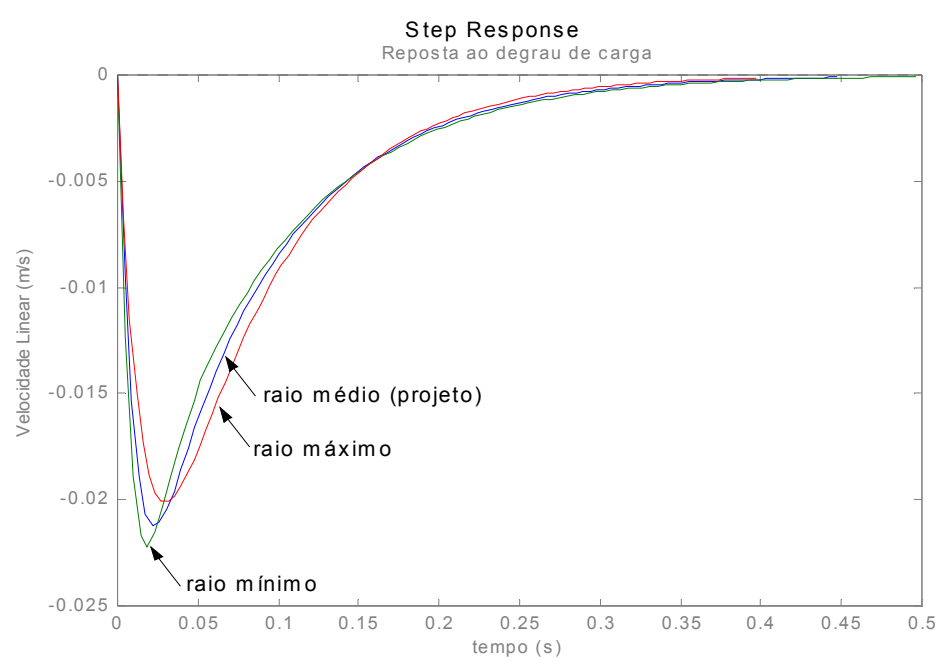

FIGURA 9.39 - Resposta ao degrau de carga 
Da figura 9.38, pode-se observar que as condições de projeto foram alcançadas, confirmando a eficácia do controlador para o ponto de projeto. Alterações na resposta foram observadas, entretanto, para os valores extremos de raio, sendo que para o raio máximo observa-se um pequeno erro de regime para o degrau na entrada de referência, o que é indesejado.

Com relação a figura 9.39, referente ao degrau de conjugado de carga, percebe-se que o controlador possui um bom comportamento no sentido de rejeição a esta variação.

\subsection{Resultados do Sistema de Controle Robusto Com Sensor Ultrasônico}

Nessa sessão serão apresentados os resultados obtidos com o controlador robusto utilizando a metodologia LQG/LTR, considerando novamente a presença do sensor ultrasônico na planta. Os resultados de projeto serão apresentados passo a passo e finalmente as respostas do sistema atuando com o compensador projetado serão apresentadas.

\subsubsection{Valores Singulares da Planta Nominal e Real}

A seguir estão apresentados o valor singular da planta nominal (figura 9.40) e os valores singulares da planta real (figura 9.41). Para determinar os valores singulares da planta nominal, o rolo bobinador foi considerado como contendo metade da sua capacidade. Para a planta real, os valores extremos de raio foram introduzidos, bem como uma variação de 10\% nos parâmetros do motor foi considerada.

As variações paramétricas consideradas foram utilizadas para definir o erro multiplicativo $\left(\varepsilon_{\mathrm{M}}\right)$ utilizado para a construção da barreira de robustez da estabilidade.

A barreira de robustez do desempenho foi determinada adotando-se como parâmetro de projeto que o sistema tivesse uma envoltória $p_{c}(\omega)=2$, para freqüências abaixo de $0,5 \mathrm{rad} / \mathrm{s}$, inclusive. 


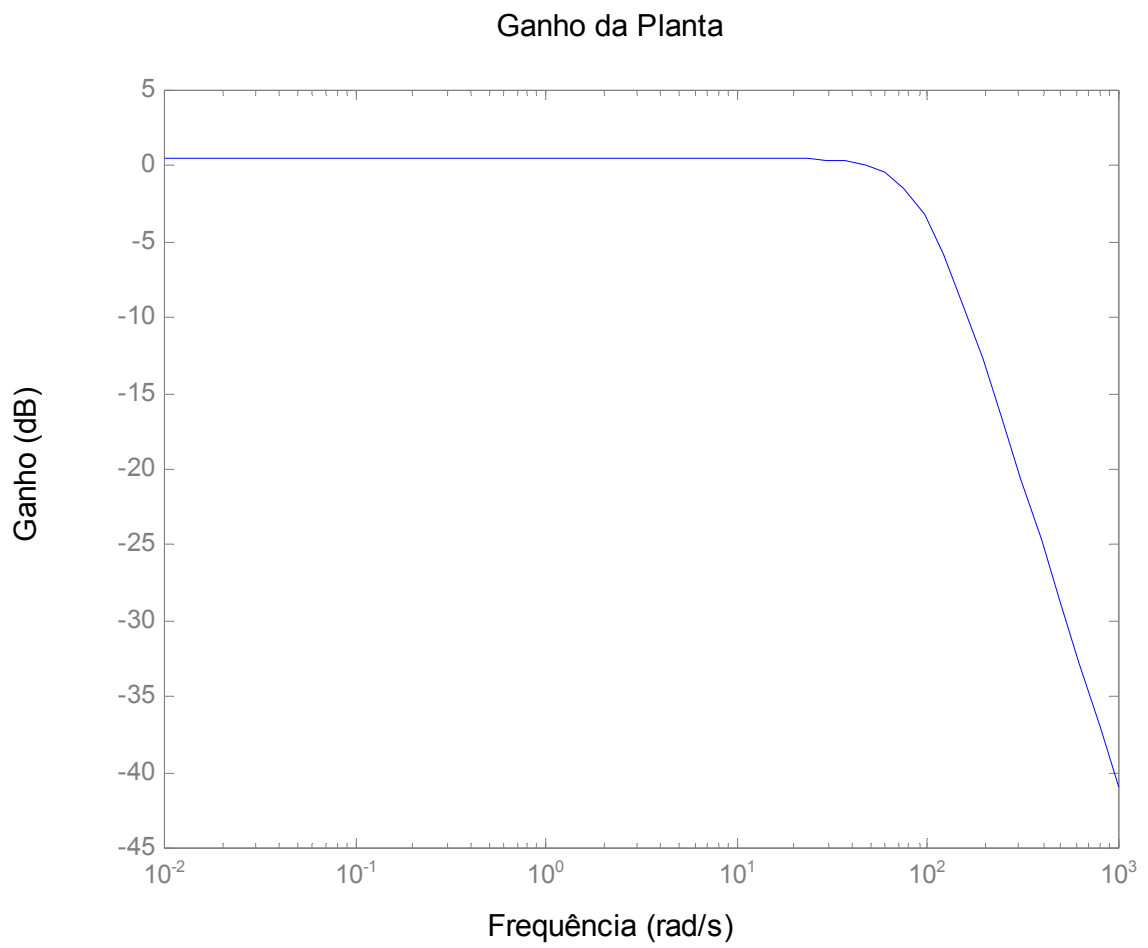

FIGURA 9.40 - Ganho da planta nominal

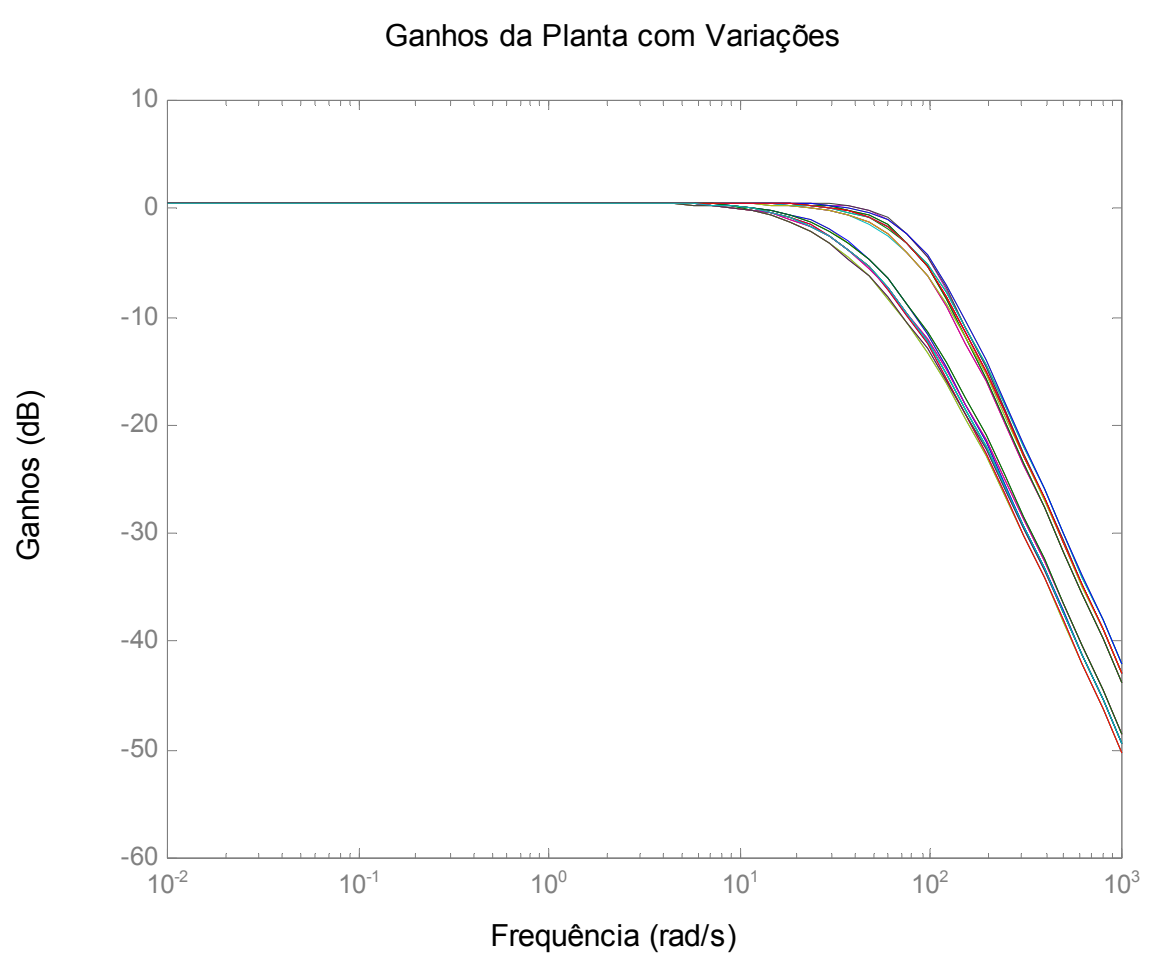

FIGURA 9.41 - Ganhos da planta real 


\subsubsection{Barreiras de Robustez e Malha Objetivo}

As barreiras de robustez da estabilidade e do desempenho, determinadas conforme descrição anterior são apresentadas na figura 9.42. Nesta figura apresentase também o valor singular aproximado da malha objetivo calculado através do parâmetro $\mu$ e da matriz L bem como o mesmo valor singular determinado através da matriz de ganhos do Filtro de Kalman $(\mathrm{H})$.

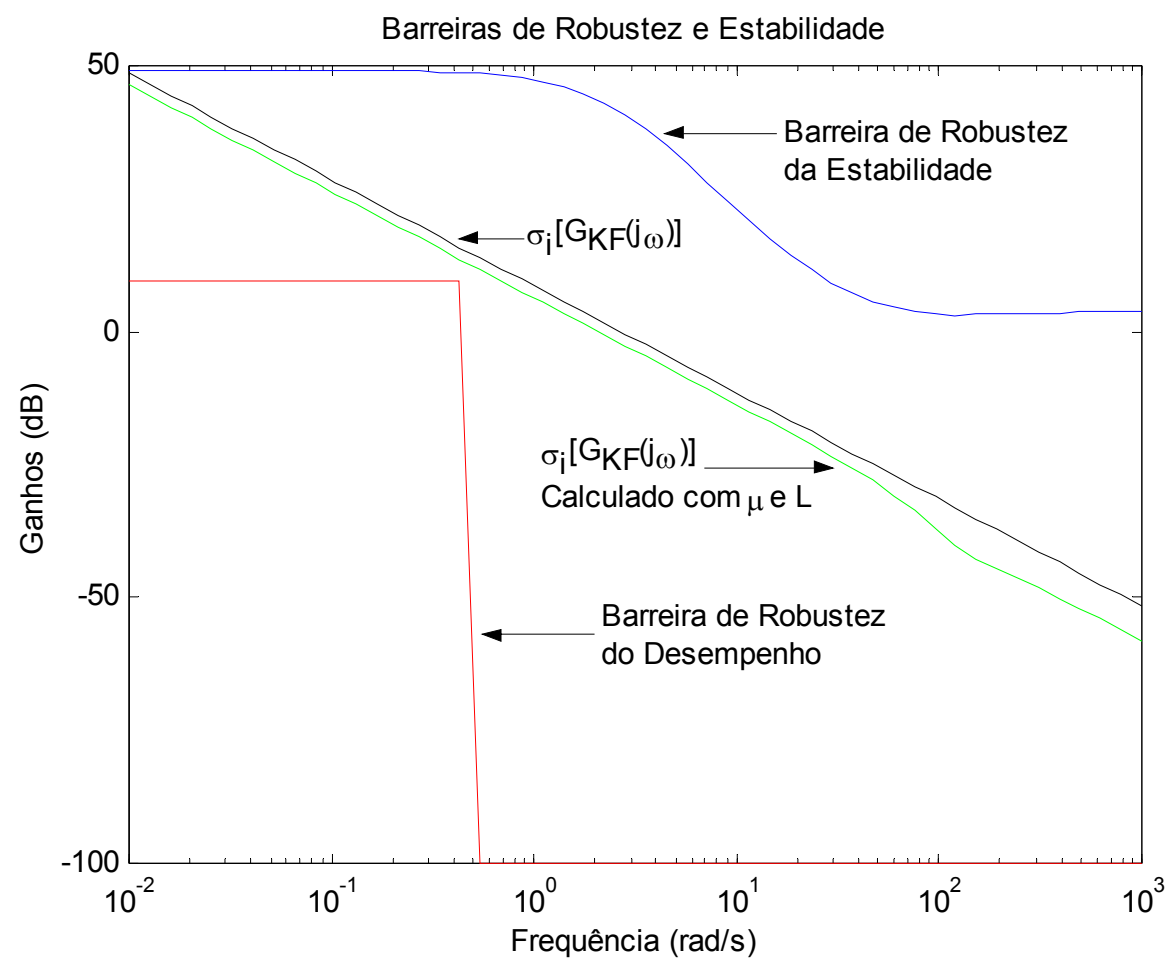

FIGURA 9.42 - Barreiras de robustez da estabilidade e desempenho e ganhos da Malha Objetivo

\subsubsection{Estabilidade da Malha Objetivo}

Após o cálculo da matriz de ganhos do Filtro de Kalman e a verificação do atendimento da Malha Objetivo às barreiras de robustez de desempenho e estabilidade verifica-se a estabilidade da Malha Objetivo fechada com realimentação unitária. A figura 9.43 apresenta esse procedimento e conclui-se que a Malha Objetivo é estável em malha fechada. 


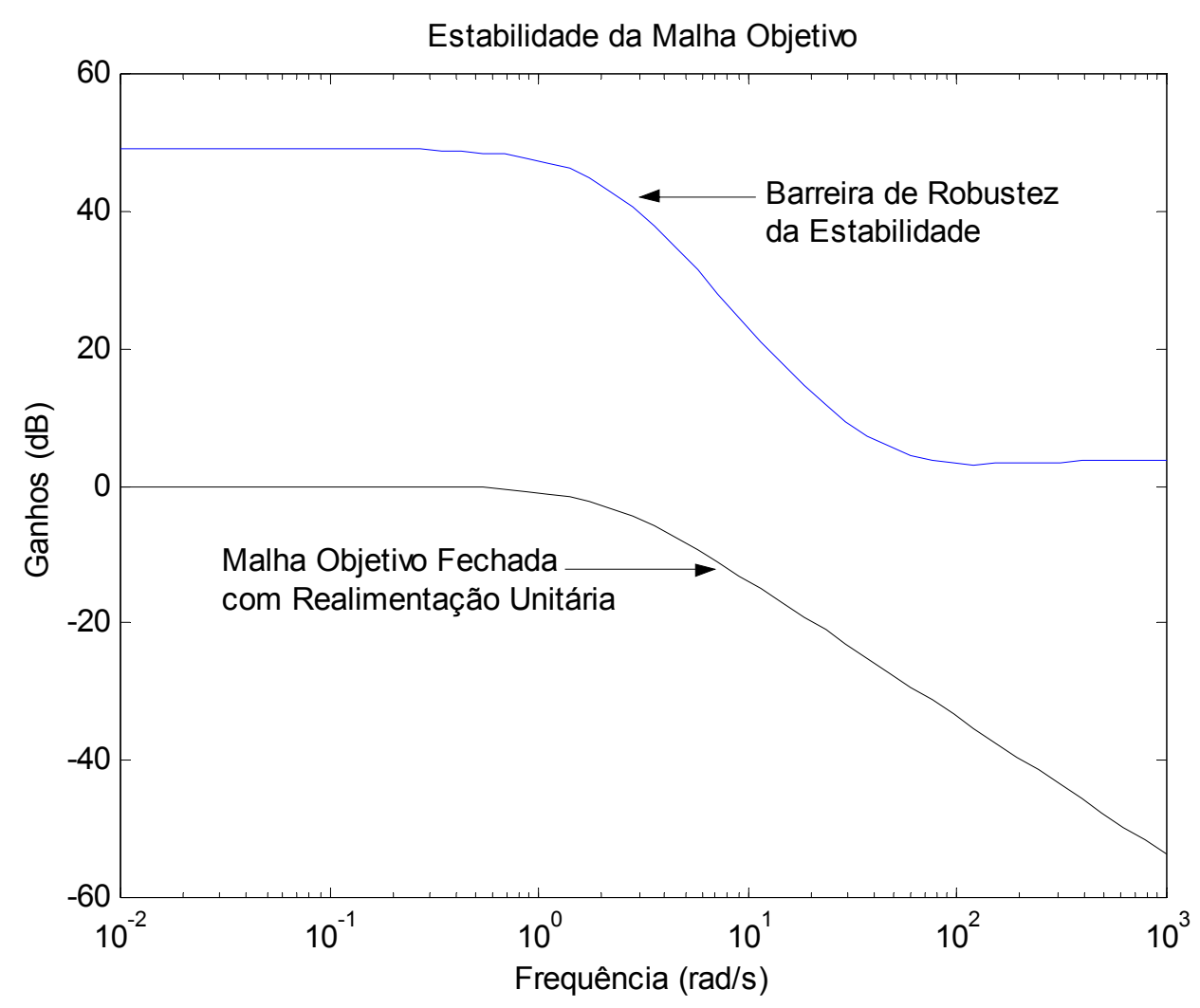

FIGURA 9.43 - Estabilidade da Malha Objetivo com realimentação

\subsubsection{Procedimento de Recuperação}

Após a determinação da matriz de realimentação de estados $(\mathrm{G})$, calcula-se a matriz de função de transferência do ramo direto $\mathrm{G}_{\mathrm{N}}(\mathrm{s}) \mathrm{K}(\mathrm{s})$, onde $\mathrm{G}_{\mathrm{N}}(\mathrm{s})$ contém os integradores adicionados à planta.

Compara-se então o valor singular da malha direta com o valor singular da Malha Objetivo apresentado na figura 9.42.

Nesse ponto, deve ser observado se a proximidade entre os dois valores singulares é aceitável. Caso contrário, o valor de $\rho_{\mathrm{c}}$ deve ser reduzido e a Equação Algébrica de Riccati para determinação da matriz de ganhos do observador de estados deve ser resolvida novamente.

Após realizado esse procedimento, chega-se a conclusão que a proximidade é aceitável, conforme apresentado na figura 9.44. 


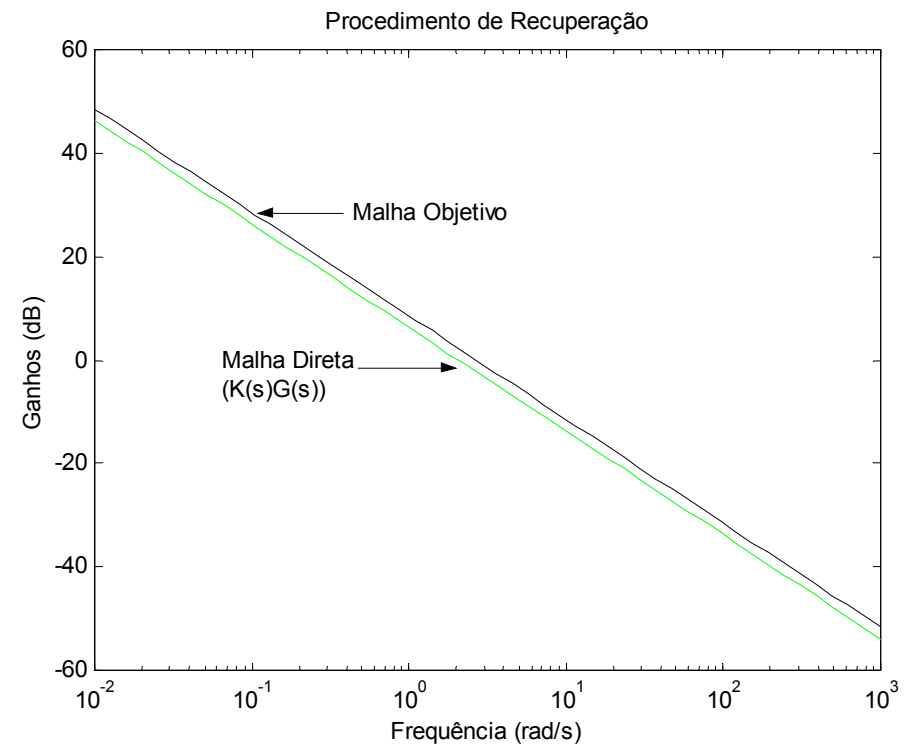

FIGURA 9.44 - Representação do procedimento de recuperação

\subsubsection{Estabilidade do Sistema Final em Malha Fechada}

Finalmente, com as matrizes de ganhos do Filtro de Kalman e do observador de estados determinada, verifica-se a estabilidade do sistema final em malha fechada. Conclui-se que o sistema é estável através da figura 9.45.

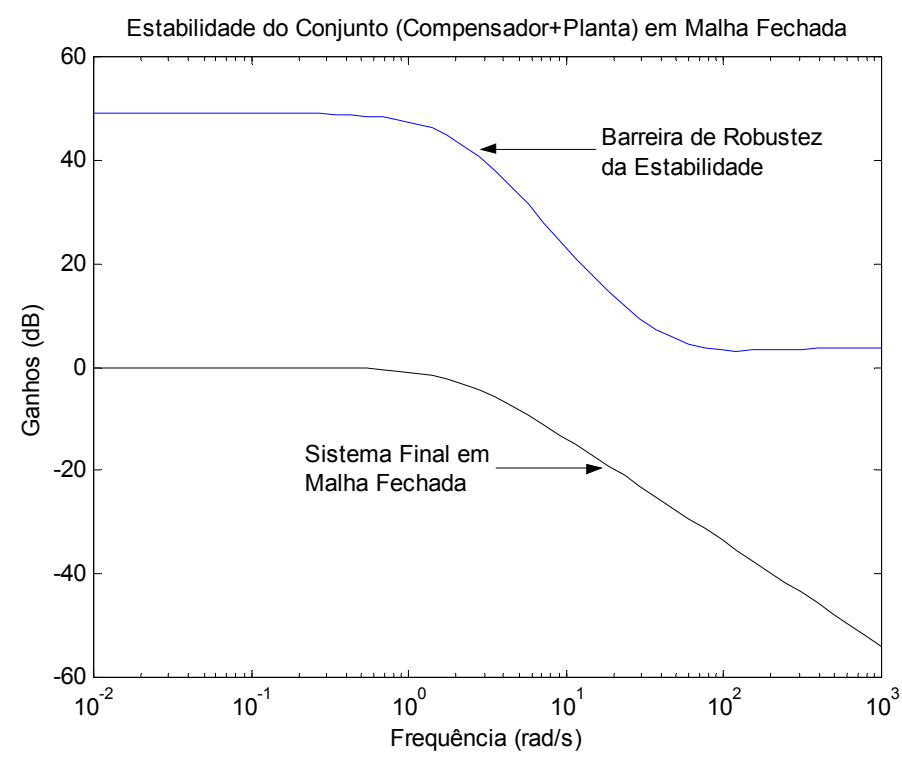

FIGURA 9.45 - Estabilidade do sistema final 


\subsubsection{Sistema Final com Compensador em Malha Fechada}

Após verificada a estabilidade do sistema final em malha fechada, implementou-se o modelo do controlador em conjunto com a planta utilizando o programa Matlab $^{\circledR} /$ Simulink $^{\mathrm{TM}}$, conforme apresentado na figura 9.46. Esse modelo foi utilizado para a realização dos testes de desempenho e estabilidade do controlador.

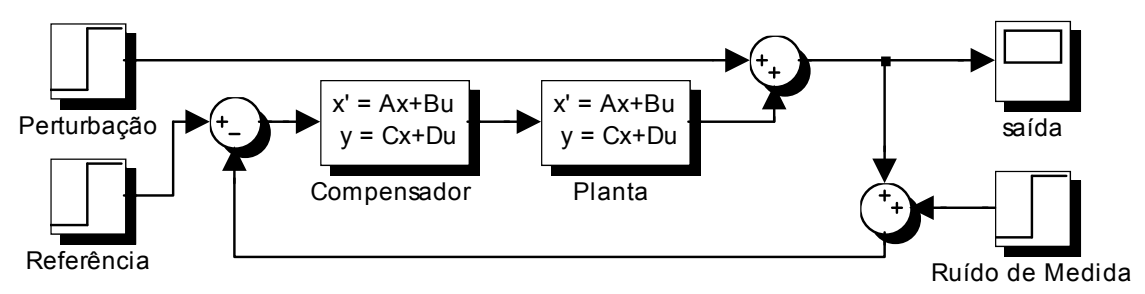

FIGURA 9.46 - Sistema de controle final em malha fechada

\subsubsection{Resposta ao Degrau na Referência}

A figura 9.47 a seguir apresenta a resposta ao degrau na referência de entrada, do sistema final com compensador da figura 9.46. Esta resposta foi obtida com o modelo nominal da planta. O compensador, entretanto, foi projetado de tal maneira que a estabilidade e desempenho sejam bons para a planta real. Dessa forma, foi aplicado um degrau de referência no sistema da figura 9.46, considerando-se, porém, a planta real.

A planta real, utilizada para o teste de acompanhamento do sinal de referência foi adotada utilizando-se os extremos superiores e inferiores das variações paramétricas do motor e de inércia do rolo bobinador.

Dessa forma, duas novas respostas ao acompanhamento do sinal de referência foram obtidas e são apresentadas na figura 9.48. Através das respostas ao acompanhamento do sinal de referência obtidas com a planta nominal e com a planta real, pode-se observar que o compensador projetado atende as especificações para ambas. 


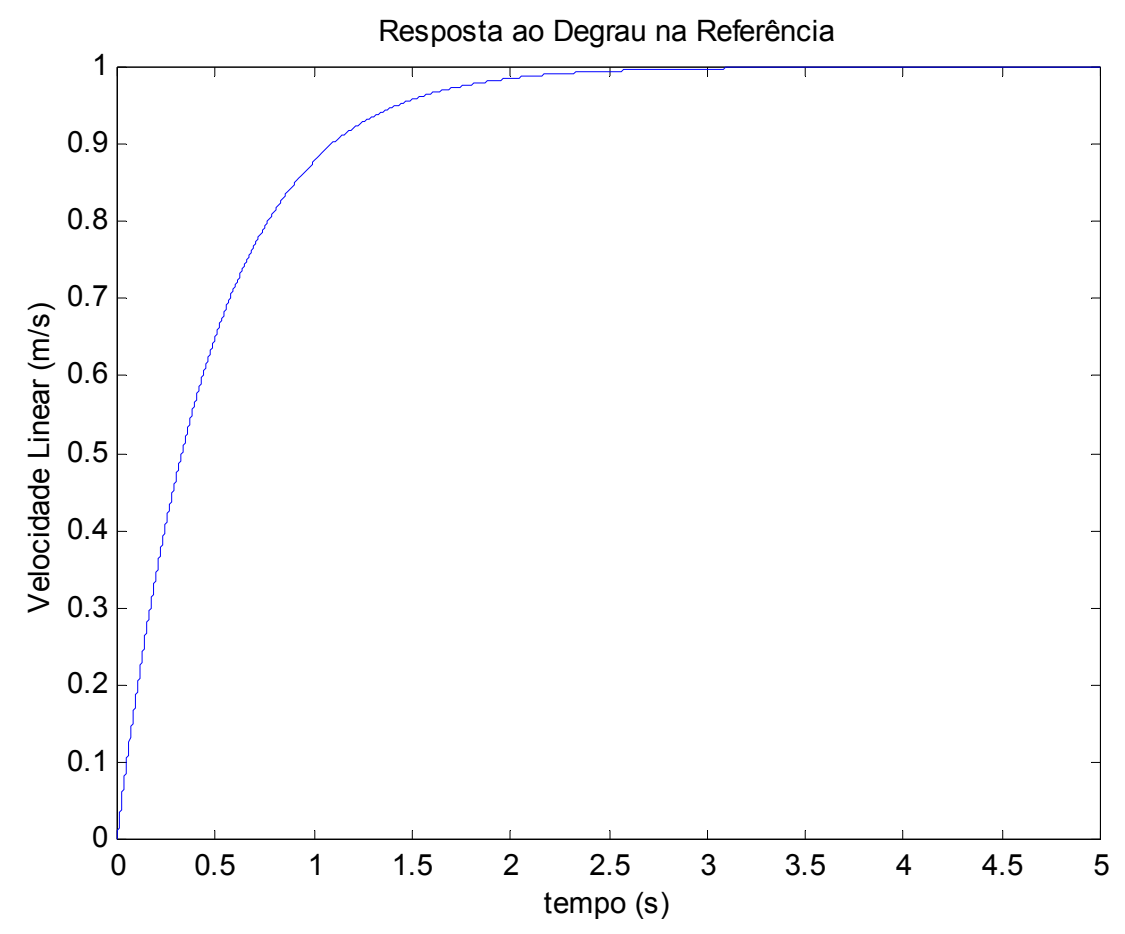

FIGURA 9.47 - Acompanhamento do sinal de referência (Planta Nominal)

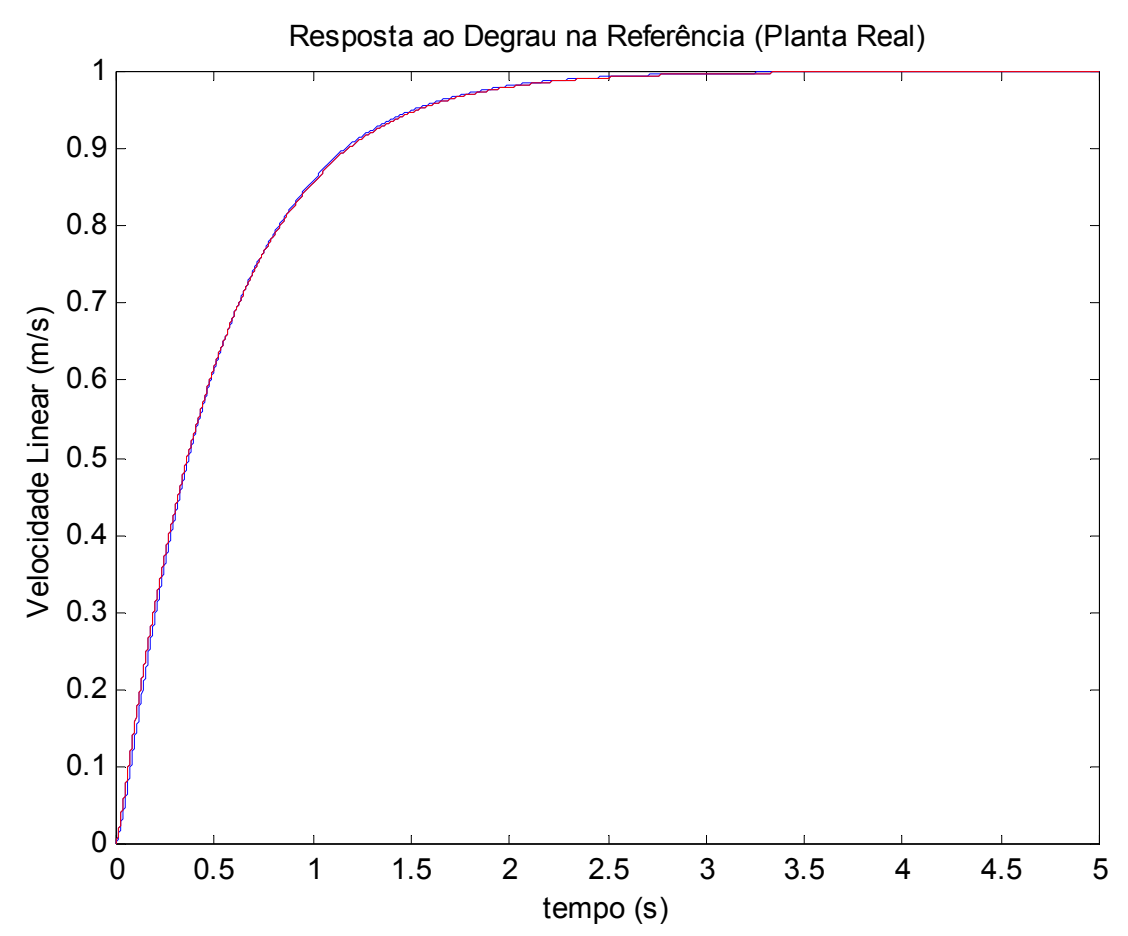

FIGURA 9.48 - Acompanhamento do sinal de referência (Planta Real) 


\subsubsection{Rejeição às Perturbações}

Outro compromisso no projeto do compensador é a boa rejeição à perturbações na saída da planta. Da mesma maneira que para o acompanhamento no sinal de referência, uma perturbação do tipo degrau unitário foi aplicada na saída da planta nominal (figura 9.49) e real (figura 9.50) apresentando o compensador uma boa resposta em ambas.

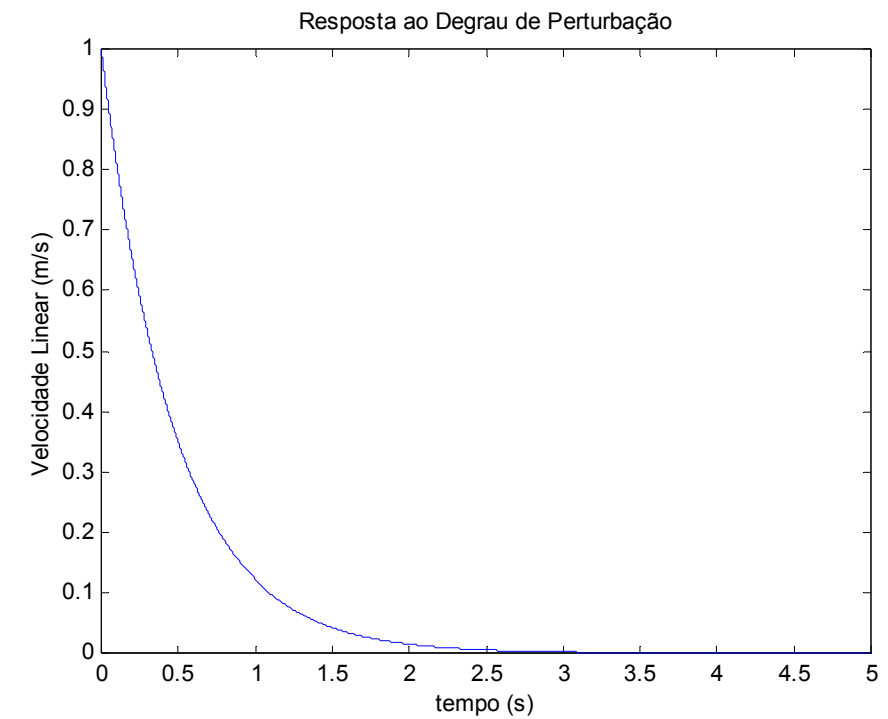

FIGURA 9.49 - Rejeição a um degrau unitário de perturbação (Planta Nominal)

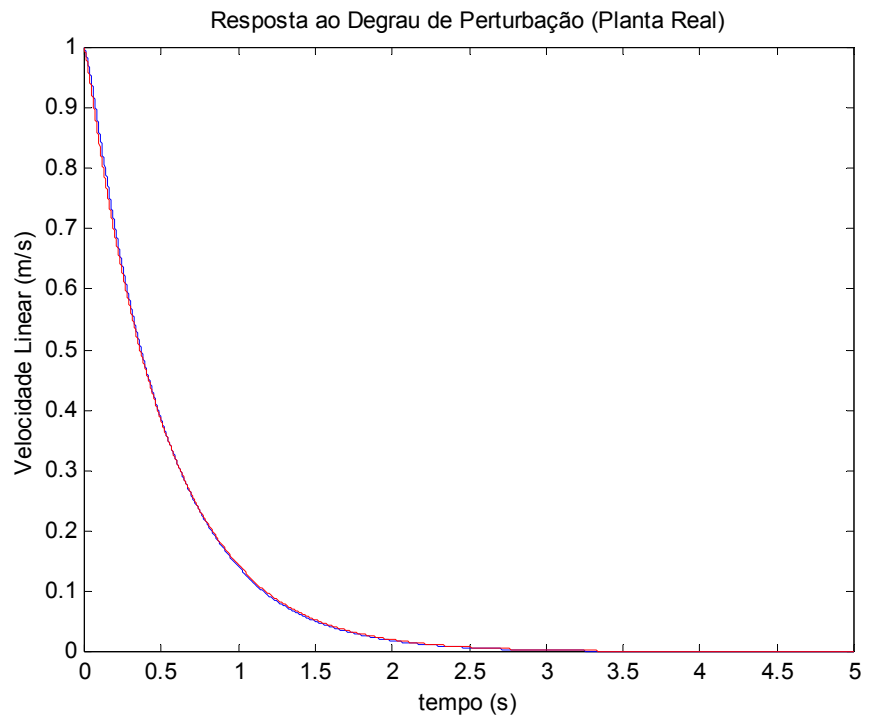

FIGURA 9.50 - Rejeição a um degrau unitário de perturbação (Planta Real) 


\subsubsection{Rejeição ao Ruído de Medida}

Finalmente, o último parâmetro a ser observado é a capacidade de rejeição ao ruído de medida. Novamente um degrau foi aplicado à entrada correspondente ao ruído de medida da figura 9.46 para a planta nominal e real. As respostas mais uma vez foram satisfatórias e são apresentadas nas figuras 9.51 e 9.52, para as plantas nominal e real, respectivamente.

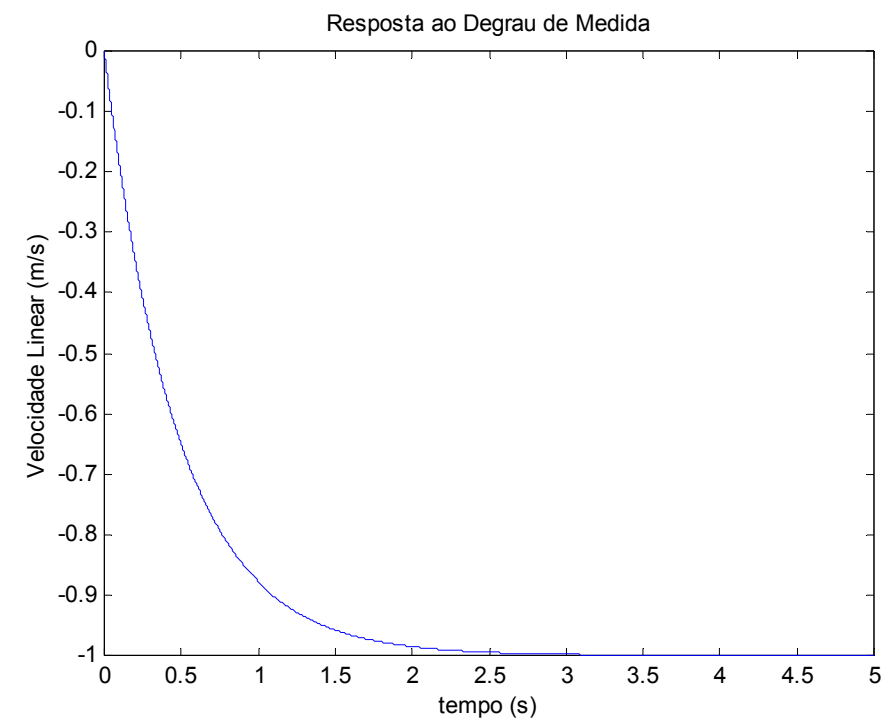

FIGURA 9.51 - Rejeição a um degrau unitário de ruído de medida (Planta Nominal)

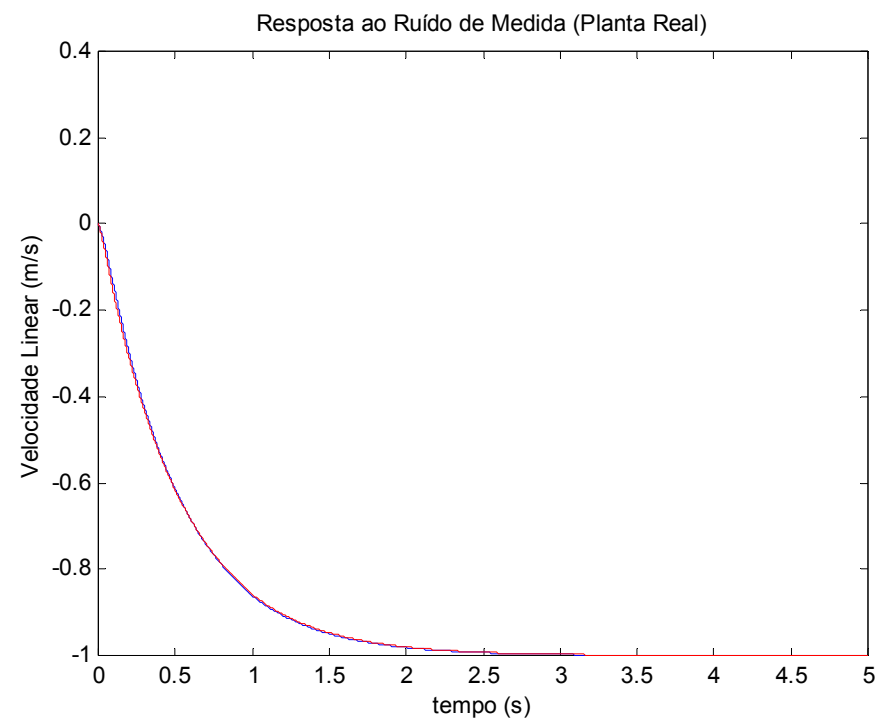

FIGURA 9.52 - Rejeição a um degrau unitário de ruído de medida (Planta Real) 


\subsection{Análise dos Resultados}

\subsubsection{Sistema de Bobinamento Sem Controle}

Após realizada a modelagem matemática do sistema de bobinamento, foram realizadas primeiramente algumas simulações do sistema, operando sem controle, ou seja, com uma tensão constante aplicada ao motor CC. A máxima velocidade que o rolo bobinador do IPT pode operar está em torno de $80 \mathrm{rpm}$. Esta, portanto, foi a velocidade considerada, por representar o pior caso possível.

É importante ressaltar ainda, que o valor do tempo de simulação, adotado como sendo de 300 segundos, faz com que o raio bobinado exceda o máximo possível para o sistema de bobinamento de tiras do IPT, mesmo para a tira de $1 \mathrm{~mm}$ de espessura. Para a tira mais espessa considerada $(5 \mathrm{~mm})$, o raio de bobinamento para o tempo de simulação adotado excede em muito a capacidade máxima do IPT. Como as variações de raio estão diretamente ligadas a variações de conjugado de carga e inércia do sistema, conclui-se que estes valores observados nas simulações também excedem o que ocorre no sistema físico de bobinamento do IPT. O tempo de simulação adotado, portanto, teve por objetivo proporcionar uma melhor visualização e análise dos resultados.

Com relação ao impacto da caixa de redução sobre o conjugado de carga, considerando-se que o conjugado máximo que o motor em questão pode fornecer é de aproximadamente $160 \mathrm{Nm}$, observa-se pelo gráfico de conjugado desenvolvido pelo motor, que o mesmo excede em muito este valor, caso a caixa de redução não seja considerada.

Incluindo-se os efeitos da caixa de redução sobre o conjugado devido à força aplicada à tira, observa-se uma grande redução dessa grandeza para o motor, sendo o conjugado desenvolvido pelo motor muito menor que na simulação anterior, já permanecendo em limites aceitáveis.

Com relação à inércia do sistema de bobinamento, pode-se perceber claramente o grande impacto da caixa de redução. Sem a caixa de redução, o momento de inércia aplicado ao eixo do motor poderia atingir valores extremamente elevados. Valores elevados de inércia teriam influência sobre o conjugado 
desenvolvido pelo motor, já que o momento de inércia determina parte do conjugado resistente. Novamente o limite nominal do motor estaria excedido.

Percebe-se ainda deste modelo, a variação da velocidade linear e da força aplicada à tira de aço, ao longo do tempo de simulação, justificando desta maneira a necessidade de aplicar-se um sistema de controle ao sistema.

Da dinâmica mecânica do motor, considerando o sistema de bobinamento sem controle, apresentada pela equação (9.2) percebe-se que o conjugado de carga devido à força aplicada à tira tem seu efeito reduzido ao longo do tempo, já que a inércia possui uma taxa de variação maior do que o conjugado devido à força aplicada à tira (figura 9.12).

Posteriormente, simulações considerando possíveis variações relativas a características próprias do material do qual é composto a tira foram realizadas. Considerando-se estas simulações, pode-se observar que a espessura da tira é o fator que possui maior impacto sobre a dinâmica do sistema de bobinamento, principalmente no que diz respeito às variáveis de força e velocidade linear.

\subsubsection{Sistema de Controle}

As simulações do sistema de controle foram realizadas com base nas considerações previamente apresentadas no capítulo 6. Dessa forma, o sistema de controle foi implementado utilizando-se um controlador do tipo PID, e as simulações demonstraram uma eficácia deste tipo de controle no que diz respeito ao controle da velocidade linear.

O controlador apresentou um tempo de resposta de aproximadamente 2 segundos, para ambas as espessuras consideradas (1 $\mathrm{mm}$ e $5 \mathrm{~mm})$. Este tempo de resposta pode ser considerado satisfatório, levando-se em consideração a dinâmica do sistema.

Os gráficos de velocidade angular também foram apresentados, comprovando o seu decréscimo com o tempo, como esperado.

\subsubsection{Sistema de Controle PID Com Sensor Ultrasônico}

A proposta de medição do raio de bobinamento utilizando um sensor ultrasônico, conforme apresentado no capítulo 7, demonstrou-se a princípio como 
sendo uma boa estratégia, já que o projeto do controlador PID pôde ser feito de maneira adequada.

Os tempos de respostas obtidos, conforme apresentado, foram excelentes, da ordem de mili segundos. Como o conjugado de carga foi modelado considerando-se a linearidade do sistema, percebe-se que o controlador possui também uma boa resposta, no sentido de rejeição ao degrau do mesmo. Entretanto, como o projeto do controlador foi realizado utilizando o método do lugar das raízes, para um valor médio de raio, percebe-se que para valores extremos de raio (e todos os efeitos associados a esta situação) o controlador possui desempenho diferente do especificado em projeto, apresentando para o maior valor de raio um pequeno erro de regime indesejado.

\subsubsection{Sistema de Controle Robusto}

Por último, têm-se os resultados do controlador robusto utilizando a metodologia LQG/LTR. O desenvolvimento do projeto é de natureza sistemática, conforme apresentado anteriormente. Os passos de projeto foram seguidos para o caso proposto do sistema de bobinamento. Considerou-se o sistema operando com o sensor ultrasônico a exemplo do sistema anterior.

Ao final, chegou-se a um compensador $\mathrm{K}(\mathrm{s})$ que demonstrou desempenho satisfatório no controle da velocidade linear, a qual está intimamente ligada ao controle de força aplicada à tira. Obteve-se um tempo de resposta para o acompanhamento do sinal de referência, rejeição à perturbações e ruído de medida de aproximadamente 3 segundos. Esse tempo ainda pode ser considerado satisfatório, considerando-se a dinâmica do sistema de bobinamento, embora seja inferior aos outros resultados de controle obtidos.

Deve-se, entretanto, levar em consideração que o controlador foi projetado em função de um planta nominal sendo as variações paramétricas próprias do bobinamento modeladas como erro, assim como variações nos parâmetros do motor, já que o método de Pasek demonstrou-se ineficaz.

Percebeu-se que o compensador obtido oferece praticamente a mesma resposta para o sistema nominal quanto para o sistema real, considerando-se as variações paramétricas. 


\subsubsection{Comparação Entre o Controlador PID e o Compensador Robusto com Sensor Ultrasônico}

Conforme apresentado anteriormente, o controle do tipo PID utilizando o sensor ultrasônico apresentou um tempo de resposta bastante superior ao compensador robusto no que diz respeito ao acompanhamento do sinal de referência. A figura 9.53, a seguir, apresenta a resposta em freqüência do controlador PID em relação ao compensador robusto, destacando as barreiras de robustez do desempenho e estabilidade apresentadas anteriormente. Percebe-se que apesar da rápida resposta ao acompanhamento do sinal de referência, a resposta em freqüência do sistema com o controlador PID não respeita a barreira de robustez da estabilidade do projeto do compensador robusto.

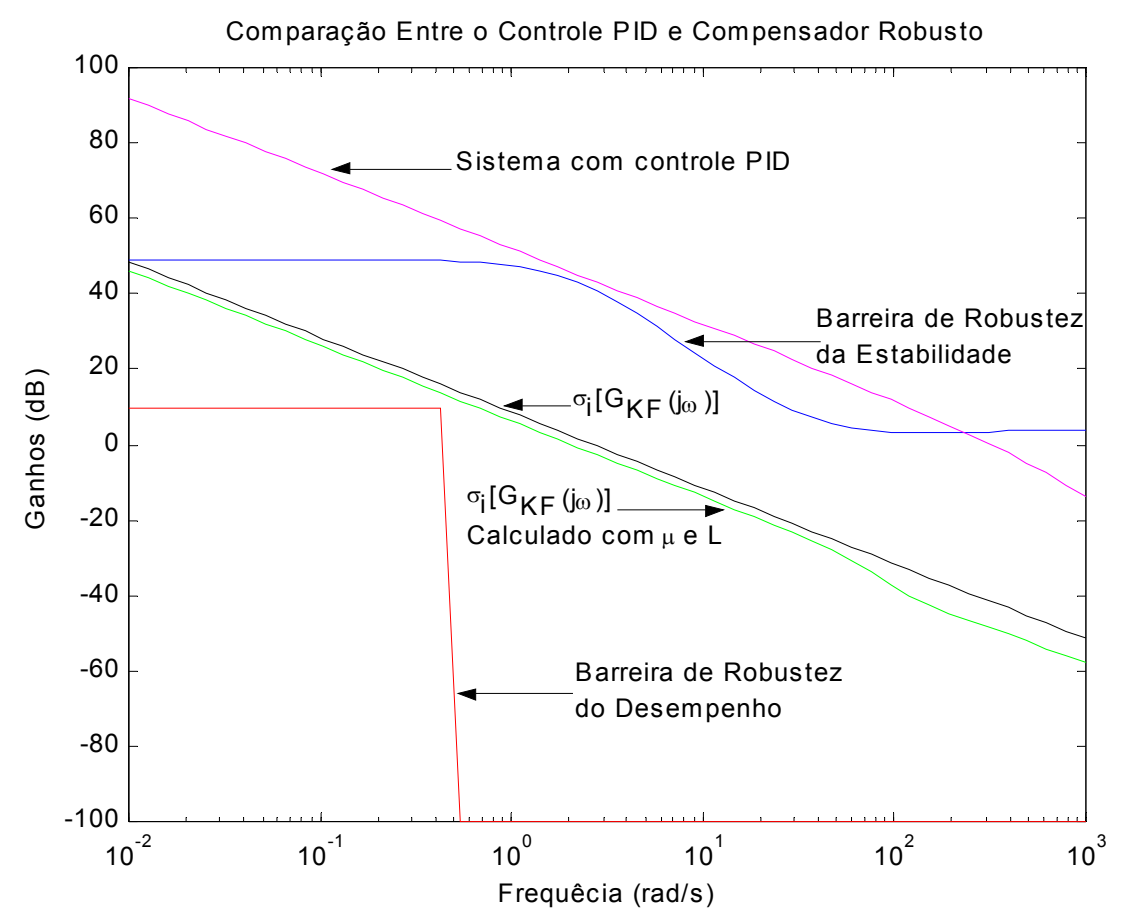

FIGURA 9.53 - Comparação entre o controlador PID e o compensador robusto

Finalmente, as figuras 9.54 e 9.55 apresentam os sinais de controle para o controlador do tipo PID e para o compensador robusto, respectivamente. 


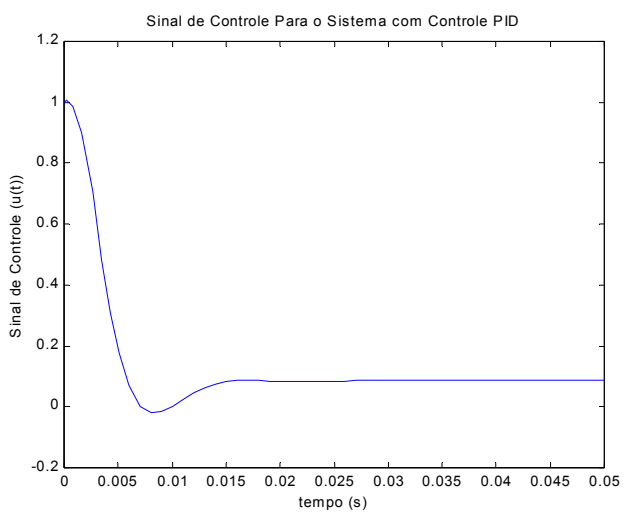

FIGURA 9.54 - Sinal de Controle (Controle PID)

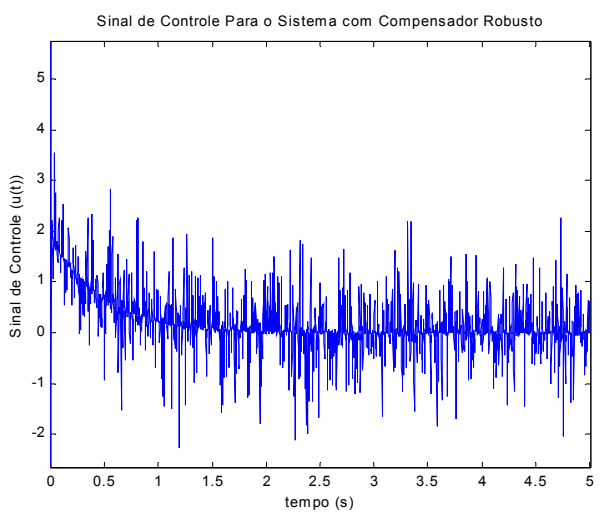

FIGURA 9.55 - Sinal de Controle (Compensador Robusto)

\subsubsection{Considerações Sobre a Potência de Acionamento}

$\mathrm{Na}$ literatura, encontra-se proposto por LEONHARD (1985) que o acionamento do motor da bobinadeira deve se dar à potência aproximadamente constante. Como apresentado nas simulações da potência eletromagnética do motor, com a atuação do controlador, percebe-se que o acionamento só se dá à potência aproximadamente constante caso o atrito do sistema - no caso o atrito viscoso - seja desconsiderado.

Esse resultado é importante, já que um acionamento à potência constante conforme proposto por LEONHARD (1985), pode produzir resultados insatisfatórios no que diz respeito ao controle de força aplicada à tira caso haja a presença de atrito no sistema (o que é uma hipótese bastante razoável em sistemas dessa natureza). 


\section{CAPÍtUlO 10}

\section{CONCLUSÕES}

O presente trabalho apresentou uma proposta para modelagem e controle de um sistema de bobinamento de tiras de aço. As tiras são produzidas através de lingotamento contínuo do tipo twin roll. Neste sentido, as características do processo de LCT do tipo twin roll foram primeiramente introduzidas. Após a produção da tira de aço pelo referido processo, apresentou-se o sistema de bobinamento, o qual foi o objetivo de estudo deste trabalho. Dessa forma, uma modelagem matemática do sistema de bobinamento foi previamente realizada, levando-se em consideração as variações paramétricas ocorridas ao longo do tempo de bobinamento, bem como os efeitos da caixa de redução de velocidade sobre o momento de inércia e conjugado de carga.

Posteriormente apresentaram-se os resultados de ensaio no motor CC. Deste ensaio foi possível obter as condições de operação do motor, bem como identificar a relação de redução de velocidade e relação tensão $\mathrm{x}$ velocidade do tacogerador. Pode-se observar ainda a ineficácia do método de Pasek, no que diz respeito à determinação dos parâmetros do motor CC (Anexo C). Com relação ao retificador, observou-se a sua operação no modo descontínuo. Analisando os valores de corrente de regime, consumida pelo motor $\mathrm{CC}$, conclui-se que seu valor (aproximadamente 0,7 A) é extremamente reduzido em comparação à sua corrente nominal (80 A). Isso se deve à baixa tensão fornecida ao motor, já que a velocidade do rolo bobinador é baixa, conforme foi apresentado, como também aos efeitos da caixa de redução de velocidade sobre o momento de inércia e conjugado de carga. 
As simulações do sistema de bobinamento sem a atuação de um sistema de controle foram de grande valia, no sentido de se determinar as características quantitativas e qualitativas do sistema, até então desconhecidas. Pôde-se observar claramente os efeitos da caixa de redução de velocidades sobre o conjugado de carga e o momento de inércia do sistema. A partir das respostas obtidas com o modelo do sistema de bobinamento, pôde-se constatar que a força aplicada à tira pode apresentar uma ampla faixa de variação, principalmente em função das variações paramétricas as quais a tira pode estar sujeita, como espessura, largura e densidade volumétrica da qual a mesma é constituída. Fica evidente, desta forma, a necessidade da implementação de um sistema de controle para este tipo de sistema.

Três alternativas para o controle do sistema de bobinamento foram propostas neste trabalho. A primeira, utilizou um controle do tipo PID ajustado através de "tentativa e erro". A motivação para se realizar este tipo de controle vem do fato da alta utilização deste tipo de controlador em aplicações industriais. Os resultados obtidos com este tipo de controle também serviram de auxílio na implementação das outras estratégias de controle propostas. A segunda proposta de controle também utiliza o controle PID, pelo mesmo motivo apresentado anteriormente. Nessa segunda proposta, porém, introduziu-se no sistema um sensor do tipo ultrasônico, para que as variações do raio de bobinamento fossem medidas. Dessa forma, o projeto do controlador PID pode ser feito de forma precisa, apresentando resultados melhores do que os anteriores, no que diz respeito ao desempenho no acompanhamento do sinal de referência. Constatou-se, porém, um pequeno erro de regime na situação em que o raio de bobinamento estava em seu valor máximo. Essa situação é indesejada pois todo o processo está sincronizado através da velocidade de produção da tira, embora o acompanhamento ao degrau de referência seja uma situação que dificilmente ocorrerá na prática para o sistema de bobinamento. Por último, implementou-se uma técnica de controle robusto utilizando-se a metodologia LQG/LTR. Nesta técnica as variações paramétricas do sistema foram modeladas como erros, inclusive as incertezas dos parâmetros do motor CC. Conclui-se que o compensador robusto projetado apresentou uma resposta satisfatória no que diz respeito ao acompanhamento do sinal de referência, tanto para a planta nominal quanto para a planta real. Mostrou-se eficaz também com relação à rejeição de 
perturbações e ruído de medida. Pode ser implementado no próprio programa supervisório, com a elaboração de uma rotina própria para tal finalidade.

As considerações sobre a potência de acionamento do sistema controlado, ou seja, operando a velocidade linear constante, levam a concluir que a potência de acionamento só é aproximadamente constante caso o atrito seja desprezado no equacionamento do sistema.

Com relação ao acionamento do motor $\mathrm{CC}$, levando-se em consideração a operação do retificador no modo descontínuo e os valores de potência de acionamento encontrados, conclui-se que o sistema pode ser reformulado, utilizando um retificador de menor potência.

Entende-se que o controle do sistema de bobinamento é de grande importância para o sucesso do processo LCT do IPT, no que diz respeito a qualidade da tira produzida, já que um bobinamento ineficaz pode comprometer esta qualidade, bem como, invalidar outras etapas anteriores de controle da planta.

Após a realização da análise do sistema de bobinamento e do projeto de controle, conclui-se que é possível implementar o sistema de controle de forma prática, a baixo custo e com confiabilidade, contribuindo para o sucesso do LCT do IPT. 


\section{ANEXo A}

\section{DADOS DE SimULAÇÃo}

TABELA A1 - Dados de Simulação

\begin{tabular}{|c|c|c|}
\hline Variável & Descrição/Unidade & Valor \\
\hline $\mathrm{e}$ & Espessura da tira (m) & 0,001 \\
\hline $\mathrm{r} 1$ & $\begin{array}{l}\text { Raio interno da bobinadeira } \\
(\mathrm{m})\end{array}$ & 0,1 \\
\hline $\mathrm{r} 2$ & $\begin{array}{l}\text { Raio externo da bobinadeira } \\
(\mathrm{m})\end{array}$ & 0,25 \\
\hline $\mathrm{V}_{\mathrm{ta}}$ & Tensão aplicada ao motor (V) & 240 \\
\hline $\mathrm{R}_{\mathrm{a}}$ & Resistência de armadura $(\Omega)$ & 0,067 \\
\hline $\mathrm{L}_{\mathrm{aq}}$ & Indutância de armadura (H) & 0,0005 \\
\hline $\mathrm{J}_{1}$ & $\begin{array}{l}\text { Momento de inércia do motor } \\
\left(\mathrm{Kg} \cdot \mathrm{m}^{2}\right)\end{array}$ & 0,4 \\
\hline $\mathrm{B}$ & Atrito viscoso (Nm.s / rad) & 0,55 \\
\hline $\mathrm{K}_{\mathrm{t}}$ & Constante de torque $(\mathrm{Nm} / \mathrm{A})$ & 1,28 \\
\hline$\rho$ & densidade volumétrica $\left(\mathrm{Kg} / \mathrm{m}^{3}\right)$ & 7800 \\
\hline M & $\begin{array}{l}\text { massa do rolo da bobinadeira } \\
(\mathrm{Kg})\end{array}$ & 100 \\
\hline $\mathrm{d}$ & Largura da tira $(\mathrm{m})$ & 0,10 \\
\hline $\mathrm{T}_{\mathrm{D}}$ & $\begin{array}{l}\text { Tempo de atraso do retificador } \\
(\mathrm{ms})\end{array}$ & 1,385 \\
\hline $\mathrm{K}_{\mathrm{D}}$ & Ganho do retificador & 10 \\
\hline $\mathrm{K}_{\mathrm{u}}$ & $\begin{array}{l}\text { Constante do sensor } \\
\text { ultrasônico }(\mathrm{V} / \mathrm{m})\end{array}$ & 7,87 \\
\hline
\end{tabular}




\section{ANEXO B}

\section{DEDUÇÃO DAS EQUAÇÕES DIFERENCIAIS DO}

\section{SISTEMA DE BOBINAMENTO}

A seguir, apresenta-se as equações diferencias do sistema de bobinamento, utilizadas para composição da s-function "velocidade". Posteriormente apresenta-se a rotina de programação da s-function.

\section{B.1 Diferencial do Raio Bobinado}

$$
\begin{gathered}
r(t)=\int_{0}^{t} \frac{\omega_{2} e}{2 \pi} d t \\
p r(t)=\frac{\omega_{2} e}{2 \pi}
\end{gathered}
$$

\section{B.2 Diferencial da Velocidade Mecânica}

$$
p \omega_{1}=\frac{T}{J_{1 e}}-\frac{\omega_{1}}{J_{1 e}} p J_{1 e}-\frac{T_{c 1}}{J_{1 e}}-\frac{B \omega_{1}}{J_{1 e}}
$$

\section{B.3 Diferencial da Inércia}




$$
J_{2}=\frac{1}{2}\left[m+\left(2 \pi r_{2} r(t)+\pi r(t)^{2}\right) \rho d\left[\left(r_{1}^{2}+\left(r_{2}+r(t)\right)^{2}\right)\right]\right.
$$

A equação (B.4) apresenta o momento de inércia para o rolo bobinador. Distribuindo-se os termos e aplicando o operador derivativo, chega-se à equação (B.5).

$$
p J_{2}=\frac{1}{2} p\left[m+2 \pi r_{2} r(t) \rho d+\pi r(t)^{2} \rho d \mathbb{I}\left(r_{1}^{2}+r_{2}^{2}+2 r_{2} r(t)+r(t)^{2}\right)\right]
$$

Distribuindo-se novamente os termos, aplicando o operador derivativo e reagrupando os termos, temos a derivada do momento de inércia apresentado na equação (B.6).

$$
\begin{gathered}
p J_{2}=\left[\left(m\left(r_{2}+r(t)\right)\right)+\pi \rho d\left(r_{2} r_{1}^{2}+r_{2}^{3}+4 r_{2}^{2} r(t)+3 r_{2} r(t)^{2}+r_{1}^{2} r(t)+r_{2}^{2} r(t)+\ldots\right.\right. \\
\left.\left.\ldots+3 r_{2} r(t)^{2}+2 r(t)^{3}\right)\right]
\end{gathered}
$$




\section{ANEXO C}

\section{RESPOSTAS TRANSITÓRIAS DE CORRENTE E VELOCIDADE (O MÉTODO DE PASEK)}

\section{C.1 Determinação dos Parâmetros do Motor}

\section{C.1.1 O Método de Pasek}

Os métodos clássicos para determinação dos parâmetros do motor de corrente contínua requerem normalmente um teste para a determinação de cada parâmetro. Este procedimento consome muito tempo sendo a maioria dos testes feitos sob condições de regime permanente, o que produz resultados insatisfatórios na análise transitória. Dentro deste panorama uma metodologia para determinação dos parâmetros do motor de corrente contínua conhecida como método de Pasek é encontrada na literatura em LORD \& HWANG (1975); LORD \& HWANG (1977) e LORD (1976).

No método de Pasek, propõe-se obter todos os parâmetros do modelo do motor a partir da análise da resposta transitória da corrente de armadura com relação a uma entrada degrau de tensão de armadura. Dessa forma, portanto, todos os parâmetros do motor de corrente contínua seriam determinados através de um único ensaio.

Para a aplicação do método de Pasek, é necessário que se defina um modelo linear para o motor CC. O modelo aqui utilizado envolve todos os parâmetros apresentados pelas eq. (3.1) e (3.2) do motor $\mathrm{CC}$, inclusive o atrito viscoso. Com base nestas equações, e considerando como entrada a tensão de armadura e como saída a velocidade angular do motor, pode-se construir um diagrama a ser utilizado para a aplicação do método de Pasek, conforme a figura C.1 abaixo: 


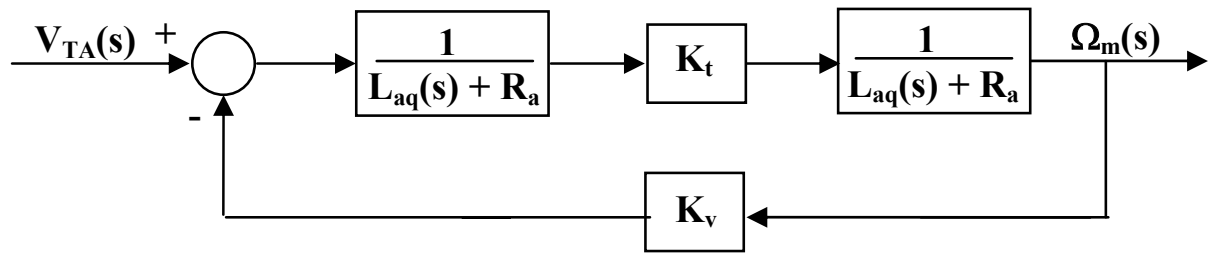

FIGURA C.1 - Modelo linear do motor CC

O modelo considerado para aplicação do método de Pasek, portanto, é de segunda ordem. A figura C.2 apresenta as respostas típicas de corrente e velocidade, quando uma entrada em degrau é aplicada ao modelo da figura 4.7.

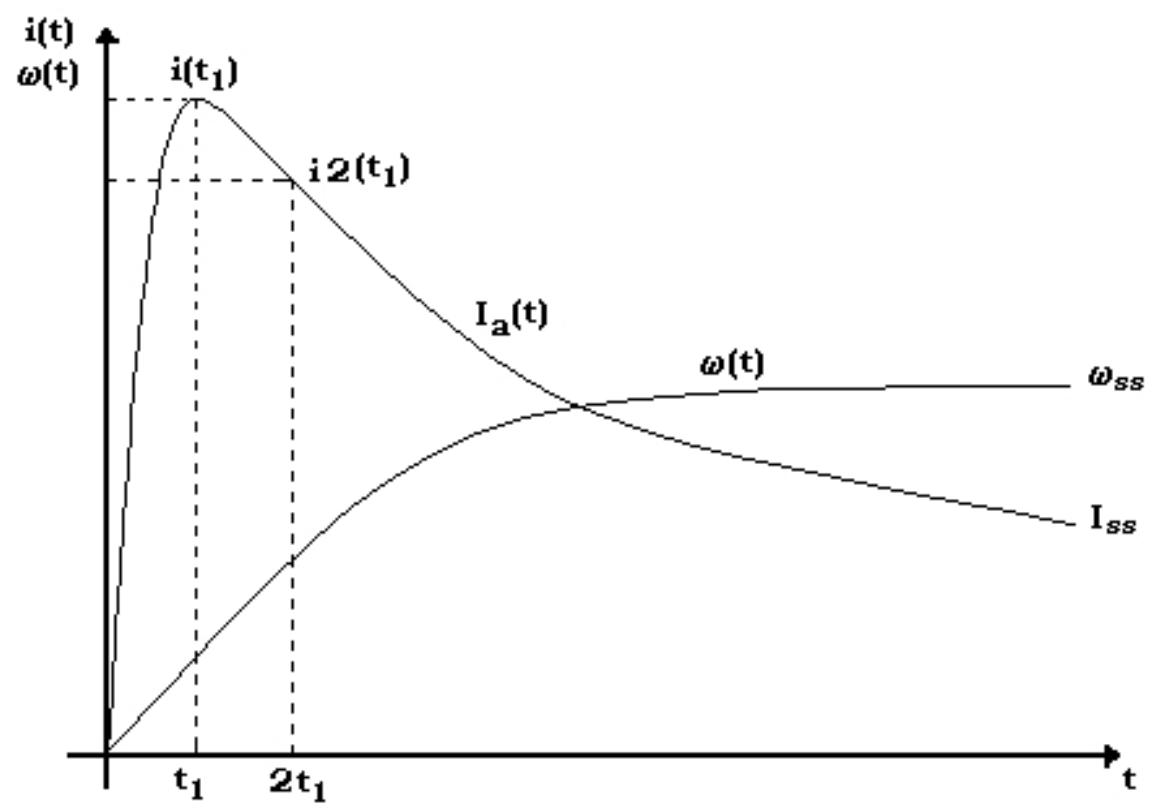

FIGURA C.2 - Resposta transitória de corrente e velocidade para o modelo de segunda ordem do motor CC

Como apresentado na figura C.2, as constantes de tempo da forma de onda de corrente são os fatores mais relevantes na aplicação do método de Pasek. Adicionalmente, necessita-se do valor do degrau de tensão aplicado à armadura do motor e a velocidade angular final. O esquema elétrico utilizado no ensaio em degrau do motor CC é apresentado na figura C.3 abaixo: 


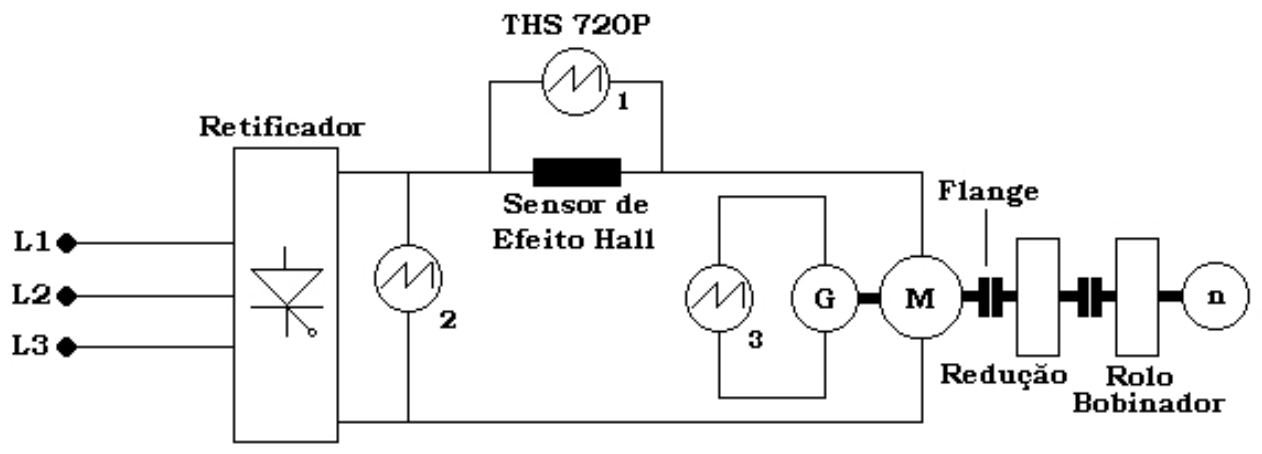

FIGURA C.3 - Ensaio no motor CC

No esquema da figura C.3, os pontos numerados por 1,2 e 3 representam as posições do osciloscópio para a obtenção das grandezas de corrente de armadura, tensão de saída do retificador e tensão de saída do tacogerador, respectivamente. Ainda com relação ao esquema da figura C.3, o tacogerador é representado pela letra $G, M$ é o motor CC, $n$ é o tacômetro e L1, L2 e L3 são as três fases de alimentação do retificador. A condição básica e necessária para a utilização do método de Pasek é que a relação apresentada pela eq. (C.1) seja respeitada:

$$
\frac{i\left(t_{1}\right)}{i\left(t_{2}\right)}=\frac{I_{S C}}{i\left(t_{1}\right)}
$$

onde $\mathrm{I}_{\mathrm{SC}}$ é a corrente de armadura para $\mathrm{L}_{\mathrm{aq}}=0$ e $\mathrm{i}\left(\mathrm{t}_{1}\right)$ e $\mathrm{i}\left(2 \mathrm{t}_{1}\right)$ são valores de corrente conforme indicado na figura C.2. A relação apresentada na eq. (4.1) não pode ser verificada facilmente, pois não se conhece o valor de $\mathrm{I}_{\mathrm{SC}}$. O método, entretanto, é aplicado admitindo que essa condição seja válida, os parâmetros são calculados e finalmente, com os valores obtidos faz-se uma simulação do sistema, confronta-se a resposta simulada com a real e avalia-se a exatidão dos parâmetros obtidos. Com os valores de corrente apresentados na figura C.2 e na eq. (4.1) mais a velocidade angular final e o valor do degrau de tensão é possível aplicar uma série de relações e determinar todos os parâmetros do motor conforme apresentado em LORD \& HWANG (1977). 


\section{C.1.2 Resultados Experimentais}

A seguir, apresentam-se os resultados experimentais obtidos através de ensaio degrau de tensão no motor $\mathrm{CC}$ da bobinadeira. $\mathrm{O}$ ensaio foi realizado conforme o circuito da figura C.3, na tentativa de levantar os parâmetros do motor através do método de Pasek.

As figuras C.4, C.5, C.6 e C.7 apresentam os resultados de corrente transitória para quatro valores de degrau de tensão aplicados ao motor CC da bobinadeira. As formas de onda de corrente transitória foram então filtradas com o auxílio do programa MATLAB ${ }^{\circledR}$, com o objetivo de localizar os pontos relevantes à aplicação do método de Pasek. A tabela C.1 apresenta os valores numéricos obtidos para cada um dos ensaios.
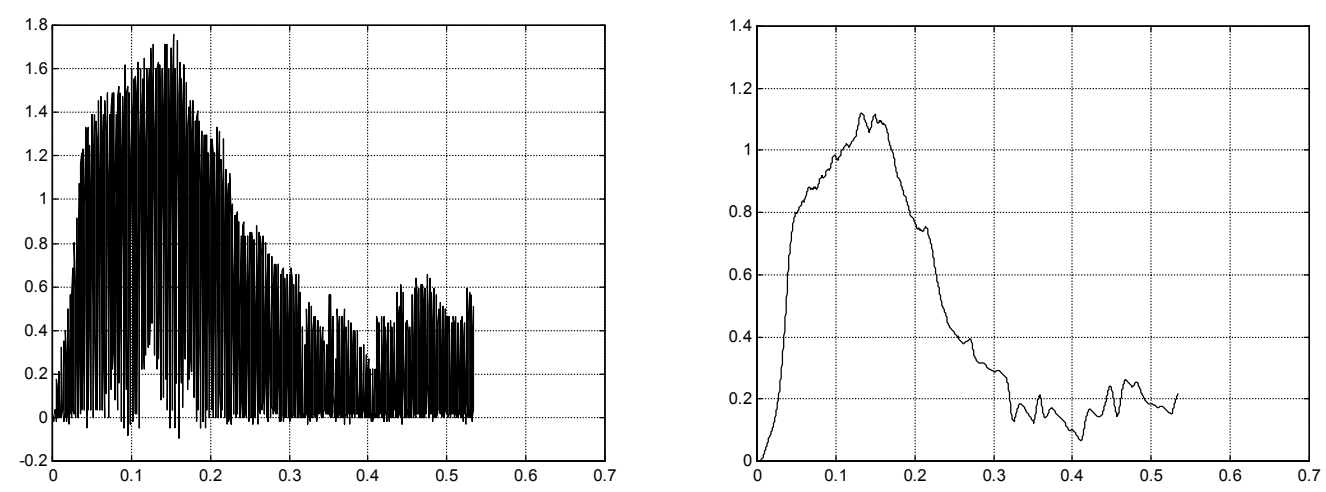

FIGURA C.4 - Respostas transitórias de corrente para entrada degrau de tensão de $8 \mathrm{~V}$
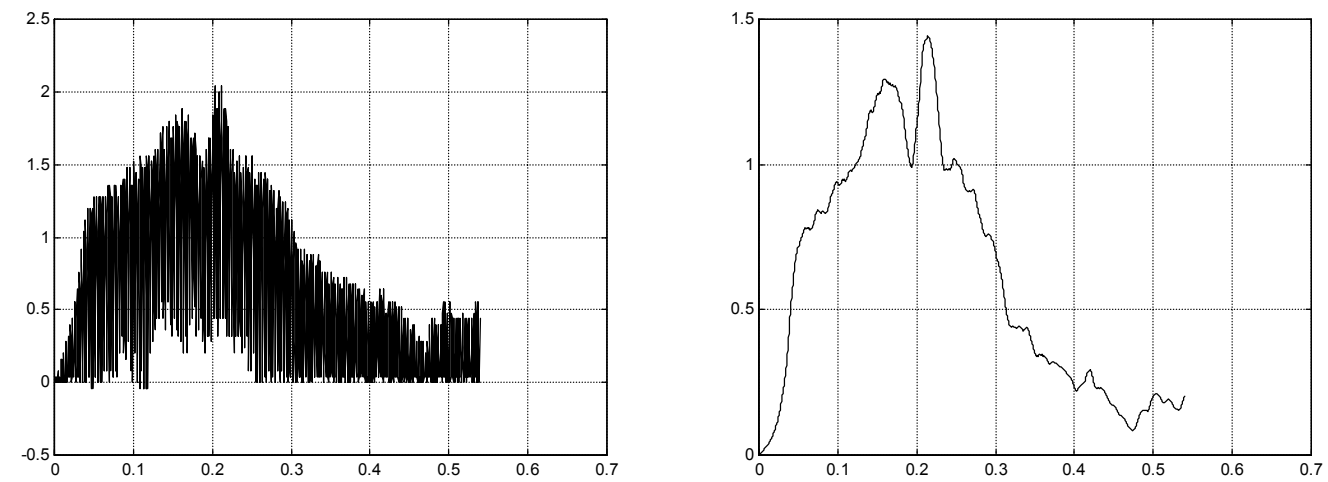

FIGURA C.5 - Respostas transitórias de corrente para entrada degrau de tensão de 

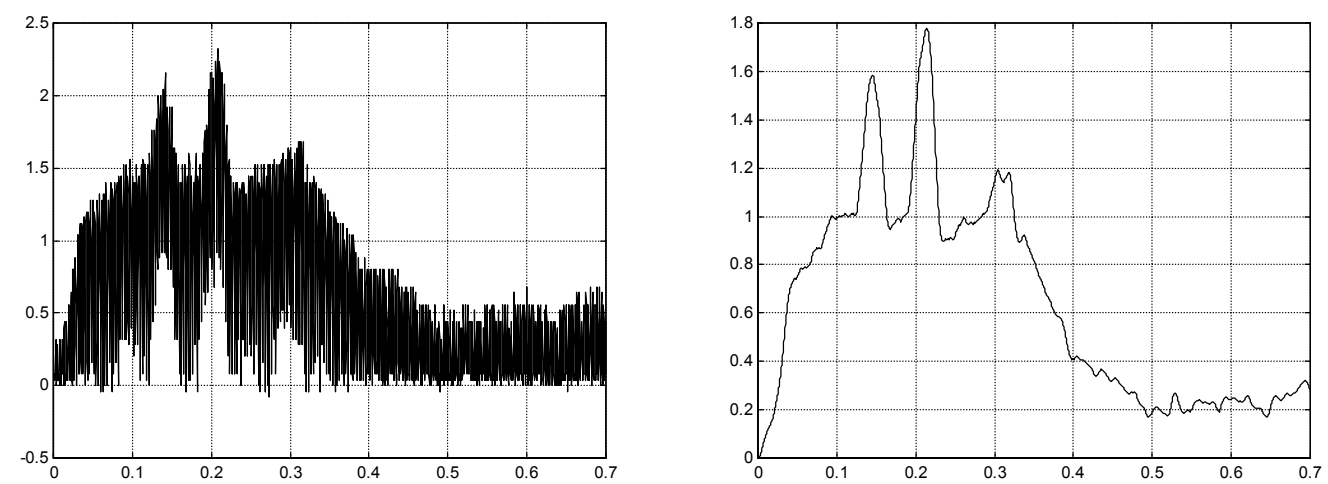

FIGURA C.6 - Respostas transitórias de corrente para entrada degrau de tensão de $15 \mathrm{~V}$
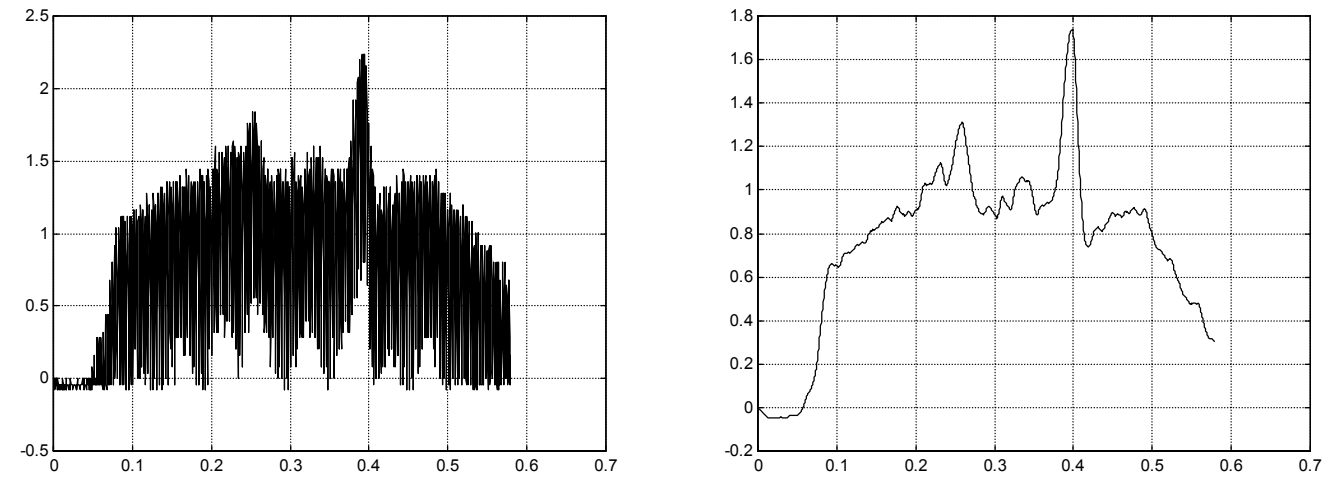

FIGURA C.7 - Respostas transitórias de corrente para entrada degrau de tensão de $17 \mathrm{~V}$

TABELA C.1 - Valores numéricos de ensaio

\begin{tabular}{|c||c||c||c||c||c||c||}
\hline Figura & $\mathbf{i}\left(\mathbf{t}_{\mathbf{1}}\right) \mathbf{( A )}$ & $\mathbf{t}_{\mathbf{1}}(\mathbf{s})$ & $\mathbf{i}\left(\mathbf{2 t}_{\mathbf{1}}\right) \mathbf{( A )}$ & $\mathbf{2}\left(\mathbf{t}_{\mathbf{1}}\right) \mathbf{( s )}$ & $\mathbf{I}_{\mathbf{s s}}(\mathbf{A})$ & $\omega_{\text {ss }}(\mathbf{r a d} / \mathbf{s})$ \\
\hline \hline C.4 & 1,122 & 0,1324 & 0,3821 & 0,2648 & 0,216 & 4,8 \\
\hline \hline C.5 & 1.44 & 0.214 & 0.2307 & 0.428 & 0.204 & 7,21 \\
\hline \hline C.6 & 1.78 & 0.2136 & 0.3417 & 0.4272 & 0.2238 & 9,39 \\
\hline \hline C.7 & 1.7436 & 0.3403 & - & 0.6806 & - & 11,597 \\
\hline
\end{tabular}

Com os valores da tabela C.1, aplicaram-se as relações apresentadas em LORD \& HWANG (1977) e constatou-se que o método não era aplicável. Ainda na 
tabela C.1, pode-se perceber que para os dados de corrente transitória apresentados pela figura C.7, os valores de $\mathrm{i}\left(2 \mathrm{t}_{1}\right)$ e $\mathrm{I}_{\mathrm{ss}}$ nem sequer puderam ser determinados por apresentarem valores incoerentes com o método.

O motor da bobinadeira do IPT possui potência de $28,4 \mathrm{KW}$. Devido a não aplicabilidade do método de Pasek ao motor, os dados de um motor CC de potência semelhante foram extraídos de KUSKO (1969), e serão utilizados daqui por diante para as análises e simulações. 


\section{REFERÊNCIAS BIBLIOGRÁFICAS}

BAU, H.H. ; ROOIJ, N.F. ; KLOECK, B. (1994). Sensors - a comprehensive survey. Mechanical sensors. VCH.

CARBONARA, R.S. (1988). Process control in direct strip casting. Casting of near net shape products.

COOK, R. ; GROCOCK, P.G. ; THOMAS, P.M. (1995). Development of the twinroll casting process. Journal of materials processing technology, v 55, p. 76-84.

CRUZ, J.J. (1996). Controle Robusto Multivariável. São Paulo, Editora da Universidade de São Paulo.

DENTI FILHO, J. ; FIGUEIREDO, B.R. ; HELMAN, H. (1996a). Modelamento e simulação do processo de bobinamento na laminação de tiras para aplicações de controle. VII Congresso latinoamericano de control automático, p. 714-719.

DENTI FILHO, J. ; FIGUEIREDO, B.R. (1996b). Sistema de bobinamento e controle de tensão à frente na laminação de tiras - uma análise. XXXIII Seminário de laminação, processos e produtos laminados e revestidos - ABM, p. 181-191.

DENTI FILHO, J. ZANANDRÉA, P.H.F. (1999). Strip coil driving system using fuzzy technique and vectorial induction motor speed control. Proceedings of the association of iron and steel engineering - international conference, Cleveland, USA.

FITZGERALD, A. E. ; KINGSLEY JR, C. ; KUSKO, A. (1975). Máquinas Elétricas. McGraw-Hill. 
FRANKLIN, G. F. ; POWELL, J.D. ; EMAMI-NAEINI, A. (1994). Feedback control of dynamic systems. Addison Wesley.

GARCIA, C. (1997). Modelagem e Simulação. São Paulo, Editora da Universidade de São Paulo.

GOES, B. ; GIL-SEVILLANO, J. ; D’HAENE, U. (1999). Modelling the evolution of residual stresses during tensile testing of elastoplastic wires subjected to a previus bending operation. International journal of mechanical sciences, v.41, p. 1031-1050.

GUO, R (1997). Modeling and simulation of run-out table cooling control using feedforward-feedback and element tracking system. IEEE Transactions on industry aplications, v. 33, n.2, Mar./Apr.

IRVING, W.R. (1993). Continuous casting of steel. The Institute of Materials.

KUSKO, A. (1969). Solid State DC Motor Drives . The M.I.T. Press, Mass.

LARKE, E.C. (1957). The rolling of strip sheet and plate. Chapman \& Hall.

LEE, D. ; LEE, J.S. ; KANG, T. (1996). Adaptive fuzzy control of the molten steel level in a strip-casting process. Control eng. Practice, v.4, n.11, p.1511-1520.

LEONHARD, W. (1985). Control of Electrical Drivers. Springer Verlag.

LIANG, X. ; PAN, F. ; ZHOU, S. ; DING, P. XU, C. (1997). Edge containment of a twin-roll caster for near net shape strip casting. Journal of materials processing technology, v.63, p.788-791.

LORD, W. (1976). Making the most of d.c. motor modelling. Electrical Review, v. 199, n.6. 
LORD, W. ; HWANG, J.H. (1977). Dc servomotors - modeling and parameter determination. IEEE Transactions on industry aplications, v. IA-13, n.3.

LORD, W. ; HWANG, J.H. (1976). Dc motor model parameters. IEEE transactions on industrial electronics and control instrumentation, v.IEC I 23, n.3, p. 335-337.

OGATA, K. (1993). Engenharia de Controle Moderno. PHB.

PEARMAN, R.A. (1980). Power Electronics - Solid State Motor Control. Reaston Publishing Company.

RASHID, M.H. (1999). Eletrônica de Potência. Makron Books.

SHEARER J. L. ; MURPHY, A. T. ; RICHARDSON, H. H. (1971). Introduction to System Dynamics. Addison Wesley.

SHIN, Y.K. ; KANG, T. ; REYNOLDS, T. ; WRIGHT, L. (1995). Development of twin roll strip caster for sheet steels. Ironmaking and steelmaking, v.22, p. 35-44.

STUBBS, D.A. ; DUTTON, R.E. (1996). An ultrasonic sensor for high-temperature materials processing. Journal of Materials, v.48, n.9, p. 29-31.

TAO, J. ; SADLER, J.P. (1995). Constant speed control of a motor driven mechanism system. Mech. Mach. Theory, v.30, n.5, p. 737-748.

TATARYN, P.D. ; SEPEHRI, N. ; STRONG, D. (1996). Experimental comparison of some compensation techniques for the control of manipulators with stick-slip friction. Control eng. Practice, v.4, n.9, p. 1209-1219.

TSELIKOV, A.I. ; SMIRNOV, V.V. (1965). Rolling mills. Pergamon Press. 
USING SIMULINK (1996), in MathWorks Handbook MathWorks.

WILDI, T. (1991). Electrical Machines, Drives, and Power Systems. Prentice Hall.

YUN, M. ; LOKYER, S. ; HUNT, J.D. (2000). Twin roll casting of aluminium alloys. Materials science and engineering, A 280, p.116-123.

ZAPUSKALOV, N. (1999). Effect of coiling operation on strip quality of $4.5 \% \mathrm{Si}$ steel in twin-roll casting process. ISIJ International, v.39, n.5, p.463-470. 


\section{APÊNDICE A}

\section{PUBLICAÇÕES}

LIMA, F.; OLIVEIRA JÚNIOR, A.A. de; TOSETTI, J.P.V. (2000). Análise e simulação de um sistema de bobinamento de tiras de aço. IV Encontro de Especialistas em Automação-ABM, p.145-155, set.

SANTOS, J.; LIMA, F.; OLIVEIRA, V.A. de, OLIVEIRA JÚNIOR, A.A. de (2000). Description of a Twin Roll Direct Strip Casting Process. IV Induscon, v.1, p. 416419, Sept.

LIMA, F.; OLIVEIRA JÚNIOR, A.A. de; TOSETTI, J.P.V. (2001). Modelling and Control of a Steel Strip Coiling System. IASTED International Conference on Modelling, Identification and Control (MIC 2001), Feb. 


\section{APÊNDICE B}

\section{ROTINAS DOS PROGRAMAS}

Após definida as equações diferenciais do sistema de bobinamento, implementou-se a rotina de programa da s-function velocidade, utilizada nas simulações do sistema de controle. A rotina do programa é apresentada a seguir:

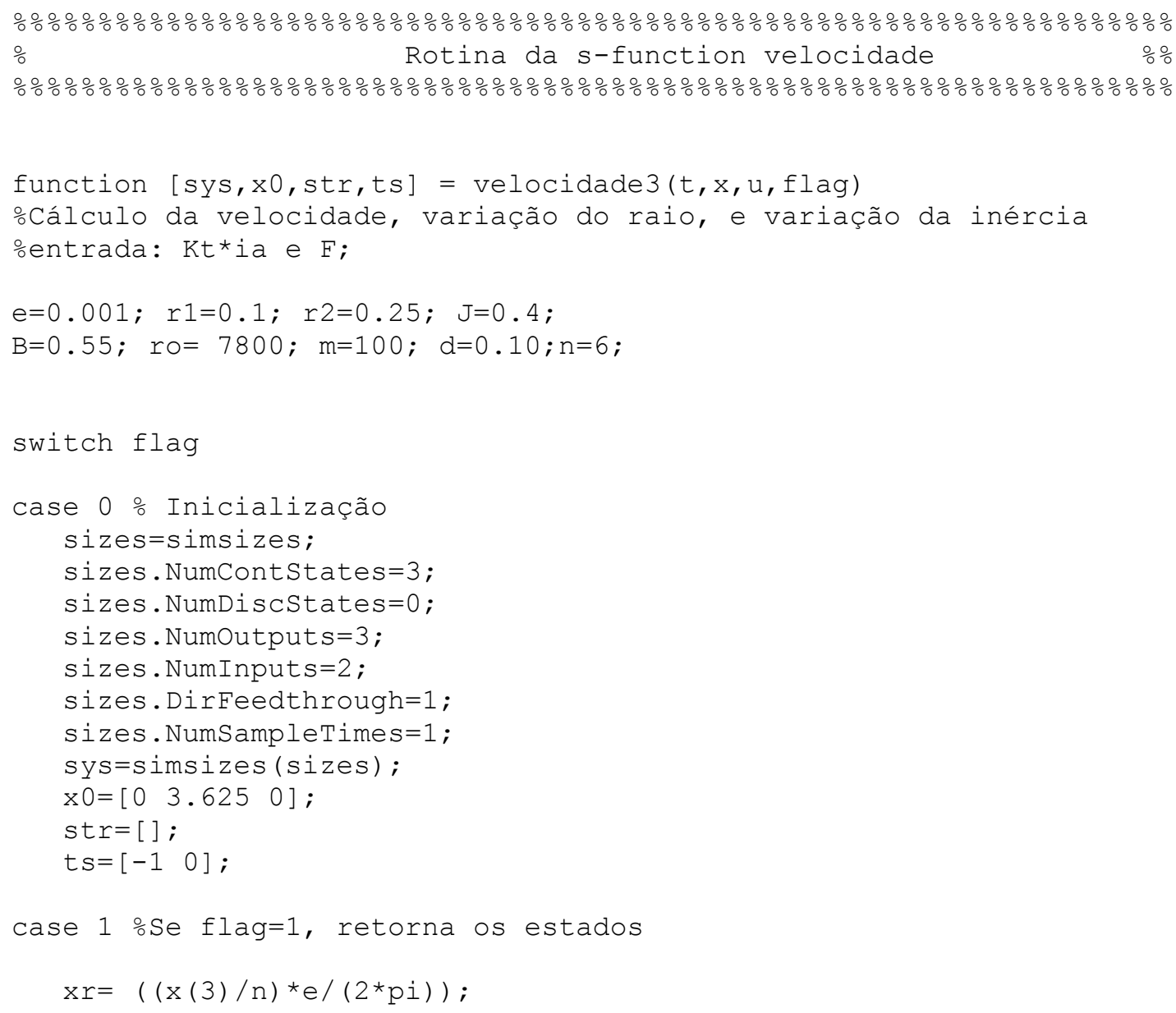




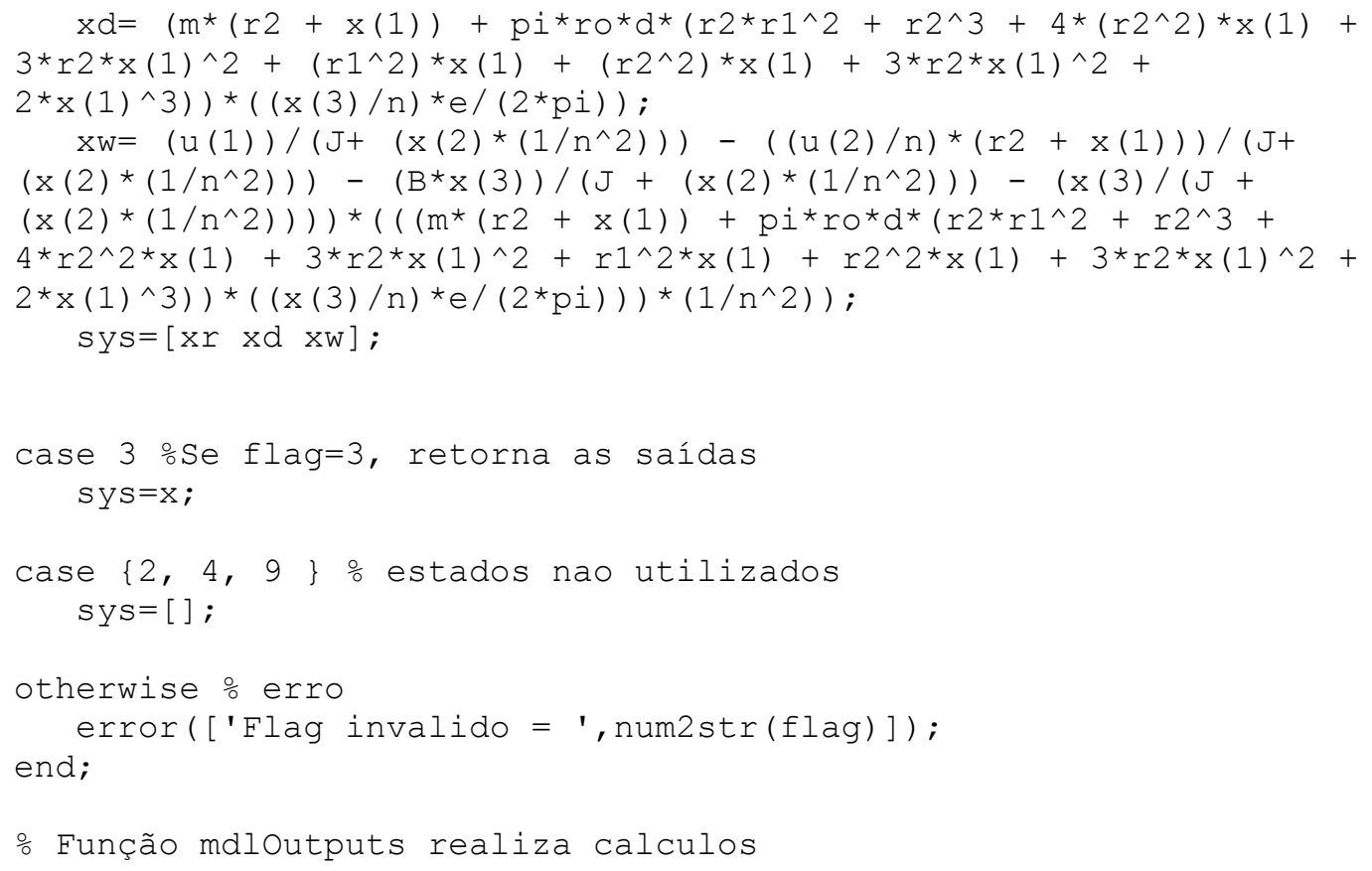

A seguir apresenta-se a listagem do programa utilizado para obtenção dos resultados do controle PID com sensor ultrasônico:

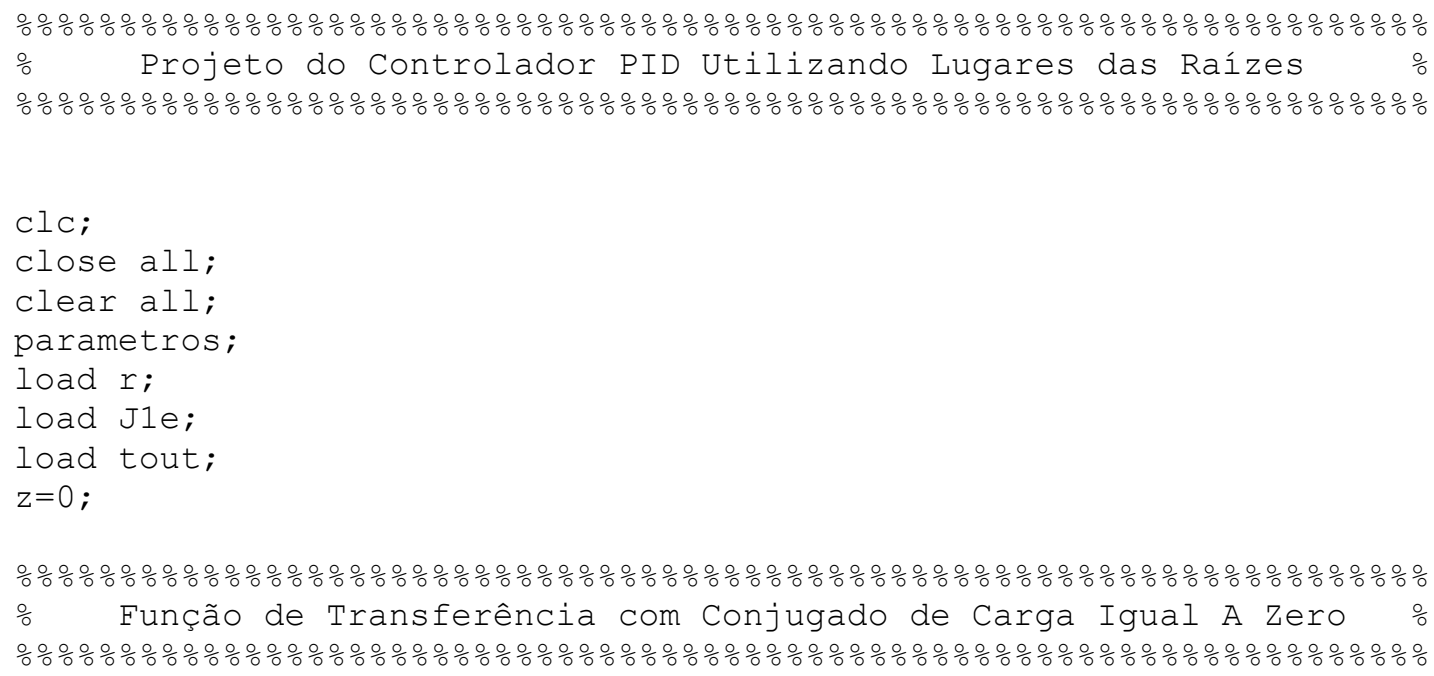

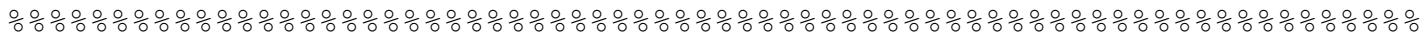
\% Calcula e Apresenta a Resposta para os Diversos Valores de Raio $\frac{0}{0}$

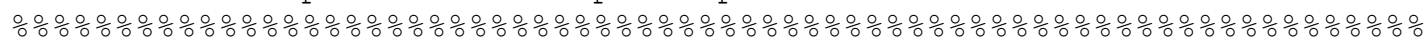

ofor $I=1: 500:$ length(tout); (Diversos Valores de raio)

$\mathrm{z}=\mathrm{z}+1$

I=30000; Valor de Raio Específico

$\mathrm{Kr}(\mathrm{I})=(\mathrm{Ku}+\mathrm{Ku} *(\mathrm{r}(\mathrm{I})))$; 
Finalmente apresenta-se a rotina do programa utilizada no projeto do compensador robusto utilizando a metodologia LQG/LTR.

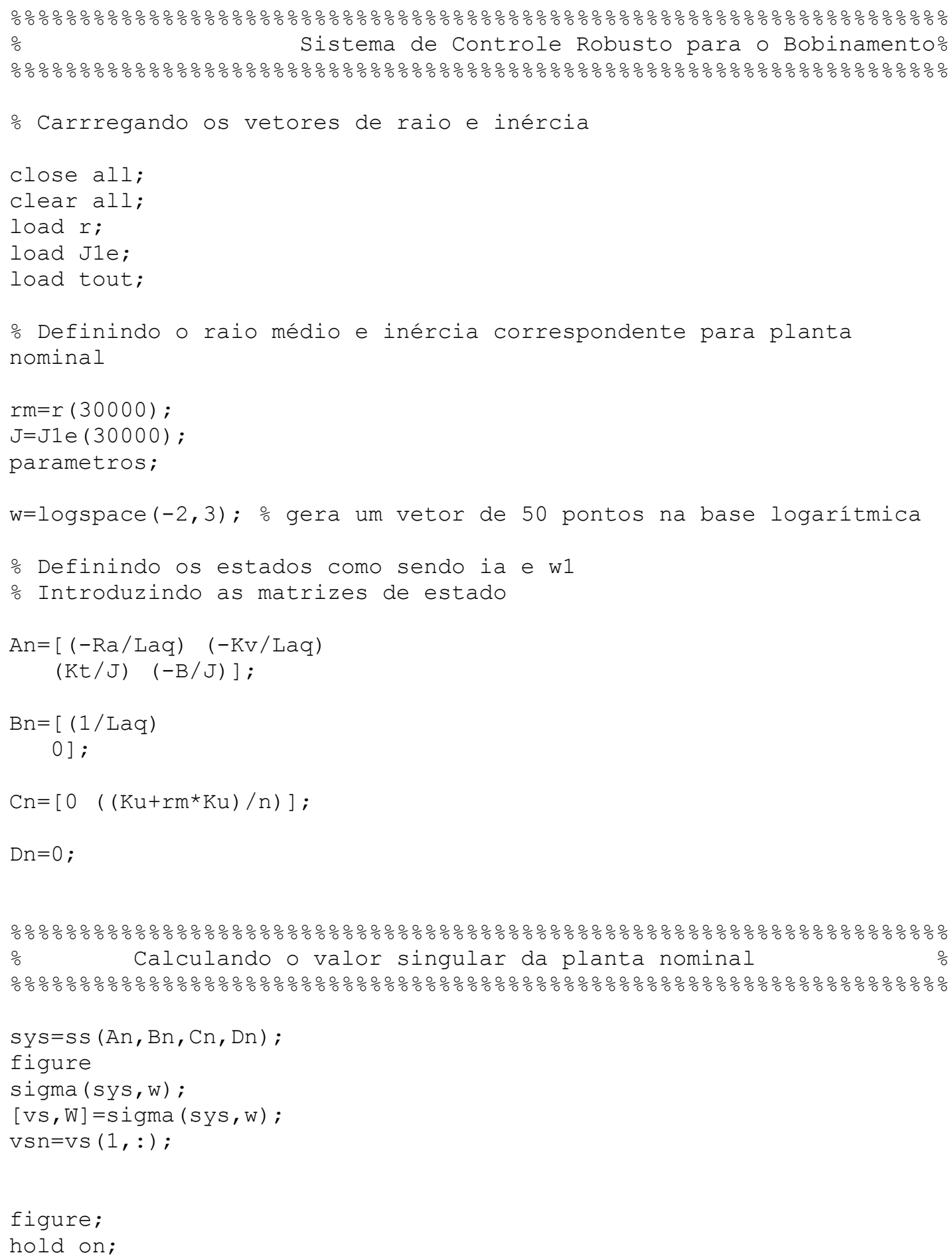


$\mathrm{VB}(1)=1.05 * \mathrm{~B}$;

$\operatorname{VB}(2)=0.95 * B$;

$\operatorname{VLaq}(1)=1.05 * \mathrm{Laq}$;

$\operatorname{VLaq}(2)=0.95 *$ Laq;

$\operatorname{VRa}(1)=1.05 * \mathrm{Ra}$;

$\operatorname{VRa}(2)=0.95 * \operatorname{Ra}$;

$\operatorname{VKt}(1)=1.05 * \mathrm{Kt}$;

$\operatorname{VKt}(2)=0.95 * K t$;

$\mathrm{VJ}(1)=\mathrm{J} 1 \mathrm{e}(1)$;

VJ (2) =J1e (length (tout)) ;

$\mathrm{z}=0$;

for $I=1: 2$

$\mathrm{B}=\mathrm{VB}(\mathrm{I})$;

for $\mathrm{Z}=1: 2$

$\mathrm{Laq}=\mathrm{VLaq}(\mathrm{Z})$;

for $\mathrm{H}=1: 2$

$\mathrm{Ra}=\mathrm{VRa}(\mathrm{H})$;

for $Y=1: 2$

$\mathrm{Kt}=\mathrm{VKt}(\mathrm{Y})$;

for $T=1: 2$

$\mathrm{J}=\mathrm{VJ}(\mathrm{T})$;

$$
\mathrm{z}=\mathrm{z}+1 \text {; }
$$

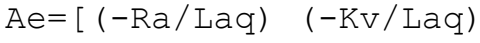

$(\mathrm{Kt} / \mathrm{J}) \quad(-\mathrm{B} / \mathrm{J})]$;

$\mathrm{Be}=[(1 / \mathrm{Laq})$

$0]$;

$\mathrm{Ce}=\left[\begin{array}{ll}0 & ((\mathrm{Ku}+\mathrm{rm} * \mathrm{Ku}) / \mathrm{n})\end{array}\right]$;

$\mathrm{De}=0 ；$

sys $1=\mathrm{ss}(\mathrm{Ae}, \mathrm{Be}, \mathrm{Ce}, \mathrm{De})$;

sigma ( $\mathrm{sys} 1, \mathrm{w})$;

$[\mathrm{vs} 1, \mathrm{~W}]=\mathrm{sigma}(\mathrm{sys} 1, \mathrm{w})$;

$\operatorname{vsa}(\mathrm{z},:)=\operatorname{vs} 1(1,:)$;

end

end

end

end

end

hold off;

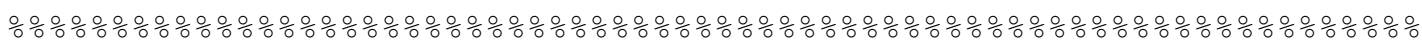

Determinação da Barreira de Robustez da Estabilidade

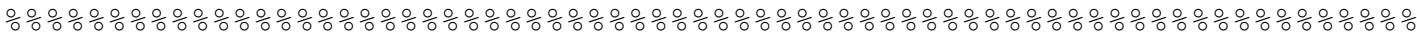

o Calculando a função erro multiplicativo EM(W) 


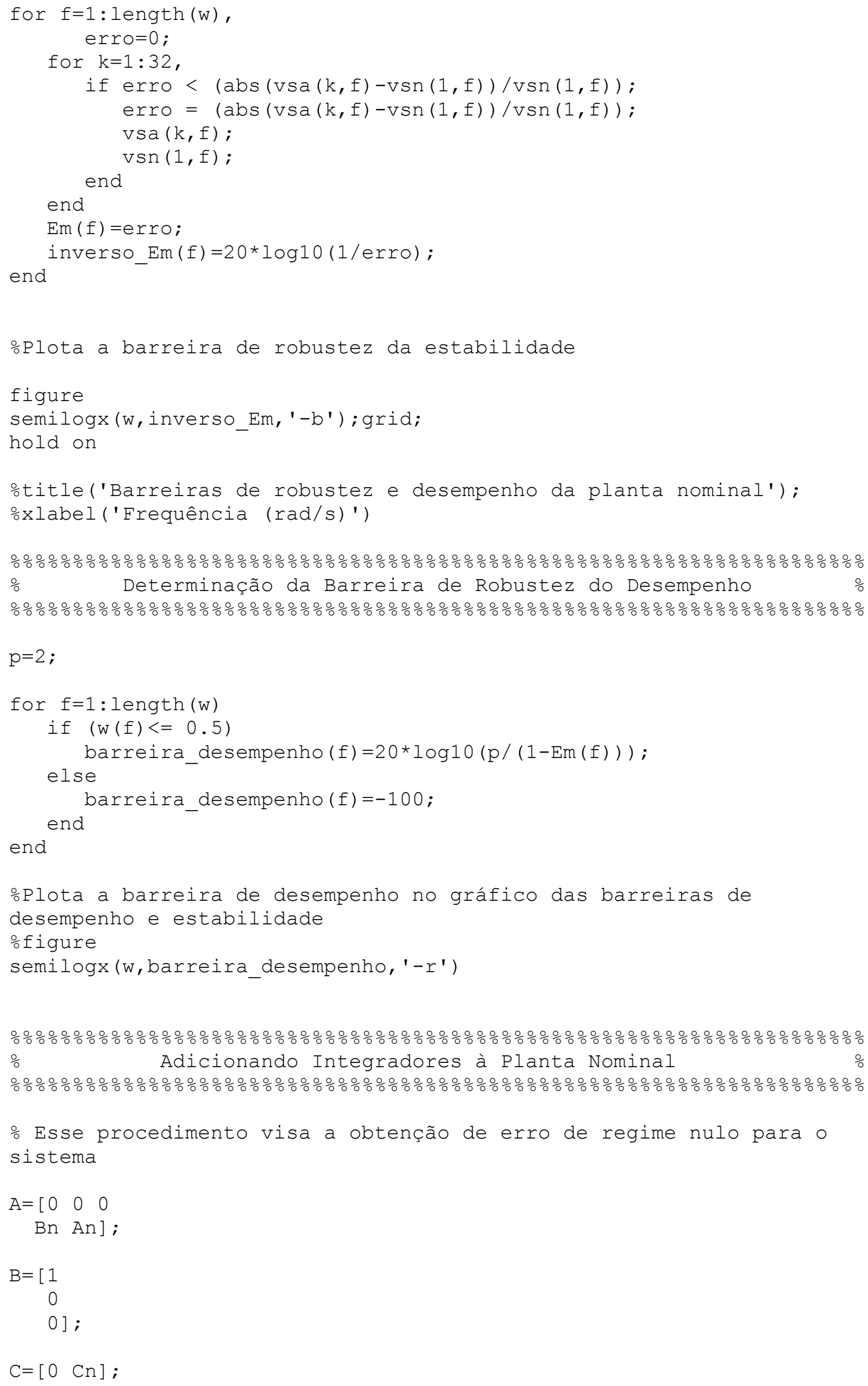




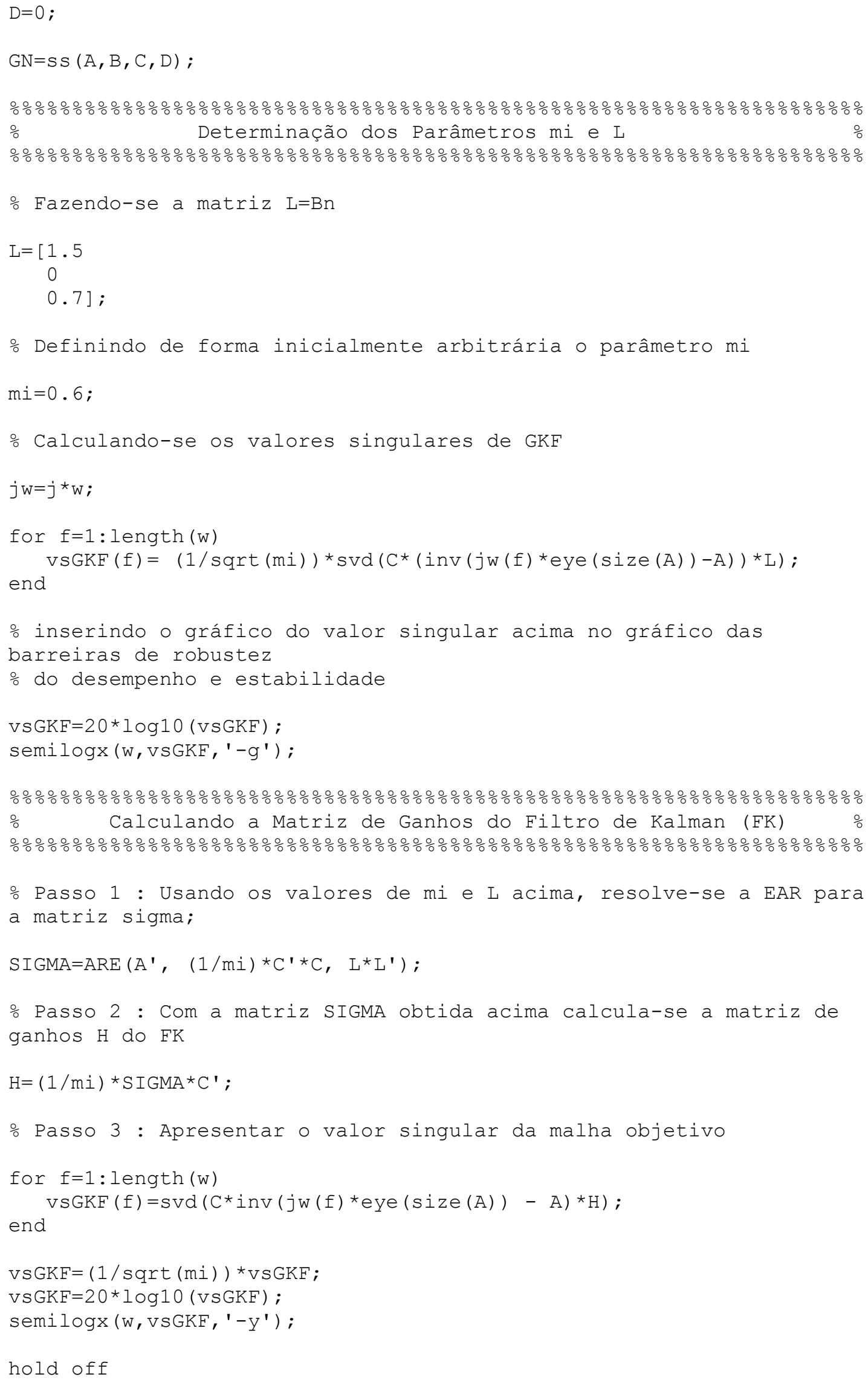




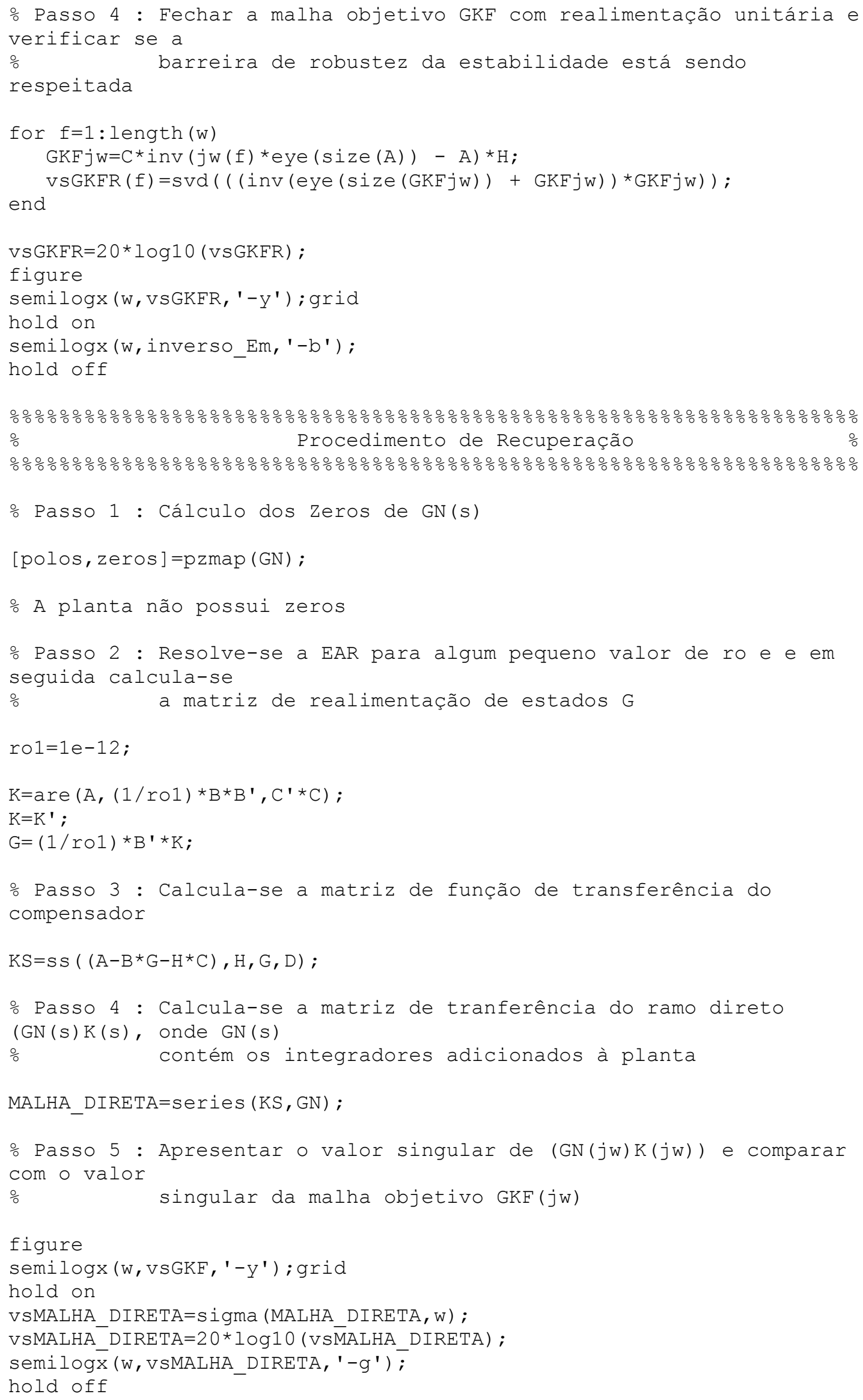




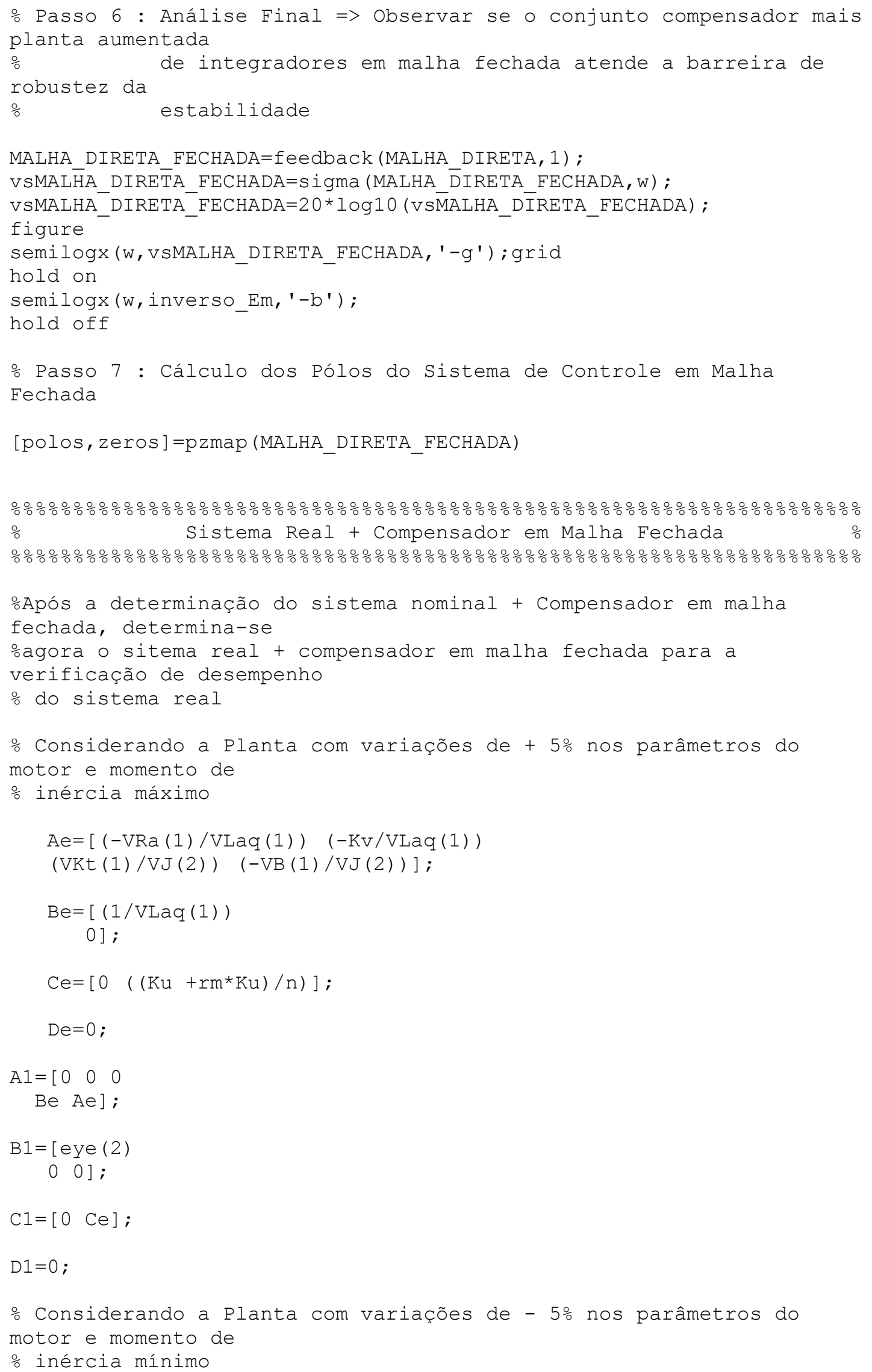




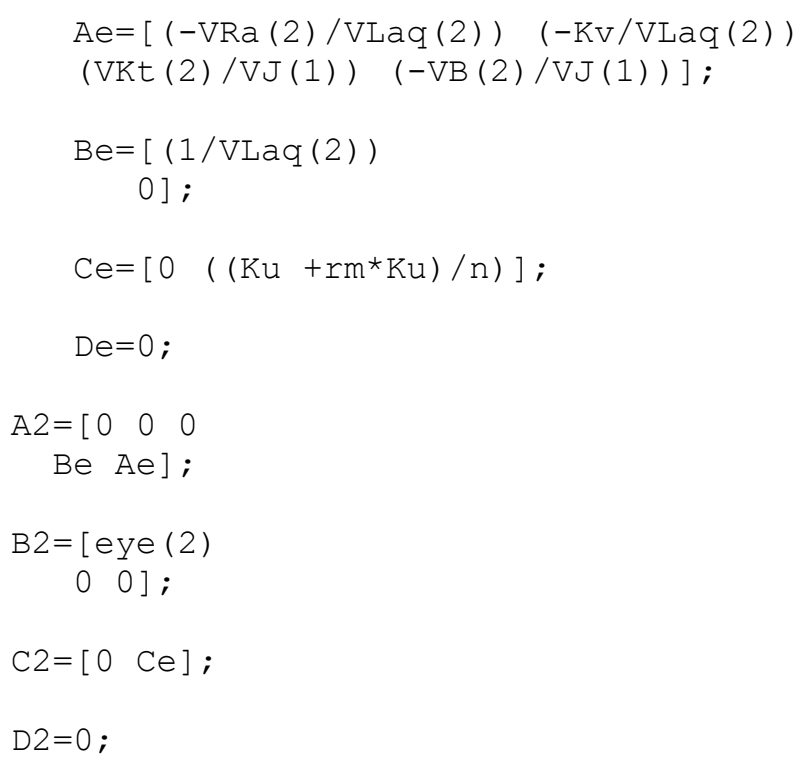

